\title{
HYDROSTATIC PRESSURE TESTING OF GRAPHITE/EPOXY CYLINDER C6-1
}

H. W. Blake

J. M. Starbuck

Date Published-July 1992

Prepared by the

Oak Ridge National Laboratory

Oak Ridge, Tennessee 37831-7294

managed by

MARTTN MARIETTA ENERGY SYSTEMS, INC.

for the

U.S. DEPARTMENT OF ENERGY

under contract DE-AC05-84OR21400

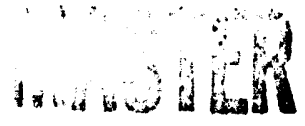

BISTRIBUTION OF THIS DOCUMENT IS UNLIMIIEU 


\section{CONTENTS}

FIGURES $\ldots \ldots \ldots \ldots \ldots \ldots \ldots \ldots \ldots \ldots \ldots \ldots \ldots \ldots \ldots \ldots \ldots \ldots$ iv

TABLES $\ldots \ldots \ldots \ldots \ldots \ldots \ldots \ldots \ldots \ldots \ldots \ldots \ldots \ldots \ldots \ldots$

ABSTRACT $\ldots \ldots \ldots \ldots \ldots \ldots \ldots \ldots \ldots \ldots \ldots \ldots \ldots \ldots \ldots \ldots \ldots \ldots \ldots \ldots \ldots$

INTRODUCTION $\ldots \ldots \ldots \ldots \ldots \ldots \ldots \ldots \ldots \ldots \ldots \ldots \ldots \ldots \ldots$

1. TEST ARTICLE DESIGN/ANALYSIS $\ldots \ldots \ldots \ldots \ldots \ldots \ldots \ldots \ldots \ldots$

1.1 PROPERTIES AND GEOMETRY $\ldots \ldots \ldots \ldots \ldots \ldots \ldots \ldots \ldots \ldots$

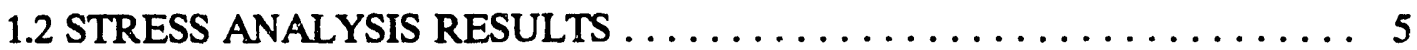

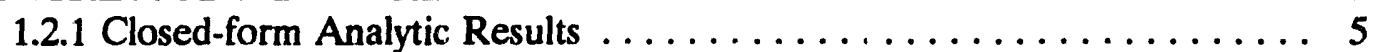

1.2.2 Finite Element Results . . . . . . . . . . . . . . . . 13

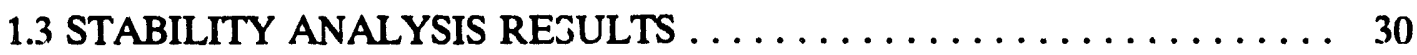

1.4 FAILURE ANALYSIS RESULTS $\ldots \ldots \ldots \ldots \ldots \ldots \ldots \ldots \ldots \ldots \ldots$

2. TEST ARTICLE FABRICATION $\ldots \ldots \ldots \ldots \ldots \ldots \ldots \ldots \ldots \ldots \ldots$

3. TEST ARTICLE TESTING $\ldots \ldots \ldots \ldots \ldots \ldots \ldots \ldots \ldots \ldots \ldots \ldots \ldots$

3.1 INSTRUIMENTATION $\ldots \ldots \ldots \ldots \ldots \ldots \ldots \ldots \ldots \ldots \ldots \ldots \ldots$

3.2 TEST FACILITY $\ldots \ldots \ldots \ldots \ldots \ldots \ldots \ldots \ldots \ldots \ldots \ldots \ldots \ldots \ldots$

3.3 TEST ASSEMBLY $\ldots \ldots \ldots \ldots \ldots \ldots \ldots \ldots \ldots \ldots \ldots \ldots \ldots \ldots$

3.4 TEST RESULTS $\ldots \ldots \ldots \ldots \ldots \ldots \ldots \ldots \ldots \ldots \ldots \ldots \ldots \ldots$

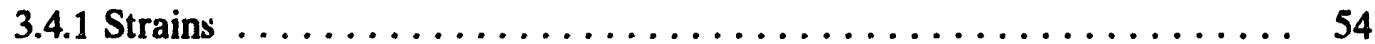

3.4.2 Experimental Correlation ...................... 64

3.4.3 Ring Tests .......................... 67

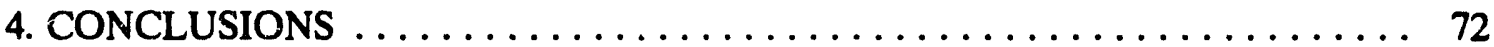

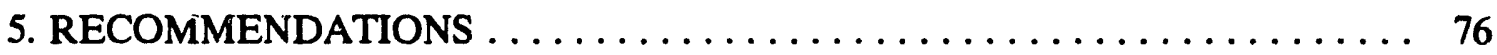

Appendix A. END CLOSURE DESIGN/ANALYSIS . . . . . . . . . . . 77

Appendix B. CYLINDER WEIGHT-TO-DISPLACEMENT RATIO . . . . . . 96

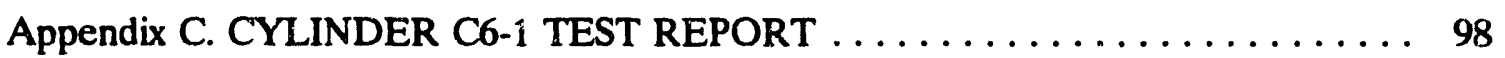

REFERENCES $\ldots \ldots \ldots \ldots \ldots \ldots \ldots \ldots \ldots \ldots \ldots \ldots \ldots \ldots \ldots \ldots \ldots \ldots$ 


\section{FIGURES}

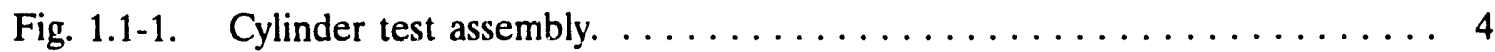

Fig. 1.2.1-1. Cylinder geometry and loading. $\ldots \ldots \ldots \ldots \ldots \ldots \ldots \ldots \ldots \ldots$

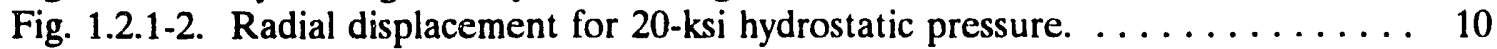

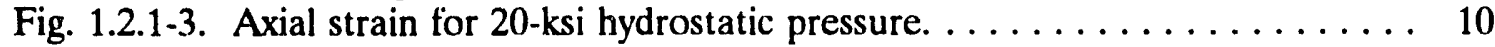

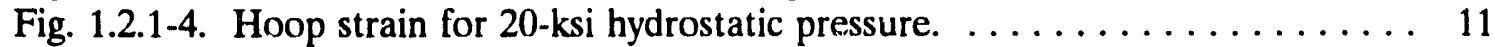

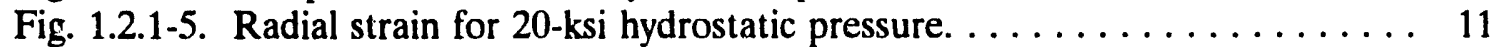

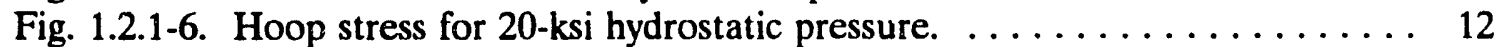

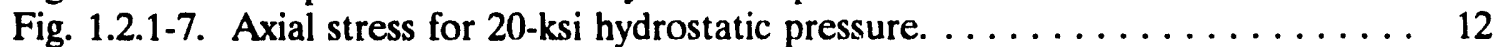

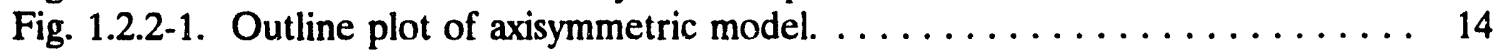

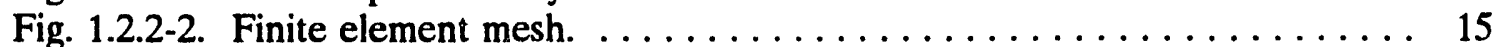

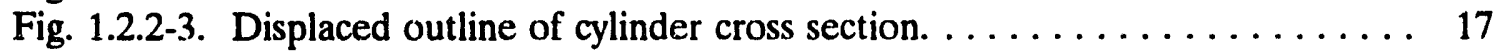

Fig. 1.2.2-4. Contours of radial displacement. $\ldots \ldots \ldots \ldots \ldots \ldots \ldots \ldots \ldots$

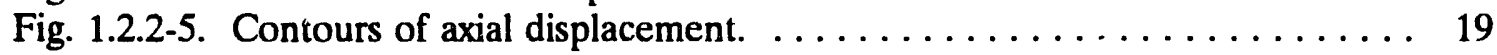

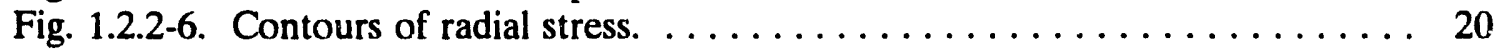

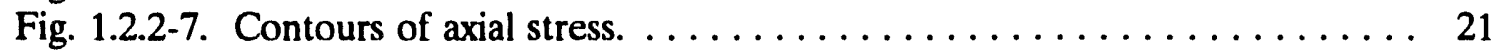

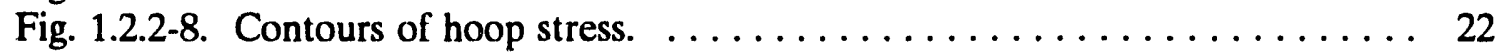

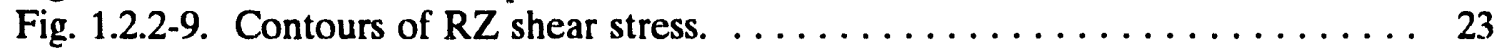

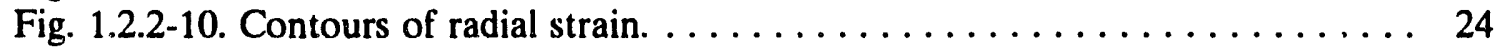

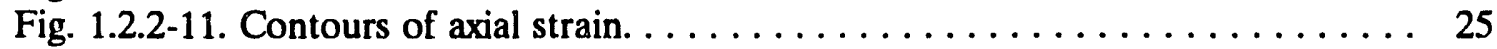

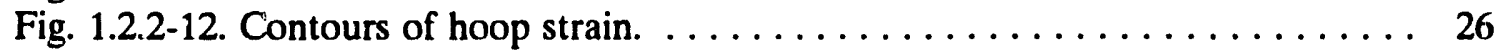

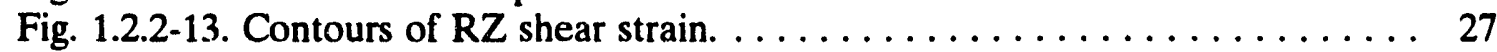

Fig. 1.2.2-14. Pressure profile history on cylinder end surface. $\ldots \ldots \ldots \ldots \ldots \ldots 28$

Fig. 1.2.2-15. Shear profile history on cylinder end surface. . . . . . . . . . . . 29

Fig. 1.3-1. Critical axial pressure versus cylinder $\mathrm{L} / \mathrm{D}$ ratio. $\ldots \ldots \ldots \ldots \ldots \ldots$

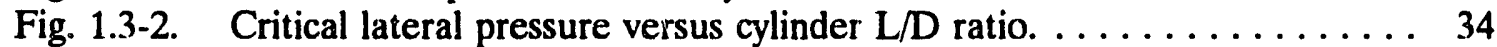

Fig. 1.3-3. Critical hydrostatic pressure versus cylinder $\mathrm{L} / \mathrm{D}$ ratio. . . . . . . . . 34

Fig. 1.4-1. Predicted failure pressures for different transverse compressive

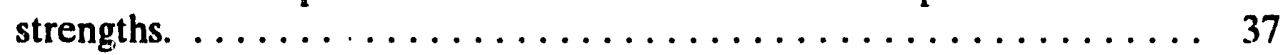

Fig. 2-1. Macrograph of head stock cross section (4.5X magnification). . . . . 43

Fig. 2-2. Macrograph of tail stock cross section (4.5X magnification). . . . . . 43

Fig. 2-3. Montage of head stock cross section (20X magnification). . . . . . . 44

Fig. 2-4. Montage of tail stock uross section (20X magnification). . . . . . . . 45

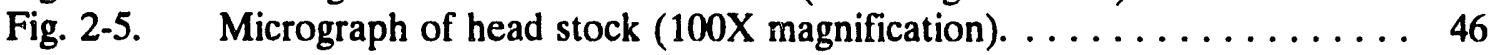

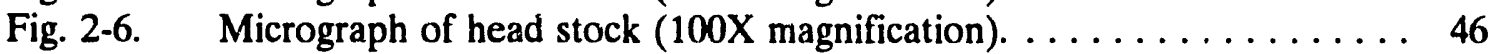

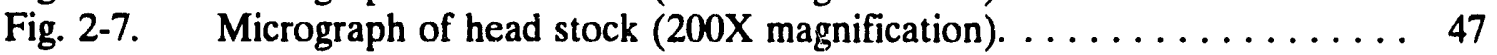

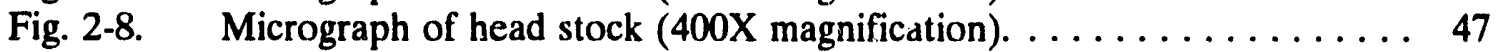

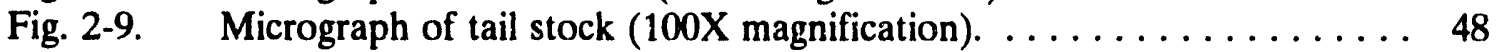

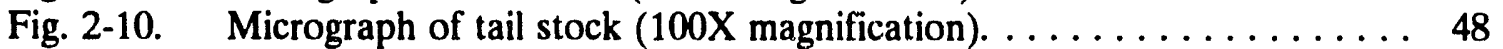

Fig. 2-11. Micrograph of tail stock (200X magnification). . . . . . . . . . 49

Fig. 2-12. Micrograph of tail stock (400X magnification). . . . . . . . . . . . . 49

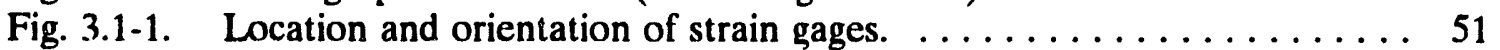

Fig. 3.2-1. Stachiw Associates test facility pres sure vessel (20,000-psi capacity). . . 52

Fig. 3.2-2. Test facility instrumentation. ................... 53

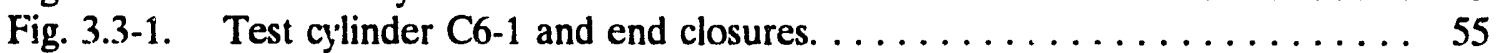

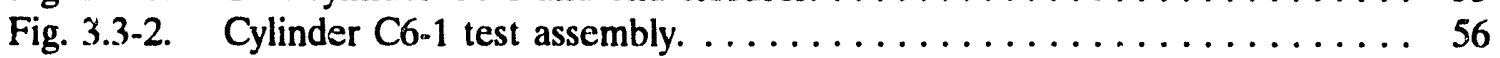

Fig. 3.4.1-1. Midbay interior hoop strains versus pressure. . . . . . . . . . 61 


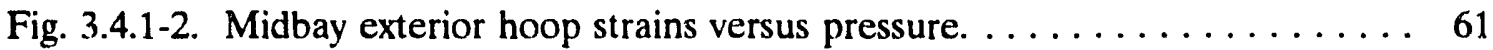

Fig. 3.4.1-3. Midbay interior axial strains versus pressure. $\ldots \ldots \ldots \ldots \ldots \ldots \ldots$

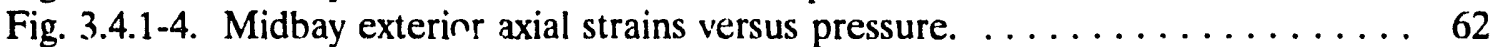

Fig. 3.4.1-5. Interior hoop strains at 4.5 in. from end versus pressure. . . . . . . 63

Fig. 3.4.1-6. Interior axial strains at 4.5 in. from end versus pressure. . . . . . . 63

Fig. 3.4.1-7. Exterior hoop strains at 0.5 in. from end versus pressure. . . . . . . 64

Fig. 3.4.2-1. Analytical/experimental comparison for the midbay interior hoop strains. . . .......................... 65

Fig. 3.4.2-2. Analytical/experimental comparison for the midbay exterior hoop

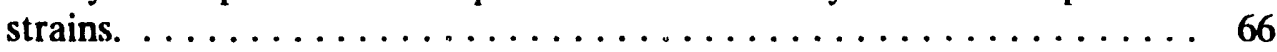

Fig. 3.4.2-3. Analytical/experimental comparison for the midbay interior axial strains. 66

Fig. 3.4.2-4. Analytical/experimental comparison for the midbay exterior axial

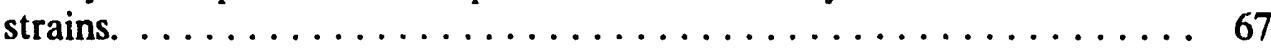

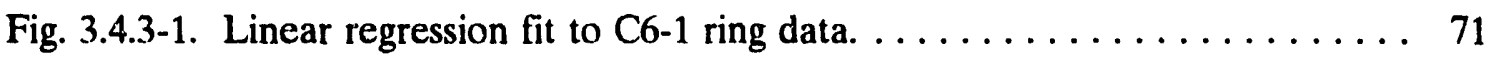

Fig. 3.4.3-2. Linear regression fit to $\mathrm{C} 6-3$ ring data $\ldots \ldots \ldots \ldots \ldots \ldots \ldots$

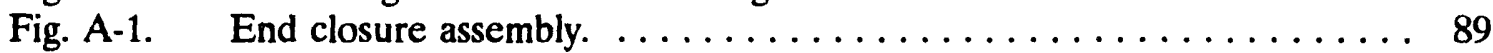

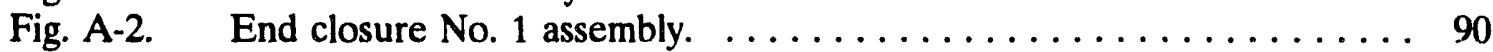

Fig. A-3. End closure No. 2 assembly. $\ldots \ldots \ldots \ldots \ldots \ldots \ldots \ldots \ldots \ldots \ldots$

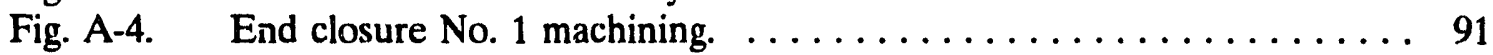

Fig. A-5. End closure No. 2 machining. $\ldots \ldots \ldots \ldots \ldots \ldots \ldots \ldots \ldots \ldots$

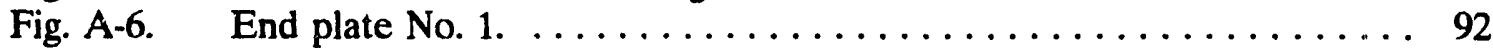

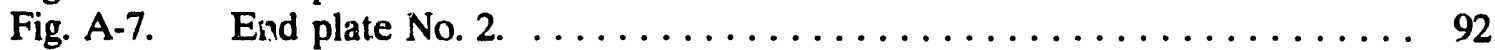

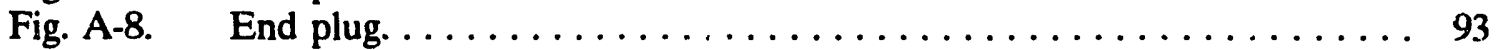

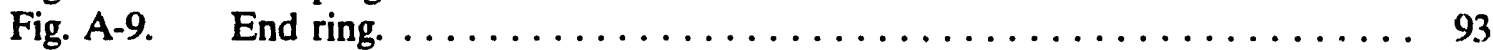

Fig. A-10. Comparison of finite element derived and experimental strains. . . . . 94 


\section{TABLES}

Table 1.1-1. Cylinder C6-1 geometric properties $\ldots \ldots \ldots \ldots \ldots \ldots \ldots \ldots \ldots$

Table 1.1-2. CLASS computed layer properties $\ldots \ldots \ldots \ldots \ldots \ldots \ldots \ldots \ldots \ldots \ldots$

Table 1.1-3. NDPROP computed laminate properties $\ldots \ldots \ldots \ldots \ldots \ldots \ldots \ldots$

Table 1.1-4. IM6/ERL-2258 layer strengths $\ldots \ldots \ldots \ldots \ldots \ldots \ldots \ldots \ldots \ldots \ldots$

Table $1.2 .1-1$. Radial displacement results for $20-\mathrm{ksi}$ hydrostatic pressure $\ldots \ldots \ldots \ldots 7$

Table $1.2 .1-2$. Normal strains for 20 -ksi hydrostatic pressure $\ldots \ldots \ldots \ldots \ldots \ldots \ldots$

Table 1.2.1-3. Maximum hoop and axial stresses for 20 -ksi hydrostatic pressure $\ldots \ldots 8$

Table 1.3-1. Stability analysis results for hydrostatic pressure (layered analysis) . . . 31

Table 1.3-2. Stability analysis results for hydrostatic pressure (smeared property

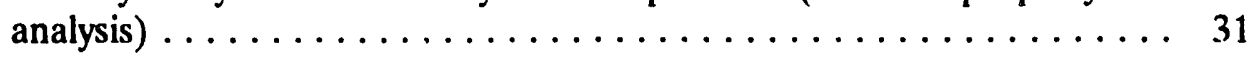

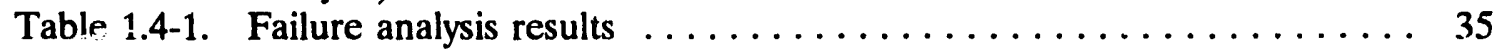

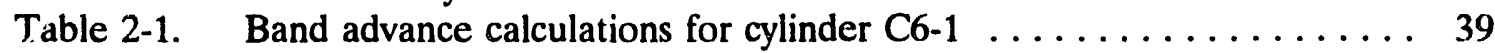

Table 2-2. Composition data for cylinder C6-1 . . . . . . . . . . . . 40

Table 2-3. Dimensional inspection results for C6-1 diameters and thickness . . . . 40

Table 2-4. Dimensional inspection results for run-out of cylinder C6-1 . . . . . 41

Table $3.4-1$. Strain gage readings (gages $1-6) \ldots \ldots \ldots \ldots \ldots \ldots \ldots \ldots \ldots$

Table $3.4-2$. Strain gage readings (gages $7-14) \ldots \ldots \ldots \ldots \ldots \ldots \ldots \ldots \ldots$

Table $3.4-3$. Average strain gage readings $\ldots \ldots \ldots \ldots \ldots \ldots \ldots \ldots \ldots \ldots \ldots$

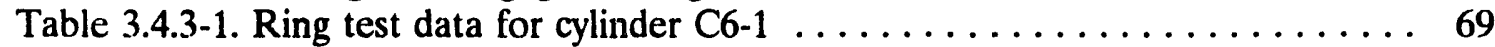

Table $3.4 .3-2$. Ring test data for cylinder $\mathrm{C} 6-3 \ldots \ldots \ldots \ldots \ldots \ldots \ldots \ldots$ 


\begin{abstract}
This report details the design, fabrication, and testing of IM6 graphite cylinder C6-1, which achieved a record pressure in hydrotest without failure. Included are the details of the cylinder construction, the design calculations for stress and buckling, and the cylinder failure predictions. Also provided are the design details of the metal end closures including the design calculations for the linear tapered end plugs. Finally, the test data and observations from the hydrotest are summarized. This work is performed under the Oak Ridge National Laboratory, Laboratory Directed Research and Development Program. The project is funded by the Director as a three-year project.
\end{abstract}




\section{INTRODUCTION}

In work, to date, by a variety of organizations in the United States, ${ }^{1-4}$ the measured performance of thick-section composite cylindrical pressure vessels has fallen far short of analytical predictions. Also, the reported stress values in test cylinders have not achieved the compressive strengths measured in flat coupon tests. The variety of test methods currently being used for determining the compression performance of thick-section composite cylinders has greatly contributed to the variability of reported results. The overall difficulty of predicting performance in laminated composites and the nonexistence of standardized test methods for cylinders explains in part the current lack of success. Success in this area will require careful experimentation and the parallel development of supporting failure theories.

In a combined experimental/analytical approach for predicting performance of laminated composite cylinders, analytical tools are needed for the determination of ply-level stress states and elastic stability and the application of various failure criteria. The validity of a certain failure criterion can be established by carefully designing and testing a series of cylinders to measure the performance and to identify the possible failure modes. Standardized test methods will be required before consistent data can be obtained.

This report summarizes the design, analysis, fabrication, and testing of a composite cylinder for the purpose of performance model validation and test method standardization. The cylinder is fabricated from graphite fiber reinforced epoxy using a 2:1 hoop:axial ply ratio and is subjected to hydrostatic pressure. The cylinder has a nominal diameter of 6.0 inches and a nominal design wall thickness equal to 0.5 inches. The layers or plies of the cylinder wall are constructed from IM6 graphite fibers and an ERL-2258 epoxy resin. The cylinder identification for the test article is C6-1. 


\section{TEST ARTICLE DESIGN/ANALYSIS}

The analytical methodology for the design of composite cylinder test articles is based on using state-of-the art analytical and numerical techniques for determining the internal stresses and stability. The closed-form analytical solutions for predicting ply-level stress states are based on the mathematical theory of elasticity, whereas the global stability of the cylinder is calculated using an orthotropic laminated shell theory. The initial buckling predictions are modified to include the effect of transverse shear deformations. The numerical method of finite elements is used for validation of the analytic solutions and for determining stresses associated with more realistic and complex boundary conditions, e.g., stresses associated with the transfer of load from the test assembly end closures to the ends of the cylinder. The design iteration process is facilitated by having closed-form analytic solutions which can be evaluated computationally much faster than the numerical techniques. However, the closed-form solutions can not accurately predict the cylinder response at the supported ends.

The design of the test cylinder includes he specification of the materials and the laminate stacking sequence. The design is based on parametric studies conducted with the analytic tools described above and on a clearly defined test objective. Results from the stress and buckling analyses are the basis for the selection of material type, specification of material lay-up, and specification of test article dimensions. The test article is specified in drawing form to the required level of detail to accomplish the fabrication, cutoff, and final machining.

\subsection{PROPERTIES AND GEOMETRY}

Cylinder C6-1 was designed to have a nominal 2:1 hoop to axial ply ratio with one extra hoop ply placed at both the inner and outer radii (see Sect. 2 for a detailed description of this cylinder). The nomenclature for the laminate stacking sequence is given by

$$
\left[90 /\left(90_{2} / 0_{2} / 90_{2}\right)_{\mathrm{n}} / 90\right]_{\mathrm{T}}
$$

where each layer consists of IM6 graphite fibers, ERL-2258 epoxy matrix, and an assumed fiber volume fraction of $67 \%$. The number of repeating patterns, $n$, is determined by the target wall thickness. The preliminary design was based on the AUSS ${ }^{5}$ subscale cylinder dimensions, i.e., a nominal inner diameter of 5.31 inches and an outer diameter of 6.35 inches. This corresponds to a cylinder wall thickness equal to 0.52 inches and $\mathrm{n}$ being equal to 13 for an assimed average layer thickness of 6.5 mils. During fabrication of the test article C6-1, measurements of the cylinder outer diameter indicated layer thicknesses were greater than the assumed design value of 6.5 mils. To avoid fabricating a cylinder with a total wall thickness greater than the 0.52 design estimate, the number of repeating patterns was reduced to 12. Dimensional inspection of the test article after fabrication (see Sect. 2) resulted in geometric properties for the analytical cylinder model as shown in Table 1.1-1. The machined length of 18 inches and the unsupported length of 10 inches were determined on the basis of stability considerations discussed in Sect. 1.3. 
Table 1.1-1. Cylinder C6-1 geometric properties

\begin{tabular}{ll}
\hline Inner diameter $\left(D_{\mathrm{i}}\right)$ & $5.318 \mathrm{in.}$ \\
Outer diameter $\left(D_{\mathrm{o}}\right)$ & $6.308 \mathrm{in.}$ \\
Inner radius $\left(R_{\mathrm{i}}\right)$ & $2.659 \mathrm{in.}$ \\
Outer radius $\left(R_{\mathrm{o}}\right)$ & $3.154 \mathrm{in.}$ \\
Mean radius $\left(R_{\mathrm{m}}\right)$ & $2.9065 \mathrm{in}$. \\
Wall thickness $(H)$ & $0.495 \mathrm{in}$. \\
$R_{\mathrm{m}} / H$ & 5.8717 \\
Unsupported length $(L)$ & $10.0 \mathrm{in}$. \\
Machined length & $18.0 \mathrm{in}$. \\
Layer thickness $(t)$ & $0.0066892 \mathrm{in}$. \\
\hline
\end{tabular}

For an IM6/ERL-2258 graphite/epoxy layer, Table 1.1-2 shows the CLASS ${ }^{6}$ computed material properties in the principal material directions. The layer is assumed to be transversely isotropic with the properties in the $2-3$ plane being equal in all directions, i.e., the $2-3$ plane is a plane of material property symmetry and the 2 and 3 subscripts are interchangeable.

Table 1.1-2. CLASS computed laver properties

\begin{tabular}{ll}
$\mathrm{E}_{1}$ & $22.63 \mathrm{MSI}$ \\
$\mathrm{E}_{2}$ & $1.489 \mathrm{MSI}$ \\
$\mathrm{E}_{3}$ & $1.489 \mathrm{MSI}$ \\
$\mathrm{G}_{12}$ & $0.8571 \mathrm{MSI}$ \\
$\mathrm{G}_{13}$ & $0.8571 \mathrm{MSI}$ \\
$\mathrm{G}_{23}$ & $0.5400 \mathrm{MSI}$ \\
$\nu_{12}$ & 0.3117 \\
$\nu_{13}$ & 0.3117 \\
$\nu_{23}$ & 0.3781 \\
\hline
\end{tabular}

Finite element models were constructed for the test cylinder assembly and analyzed to determine local stress values within the volume and on the surfaces of the cylinder and the metal end closures. The drawing of a typical test assembly is shown in Fig. 1.1-1. For input into the finite element analysis, an equivalent set of three-dimensional effective elastic constants or smeared laminate properties were computed. A program called NDPROP? which yields volume averaged composite elastic properties from input layer properties and la ninate stacking sequence, was used for this purpose. The calculated properties are in the global reference frame and are given in Table 1.1-3. 


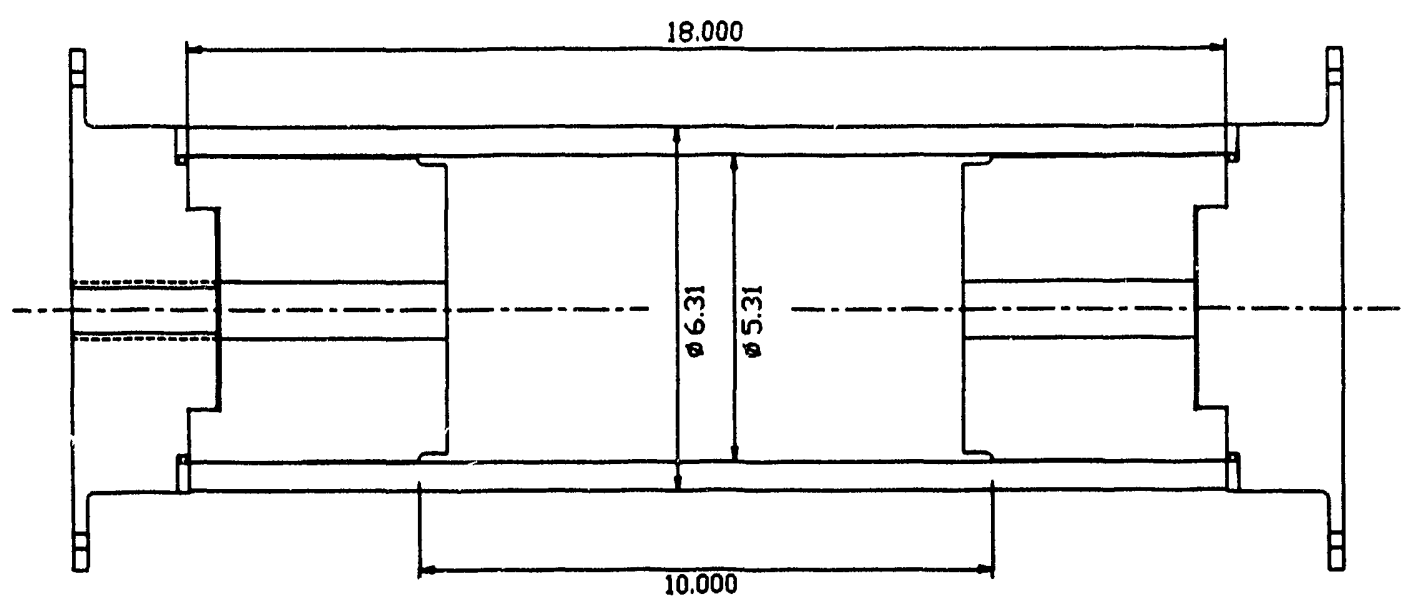

Fig. 1.1-1. Cylinder test assembly.

Table 1.1-3. NDPROP computed laminate properties

\begin{tabular}{ll||ll}
\hline $\mathrm{E}_{\mathrm{x}}$ & $8.3872 \mathrm{MSI}$ & $\nu_{\mathrm{x} \theta}$ & 0.0294 \\
$\mathrm{E}_{\theta}$ & $15.852 \mathrm{MSI}$ & $\nu_{\mathrm{xx}}$ & 0.3894 \\
$\mathrm{E}_{\mathrm{r}}$ & $1.6763 \mathrm{MSI}$ & $\nu_{\theta \mathrm{r}}$ & 0.3954 \\
$\mathrm{G}_{\mathrm{x} \theta}$ & $0.8570 \mathrm{MSI}$ & $\nu_{\theta \mathrm{x}}$ & 0.0555 \\
$\mathrm{G}_{\mathrm{xx}}$ & $0.6429 \mathrm{MSI}$ & $\nu_{\mathrm{rx}}$ & 0.0778 \\
$\mathrm{G}_{\theta \mathrm{r}}$ & $0.7543 \mathrm{MSI}$ & $\nu_{\mathrm{r} \theta}$ & 0.0418 \\
\hline
\end{tabular}

For an IM6/ERL-2258 layer, the three-dimensional strength allowables used in the failure analyses are given in Table 1.1-4. The transverse compressive strength was initially assumed to range from $10 \mathrm{ksi}$ to $20 \mathrm{ksi}$. The allowables are specified for the principal material directions, where $X$ corresponds to strengths in the fiber direction and $Y$ corresponds to strengths transverse to the fiber direction.

Table 1.1-4. IM6/ERL-2258 layer strengths

\begin{tabular}{ll}
\hline Axial tensile $-X_{\mathrm{t}}$ & $500,000 \mathrm{psi}$ \\
Axial compressive $-X_{\mathrm{c}}$ & $250,000 \mathrm{psi}$ \\
Transverse tensile $-Y_{\mathrm{t}}$ & $5,000 \mathrm{psi}$ \\
Transverse compressive $-Y_{\mathrm{c}}$ & $10,000 \mathrm{psi}$ \\
& $15,000 \mathrm{psi}$ \\
& $20,000 \mathrm{psi}$ \\
Axial shear $-S_{\mathrm{a}}$ & $10,000 \mathrm{psi}$ \\
Transverse shear $-S_{\mathrm{t}}$ & $5,000 \mathrm{psi}$ \\
\hline
\end{tabular}




\subsection{STRESS ANALYSIS RESULTS}

The cylinder characteristics described by the geometry, properties, and strengths stated in Sect. 1.1 were used in modeling the C6-1 test article. A program called CCAP was developed for performing the closed-form analytic stress computations. The results obtained from the elasticity solution in CCAP were compared with laminated shell theory (LST) results when layered analyses were perfo med and with finite element method (FEM) results when equivalent smeared properties were used. The LST results were generated from a program called CYLAN ${ }^{8}$ and the FEM results were generated from NIKE2D.'

The solution procedure in CCAP is based on an elasticity formulation by Hyer, ${ }^{10}$ with two noteworthy exceptions. First, the program contains the exact solution for isotropic and transversely isotropic layers, i.e., the solution to the governing differential equation for the case of repeated roots equal to 1.0. This eliminates the numerical difficulty of dividing by zero that exists in Hyer's formulation. Second, in addition to axisymmetric thermal and mechanical loading, the program can determine the hygroscopic response of a laminated cylinder. The mechanical loadings available in CCAP are uniform internal and external lateral pressure, axial force, torque, and hydrostatic pressure. The number of stress calculation points in each layer is a specified variable, and hybrid cylinders can be analyzed. A more detailed description of CCAP and other analytical tools used in the design and analysis of test articles is presented by Blake, et al. ${ }^{11}$

The closed-form analytic solution in CCAP is limited by generalized plane strain assumptions that approximately model the cylinder midplane where axial bending and shear stresses are negligible. The finite element model was used to provide detailed stress results in the regions adjacent to the end closures where high axial bending and shear stresses occur. In addition to the detailed model of the entire test assembly, which includes the cylinder and end closures, a model of the cylinder (without the end closures) was also constructed. This "cylinder only" model provided displacements, strains, and composite stress values for comparison with the CCAP analytic solutions. Stress values from these initial FEM analyses, which model the cylinder as a single layer having smeared elastic properties, are composite stresses rather than the la\} $r$ stresses.

The cylinder model used in CCAP is a three-dimensional, axisymmetric model. The laminated shell theory solution in CYLAN is a two-dimensional plane stress model and is not capable of predicting radial displacements, radial strains, and raaial stresses. In CYLAN, the in-plane stress and strain calculations are based on a Vlasov-Ambartsumyan ${ }^{12,13}$ type of laminated shell theory with modifications by Whitney ${ }^{14}$ to include through-the-thickness strain effects. The two-dimensional plane stress results from CYLAN are compared with the three-dimensional elasticity solution used in CCAP.

\subsubsection{Closed-form Analytic Results}

The geometry of the laminated cylinder model in CCAP is shown in Fig. 1.2.1-1, where the cylindrical coordinate system, $x, \theta$, and $r$, represents the axial, circumferential, and radial directions, respectively. For an applied hydrostatic pressure loading, the cylinder is subjected to a uniform external lateral pressure, $p_{0}$, and an axial compressive force, $P_{x}$ due to the component of hydrostatic pressure acting on the end plugs. The results from the closed-form analytic solution in CCAP are summarized in this section. 


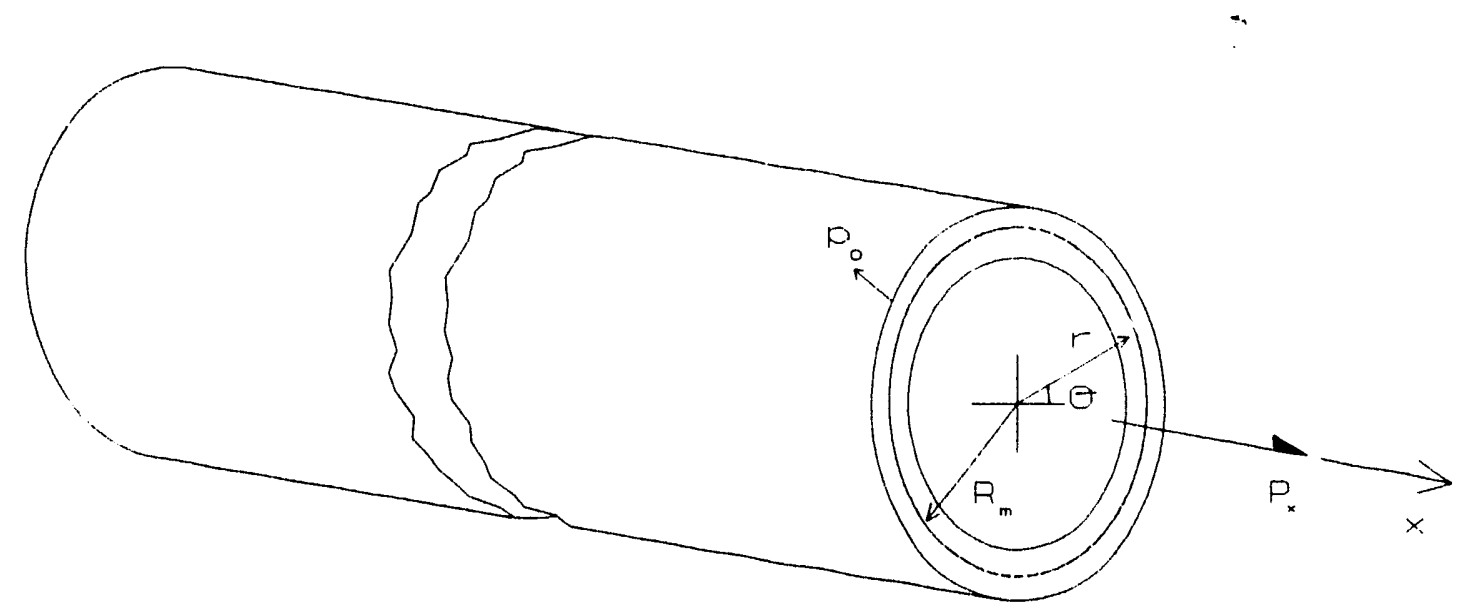

Fig. 1.2.1-1. Cylinder geometry and loading.

In the as-fabricated condition, cylinder C6-1 had 74 layers. However, the model cylinder treated in the analyses had only 38 layers, where adjacent plies in the repeating pattern having the same fiber orientation were modeled as a single layer. An applied hydrostatic pressure of $\mathbf{2 0} \mathrm{ksi}$ was specified, and results for the radial distribution of strains, stresses, and radial displacement were generated.

The distribution of the radial displacement, $w$, through the thickness is plotted in Fig. 1.2.1-2. The plotted results are from CCAP using both layered anci smeared properties and from NIKE2D FEM at the cylinder midlength. Details of the finite element modeling are described in Sect. 1.2.2. The results indicate an excellent agreement between CCAP and FEM, with the FEM results being slightly smaller. Also, the smeared property analysis is shown to predict almost the same results as does the layered analysis, with a nearly identical distribution across the cylinder wall. This will only be the case when the deformations are assumed to be continuous in the radial direction and a large number of layers having an interspersed stacking sequence exist across the cylinder wall. All three analyses predict slightly larger zadial deflections at the: outer radius compared to the inner radius. The magnitudes of $w$ at the inner and outer radii of the cylinder wall from the three analyses are given in Table 1.2.1-1. 
Table 1.2.1-1. Radial displacement results for 20-ksi hydrostatic pressure

\begin{tabular}{lcc}
\hline & \multicolumn{2}{c}{$\mathrm{w}$ (mils) } \\
\cline { 2 - 3 } Analysis & Inner radius & Outer radius \\
\hline CCAP - Layered analysis & -22.298 & -22.314 \\
CCAP - Smeared analysis & -22.310 & -22.326 \\
NIKE2D - FEM analysis & -22.226 & -22.242 \\
\hline
\end{tabular}

For the C6-1 cylinder construction, where only axial and circumferential plies are used, the analytical formulation in CCAP predicts vanishing shear strains. The normal components of strain (axial, hoop, and radial) have a distribution through the cylinder wall as predicted by CCAP as shown in Figs. 1.2.1-3, 1.2.1-4, and 1.2.1-5, respectively. Also presented in Figs. 1.2.1-3, 1.2.1-4, and 1.2.1-5 are the finite element results at the cylinder midlength. These three figures show that the results from CCAP and FEM are in excellent agreement and that the normal strains are uniform through the thickness, i.e., continuous across the layer interfaces. The distribution of the axial strain is constant across the wall thickness, whereas the radial and hoop strains have gradients. The radial component of strain has an almost linear distribution with steps resulting from the layered analysis and varies from being tensile at the inner radius to compressive at the outer radius.

The FEM models the laminated cyinder as a single homogeneous layer having equivalent smeared orthotropic properties. The slight disagreement between the elasticity solution and the FEM results for the radial strain near the inner and outer radii is a result of the numerical extrapolation from the Gauss points to the boundary used in FEM. As was discussed previously for the radial displacement, the normal components of strain are continuous quantities and the results using smeared properties are nearly identical to the layered analysis results. For the C6-1 cylinder, the ratio of hoop to axial plies is 2:1 and the analytic results predict approximately a $1: 1$ ratio of hoop to axial strain over the exterior half of the cylinder wall. Over the interior half, the hoop strains become increasingly larger than the axial strains (up to $15 \%$ larger at the inner radius).

In Figs. 1.2.1-3 and 1.2.1-4 the distribution of the axial and hoop strains, respectively, from CCAP are compared with the two-dimensional predictions of CYLAN. The results indicate that the CYLAN prediction for the hoop strain is $7.9 \%$ less than the CCAP prediction at the inner radius, whereas the axial strain from CYLAN is $7.6 \%$ greater than the three-dimensional CCAP prediction. Also, the ratio of the hoop to axial strain exhibits a different behavior in the two-dimensional analysis from that in the three-dimensional analysis. For the two-dimensional stress state the hoop to axial strain ratio is approximately equal to 1.0 at the inner radius. However, the ratio of hoop to axial strain decreases to a value of 0.84 at the outer radius. The magnitudes of the normal strain components at the inner and outer radii are given in Table 1.2.1-2. Results from LST, FEM, and CCAP using both layered and smeared properties are presented. The results using smeared properties indicate accurate strains can be predicted by modeling the C6-1 cylinder as a single layer having equivalent smeared orthotropic properties. 
Table 1.2.1-2. Normal strains for 20-ksi hydrostatic pressure

\begin{tabular}{lcccccc}
\hline & \multicolumn{2}{c}{ Axial strain (\%) } & \multicolumn{2}{c}{ Hoop strain (\%) } & \multicolumn{2}{c}{ Radial strain (\%) } \\
\cline { 2 - 7 } Analysis & $\begin{array}{l}\text { Inner } \\
\text { radius }\end{array}$ & $\begin{array}{l}\text { Outer } \\
\text { radius }\end{array}$ & $\begin{array}{c}\text { Inner } \\
\text { radius }\end{array}$ & $\begin{array}{l}\text { Outer } \\
\text { radius }\end{array}$ & $\begin{array}{c}\text { Inner } \\
\text { radius }\end{array}$ & $\begin{array}{c}\text { Outer } \\
\text { radius }\end{array}$ \\
\hline CCAP - layered & -0.72870 & -0.72870 & -0.83862 & -0.70746 & +0.64452 & -0.54692 \\
CYLAN - LST & -0.78400 & -0.78400 & -0.77200 & -0.66000 & - & - \\
CCAP - smeared & -0.72864 & -0.72864 & -0.83904 & -0.70788 & +0.64314 & -0.54854 \\
NIKE2D - FEM & -0.72908 & -0.72944 & -0.83566 & -0.70512 & -0.57054 & -0.48864 \\
\hline
\end{tabular}

In contrast to the strains, which are continuous functions across the cylinder wall for a layered analysis, the hoop and axial stresses are discontinuous. However, continuity of the normal radial component of stress was ensured as part of the analytical development in CCAP. The assumed state of stress and axisymmetry considered in the CCAP analysis resulted in the in-plane component of shear stress, $\tau_{x o}$, being the only nonzero shear stress, but for the case of having only axial and hoop plies in the C6-1 cylinder construction, $\tau_{x t}$ is also zero. The distribution of the hoop and axial components of stress across the wall thickness was determined using CCAP and CYLAN.

In Fig. 1.2.1-6 the hoop stress distribution is plotted and in Fig. 1.2.1-7 the axial stress distribution is showr. From Fig. 1.2.1-6 it is seen that the hoop stress has a maximum compressive value in the inner hoop ply and that the two-dimensional CYLAN analysis predicts a maximum hoop stress which is $7.8 \%$ less than the prediction from the threedimensional analysis of CCAP. The resuits in Fig. 1.2.1-7 show that the axial stress is a maximum in the outermost axial ply, with slightly larger compressive stresses being predicted by CYLAN. For an applied pressure of $20 \mathrm{ksi}$, the magnitudes of the maximum axial stress are reported in Table 1.2.1-3 along with the maximum hoop stresses. For a test pressure of $20 \mathrm{ksi}$, the maximum hoop stress is $194 \mathrm{ksi}$ and the maximum axial stress is $178 \mathrm{ksi}$. These are the highest reported values achieved, to date, in a graphite composite cylinder. The ratio of the hoop to axial stress is 1.095 .

Table 1.2.1-3. Maximum hoop and axial stresses for 20-ksi hydrostatic pressure

\begin{tabular}{lcccc}
\hline Analysis & $\begin{array}{c}\text { Hoop stress } \\
(\mathrm{ksi})\end{array}$ & Location & $\begin{array}{c}\text { Axial stress } \\
(\mathrm{ksi})\end{array}$ & Location \\
\hline CCAP - Layered & -194.402 & Inner hoop ply & -177.496 & Outer axial ply \\
CYLAN - LST & -179.200 & Inner hoop ply & -181.600 & Outer axial ply \\
CCAP - Smeared & -136.620 & Inner radius & -72.548 & Outer radius \\
NIKE2D - FEM & -136.220 & Inner radius & -72.274 & Outer radius \\
\hline
\end{tabular}


As discussed previously, accurate predictions for the strains was possible by modeling the laminated cylinder as a single homogeneous layer having equivalent smeared properties. However, this is not the case for predicting stresses, as seen by the smeared property CCAP results in Table 1.2.1-3. The single-layered composite cylinder analyses, which includes the FEM results, severely underpredict the maximum hoop and axial stresses. The maximum composite stresses are $137 \mathrm{ksi}$ and $72 \mathrm{ksi}$ in the hoop and axial directions, respectively. It should be noted that the FEM results are in excellent agreement with the elasticity solution results when smeared properties are used in CCAP. 


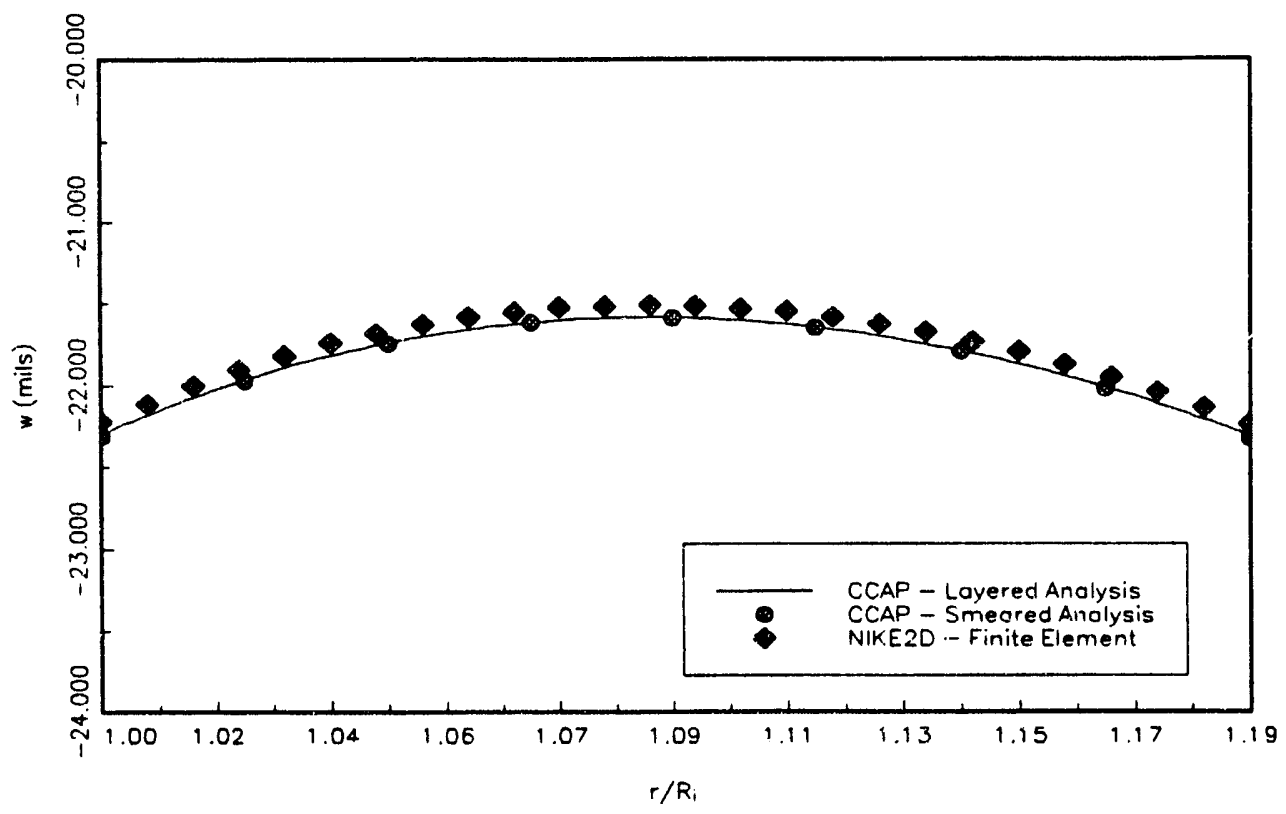

Fig. 1.2.1-2. Radial displacement for $20-\mathrm{ksi}$ hydrostatic pressure.

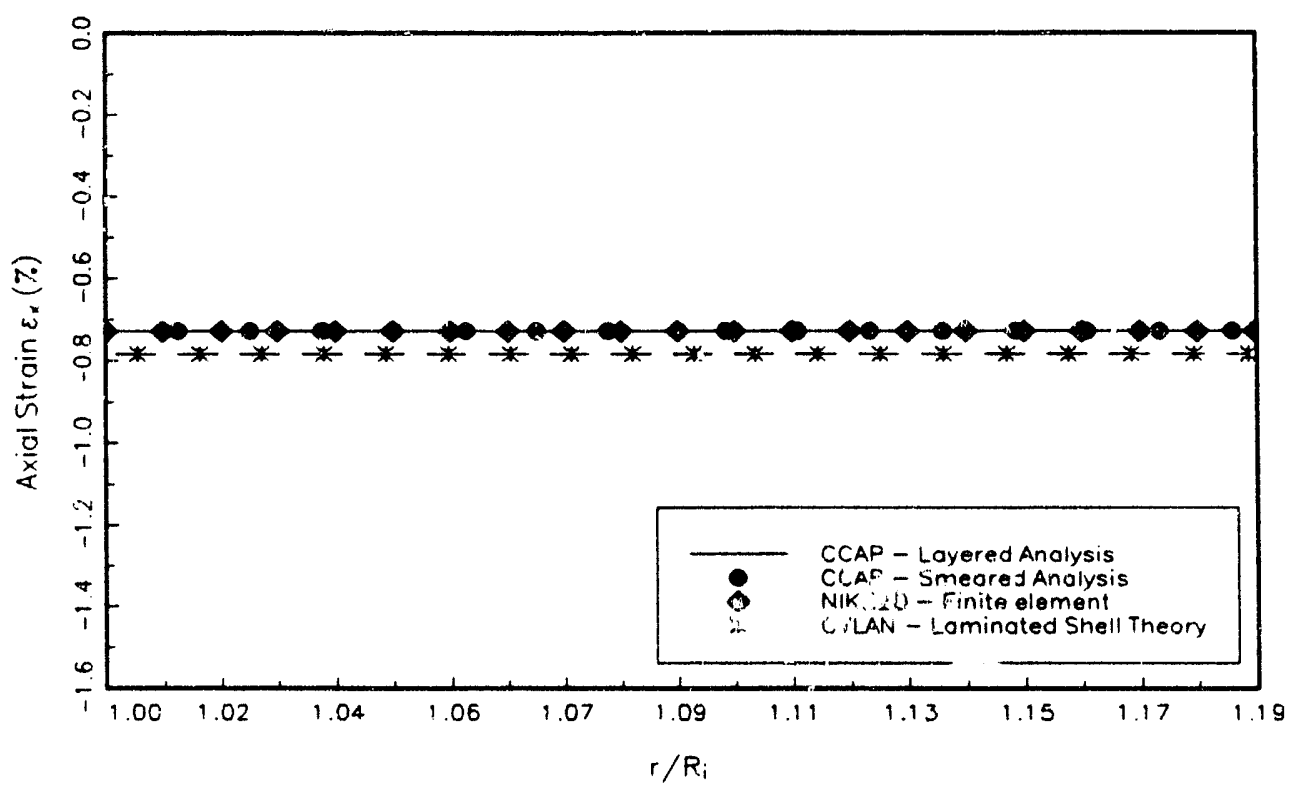

Fig. 1.2.1-3. Axial strain for 20-ksi hydrostatic pressure. 


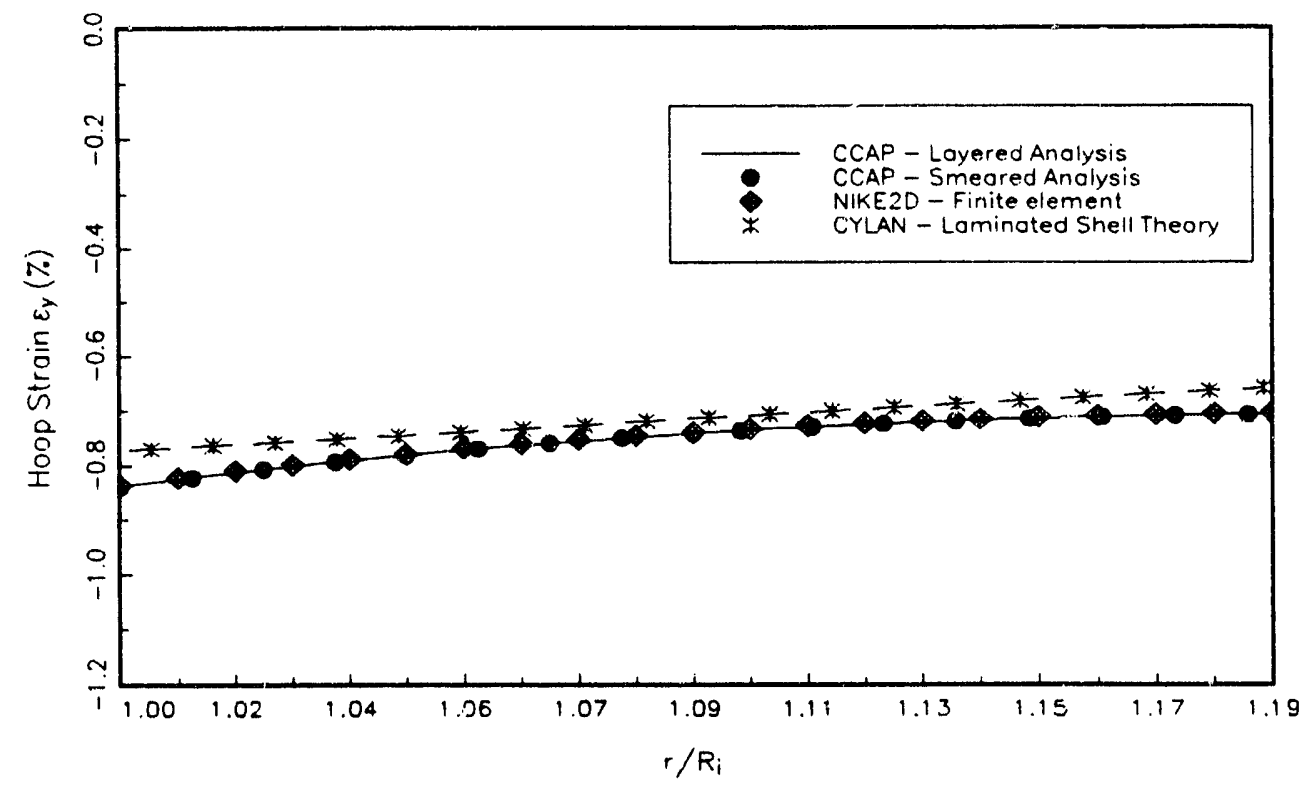

Fig. 1.2.1-4. Hoop strain for 20-ksi hydrostatic pressure.

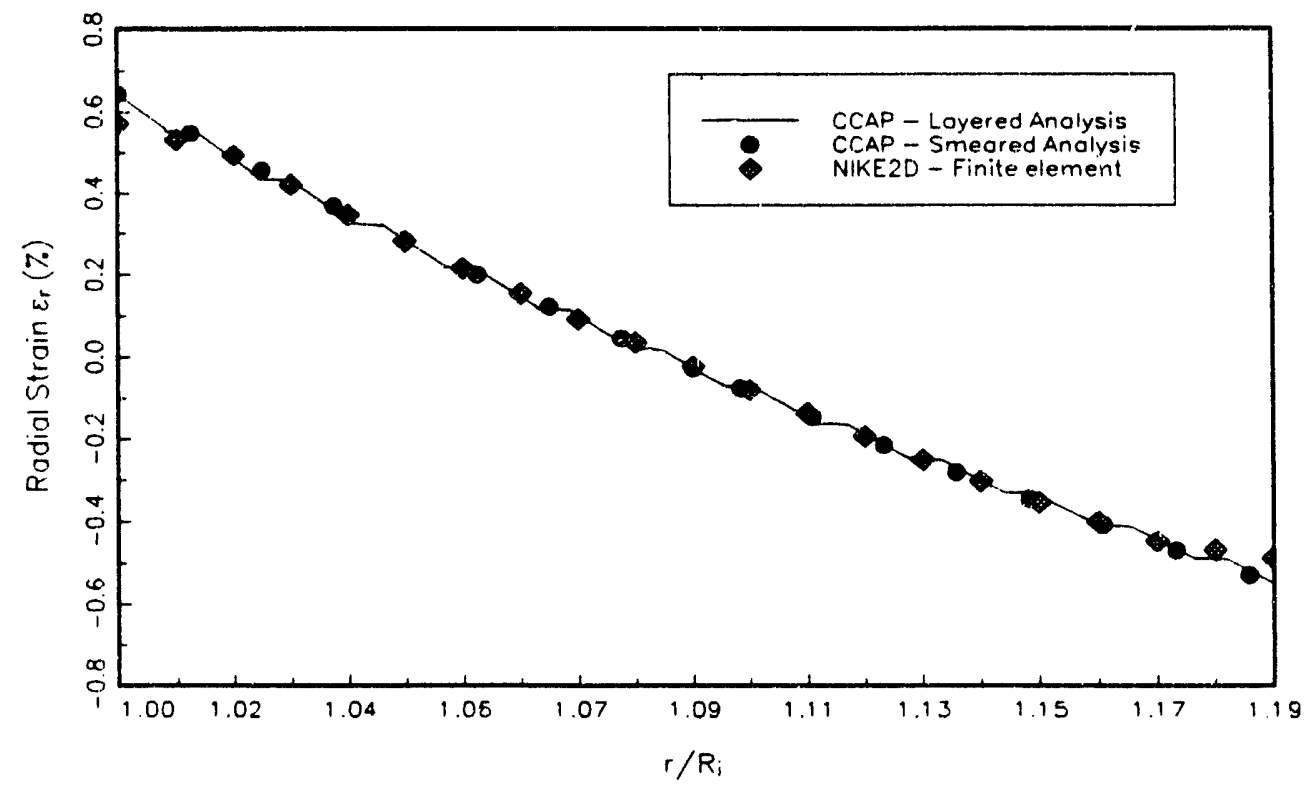

Fig. 1.2.1-5. Radial strain for 20-ksi hydrostatic pressure. 


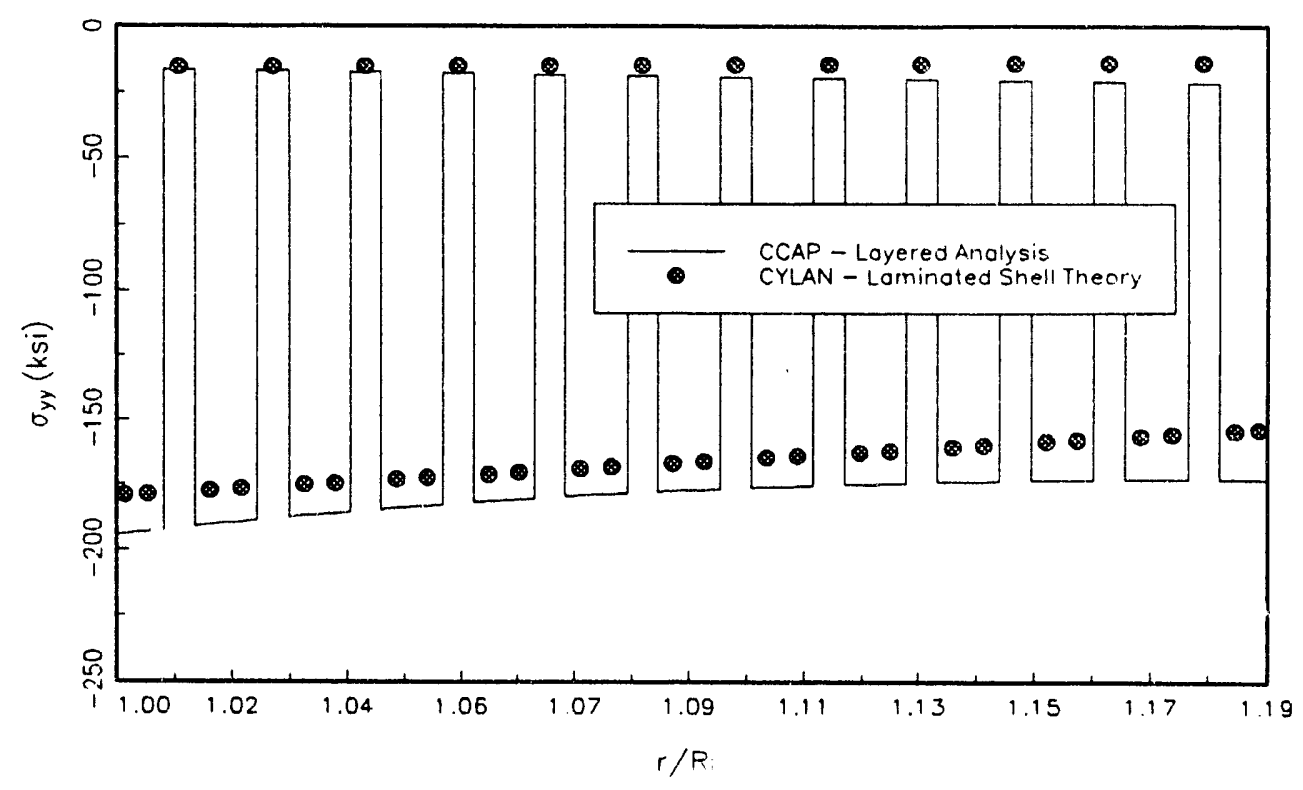

Fig. 1.2.1-6. Hoop stress for 20-ksi hydrostatic pressure.

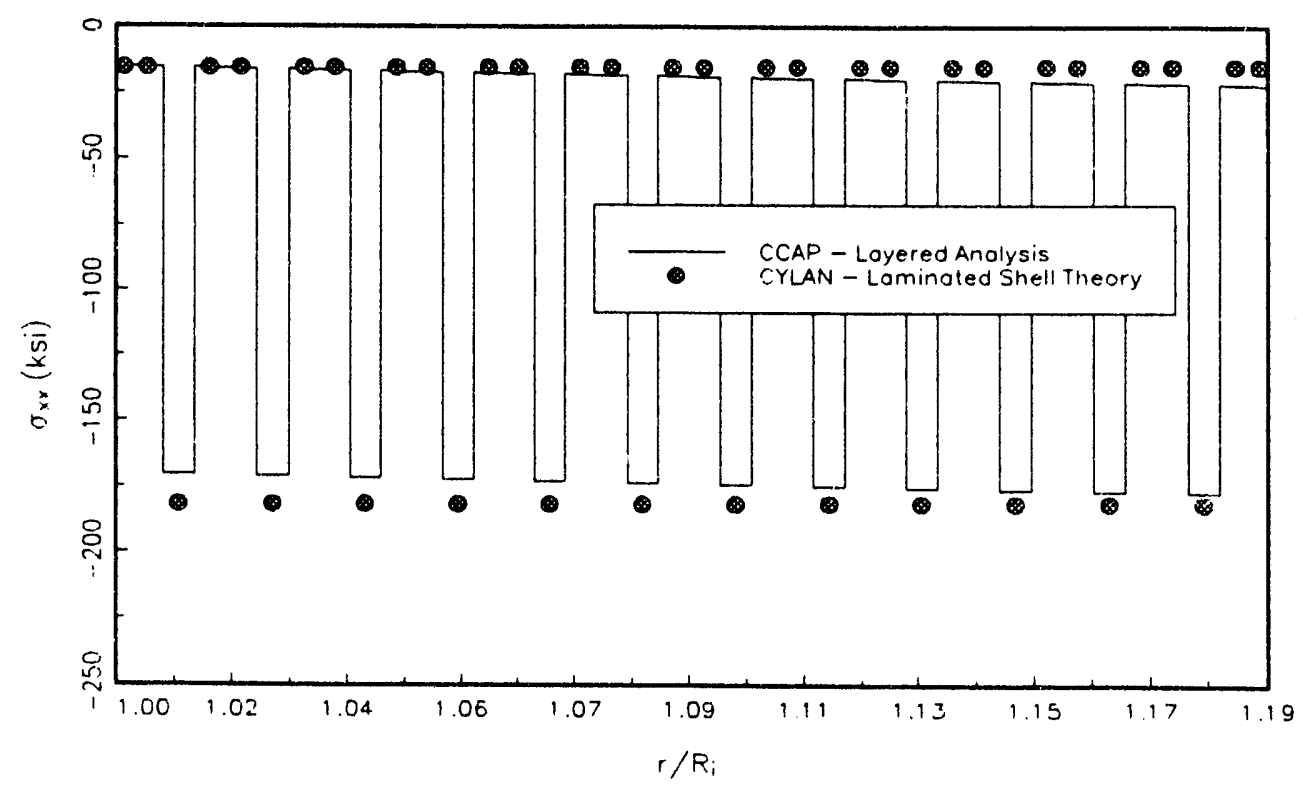

Fig. 1.2.1-7. Axial stress for 20-ksi hydrostatic pressure. 


\subsubsection{Finite Element Results}

Stress analysis results from the finite element model of the test assembly for cylinder C6-1 are summarized in this section. This cylinder was the first test cylinder assembly which utilized the end closures of the improved linear taper design. This cylinder was subjected to external pressurization ${ }^{15}$ and sustained a maximum hydrostatic pressure of 20,000 psig without failure (see Sect. 3.4). This was the highest pressure achieved, to date, for this material and cylinder configuration.

An axisymmetric finite element model of the cylinder test assembly was constructed for analysis with the NIKE2D FEM program written by Lawrence Livermore National Laboratory (LLNL) (see Ref. 9). The model was generated by using the LLNL mesh generation program MAZE. ${ }^{16}$ Postprocessing of the analysis results from NIKE2D was done using the LLNL program ORION. ${ }^{17}$ The model outline is shown in Fig. 1.2.2-1 and included only one quadrant of the test assembly cross section. This "one-quarter" model was sufficient because of the axisymmetric geometry and symmetry of the stress distributions at the cylinder midplane. The model included the cylinder and the end closure assembly.

The end closure assembly is made of four parts: a steel end plate, an aluminum end plug, a steel end ring, and an o-ring seal (see Fig 1.1-1 and Fig. A-1 in Appendix A). The aluminum end plug is joined to the end plate by thermal shrink fit of the plug over a boss on the end piate. The two-piece design of the end plate/end plug assembly allows the end plates to be used with several different end plug designs ard facilitates the replacement of the plug whenever it is damaged during a cylinder failure. The aluminum end plug also reduces the weight of the end closure assembly as compared to an all-steel closure.

Several simplifications were made in the FEM model to facilitate the analysis. The end plug and end plate were perfectly joined across a plane interface in the FEM analysis, whereas the actual parts are joined by thermal shrink fit of the plug onto the protrusion on the end plate. These details were not modeled in the FEM representation because the primary objective of the analysis was to determine the cylinder stresses rather than detailed stresses in the end closure. The robust design of the end plate and end plug insured that the stresses in the metal components were low.

The end plates have an integral flange and bolt circle that provide points of attachment for threaded tie rods which connect between the two end closures. The tie rods are tensioned via locking nuts to obtain an initial clamping force to secure the end closures against each end of the cylinder. To simplify the model, the flange, bolt circle, and tie rods were not included. These features were not expected to significantly affect the cylinder stresses because the stiffness of the flange is low and the clamping load is small compared to the loads that result from the hydrostatic pressure.

One of the two end closures has a 1-inch threaded hole in the end plate for a penetrator that provides feedthrough for the strain gage lead wires from the interior strain gages. The hole was included in the model but the penetrator itself was not modeled. The axial thrust load for the penetrator was included by multiplying the pressure applied to the end area of the plate by an appropriate area ratio. 


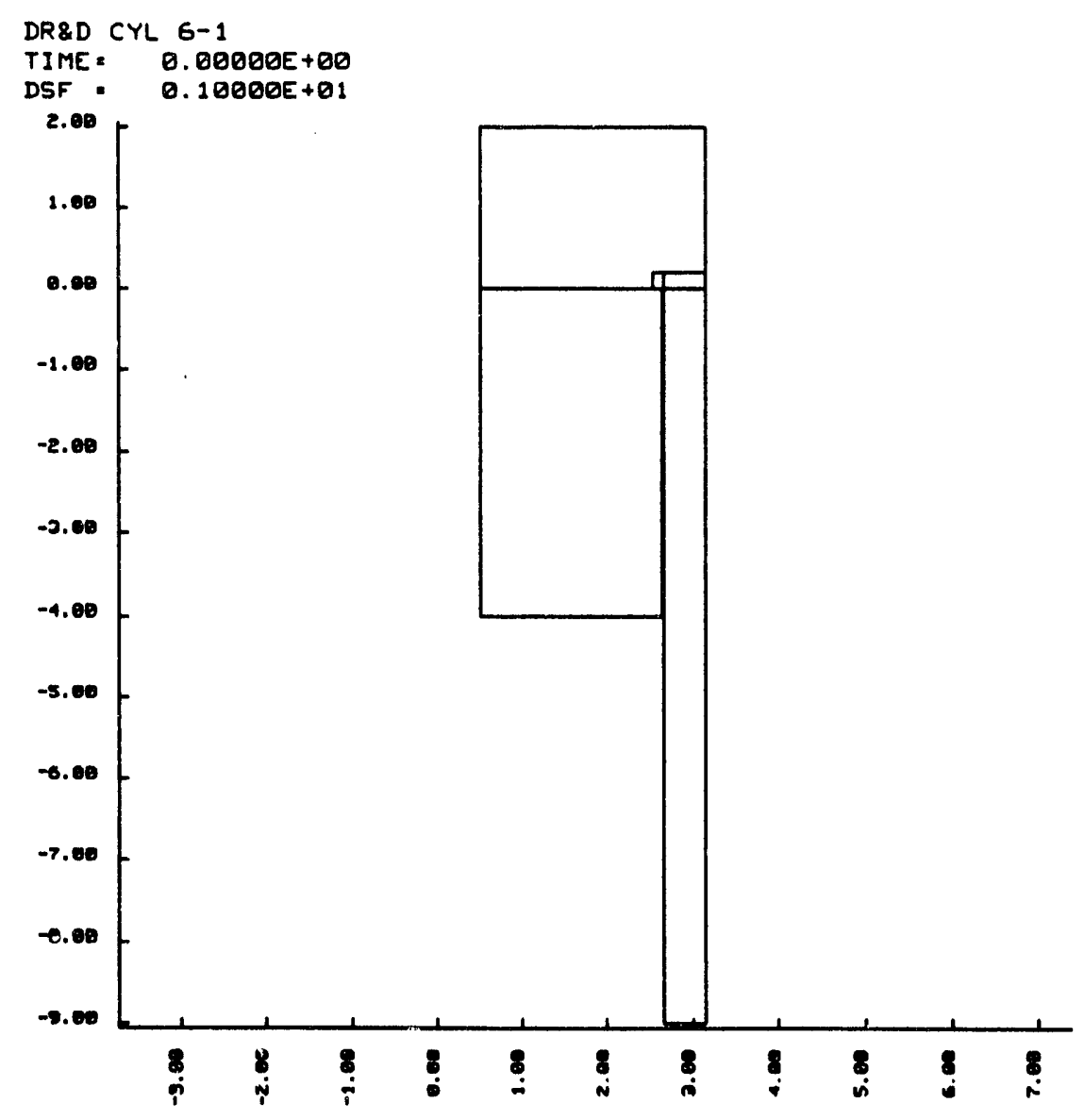

Fig. 1.2.2-1. Outline plot of axisymmetric model.

The end ring is held in place in the end closure assembly by the o-ring. The o-ring provides centering of the end ring relative to the end plate and end plug. This insures that the end ring is held concentric with the end plug until the end closures are secured with the tie rods. The o-ring was not included in the initial model. After this initial cylinder test, the o-ring was replaced by a "quad" ring. The quad ring was included in all subsequent finite element models.

The frictional sliding and contact between the cylinder and end closure was modeled using the nonlinear frictional slideline capabilities of NIKE2D. Three interfaces were modeled. These were the interface between the cylinder end and the end ring, the interface between the end ring and the end plate, and the interface between the inner surface of the cylinder and the tapered surface of the end plug. These interfaces wcre modeled using a slideline option that allows for sliding friction and a gap as required for the specified initial clearances and for overall equilibrium. The slideline option also prevents penetration of one material into the other. The normal pressure and maximum shear stress on the contacting surfaces are related by a specified coefficient of friction. Frictional sliding occurs as demanded for overall equilibrium. This permits sliding of the cylinder ends relative to the end rings and sliding of the end rings relative to the end plates. The end ring has a slight conical taper on the side that contacts the end plate. The initial clearance due to this taper closes as the pressure is applied. This action provides for a controlled rotation of the 
cylinder end. There is also an initial radial clearance between the inner radius of the cylinder and the outer radius of the end plug. This clearance closes as the external pressure is applied, providing radial support to the cylinder as the pressure increases.

The FEM mesh is shown in Fig. 1.2.2-2. The elements in this model were twodimensional, four-noded, axisymmetric, quadrilateral, isoparametric solid elements. The NIKE2D code has only the four-noded quadrilateral element in its element library. These elements are essentially linear and use a low order of interpolation and numerical integration. This type of element requires a relatively fine mesh to reduce discretization errors and to provide the required accuracy. Other codes such as NISA II, ${ }^{18}$ ABAQUS, ${ }^{19}$ and $A D I N A^{20}$ offer higher-noded elements having higher order interpolation and integration. A coarser mesh can be used with these elements than with the linear fournoded element. However, NIKE2D is attractive for this application because it has the advantage of automatic mesh generation with MAZE and automatic generation of slideline and pressure data, and data for frictional slidelines. Model generation for ABAQUS and ADINA is more laborious and tedious becuuse of the limited mesh generation capabilities provided with these codes. Both MAZE and NIKE2D also offer automatic bandwidth optimization of the stiffness matrix. This is particularly beneficial when slidelines are used. The model in Fig. 1.2.2-2 contained 1868 elements and 2083 nodes. The model had a total of 4160 unconstrained degrees of freedom.

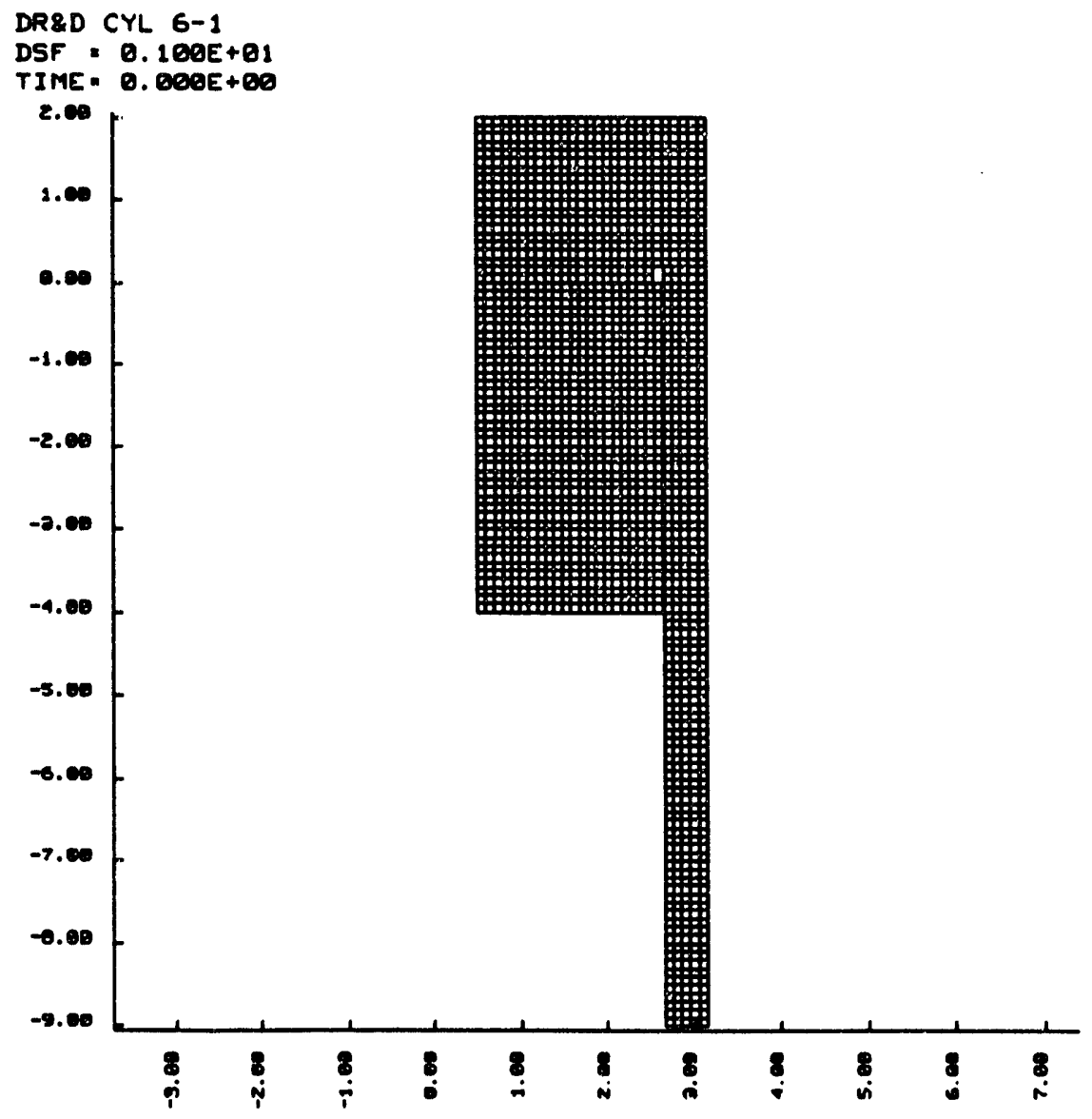

Fig. 1.2.2-2. Finite element mesh. 
An incremental nonlinear solution method was applied with the pressure increasing incrementally in accordance with a linear increase from 0 psig to a maximum value of 20,000 psig. The load was applied in 20 equal load increments. Equilibrium iterations and stiffness matrix reformations were permitted at each load step. The solution converged over the entire range of pressures within the tolerances prescribed.

The analysis results were postprocessed with the ORION code. In general, several types of plots were generated at selected load states. These included contour plots of the displacements, stresses and strains, displaced outline plots and interface plots. Line plots of selected variables were also produced for selected boundary lines on the cylinder. The line plots give the variation of the selected variable along the chosen boundary. Line plots are selected for free edges or planes of symmetry. Interface plots are produced for contacting surfaces.

The displaced outline plots are particularly useful for visualizing the deformations and the relative displacement of mating parts during the load application. In this case, the displaced outline plots show the closing of the clearance between the cylinder and end plug as pressure is increased. This was used to verify the end plug design calculations. The displaced outline plot of the cylinder is shown in Fig. 1.2.2-3 for an applied pressure of 20,000 psig. This plot shows the cross section of the cylinder and portions of the end plug, end plate, and end ring. Because a zoom feature was used in ORION to select the area for plotting, the aspect ratio of this plot is not $1: 1$. This plot shows that at the maximum pressure $(20,000 \mathrm{psig})$, the initial radial clearance between the cylinder and plug has completely closed along the entire length of the plug. This was also confirmed by the interface plot of the normal pressure between the cylinder and the plug.

Contour plots were generated for displacements, stresses, and strains for several different pressures values. To illustrate the results, plots for 20,000 psig are included. The contour plots for radial and axial displacements are given in Figs. 1.2.2-4 and 1.2.2-5. The radial displacement of the cylinder inner radius at 20,000 psig is slightly greater than the initial radial clearance at the end of the plug. This result validates the design of the taper and gap of the plug. The axial displacement contour lines in the cylinder (see Fig. 1.2.2-5) are nearly horizontal, which indicates that the axial load is nearly uniform across the end face of the cylinder. This result verifies the function of the end ring.

Stress contour plots for each component of stress are shown in Figs. 1.2.2-6 through 1.2.2-9. These stresses are the smeared composite stresses rather than layer stresses. Layer stress values can be estimated from the composite stress values if given the ply ratio of the lay-up. The axial stress and shear stress plots are used to determine the peak bending and shear stress in the cylinder near the end of the plug. These contour plots indicate that the bending stress is below $5 \mathrm{ksi}$ and that the peak shear stress is approximately 700 psi.

Strain contour plots for each component of strain are given in Figs. 1.2.2-10 through 1.2.2-13. The strain values apply to either the layered or smeared materials because of strain compatibility in the laminate formulation. 


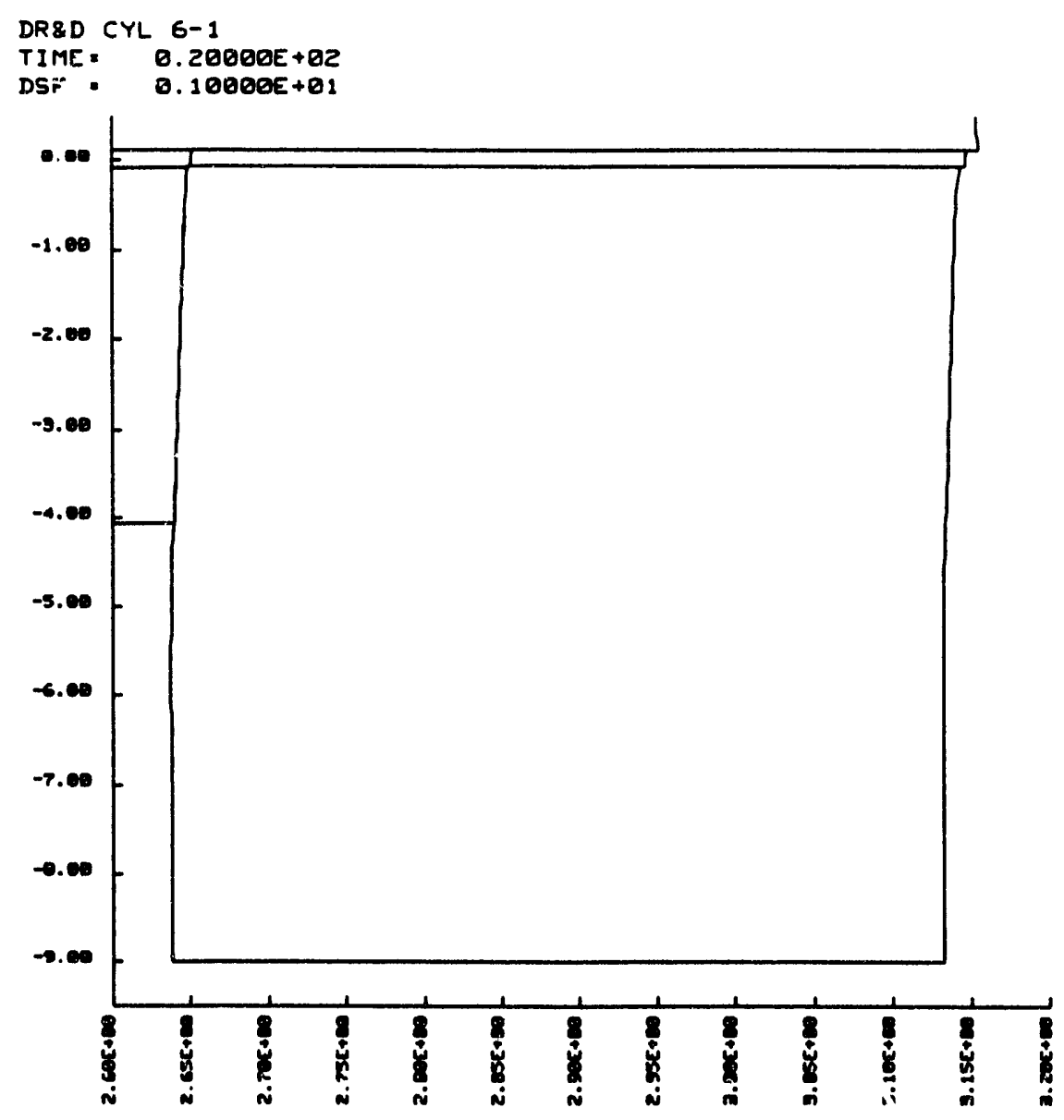

Fig. 1.2.2-3. Displaced outline of cylinder cross section.

Interface plots for the interface between the cylinder end face and the end ring were generated for a range of load states. Figs 1.2.2-14 and 1.2.2-15 give the plots for the normal pressure and shear stress. The abscissa in Figs. 1.2.2-14 and 1.2.2-15 is the distance along the interface measured from the outer radius toward the inner radius. Each curve in these plots corresponds to a single pressure value. The state numbers correspond to the pressure, expressed in ksi, plus one (i.e., state 21 corresponds to $20,000 \mathrm{psig}$ ). The pressure curves at the higher load states are nearly horizontal, indicating uniform loading of the cylinder end by the end closure. The peak axial stress occurs at the outer radius of the cylinder but is only slightly higher than the axial stress value at the inner radius (i.e., $79 \mathrm{ksi}$ versus $64 \mathrm{ksi}$ ). The interface shear stress values are low except for the end point values (near the corners of the cylinder cross section). These values are probably not accurate; FEM has inaccuracies at corner elements due to the four-noded element and the interpolation of the interior point values to the edges. 


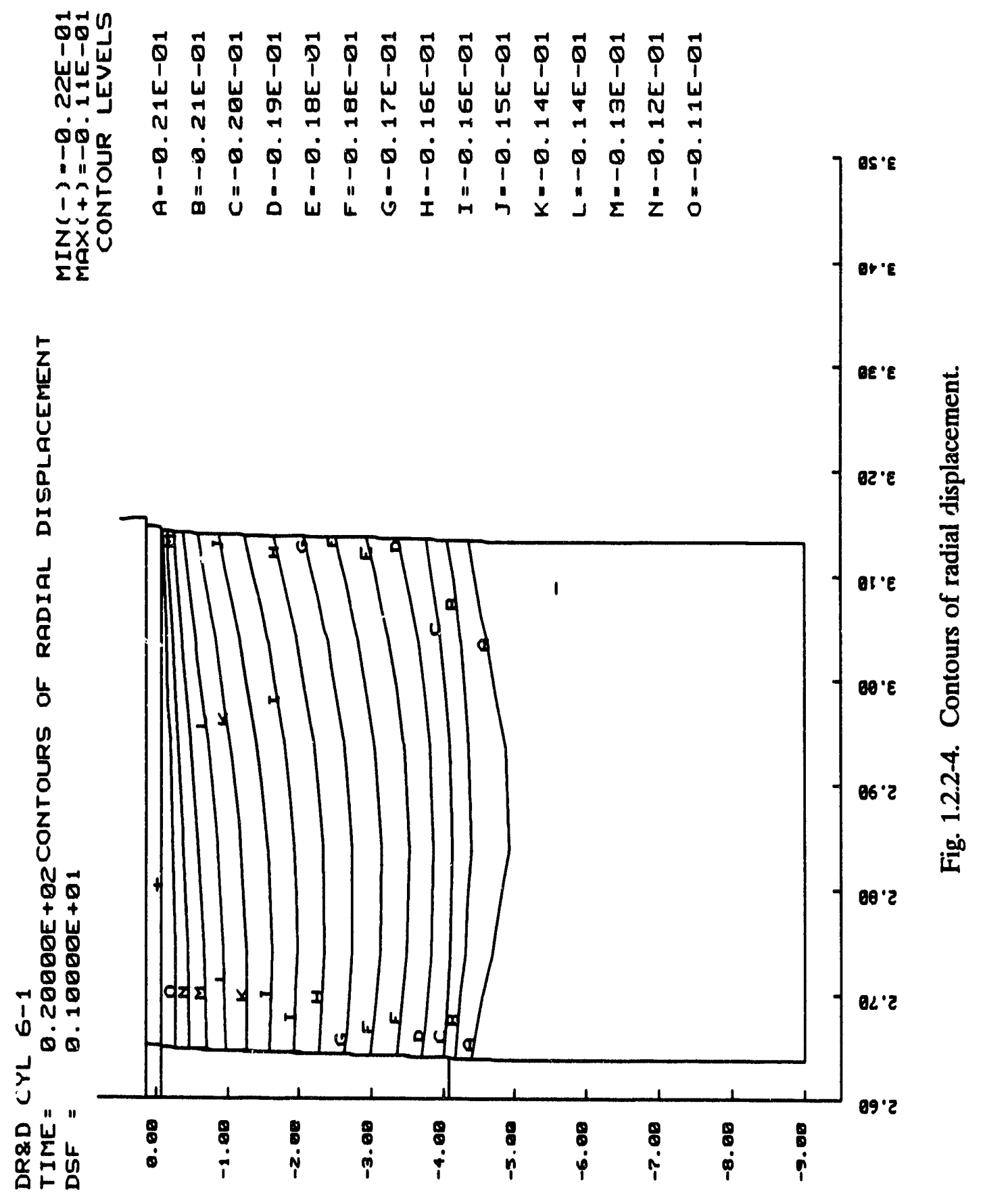




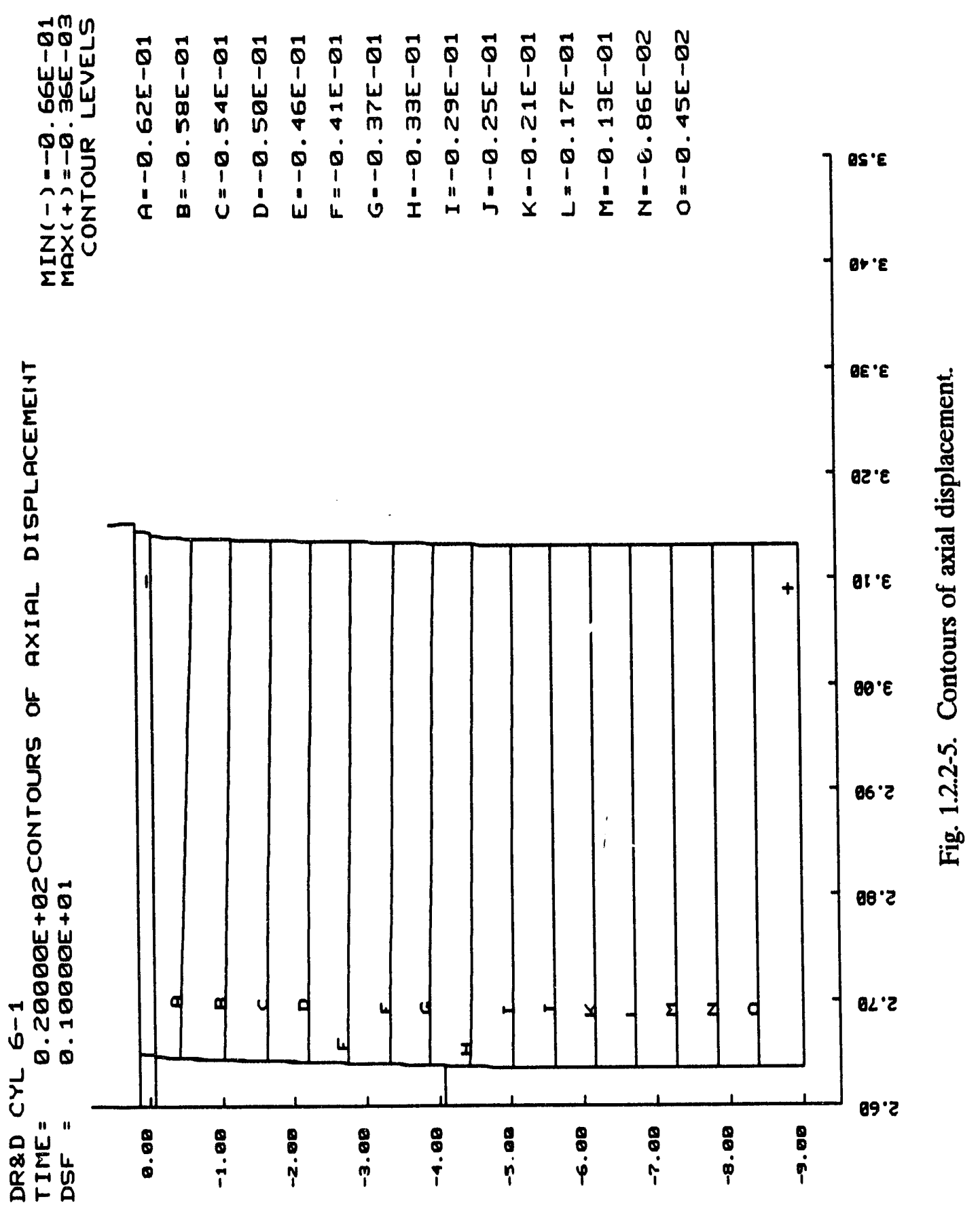




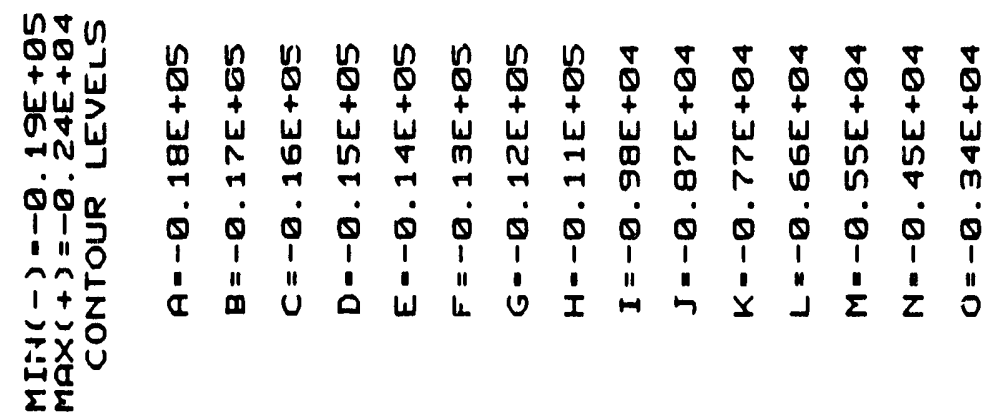

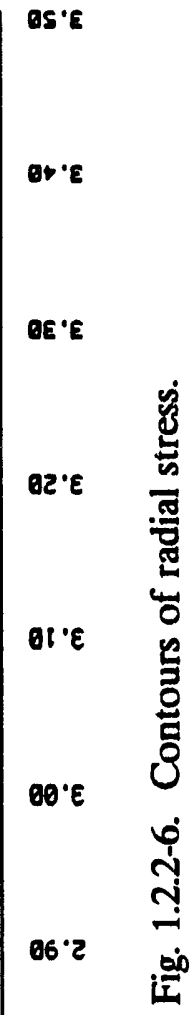
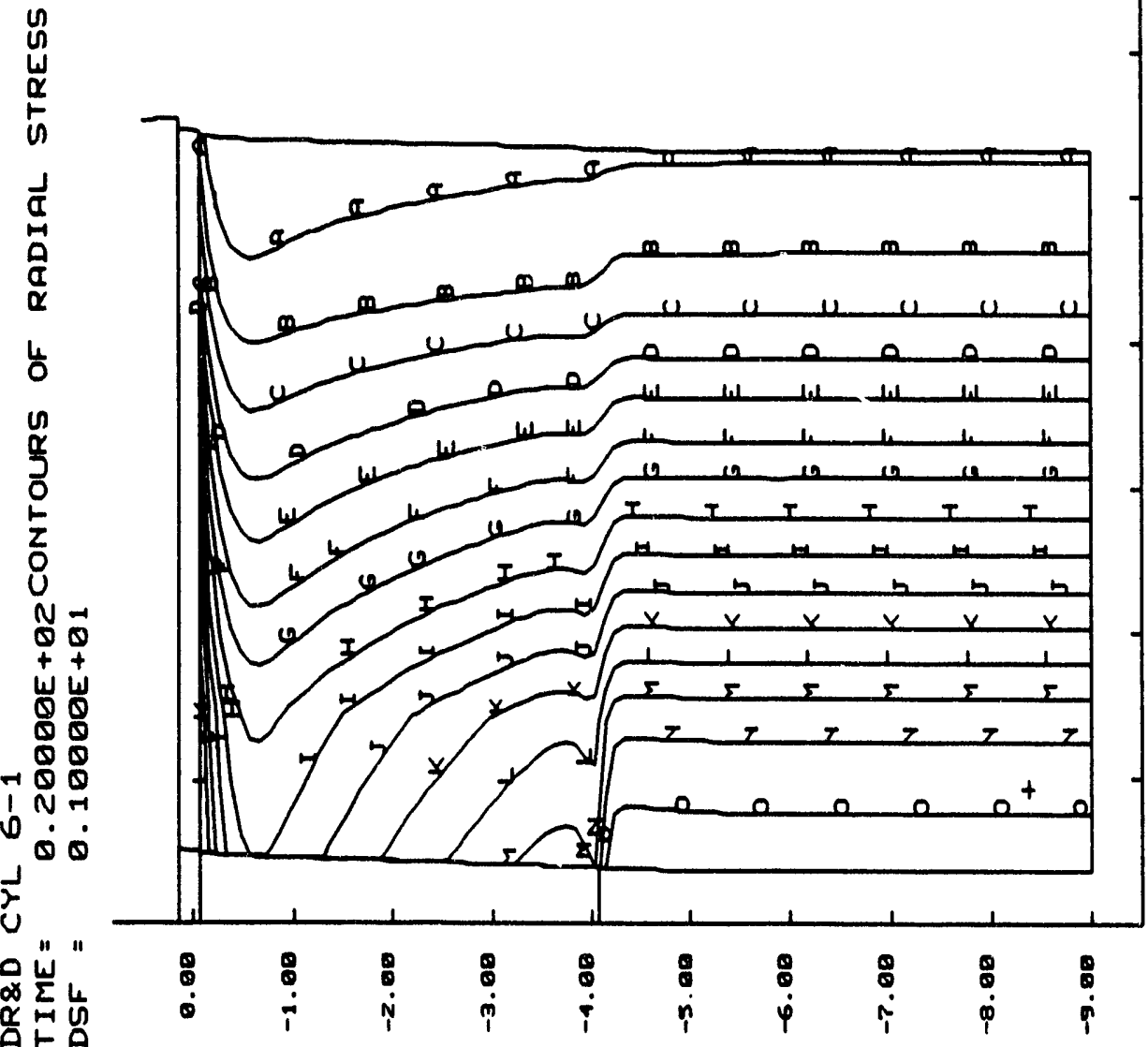

$88 \cdot 2$

02. 2 

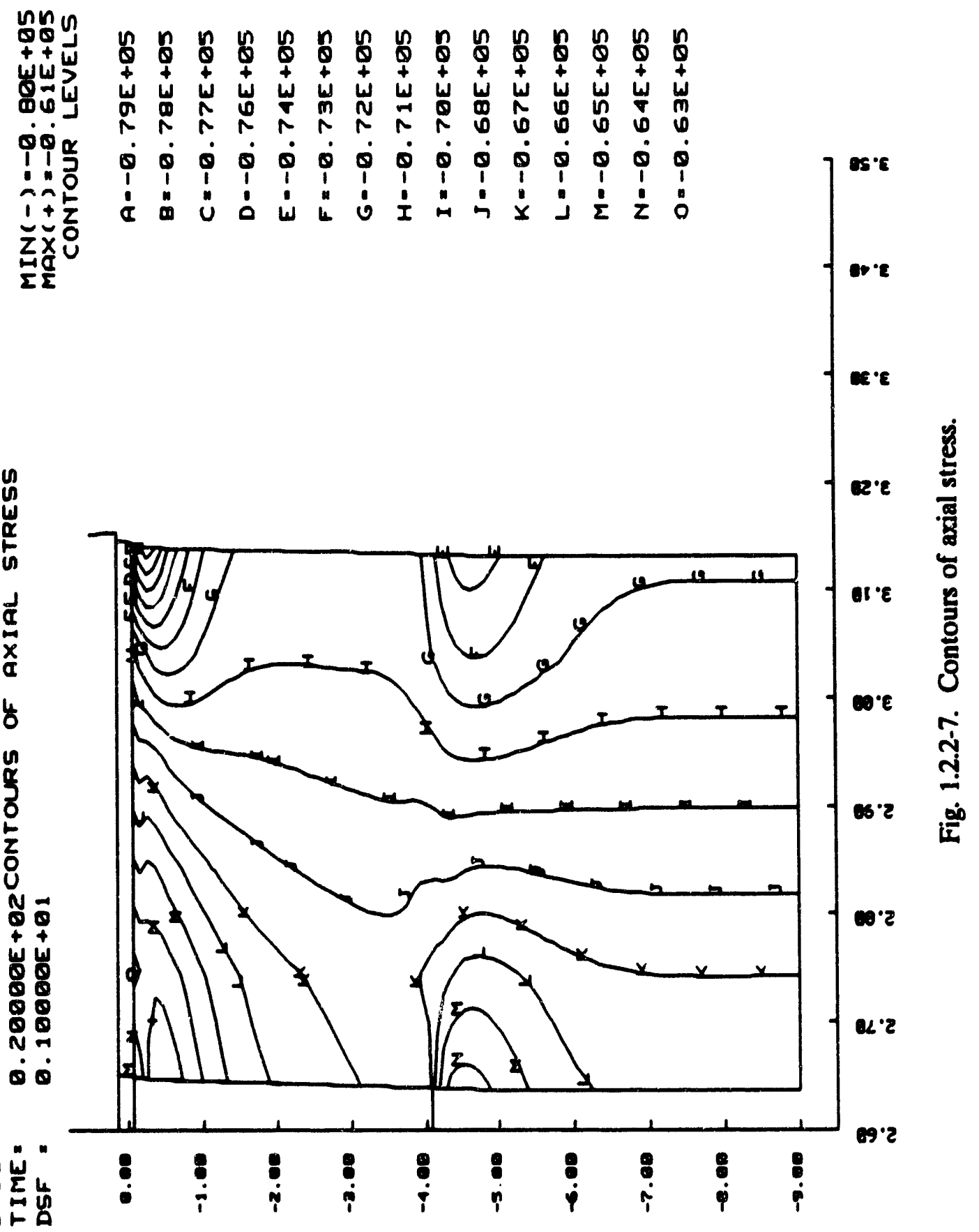


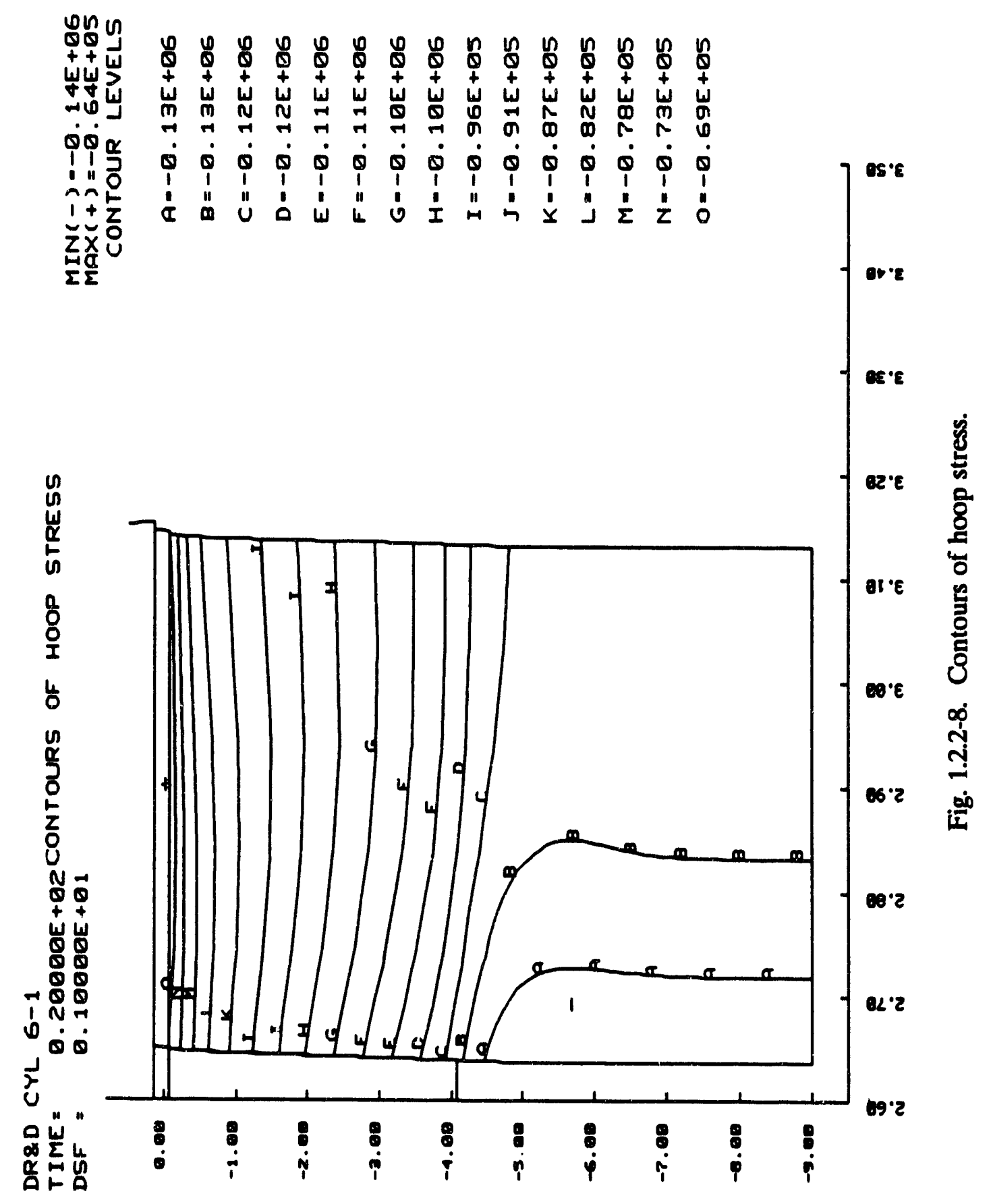



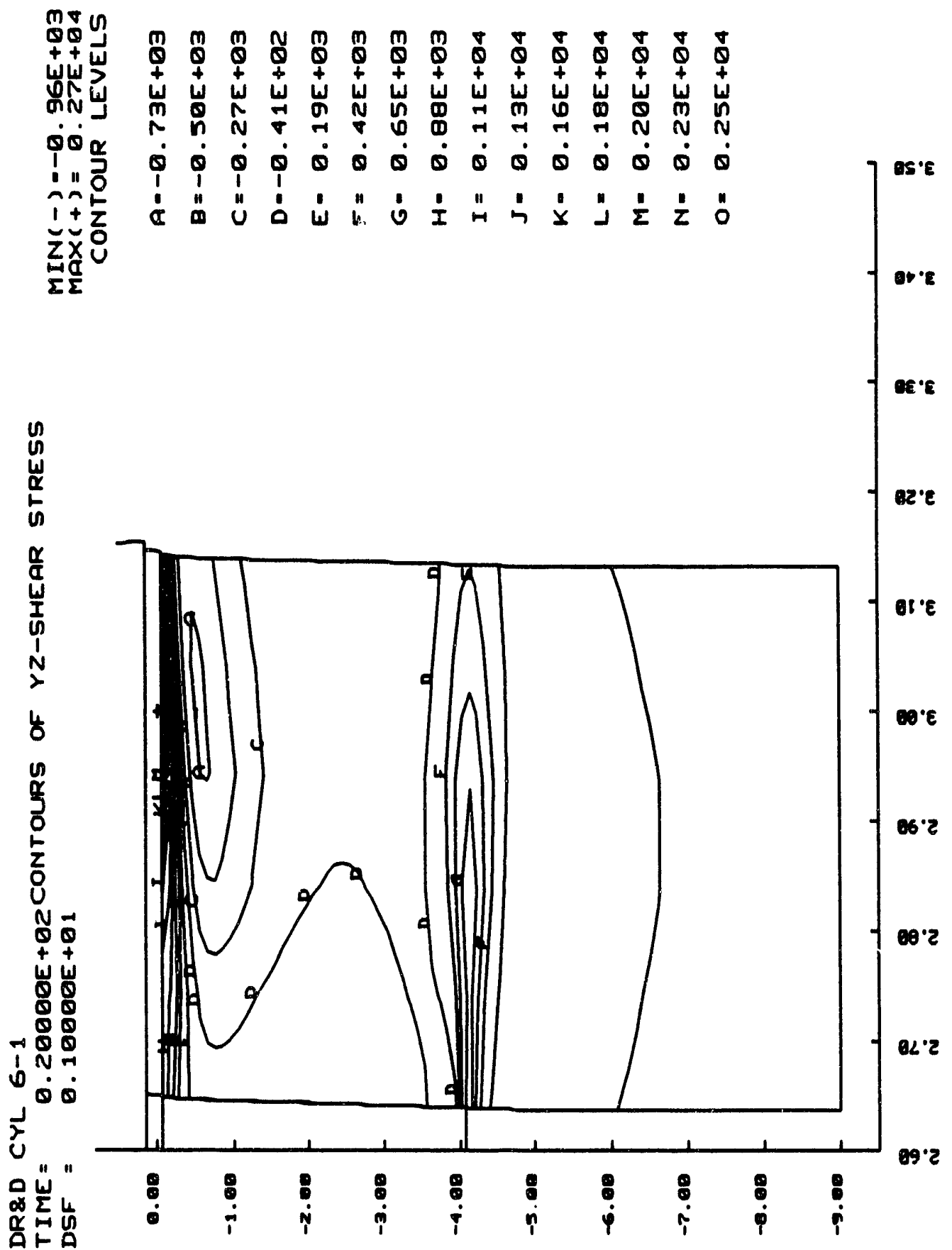

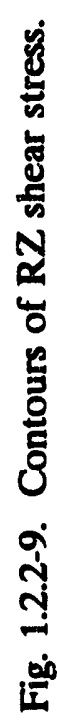
'2 2 

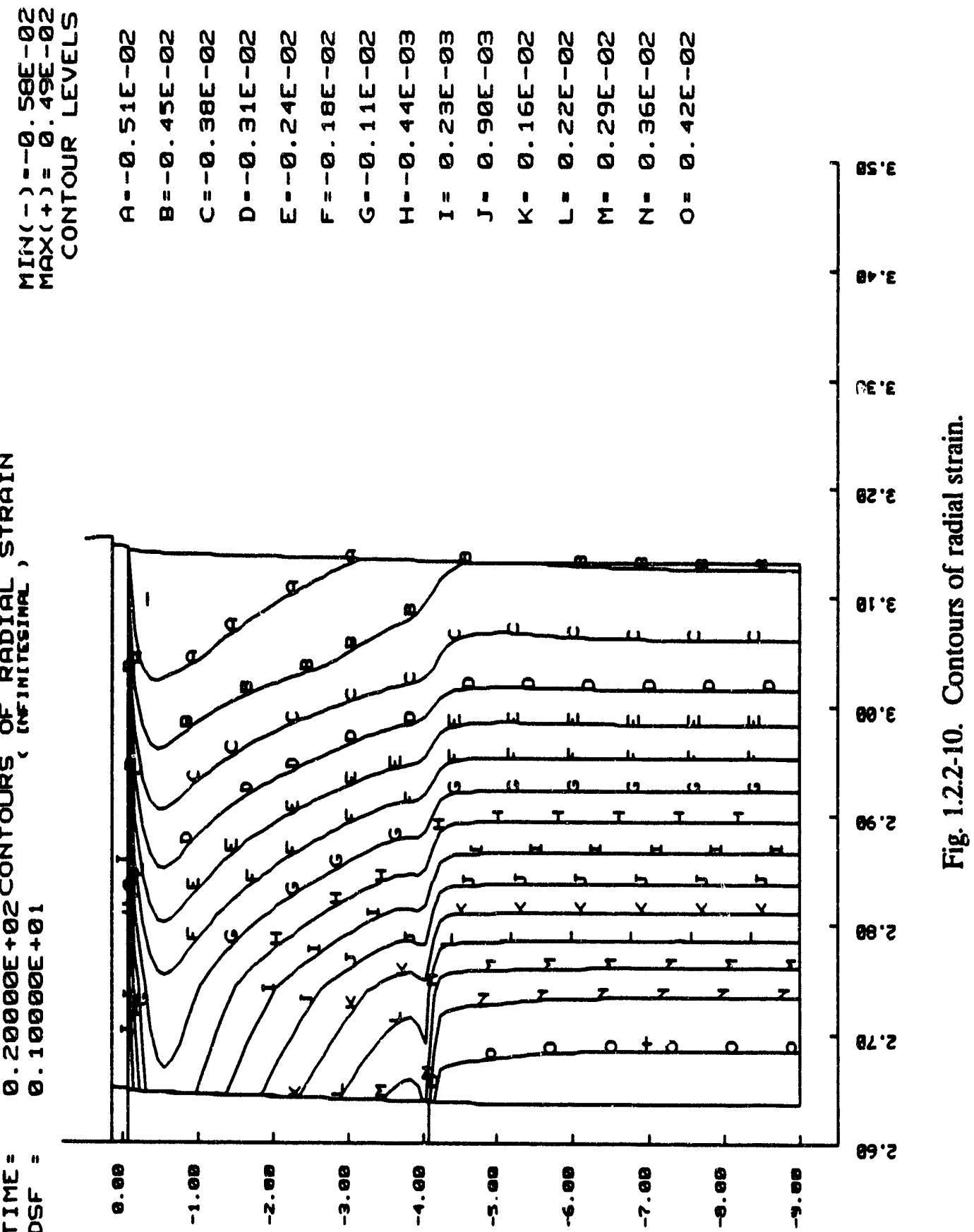

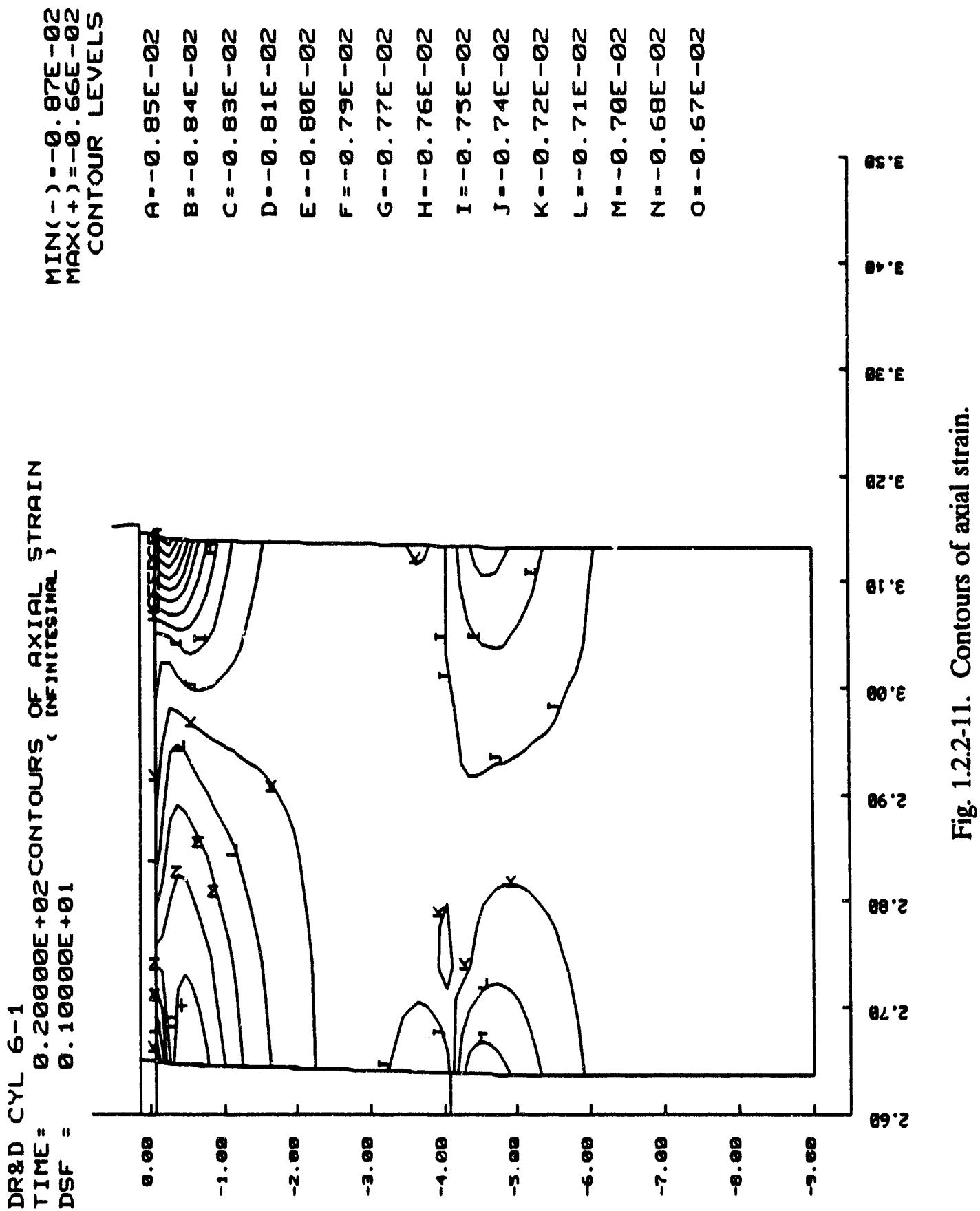
NNin

11,

\begin{tabular}{lllllllllllllll}
$N$ & $N$ & $N$ & $N$ & $N$ & $N$ & $N$ & $N$ & $N$ & $N$ & $N$ & $N$ & $N$ & $N$ & $N$ \\
\hline & 0 & $Q$ & 0 & 0 & 0 & 0 & 0 & 0 & 0 & 0 & 0 & 0 & 0 & 0
\end{tabular}

领

由m

iि

Q⿱艹

1"

$1+\frac{1}{2}$

žxu

$\Sigma \bar{\Sigma}$

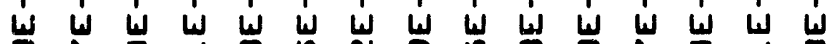

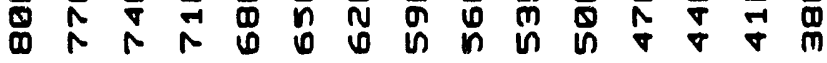

$\dot{\theta} \dot{\theta} \dot{\theta} \dot{\theta} \dot{\theta} \dot{\theta} \dot{\theta} \dot{\theta} \dot{\theta} \dot{\theta} \dot{\theta}$

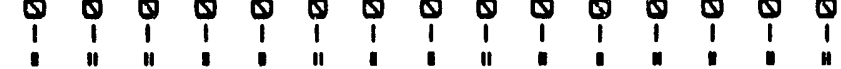

d

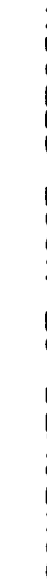

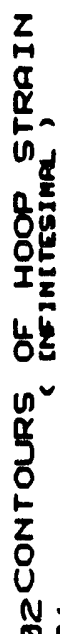

O

岁

罗要

$+80$

i N

0 0ं

ว

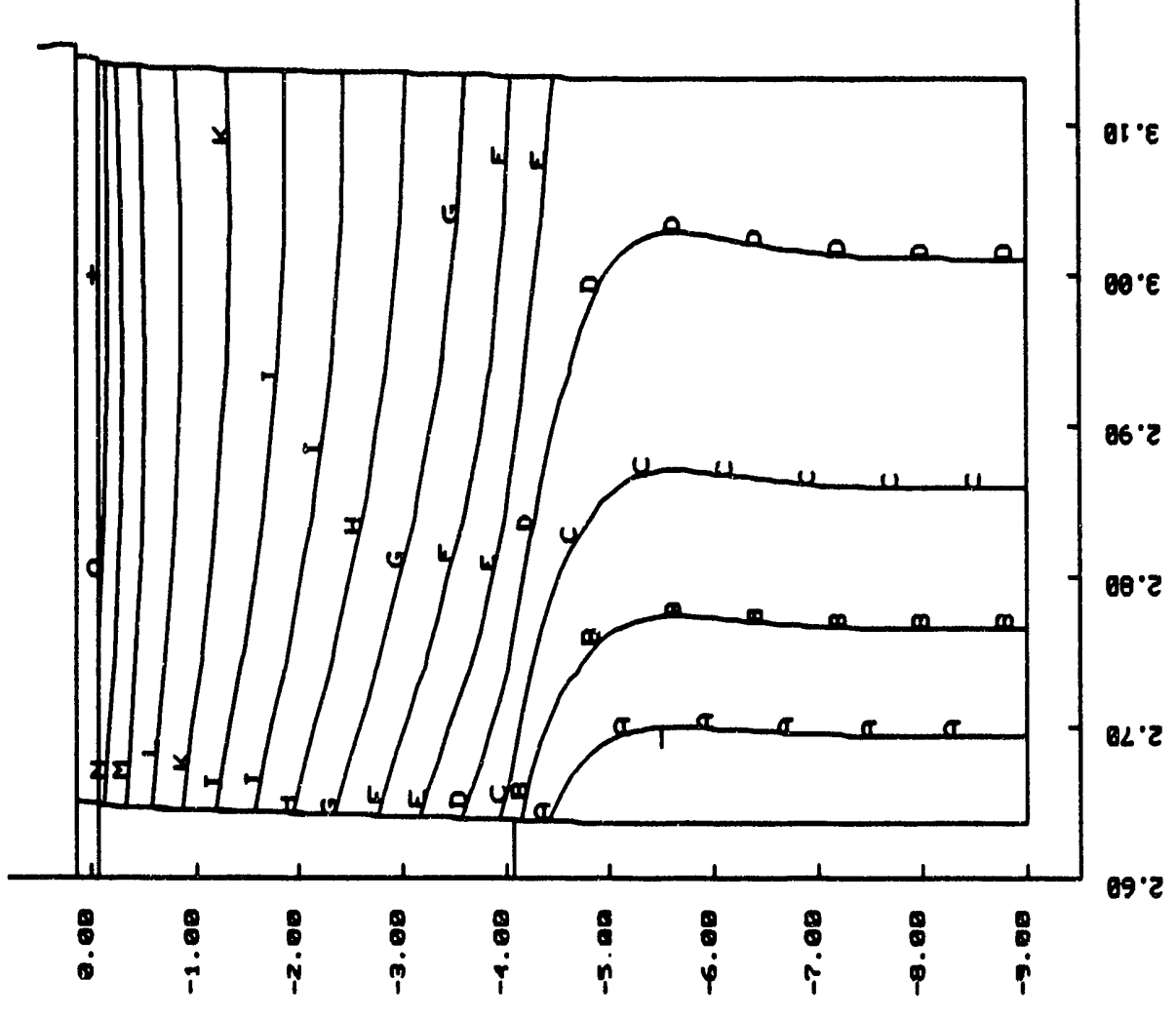

○"

员崖岇

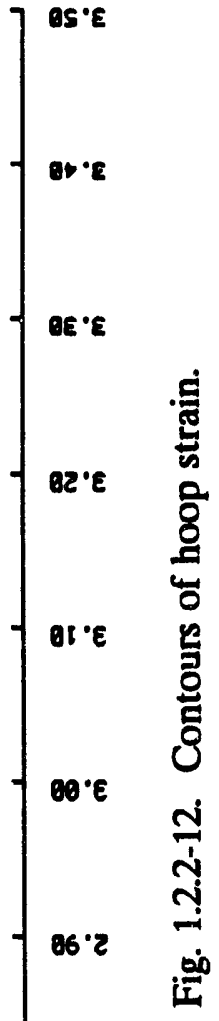




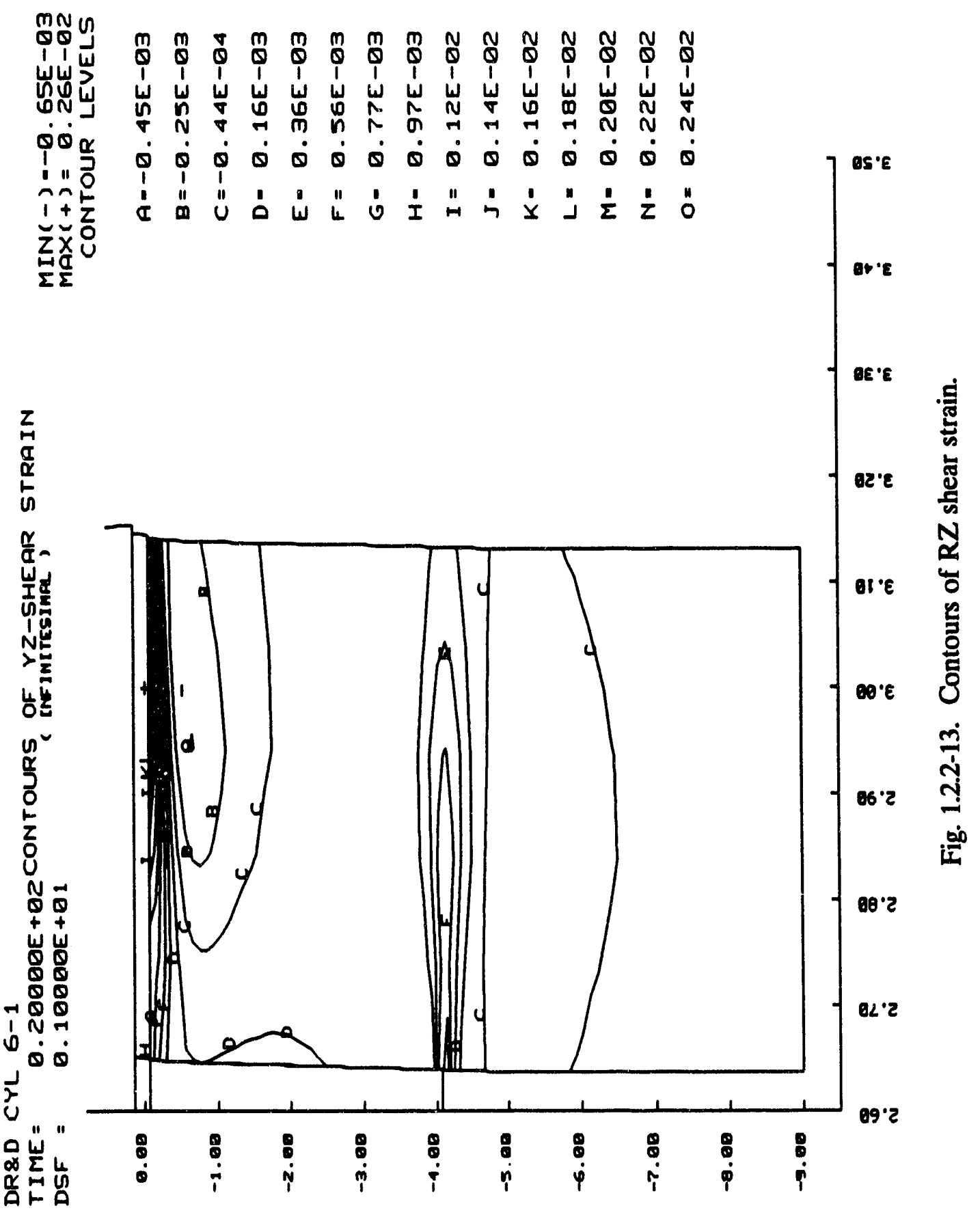




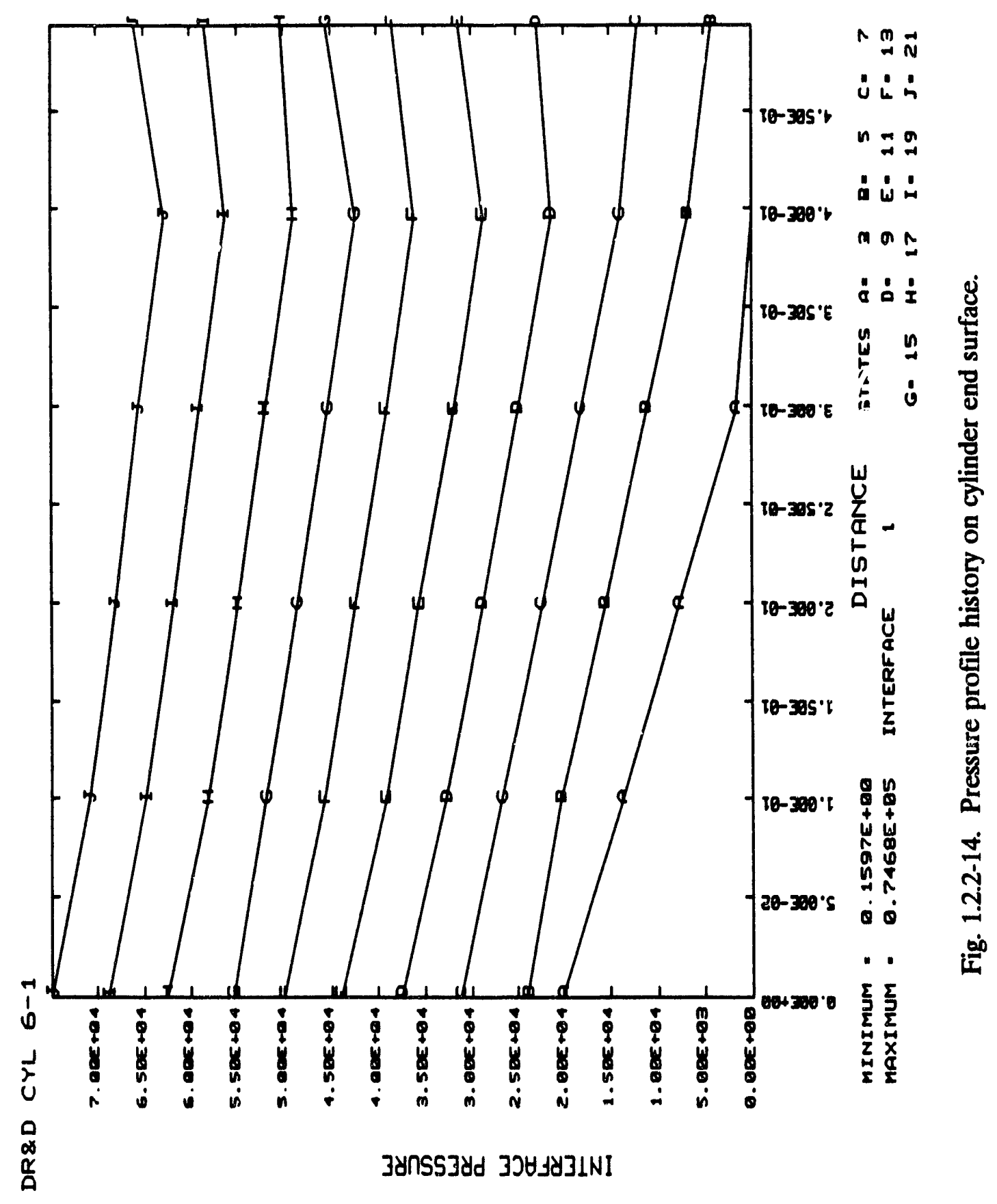




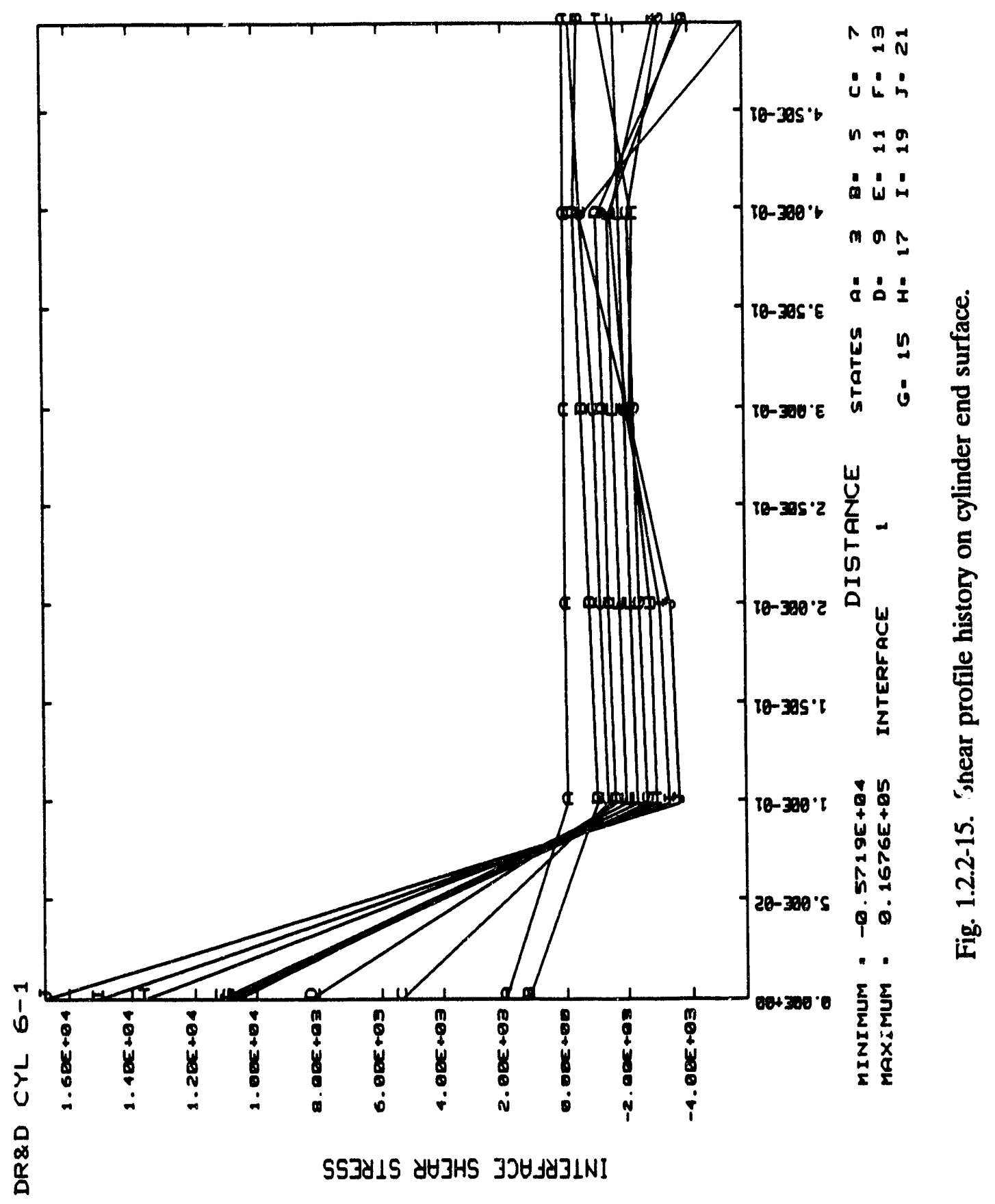




\subsection{STABILITY ANALYSIS RESULTS}

Existing closed-form analytic solutions for buckling of laminated composite cylindrical shells are most commonly formulated by using an orthotropic stiffness layer approach or a laminated shell theory approach. Typically, both of these formulations are based on smalldeflection, thin-shell theory (i.e., Donnell type equilibrium equations ${ }^{21}$ ) and no transverse shear deformations. In most cases the assumed form of the displacements satisfies ideal simply supported boundary conditions at the cylinder ends. In review of existing closed-form buckling equations, inconsistencies were discovered in the expressions used for the midplane curvatures. The kinematic relations for the strains in laminated shell theory are expressed in terms of the midplane strains and the midplane curvatures. These equations are derived from the integration of the strain-displacement relations and vanishing transverse shear strains. Results are presented in this section for the stability of test article C6-1, and the effect of using different curvature expressions in the kinematic relations for the strains is discussed.

A previously developed computer program called CYBUCK was used to calculate the critical buckling pressures for simply supported boundary conditions. In addition to hydrostatic pressure loading, results were obtained for the critical uniform axial compression and the critical uniform lateral pressure. CYBUCK includes buckling solutions based on orthotropic stiffness layer theory (ORSLT) and LST. The ORSLT solutions are derived from the works of Jacobsen ${ }^{22}$ and Baker ${ }^{23}$. The LST solutions are derived from Jones $^{24,25}$ work and from an extension to Flugge's ${ }^{26}$ governing equations. The extension to Flugge's work for predicting the buckling pressures uses four different expressions for the midplane curvatures: Timoshenko ${ }^{27}$ and Love, ${ }^{28}$ Ambartsumyan, ${ }^{13}$ Whitney, ${ }^{14}$ and the Donnell approximations. The expressions given by Whitney account for transverse normal strains and are an extension of Ambartsumyan's work. The current version of CYBUCK, which was updated after completing the design of cylinder (6-1, also has a buckling solution based on curvature expressions that include the effect of transverse shear deformations. A more detailed description of the various stability theories, which neglect transverse shear, and the CYBUCK program are described by Blake et al. (see Ref. 11). For a description of the governing equations incorporating the effects of transverse shear deformations see the work of Christoforou and Swanson ${ }^{29}$.

Buckling analyses were performed for C6-1 cylinder models having both layered properties and equivalent smeared properties. Analytic predictions were made for the critical buckling pressures as a function of the length to diameter (L/D) ratio of the cylinder. The as-fabricated cylinder, after removal of scrap material from the ends, had an overall length of 26 inches. The final machined length of the cylinder was determined from the buckling results described in the following paragraphs.

Critical hydrostatic pressure results are presented for cylinder lengths of 18, 10, and 6 inches in Table 1.3-1 for the layered analysis and in Table 1.3-2 for the smeared property analysis. In comparing the different closed-form expressions for calculating the buckling pressure for a laminated cylinder, the tabulated results show that the equations of Jacobsen, Baker, and Jones all predict approximately the same values. Nearly identical values were obtained when the Donnell approximation for the curvatures was made in the extension of Flugge's work. In the equations derived from Flugge's governing equation where the Donnell approximation is not used, lower buckling pressures are predicted. The tabulated 
results also indicate that the curvature expressions given by Timoshenko and the expressions given by Ambartsumyan predict essentially the same critical pressure. For the C6-1 cylinder construction and for the three lengths used in Tables 1.3-1 and 1.3-2, the results from using Whitney's curvature expressions indicate that the effects of a transverse normal strain are negligible. However, the effects of transverse shear deformations are significant, as demonstrated by the large reduction predicted for the critical pressure when transverse shear is included in the kinematic relations. Also, in comparing the results from Table 1.3-1 to the results from Table 1.3-2, it is seen that accurate buckling picissures can be predicted by modeling the C6-1 laminated cylinder as a single layer having equivalent smeared properties.

Table 1.3-1. Stability analysis results for hydrostatic pressure (layered analysis)

\begin{tabular}{lccc}
\hline \multirow{2}{*}{ Equation } & \multicolumn{3}{c}{ Critical pressure (ksi) } \\
\cline { 2 - 4 } & $L=18$ in. & $L=10$ in. & $L=6$ in. \\
\hline Timoshenko/Love & 20.812 & 24.829 & 35.210 \\
Ambartsumyan & 20.881 & 24.948 & 35.424 \\
Whitney & 20.804 & 24.813 & 35.277 \\
Donnell approximation & 27.387 & 30.961 & 40.296 \\
Jones & 27.206 & 30.254 & 39.498 \\
Jacobsen (ORSLT) & 27.054 & 30.102 & 39.676 \\
Baker (ORSLT) & 27.356 & 30.761 & 41.072 \\
\hline Transverse shear & 16.940 & 21.238 & 31.813 \\
\hline
\end{tabular}

Table 1.3-2. Stability analysis results for hydrostatic pressure (smeared property analysis)

\begin{tabular}{lccc}
\hline \multirow{2}{*}{ Equation } & \multicolumn{3}{c}{ Critical pressure $(\mathrm{ksi})$} \\
\cline { 2 - 4 } & $L=18$ in. & $L=10$ in. & $L=6$ in. \\
\hline Timoshenko/Love & 20.339 & 24.435 & 35.074 \\
Ambartsumyan & 20.406 & 24.552 & 35.289 \\
Whitney & 20.330 & 24.420 & 35.145 \\
Dunnell approximation & 26.752 & 30.378 & 40.050 \\
Jones & 26.565 & 29.685 & 39.167 \\
Jacobsen (ORSLT) & 26.536 & 29.649 & 39.461 \\
Baker (ORSLT) & 26.712 & 30.182 & 40.728 \\
\hline \hline Transverse shear & 16.638 & 20.997 & 31.765 \\
\hline
\end{tabular}


Further comparisons were made by plotting the critical pressure as a function of the L/D ratio. Shown in Figs. 1.3-1 through 1.3-3 are the predicted critical axial pressure, lateral pressure, and hydrostatic pressure, respectively. For all $L / D$ ratios considered and for all three pressure loadings, the predicted buckling pressures based on using the curvature expression from Timoshenko were nearly identical to the pressures predicted from using the Ambartsumyan curvatures. Also, it was seen that for the cylinder being studied, i.e., a cylinder having only hoop and axial plies, the transverse normal strains had a negligible effect on the buckling pressures independent of the $L / D$ ratio.

In Fig. 1.3-1 large discrepancies are depicted between the critical axial pressure predicted by Jones and all other predictions. The results based on Jones' formulation show the critical axial pressure to increase as the $L / D$ ratio increases. In fact, the analytic solution from Jones predicts an infinite axial pressure as the length of the cylinder approaches infinity. For the other formulations the results decrease as the $\mathrm{L} / \mathrm{D}$ ratio increases and converge to an infinite length cylinder solution. The effect of transverse shear deformations on the critical axial pressure are showi to be significant only for L/D ratios less than 2 .

The behavior of the critical lateral pressure and the critical hydrostatic pressure as a function of the cylinder L/D ratio are shown in Figs. 1.3-2 and 1.3-3 to be similar. Larger pressures are predicted for the case of uniform lateral pressure as compared to the hydrostatic pressure. The lower critical hydrostatic pressures are due to the added axial compression associated with hydrostatic loading. The axial component of pressure in the hydrostatic loading becomes negligible when $\mathrm{L}$ becomes large, as indicated by the magnitude of the critical hydrostatic pressure being the same as the critical lateral pressure.

In Fig. 1.3-3 the results show that as $\mathrm{L} / \mathrm{D}$ becomes large, the solutions based on the Donnell approximation and Jones formulation approach a magnitude of $4 D_{\mathrm{y}} / R_{\mathrm{m}}{ }^{3}$. The same expression, where $R_{\mathrm{m}}$ is the mean radius, was obtained analytically by letting the length of the cylinder, $L$, approach infinity in the limit. For an orthotropic cylinder,

$$
D_{y y}=\frac{E_{y y} I}{1-v_{x y} v_{y x}},
$$

where $I=h^{3} / 12$, and $h$ is the cylinder thickness. When derivatives of the axial and hoop displacement components are retained in the curvature expressions (e.g., Whitney, Ambartsumyan, and Timoshenko), lower critical hydrostatic pressures are predicted that approach $3 D_{\mathrm{yy}} / R_{\mathrm{m}}{ }^{3}$ as L/D becomes large. This agrees with Timoshenkos well-known result for an isotropic tube. Again, it was analytically shown that by letting $L$ go to infinity in the solution, the expression for the critical hydrostatic pressure reduces to $3 D_{\mathrm{yy}} / R_{\mathrm{m}}{ }^{3}$. This figure also illustrates that the critical pressure approaches the infinite length solution very rapidly and at a rather small L/D ratio equal to approximately 7.0. For an infinite length cylinder, an approximate solution that includes transverse shear is given by

$$
P_{e r}^{-\infty}=\frac{3 D_{y y}}{R_{m}^{3}}\left[\frac{1}{1+0.4\left(\frac{h}{R_{m}}\right)^{2} \frac{D_{y y}}{G_{y r} I}}\right],
$$


where $G_{\mathrm{yr}}$ is the transverse shear modulus and $D_{\mathrm{yy}}$ is given in Eq. (1.3-1). For a material that has an infinite transverse shear stiffness, i.e., $G_{\mathrm{yr}}$ is very large, Eq. (1.3-2) reduces to an infinite length solution that agrees with Timoshenkos isotropic tube solution.

The C6-1 cylinder was tested in a pressure vessel rated for use up to 20,000-psi hydraulic pressure (see Sect. 3.2). A design consideration for C6-1 was that it not be buckling critical, which means the allowable buckling pressure must be greater than allowable strength. It is ciesirable to have the unsupported cylinder length as long as possible to minimize any end closure effects on the gage section stress state but short enough to preclude buckling failure. The design assumption was to have the allowable buckling pressure greater than the pressure vessel capability of 20,000 psi with a margin of safety. The results plotted in Fig. 1.3-3 for buckling pressures that neglected transverse shear deformations indicated an unsupported length of 10 inches would not be a buckling critical design. The predicted buckling pressure for this case was equal to 24,813 psi (see Table 1.3-1). The end closures utilized in the testing of C6-1 were 4.0 inches long, which for a 10-inch unsupported length resulted in a machined length of 18 inches for the cylinder. Subsequent analyses that included the $\mathrm{effects}$ of transverse shear deformations indicated this design to be marginally safe with regards to buckling considerations. Table 1.3-1 indicates that accounting for transverse shear effects reduces the critical buckling pressure to 21,238 psi.

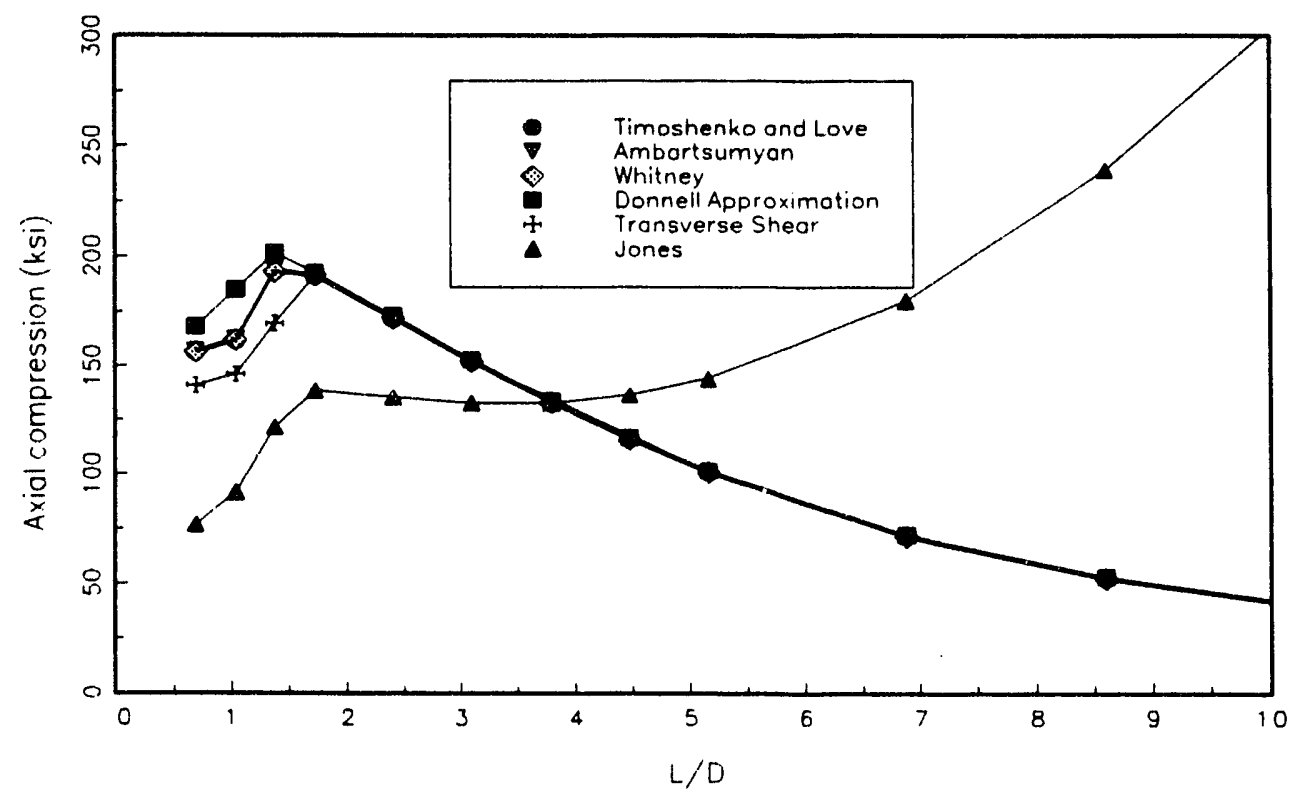

Fig. 1.3-1. Critical axial pressure versus cylinder $\mathrm{L} / \mathrm{D}$ ratio. 


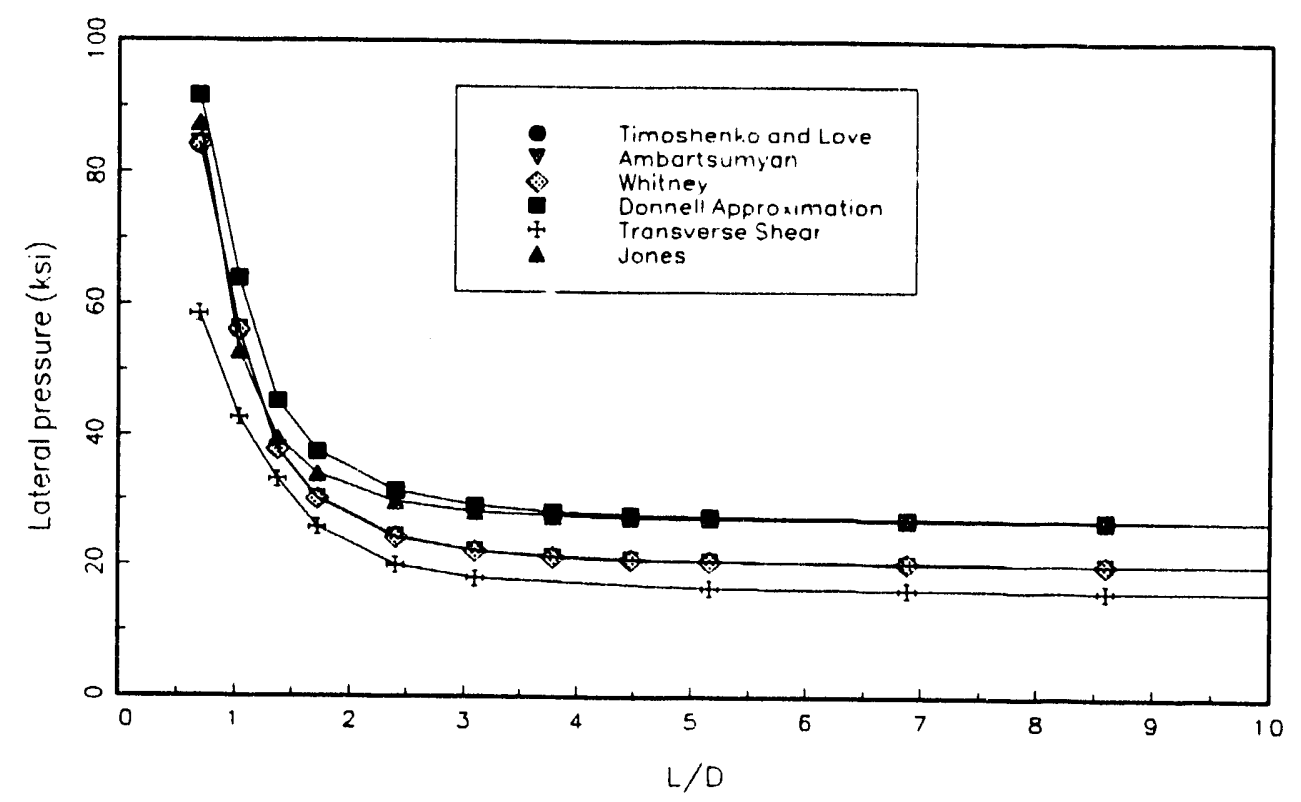

Fig. 1.3-2. Critical lateral pressure versus cylinder L/D ratio.

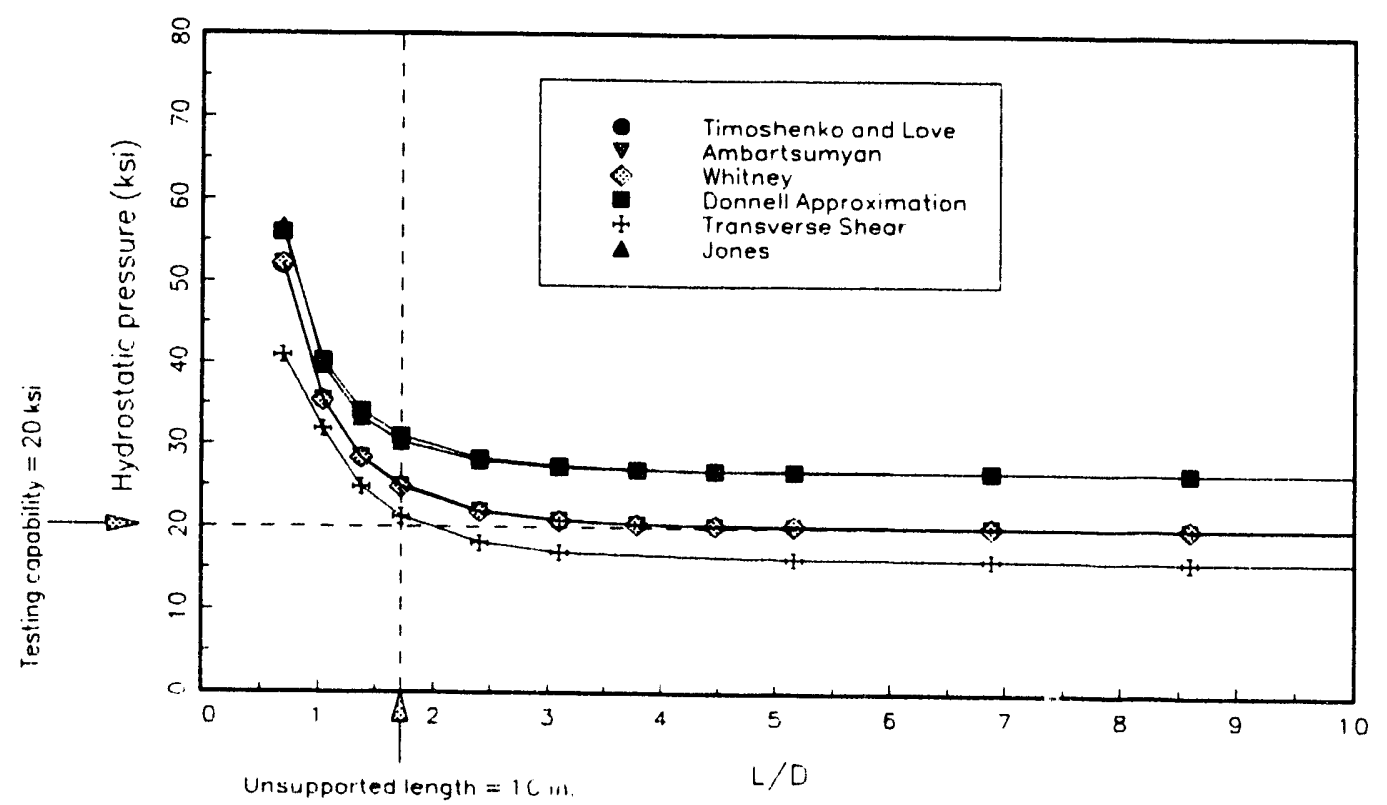

Fig. 1.3-3. Critical hydrostatic pressure versus cylinder L/D ratio. 


\subsection{FAILURE ANALYSIS RESULTS}

Closed-form analytic solutions were used to calculate the ply-level stress distributions in cylinder C6-1 when it was subjected to a 1-ksi hydrostatic pressure. The stresses in the cylindrical coordinate system were rotated to the lamina principal material directions, and failure theories were applied at the ply-level. In the program CCAP, first-ply failure was predicted based on Hashin's ${ }^{30}$ criteria, the Tsai-Wu ${ }^{31}$ criterion, maximum stress, and maximum strain. The Tsai-Wu criterion used in CCAP was also implemented by Roy ${ }^{32}$ in his program, CYLIN, and in the program CYLAN, which was described in Sect. 1.2. Roy also predicted first-ply failure based on a two-dimensional stress state (thin wall solution) and Tsai-Wu's criterion. The results of theses analyses are presented in Table 1.4-1.

Table 1.4-1. Failure analysis results

\begin{tabular}{|c|c|c|c|c|c|c|c|c|}
\hline \multirow{2}{*}{$\begin{array}{l}\text { Failure } \\
\text { criteria }\end{array}$} & \multicolumn{2}{|c|}{$Y_{s}=10 \mathrm{ksi}$} & \multicolumn{2}{|c|}{$Y_{c}{ }^{c}=15 \mathrm{ksi}$} & \multicolumn{2}{|c|}{$Y_{c}{ }^{c}=20 \mathrm{ksi}$} & \multicolumn{2}{|c|}{$Y_{c}{ }^{c}=30 \mathrm{ksi}$} \\
\hline & layer & $p_{a}(k s i)$ & layer & $P_{\alpha}(k s i)$ & layer & $p_{a}$ (ksi) & layer & $P_{\alpha}$ (ksi) \\
\hline Hashin & 36 & 13.404 & $1^{b}$ & 20.219 & $1^{*}$ & 25.720 & $1^{c}$ & 25.720 \\
\hline Tsai-Wu & 1 & 14.134 & 1 & 21.830 & 1 & 29.733 & 1 & 45.691 \\
\hline Max. v & 38 & 9.1058 & 38 & 13.659 & 38 & 18.212 & 1 & 25.720 \\
\hline Max. $\epsilon$ & 3 & 16.225 & 3 & 24.338 & 1 & 26.347 & 1 & 26.347 \\
\hline $\operatorname{Roy}(3-D)$ & 1 & 14.200 & 1 & 21.933 & 1 & 29.880 & 1 & 45.953 \\
\hline $\operatorname{Roy}(2-D)$ & 3 & 15.097 & 3 & 23.315 & 3 & 31.807 & 1 & 49.223 \\
\hline CYLAN & 1 & 13.644 & 1 & 21.090 & 1 & 28.785 & 1 & 44.545 \\
\hline
\end{tabular}

- Transverse compressive strength

Compressive matrix mode

- Compressive fiber mode

\section{Notes:}

Layer no. 1 = innermost hoop ply

Layer no. 3 = innermost axial ply

Layer no. 38 = outermost hoop ply

Hashin's three-dimensional failure criteria for unidirectional fiber composites was applied to each ply in the laminated cylinder. These criteria not only determined the critical pressure for first-ply failure but also the failure mode. The four distinct failure modes considered are tensile fiber mode, tensile matrix mode, compressive fiber mode. and compressive matrix mode. Each mode is modeled separately and the criteria are formulated in terms of quadratic stress polynomials, which results in a piecewise smooth failure surface. First-ply failure is determined by the minimum value of a stress ratio, $R$, defined to be

$$
\{\sigma\}_{\text {MX }}=R\{\sigma\}_{\text {APPUED }} \text {. }
$$


For an applied unit pressure, the magnitude of $R$ determines the critical pressure and the location of the minimum value defines the first-ply to fail.

The specified layer strengths used in the failure criteria were given in Table 1.1-4. Due to the uncertainty of the exact value to use for the allowable transverse compressive strength, a preliminary design assumption was to assume a minimum strength of $10 \mathrm{ksi}$ and a maximum strength of $20 \mathrm{ksi}$. The failure analysis was also performed using an intermediate allowable transverse compressive strength of $15 \mathrm{ksi}$, and results are presented in Table 1.4-1 for these three different allowables.

The results show that all criteria used in the failure analysis predict an increase in the allowable pressure for first-ply failure when the transverse compressive strength is increased. As stated above, the application of Hashin's criteria identifies one of four different failure modes associated with the allowable pressure at first-ply failure. For allowable transverse compressive strengths of $10 \mathrm{ksi}$ and $15 \mathrm{ksi}$, the results indicate a compressive matrix mode of failure. An increase in the allowable transverse compressive strength to $20 \mathrm{ksi}$ changes the failure mode to a compressive fiber mode. This illustrates that the mode of failure depends on the magnitude of the transverse compressive strength used in the failure analysis. The location of the first ply to fail is also seen to be a function of the transverse compressive strength. For a value of $10 \mathrm{ksi}$ the innermost axial ply is predicted to fail first, whereas, when a transverse compressive strength of $15 \mathrm{ksi}$ and higher is used, the first-ply failure occurs in the innermost hoop ply.

An additional column of predicted failure pressures is given in Table 1.4-1 for the case of an allowable transverse compressive strength equal to $30 \mathrm{ksi}$. The $30-\mathrm{ksi}$ strength value was determined experimentally in a test of an all-circumferentially wound IM6 carbon cylinder that was conducted after testing the C6-1 cylinder. The failure pressure, mode of failure, and location of first-ply failure predicted from Hashin's criteria are the $s^{n}$ ine for the two transverse compressive strengths of $20 \mathrm{ksi}$ and $30 \mathrm{ksi}$. Both of these cases predict a compressive fiber mode in the innermost hoop ply, and the maximum pressure is directly related to the allowable axial compressive strength and the calculated hoop stresses at the inner radius of the cylinder wall. This is more apparent in the case of a 30-ksi allowable strength where the results for Hashin's criteria predict a failure pressure that is equal to the maximum stress prediction.

The axial stress in the outer hoop layer is the critical stress component when a transverse compressive strength less than or equal to $20 \mathrm{ksi}$ is used in the one-dimensional maximum stress criterion. When a transverse compressive strength of $\mathbf{3 0} \mathrm{ksi}$ is used in the failure analysis, the hoop stress in the inner hoop layer becomes the critical component. Therefore, based on a maximum stress criterion, the failure mode switches from a transverse or matrix compressive mode to an axial or fil,er compressive mode when the material has an allowable transverse compressive strength of $\mathbf{3 0} \mathrm{ksi}$.

A much larger difference is seen in Table 1.4-1 between the Hashin prediction and the Tsai-Wu prediction for the case of a 30-ksi transverse compressive strength. The two predictions start to diverge for transverse compressive strengths equal to or greater than $20 \mathrm{ksi}$ where the mode changes in Hashin's criteria from a compressive matrix mode to a compressive fiber mode. This is illustrated in Fig. 1.4-1 where the predicted failure pressures :re plotted as a function of the transverse compressive strength. When the 
revised strength predictions, based on the measured transverse compressive strength of $30 \mathrm{ksi}$, are compared with the buckling predictions discussed in Sect. 1.3, the C6-1 cylinder design is seen to be buckling critical for an unsupported length of 10 inches.

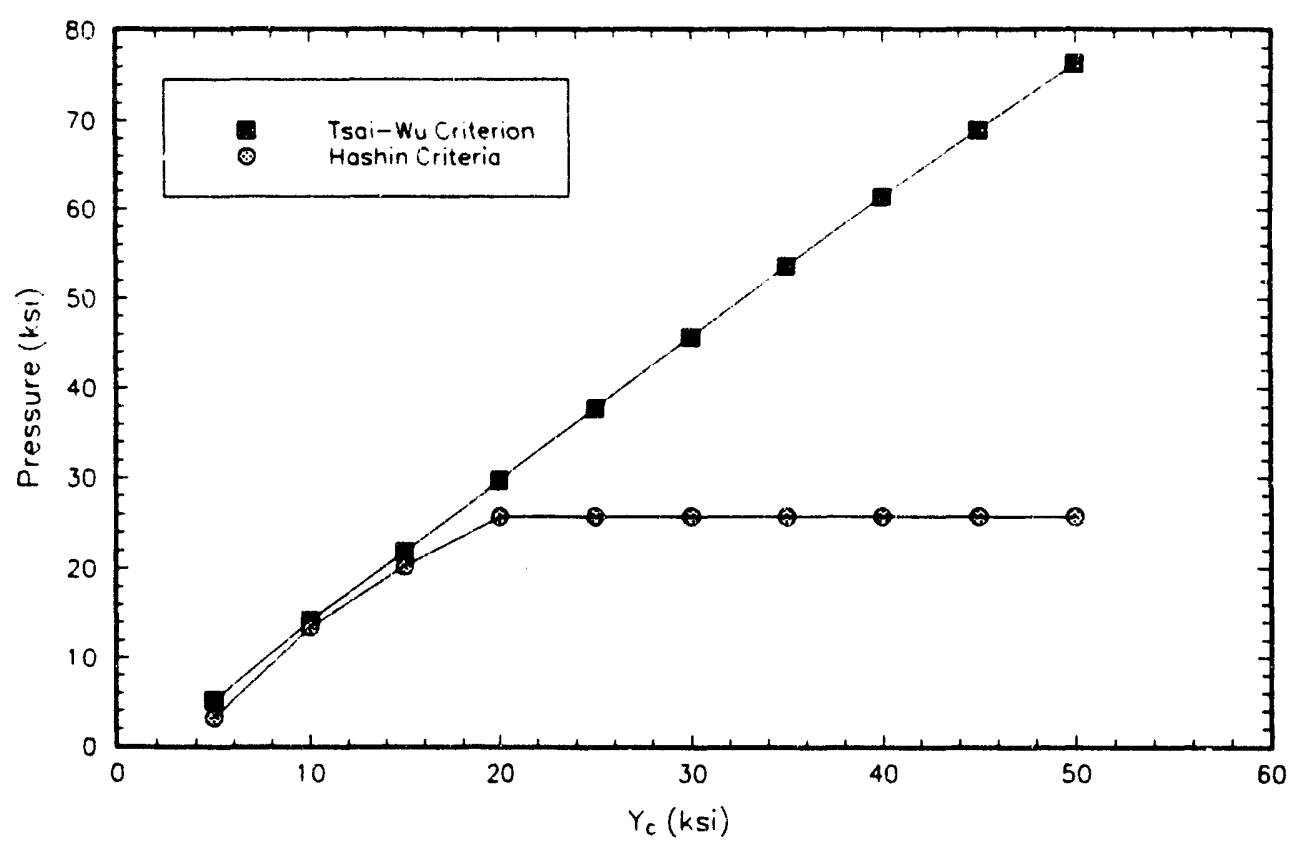

Fig. 1.4-1. Predicted failure pressures for different transverse compressive strengths. 


\section{TEST ARTICLE FABRICATION}

Cylinder C6-1 was wet wound on an aluminum mandrel using a four-axis computer controlled winding machine. The aluminum mandrel had a nominal 5.31-inch diameter and was 30 inches long. A combination comb and roller feedeye was used to maintain fiber placement during axial and hoop fabrication. Sprocket-shaped "pin-rings" were attached to each end of the mandrel to maintain placement of the axial strands. Winding pattern band advance for the axial layers was chosen to maximize coverage for the increasing part diameter. Axial layer band advance calculations for the cylinder are listed in Table 2-1. The lay-up design was a 2:1 ratio of hoop oriented fiber $\left(90^{\circ}\right)$ to axially oriented fiber $\left(0^{\circ}\right)$. The materials of construction for both the axial and hoop layers were Hercules IM6-G carbon fiber from lot X672-3P and Union Carbide ERL/2258, a 50/50 blend of diglycidyl ether of bisphenol $A$ and bis (2,3 epoxycyclopentyl) ether. The system was cured with 25 pphr mphenylenediamine.

The nominal processing conditions utilized for the cylinder design are described below. The $76 \mathrm{~cm}$ (30 in.) long aluminum mandrel was preheated to $54^{\circ} \mathrm{C}\left(130^{\circ} \mathrm{F}\right)$ prior to initiating fabrication. The resin temperature was maintained between $52^{\circ} \mathrm{C}\left(125^{\circ} \mathrm{F}\right)$ and $57^{\circ} \mathrm{C}\left(135^{\circ} \mathrm{F}\right)$ during impregnation, and heat was applied to the mandrel during the winding operation to promote resin bleed-out. The carbon tows were tensioned at the 5- to 5.5-kg (11- to 12-lb) range during hoop winding and the 2- to $2.5-\mathrm{kg}$ (4- to 5-lb) range during axial winding. The cylinder was fabricated in two stages with a B-staged cure, approximately $54^{\circ} \mathrm{C}\left(130^{\circ} \mathrm{F}\right)$, for a minimum of 16 hours between stages. The incremental B-staged cure was performed at a thickness of approximately $0.75 \mathrm{~cm}(0.3 \mathrm{in}$.), which was nominally 6 layers (or $0.10 \mathrm{~cm}$ [0.04 in.]) greater than half thickness. After completion of the winding, the part was staged at $54^{\circ} \mathrm{C}\left(130^{\circ} \mathrm{F}\right)$ for 16 hours and then cured in a forced air oven. The part was ramped to $85^{\circ} \mathrm{C}\left(185^{\circ} \mathrm{F}\right)$, held for 2 hours, ramped to $152^{\circ} \mathrm{C}\left(305^{\circ} \mathrm{F}\right)$, held for four hours, and allowed to cool to ambient overnight. The cylinder was removed from the mandrel by chilling the part and mandrel with liquid nitrogen. The cylinder was sampled for composition and dimensionally inspected.

The as-fabricated composition of the test article was determined by sampling the material at each end of the cylinder. Three samples were taken from the head stock and the tail stock, and then averaged. The results for the density, percent volume fraction of fibers $\left(V_{f}\right)$, percent volume fraction of resin $\left(V_{f}\right)$, and percent volume fraction of voids $\left(V_{v}\right)$ are presented in Table 2-2.

The target tube dimensions were approximately $13.49 \mathrm{~cm}(5.31 \mathrm{in}$.) for the inside diameter (ID) and nominally $1.27 \mathrm{~cm}(0.5 \mathrm{in}$ ) thick. The measured diameters and thicknesses of the C6-1 cylinder are shown in Table 2-3. The inner and outer diameters of the cylinder were dimensionally inspected at $90^{\circ}$ intervals around the circumference and at three places along the uncut length, e.g., head stock, center, and tail stock. The wall thickness was measured every $45^{\circ}$ around the circumference at the head stock, center, and tail stock. The cylinder was machined to its test length of 18 inches then dimensionally inspected for total run-out at $10^{\circ}$ intervals. The results of the dimensional inspection for radial run-out are given in Table 2-4. The total indicator reading (TIR) given at the bottom of Table $2-4$ is calculated as the algebraic difference between the maximum positive radial run-out and the maximum negative radial run-out as the test article is rotated through $360^{\circ}$. 
Table 2-1. Band advance calculations for cylinder C6-1

\begin{tabular}{|c|c|c|c|c|c|c|}
\hline & Layer & $\begin{array}{l}\text { Added } \\
\text { thickness } \\
\text { (in.) }\end{array}$ & $\begin{array}{l}\text { Added } \\
\text { diameter } \\
\text { (in.) }\end{array}$ & $\begin{array}{c}\text { Part } \\
\text { diameter } \\
\text { (in.) }\end{array}$ & $\begin{array}{l}\text { Circum. } \\
\text { (in.) }\end{array}$ & $\begin{array}{c}\text { Band } \\
\text { advance } \\
\text { (degrees) }\end{array}$ \\
\hline \multirow[t]{2}{*}{$\mathbf{0}$} & Mandrel & & & 5.310 & 16.682 & \\
\hline & 3 hoops & 0.021 & 0.039 & 5.349 & 16.804 & 7.258 \\
\hline \multirow[t]{2}{*}{1} & 2 axials & 0.014 & 0.028 & 5.377 & 16.892 & \\
\hline & 4 hoops & 0.028 & 0.056 & 5.433 & 17.068 & 7.146 \\
\hline \multirow[t]{2}{*}{2} & 2 axials & 0.014 & 0.028 & 5.461 & 17.156 & \\
\hline & 4 hoope & 0.028 & 0.056 & 5.517 & 17.332 & 7.037 \\
\hline \multirow[t]{2}{*}{3} & 2 axials & 0.014 & 0.028 & 5.545 & 17.420 & \\
\hline & 4 hoops & 0.028 & 0.056 & 5.601 & 17.596 & 6.932 \\
\hline \multirow[t]{2}{*}{4} & 2 axials & 0.014 & 0.028 & 5.629 & 17.684 & \\
\hline & 4 hoops & 0.028 & 0.056 & 5.685 & 17.860 & 6.829 \\
\hline \multirow[t]{2}{*}{5} & 2 axials & 0.014 & 0.028 & 5.713 & 17.948 & \\
\hline & 4 hoops & 0.028 & 0.056 & 5.769 & 18.124 & 6.730 \\
\hline \multirow[t]{2}{*}{6} & 2 axials & 0.014 & 0.028 & 5.797 & 18.212 & \\
\hline & 4 hoops & 0.028 & 0.056 & 5.853 & 18.388 & 6.633 \\
\hline \multirow[t]{2}{*}{7} & 2 axials & 0.014 & 0.028 & 5.881 & 18.476 & - \\
\hline & 4 hoops & 0.028 & 0.056 & 5.937 & 18.652 & 6.539 \\
\hline \multirow[t]{2}{*}{8} & 2 axials & 0.014 & 0.028 & 5.965 & 18.740 & \\
\hline & 4 hoops & 0.028 & 0.056 & 6.021 & 18.916 & 6.448 \\
\hline \multirow[t]{2}{*}{9} & 2 axials & 0.014 & 0.028 & 6.049 & 19.003 & \\
\hline & 4 hoops & 0.028 & 0.056 & 6.105 & 19.179 & 6.359 \\
\hline \multirow[t]{2}{*}{10} & 2 arials & 0.014 & 0.028 & 6.133 & 19.267 & \\
\hline & 4 hoops & 0.028 & 0.056 & 6.189 & 19.443 & 6.273 \\
\hline \multirow[t]{2}{*}{11} & 2 axials & 0.014 & 0.028 & 6.217 & 19.531 & \\
\hline & 4 hoops & 0.028 & 0.056 & 6.273 & 19.707 & 6.189 \\
\hline \multirow[t]{2}{*}{12} & 2 axials & 0.014 & 0.028 & 6.301 & 19.795 & \\
\hline & 3 hoops & 0.021 & 0.042 & 6.343 & 19.927 & \\
\hline
\end{tabular}


Table 2-2. Composition data for cylinder C6-1

\begin{tabular}{cccccccccc}
\hline & \multicolumn{4}{c}{ Head stock } & \multicolumn{5}{c}{ Tail stock } \\
\cline { 2 - 9 } & Sample 1 & Sample 2 & Sample 3 & Avg. & Sample 1 & Sample 2 & Sample 3 & Avg. \\
\hline $\begin{array}{c}\text { Density } \\
(g / c c)\end{array}$ & 1.5745 & 1.5745 & 1.5765 & 1.5752 & 1.5755 & 1.5755 & 1.5755 & 1.5755 \\
\hline$V_{f}(\%)$ & 68.28 & 68.19 & 68.42 & 68.30 & 68.58 & 68.24 & 67.97 & 68.26 \\
$V_{r}(\%)$ & 30.26 & 30.39 & 30.22 & 30.29 & 29.92 & 30.41 & 30.79 & 30.37 \\
$V_{v}(\%)$ & 1.46 & 1.42 & 1.35 & 1.41 & 1.50 & 1.36 & 1.24 & 1.37 \\
\hline
\end{tabular}

Table 2-3. Dimensional inspection results for C6-1 diameters and thicknesses

\begin{tabular}{|c|c|c|c|c|}
\hline Location & & Head stock & Center & Tail stock \\
\hline \multirow[t]{5}{*}{ Inner diameter (in.) } & 0.0 & 5.3166 & 5.3177 & 5.3177 \\
\hline & 90.0 & 5.3166 & 5.3178 & 5.3184 \\
\hline & 180.0 & 5.3166 & 5.3183 & 5.3179 \\
\hline & 270.0 & 5.3161 & 5.3179 & 5.3174 \\
\hline & AVG. & 5.3165 & 5.3179 & 5.3179 \\
\hline \multirow[t]{5}{*}{ Outer diameter (in.) } & 0.0 & 6.3101 & 6.3090 & 6.3150 \\
\hline & 90.0 & 6.3052 & 6.3141 & 6.3082 \\
\hline & 180.0 & 6.3060 & 6.3040 & 6.3080 \\
\hline & 270.0 & 6.3104 & 6.3033 & 6.3160 \\
\hline & AVG. & 6.3079 & 6.3076 & 6.3118 \\
\hline \multirow[t]{9}{*}{ Wall thickness (in.) } & 0.0 & 0.4924 & 0.4952 & 0.4975 \\
\hline & 45.0 & 0.4952 & 0.4970 & 0.4960 \\
\hline & 90.0 & 0.4965 & 0.4930 & 0.4950 \\
\hline & 135.0 & 0.4980 & 0.4910 & 0.5010 \\
\hline & 180.0 & 0.4940 & 0.4930 & 0.4960 \\
\hline & 225.0 & 0.4962 & 0.4930 & 0.4953 \\
\hline & 270.0 & 0.4972 & 0.4930 & 0.4950 \\
\hline & 315.0 & 0.4971 & 0.4925 & 0.4978 \\
\hline & AVG. & 0.4958 & 0.4935 & 0.4967 \\
\hline
\end{tabular}


Table 2-4. Dimensional inspection results for run-out of cylinder C6-1

\begin{tabular}{|c|c|c|c|c|c|c|}
\hline \multirow{2}{*}{$\begin{array}{l}\text { Location } \\
\text { (in degrees) }\end{array}$} & \multicolumn{2}{|c|}{ Head stock } & \multicolumn{2}{|c|}{ Center } & \multicolumn{2}{|c|}{ Tail stock } \\
\hline & ID & OD & ID & OD & ID & OD \\
\hline 0 & 0.0000 & 0.0000 & 0.0000 & 0.0000 & 0.0000 & 0.0000 \\
\hline 10 & 0.0001 & 0.0025 & 0.0000 & 0.0020 & 0.0001 & 0.0005 \\
\hline 20 & 0.0001 & 0.0040 & -0.0001 & 0.0022 & -0.0001 & 0.0020 \\
\hline 30 & 0.0002 & 0.0045 & 0.0000 & 0.0020 & 0.0000 & 0.0030 \\
\hline 40 & 0.0001 & 0.0027 & 0.0000 & 0.0006 & -0.0001 & 0.0030 \\
\hline 50 & 0.0003 & 0.0040 & -0.0001 & -0.0002 & -0.0001 & 0.0015 \\
\hline 60 & 0.0003 & 0.0023 & -0.0001 & 0.0005 & -0.0001 & 0.0030 \\
\hline 70 & 0.0004 & 0.0026 & -0.0001 & 0.0021 & -0.0001 & 0.0030 \\
\hline 80 & 0.0004 & 0.0048 & -0.0001 & 0.0047 & -0.0001 & 0.0060 \\
\hline 90 & 0.0004 & 0.0075 & -0.0002 & 0.0044 & -0.0002 & 0.0060 \\
\hline 100 & 0.0005 & 0.0047 & -0.0002 & 0.0048 & -0.0002 & 0.0050 \\
\hline 110 & 0.0005 & 0.0050 & -0.0001 & 0.0028 & -0.0002 & 0.0040 \\
\hline 120 & 0.0005 & 0.0086 & -0.0001 & 0.0056 & -0.0002 & 0.0070 \\
\hline 130 & 0.0005 & 0.0105 & 0.0000 & 0.0059 & -0.0002 & 0.0080 \\
\hline 140 & 0.0005 & 0.0083 & 0.0000 & 0.0057 & -0.0003 & 0.0060 \\
\hline 150 & 0.0003 & 0.0068 & 0.0001 & 0.0050 & 0.0000 & 0.0040 \\
\hline 160 & 0.0003 & 0.0041 & 0.0000 & 0.0020 & -0.0002 & 0.0040 \\
\hline 170 & 0.0002 & 0.0060 & 0.0001 & 0.0020 & -0.0002 & 0.0035 \\
\hline 180 & 0.0001 & 0.0025 & 0.0001 & 0.0015 & -0.0001 & 0.0010 \\
\hline 190 & 0.0001 & 0.0043 & 0.0002 & 0.0020 & -0.0002 & 0.0025 \\
\hline 200 & 0.0000 & 0.0047 & 0.0003 & $0.002 A$ & -0.0002 & 0.0030 \\
\hline 210 & -0.0001 & 0.0050 & 0.0002 & -0.0005 & -0.0002 & -0.0005 \\
\hline 220 & 0.0010 & 0.0051 & 0.0003 & 0.0002 & -0.0002 & 0.0000 \\
\hline 230 & 0.0000 & 0.0052 & 0.0003 & 0.0007 & -0.0001 & 0.0010 \\
\hline 240 & -0.0001 & 0.0025 & 0.0004 & -0.0012 & -0.0001 & 0.0005 \\
\hline 250 & 0.0001 & 0.0031 & 0.0003 & -0.0001 & -0.0001 & 0.0000 \\
\hline 260 & 0.0002 & 0.0025 & 0.0003 & 0.0028 & 0.0000 & 0.0020 \\
\hline 270 & 0.0004 & 0.0065 & 0.0004 & 0.0024 & 0.0000 & 0.0050 \\
\hline 280 & 0.0003 & 0.0037 & 0.0003 & 0.0012 & -0.0001 & 0.0050 \\
\hline 290 & 0.0004 & 0.0038 & 0.0003 & 0.0023 & -0.0001 & 0.0030 \\
\hline 300 & 0.0002 & 0.0065 & 0.0002 & 0.0061 & 0.0000 & 0.0010 \\
\hline 310 & 0.0001 & 0.0076 & 0.0002 & 0.0055 & 0.0001 & 0.0070 \\
\hline 320 & 0.0002 & 0.0064 & 0.0001 & 0.0058 & 0.0000 & 0.0060 \\
\hline 330 & 0.0001 & 0.0066 & 0.0001 & 0.0046 & 0.0000 & 0.0085 \\
\hline 340 & 0.0002 & 0.0043 & 0.0000 & 0.0023 & 0.0000 & 0.0040 \\
\hline 350 & 0.0001 & 0.0012 & 0.0001 & 0.0012 & 0.0000 & -0.0005 \\
\hline TIR & 0.0006 & 0.0107 & 0.0006 & 0.0083 & 0.0005 & 0.0115 \\
\hline
\end{tabular}


After cutting samples for composition, the remaining excess material was used for taking macrographs, micrographs and montages of the cylinder cross section. In Figs. 2-1 and 2-2 the macrographs of the head stock and tail stock are shown, respectively. The magnification used for the macrographs was $4.5 \mathrm{X}$. The lighter, shiny layers are the axial layers and the darker, dull layers are the hoop layers. Viewed at this magnification, the layer thicknesses appear to be uniform and the quality of material is consistent throughout the entire wall thickness.

The montages were taken at a higher magnification of $20 \mathrm{X}$ and were an assemblage of magnified views joined together to show the entire wall thickness of the cylinder. The head stock montage is shown in Fig. 2-3, and the tail stock montage is shown in Fig. 2-4. The mandrel side of the cylinder wall is located at the bottom of these figures, nearest the caption. The 2:1 ratio of hoop:axial layers is clearly shown in these figures, with the layer thicknesses being comparable in the hoop and axial directions. Also evident from Figs. 2-3 and $2-4$ is the low void content which, from the composition samples, was equal to $1.41 \%$ at the head stock and $1.37 \%$ at the tail stock (see Table 2-2).

A more detailed look at the cylinder construction was performed by taking micrographs of the cross section. These micrographs are depicted in Figs. 2-5 through 2-8 ior views of the head stock at magnification levels of $100 \mathrm{X}, 100 \mathrm{X}, 200 \mathrm{X}$, and $400 \mathrm{X}$, respectively. The tail stock micrographs are shown in Figs. 2-9 through 2-12. The darkest areas in these figures correspond to voids, whereas the gray areas are resin rich spots. The ends of the hoop direction fiber bundles are distinguishable as light-shaded dots. 


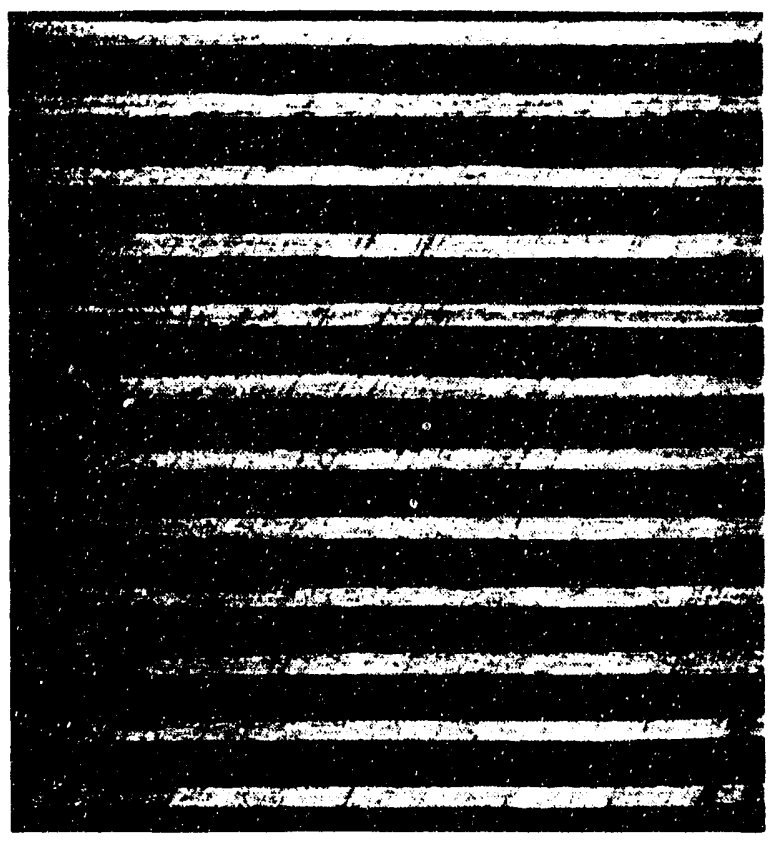

Fig. 2-1. Macrograph of head stock cross section (4.5X magnification).

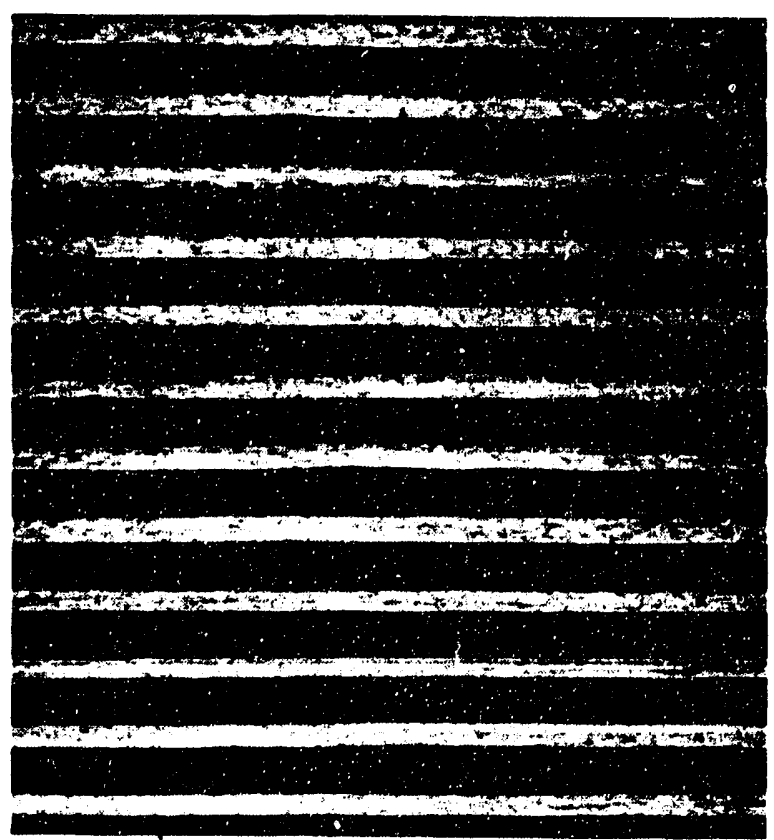

Fig. 2-2. Macrograph of tail stock cross section (4.5X magnification). 


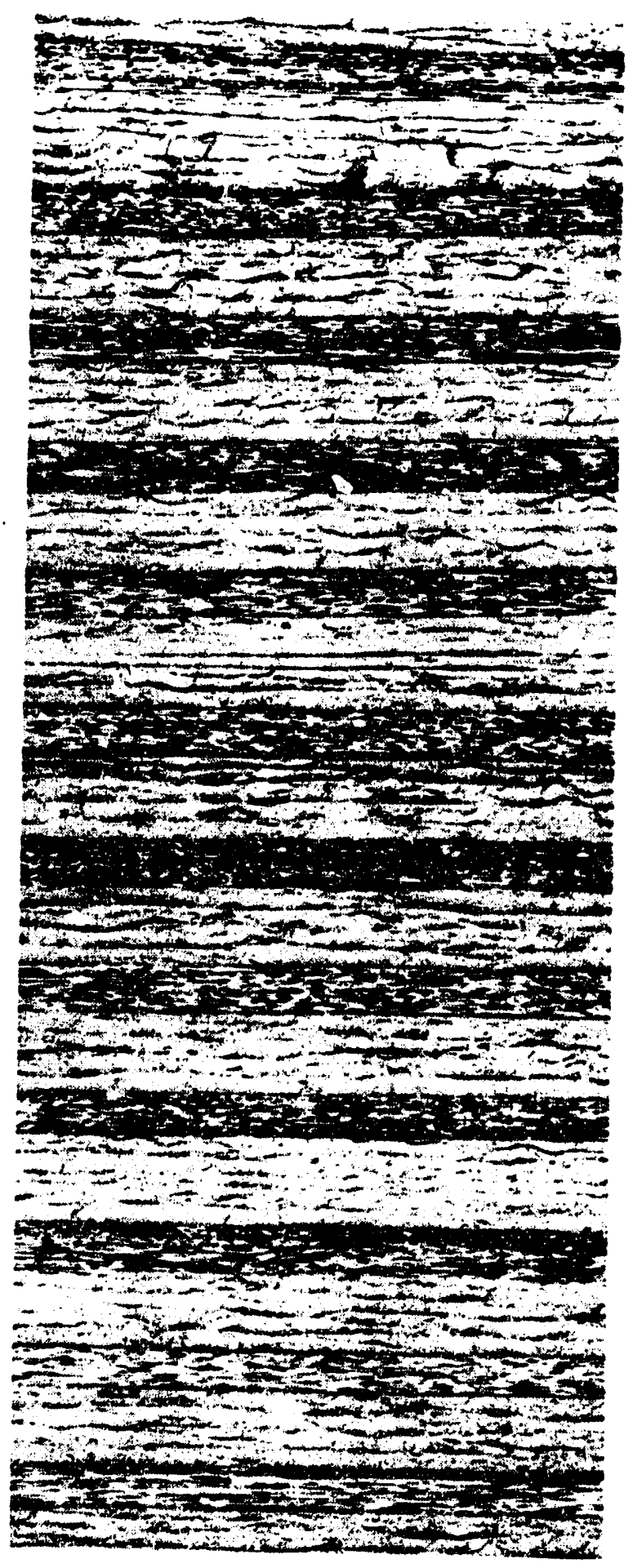

Fig. 2-3. Montage of head stock cross section (20X magnification). 


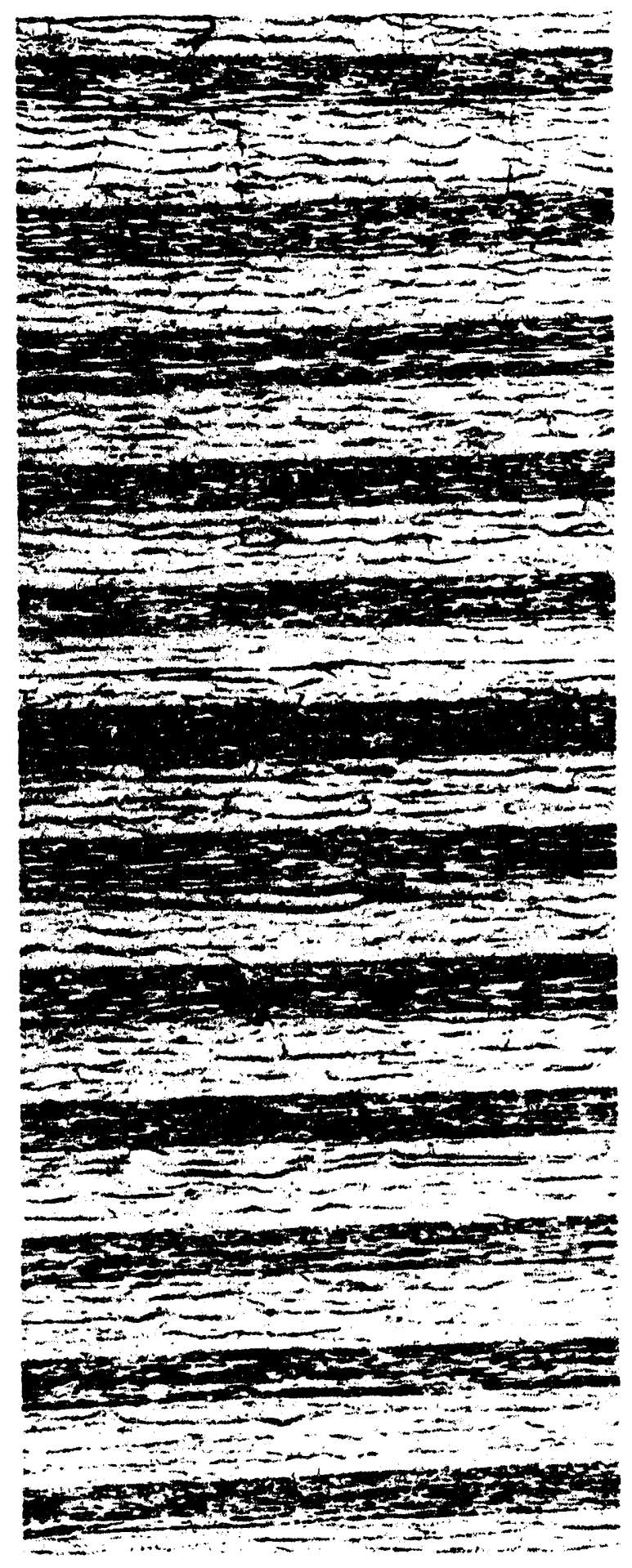

Fig. 2-4. Montage of tail stock cross section (20X magnification). 


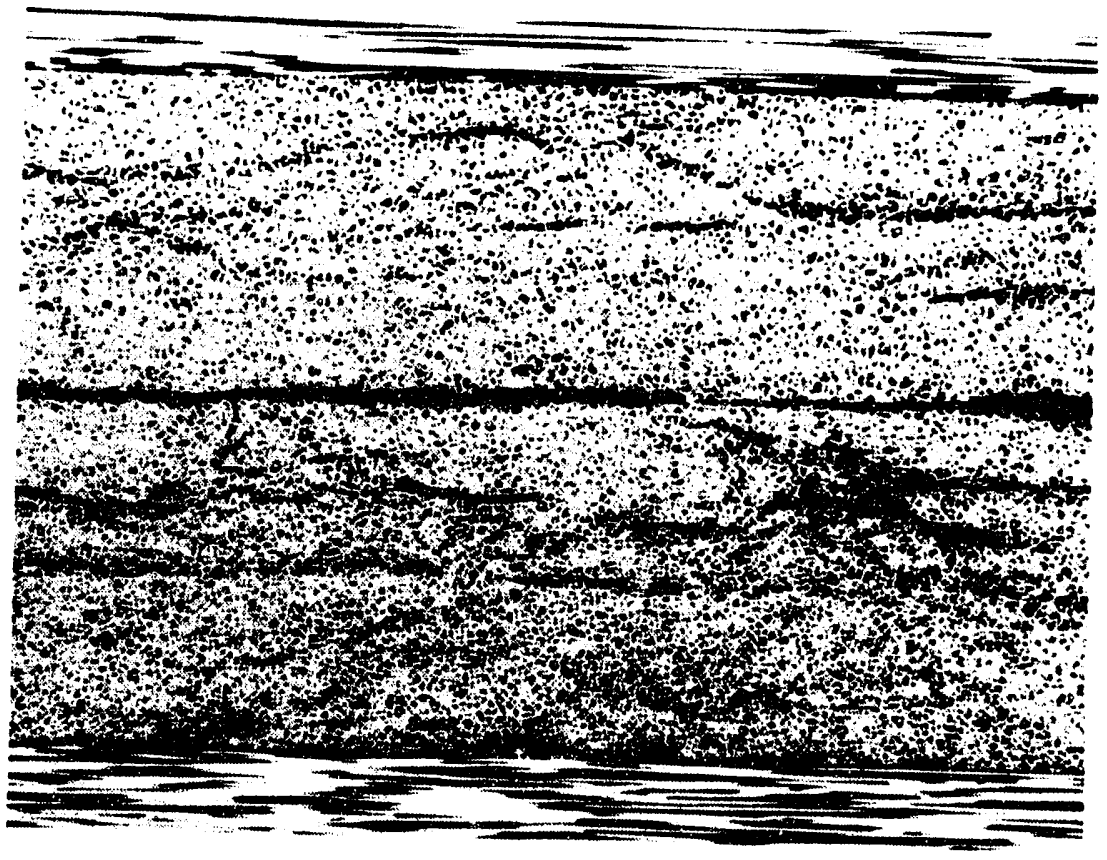

Fig. 2-5. Micrograph of head stock (100X magnification).

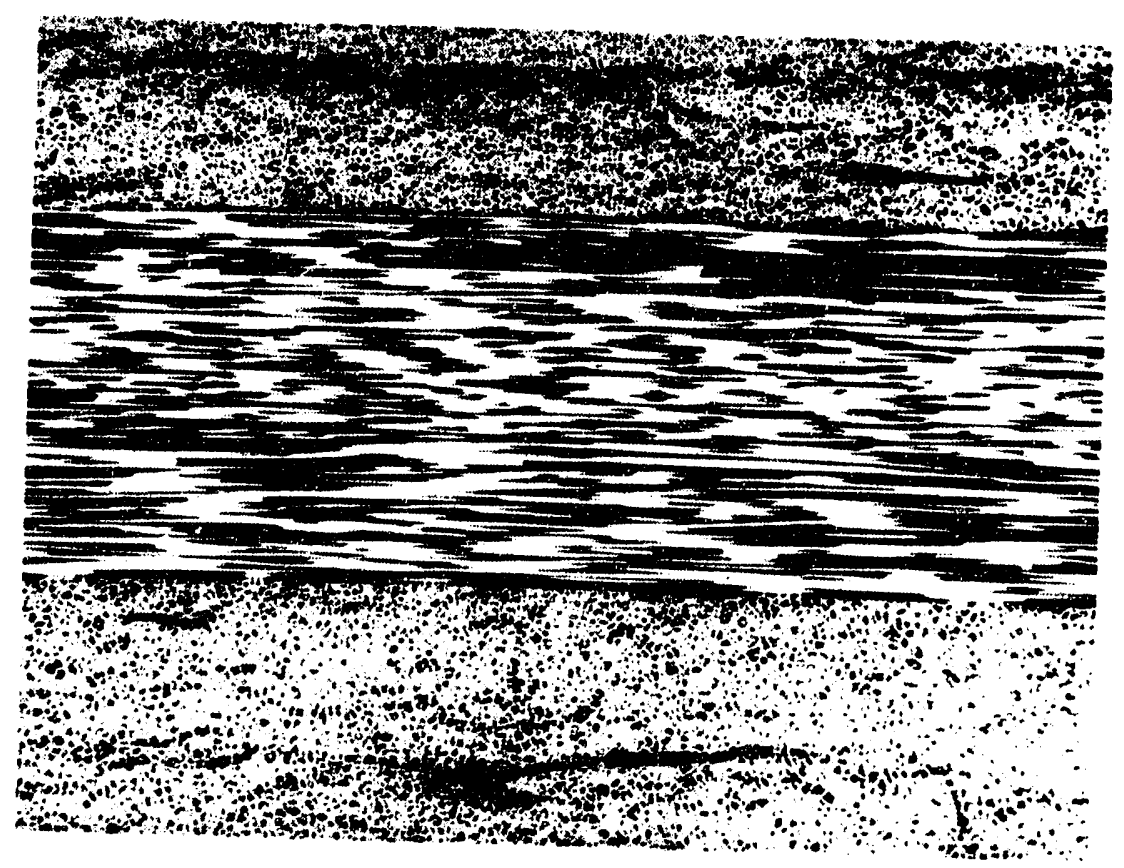

Fig. 2-6. Micrograph of head stock (100X magnification). 


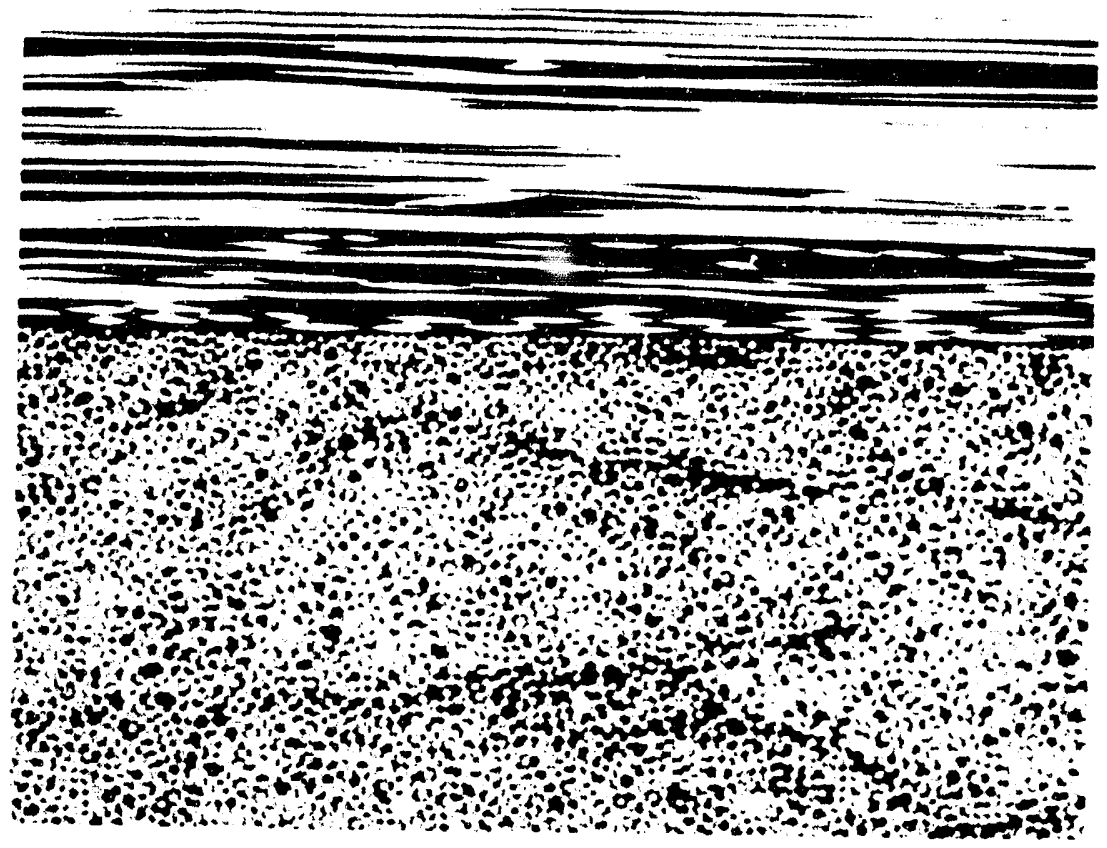

Fig. 2-7. Micrograph of head stock (200X magnification).

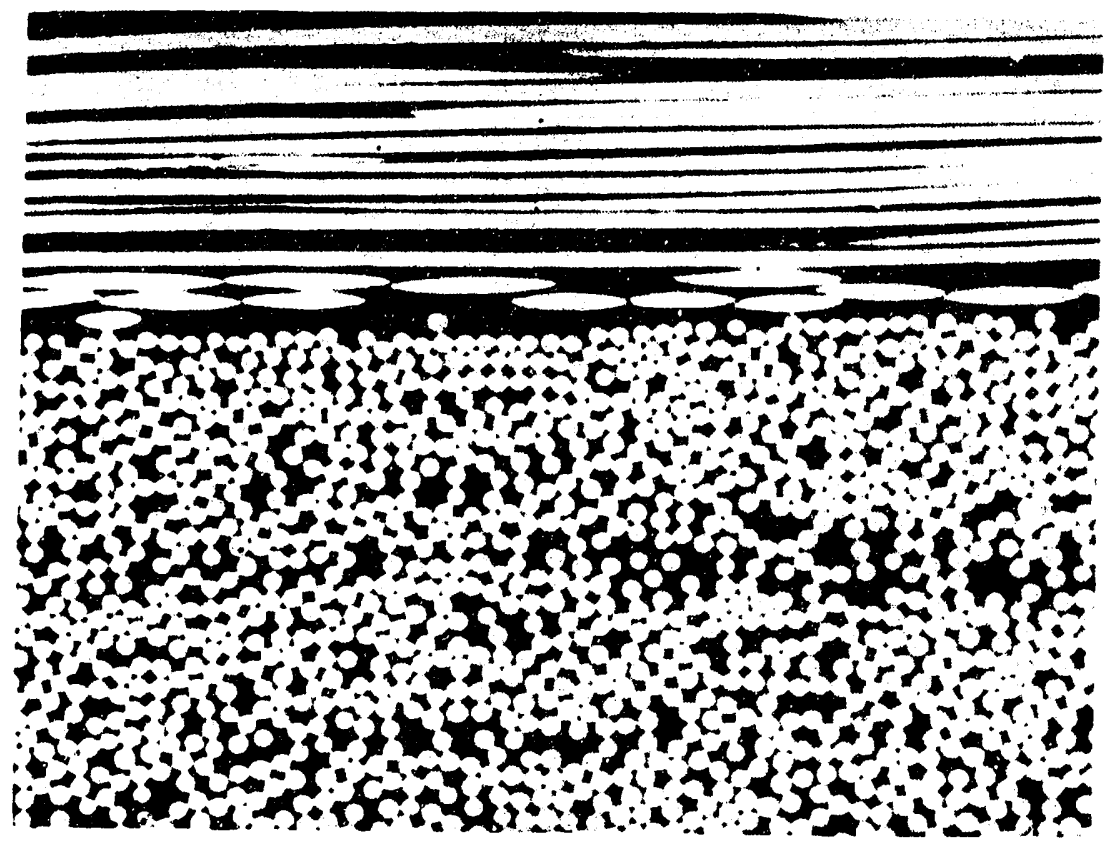

Fig. 2-8. Micrograph of head stock (400X magnification). 


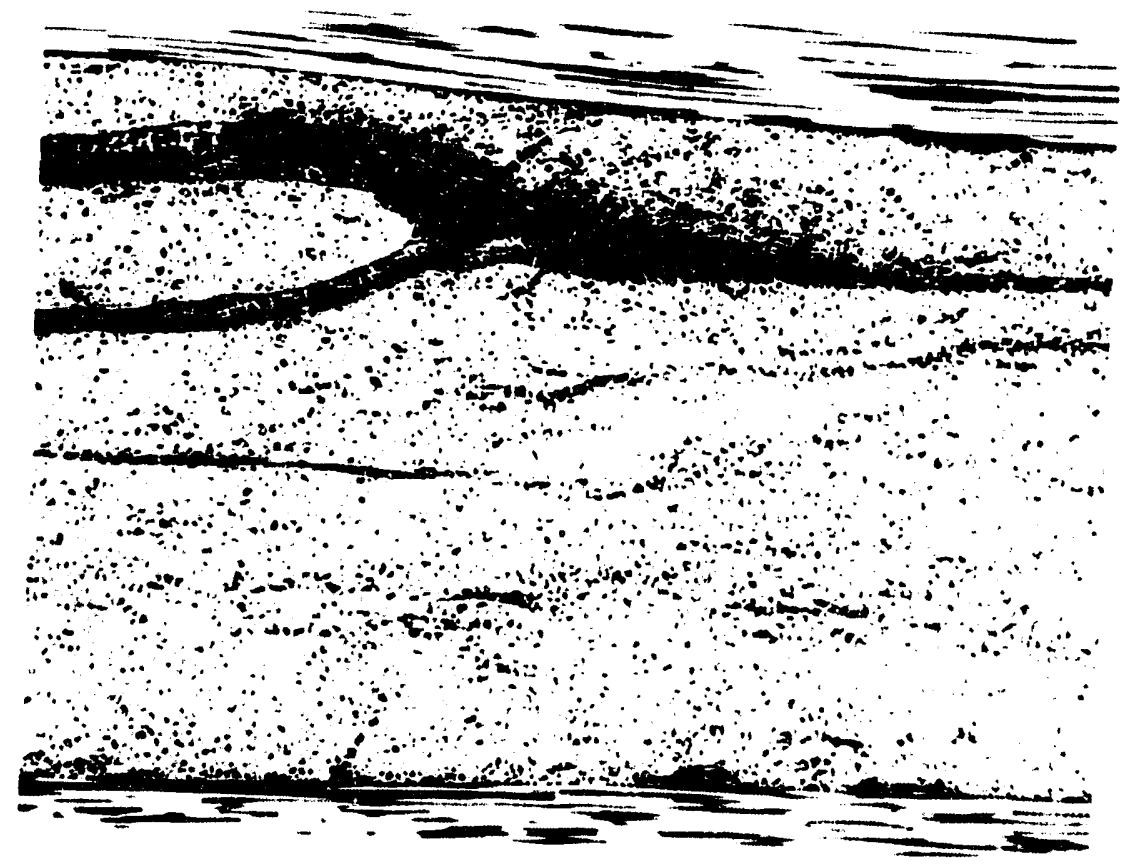

Fig. 2-9. Micrograph of tail stock (100X magnification).

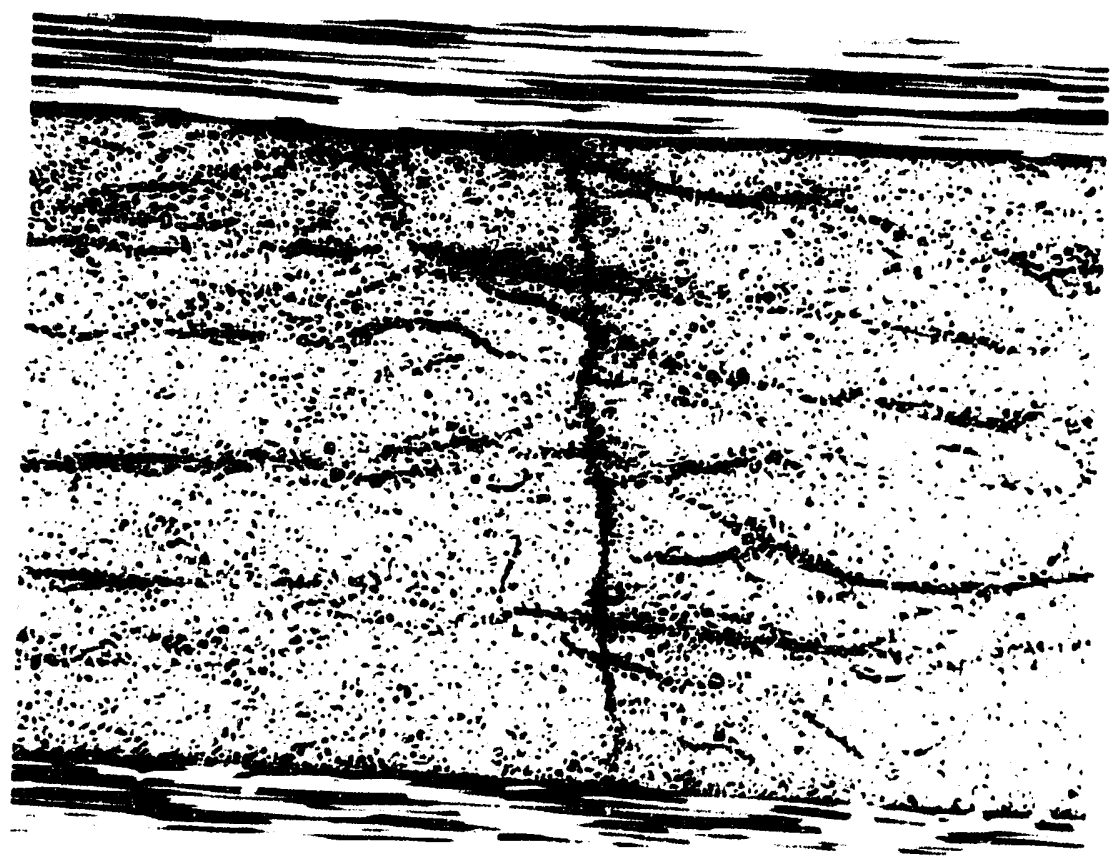

Fig. 2-10. Micrograph of tail stock (100X magnification). 


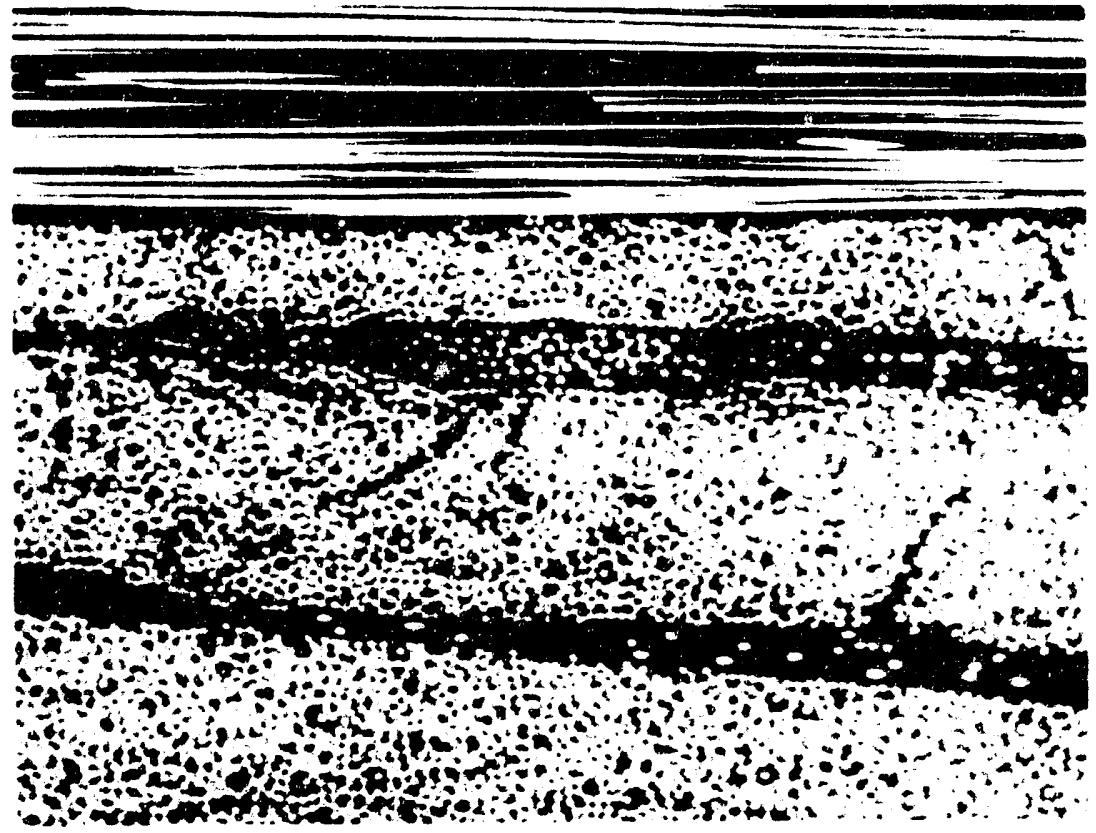

Fig. 2-11. Micrograph of tail stock (200X magnification).

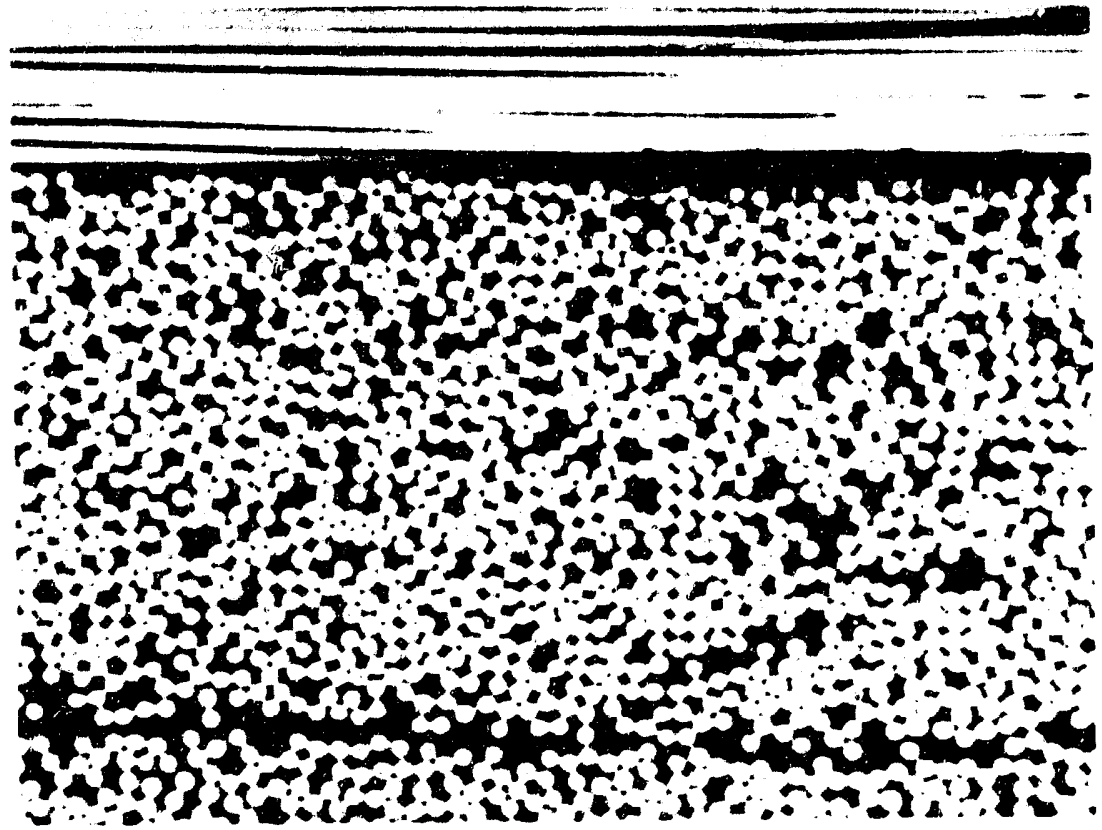

Fig. 2-12. Micrograph of tail stock (400X magnification). 


\section{TEST ARTICLE TESTING}

Existing ASTM procedures and conventional test approaches are not adequate for characterizing composite materiais under hydrostatic pressure. Efforts were directed at developing improved test methodologies and/or standard test methods for composite cylinders. In testing C6-1, prototype test devices were designed, analyzed, and evaluated experimentally. The selection of prototype test devices for C6-1 was not based solely on the criteria of wide acceptance or universality but rather on the ability to control parameters which govern a particular mode of failure. It is recognized that different tests will likely be required to completely characterize the different modes of failure in compression.

The activities related to the test fixturing for C6-1 included the development and design of improved end closures for hydrostatic testing of cylinders and ring specimens. This effort is aimed at reducing the discontinuity stresses at the cylinder ends that result from the use of rigid end closures. A typical end closure assembly of the type developed for this test is shown in Fig. A-1 (see Appendix A). This closure is based on the concept of the contoured end plug that was originally proposed by Miller. ${ }^{33}$ The design shown in Fig. A-1 is an improved concept end closure which incorporates an end plug with contour that achieves very low discontinuity stresses. The test assembly is analyzed to determine operational stress levels to insure end plug design adequacy (see Sect. 1.2.2). The details of this design and the supporting theory is summarized in Appendix A. Additional work in this area will be published in a later report. Additional stress analysis capabilities are being developed with emphasis given to closed-form analytic solutions that permit the efficient design of end closures without having to resort to detailed finite element stress analysis.

The 66-1 test was monitored using diagnostic methods for detecting failure initiation to facilitate identifying modes of failure. The test article instrumentation included electrical resistance strain gages and an acoustic emission sensor. The cylinder was subjected to a posttest visual examination to characterize any damage that may have resulted from the pressurization of the test article. The observations made and the data generated from the test will be useful for evaluation and validation of design codes.

\subsection{INSTRUMENTATION}

Twenty-four strain gages were affixed by Hydrospace Engineering Services of Richardson, Texas, to the interior and exterior walls of the test cylinder. The location and orientation of these gages are shown in Figs. 3.1-1. The axial locations for these gages were at midbay, at 4.5 inches from either end, and at 0.5 inches from either end. The three midbay gages were located on both the interior and exterior walls and consisted of three biaxial gages located at $120^{\circ}$ intervals for recording hoop and axial strains. The two gages at 4.5 inches from each end were located only on the interior wall and were biaxial gages located at $0^{\circ}$ and $90^{\circ}$ for recording hoop and axial strains. The gages at 0.5 inches from each end were lmated only on the exterior wall and were uniaxial gages located at $0^{\circ}$ and $90^{\circ}$ for recordil. op strain only.

Acoustic emission monitoring was provided by attaching an acoustic emission pickup on the outside of the pressure vessel at mid-height. The accumulative number of events was recorded from a digital indicator as a function of pressure. Also, the event amplitude and count rate were plotted as a function of time and pressure on a strip chart recorder. 


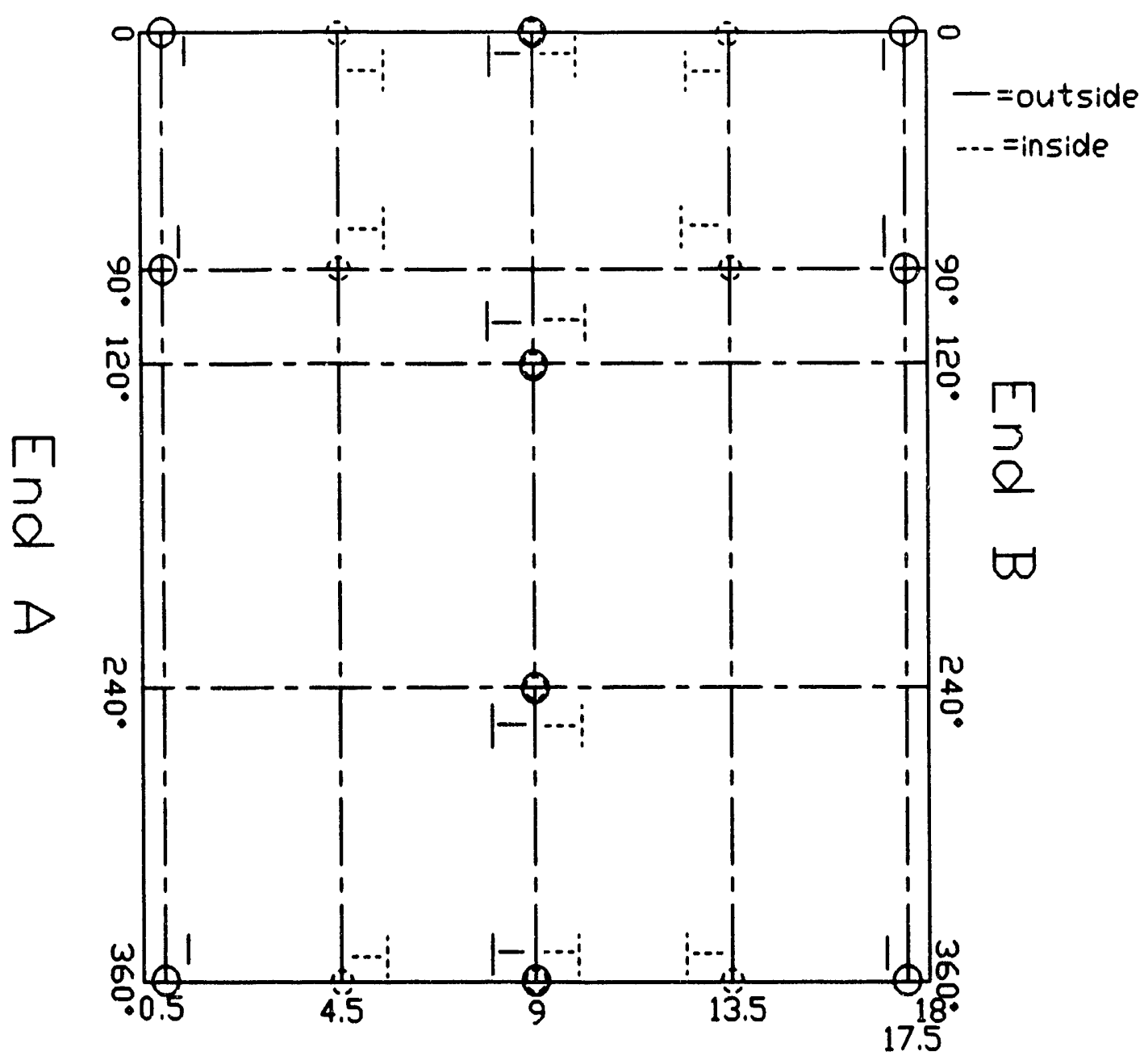

Fig. 3.1-1. Location and orientation of strain gages.

\subsection{TEST FACILITY}

The cylinder was tested under contract with Hydrospace Engineering Services of Richardson, Texas, at the Stachiw Associates facility in El Cajon, California. The test facility consisted of a pressure vessel rated for use up to 20,000-psi hydraulic pressure. Pressure control was achieved manually by starting and stopping the pressurization system and by observing an analog gage indicating vessel pressure. The test article was pressurized at 1000 -psi intervals at approximately $2000 \mathrm{psi} / \mathrm{min}$, with slower pressurization at the higher pressures. The pressure level was monitored by a pressure transducer and plotted versus time on a strip chart recorder. The vessel had associated feedthroughs for multi-channel strain gage readout. Strain gage readout consisted of decade boxes connected to a single channel digital strain indicator. Individual gage readings were made manually at the 1000-psi pressure intervals by switching in the appropriate gage and writing down the reading on a data sheet. Photographs of the test facility are shown in Figs. 3.2-1 and 3.2-2. 


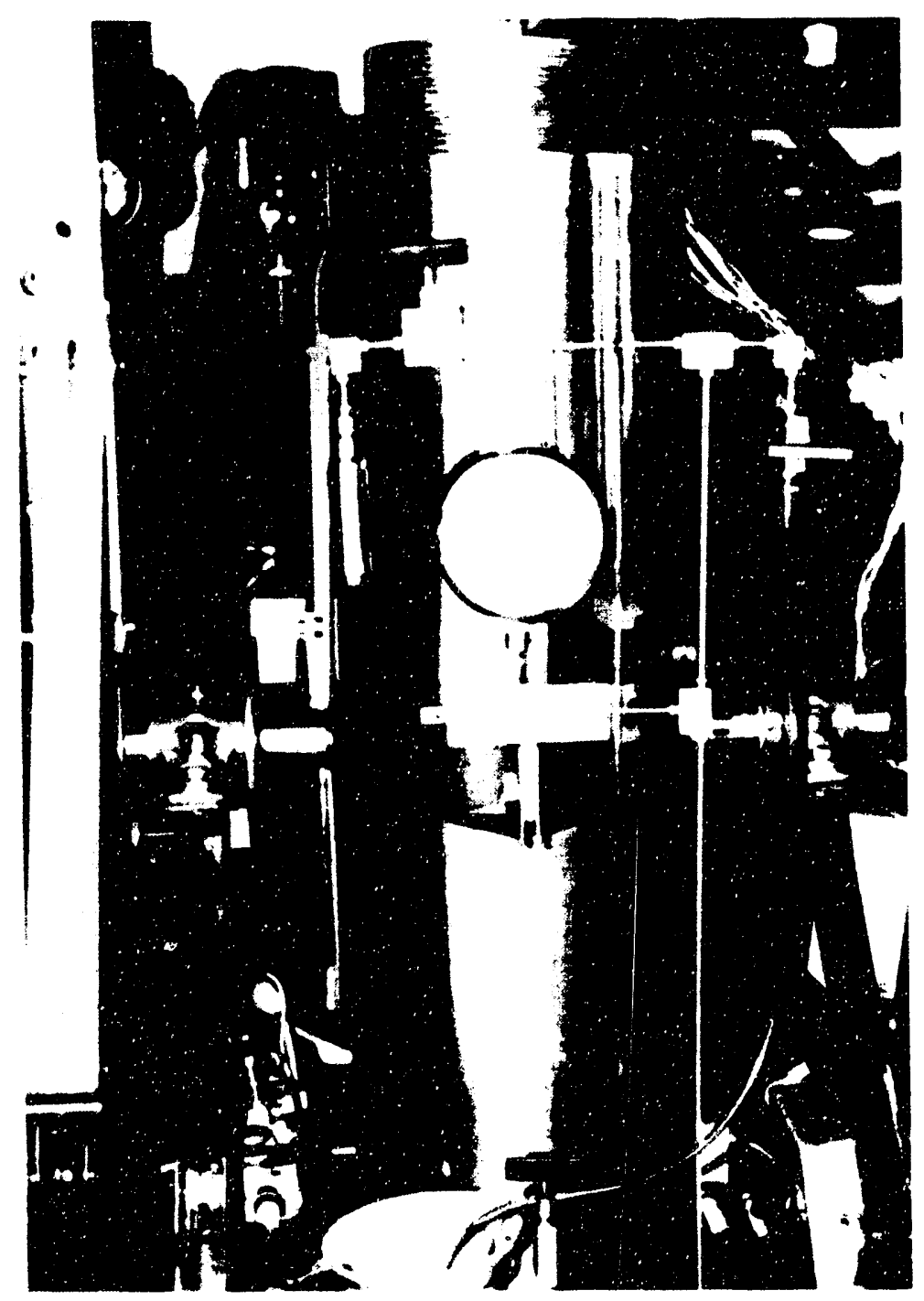

Fig. 3.2-1. Stachiw Associatestest facility pressure vessel (20,000psi capacity). 


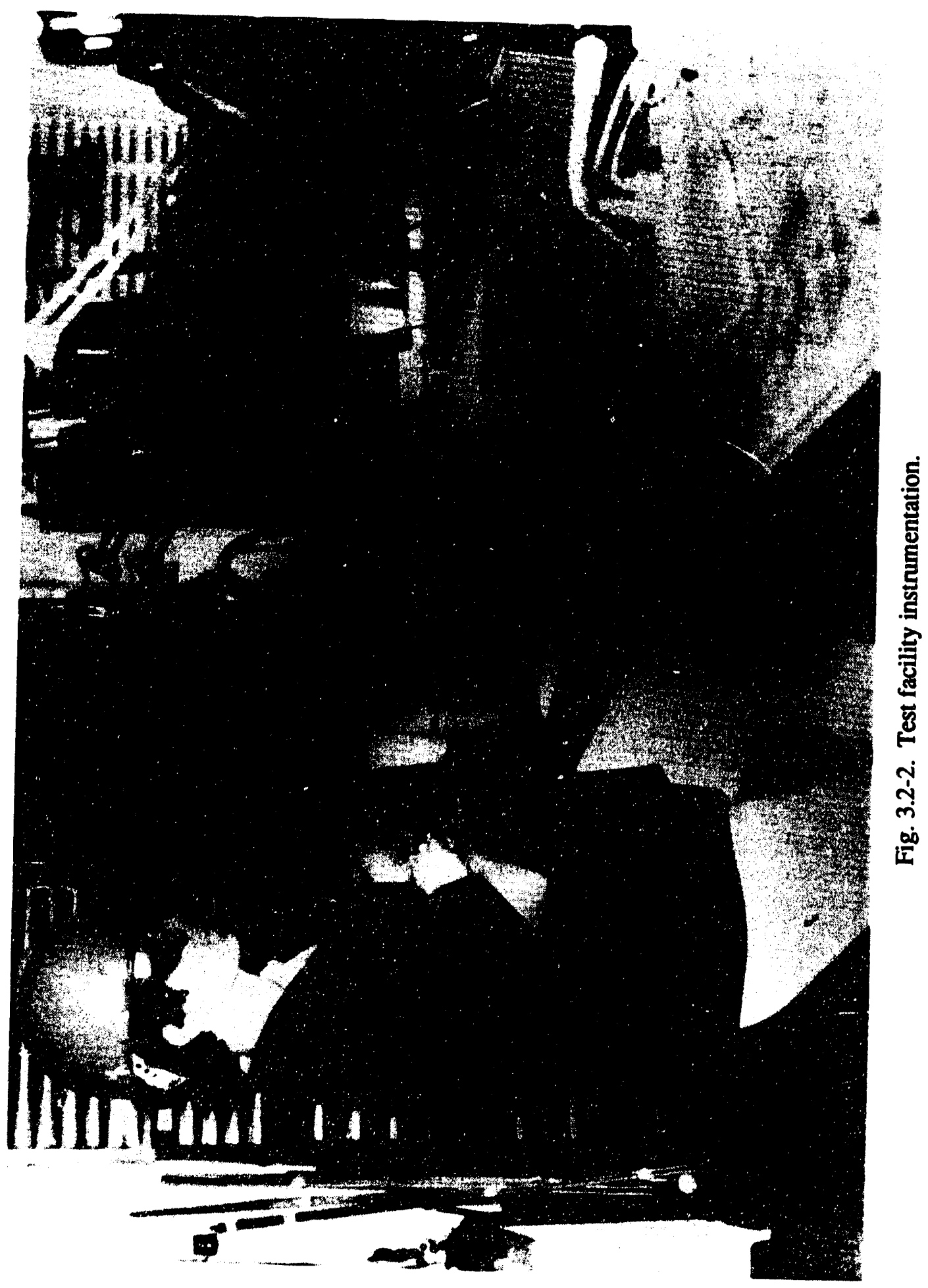




\subsection{TEST ASSEMBLY}

The cylinder under test, C6-1, was assembled to the steel and aluminum end plugs prior to testing (see test cylinder assembly drawing in Fig. 1.1-1). The assembly drawing of one end closure is shown in Fig. A-2. The internal strain gage wires were passed through the end plug, and the wires were potted and sealed in place. Steel tie rods were attached to both end plugs to assist in holding the assembly together. Finally, the junction between the cylinder and the end plugs was sealed with a rubber potting compound to provide the initial seal for pressurization. The cylinder was placed into the pressure vessel (see Fig. 3.2-1), the strain gage wires were fed out through a high-pressure feedthrough, and the pressure vessel was sealed. Photographs of the cylinder assembly are shown in Figs. 3.3-1 and 3.3-2.

\subsection{TEST RESULTS}

Pressurization of C6-1 began with stops for strain gage readings made at each 1000-psi interval. The 24 channels of strain gages plus the acoustic emission count were recorded at each 1000 -psi interval. Pressurization continued, with very little acoustic emission activity noted, to the limit of the facility $(20,000 \mathrm{psi})$ with no failure of the test cylinder. In order to preclude possible time dependent failure of the cylinder, once a pressure of 20,000 psi was reached, the vessel was depressurized after only a few seconds without waiting to acquire all 24 channels of strain data. One channel of strain data only was acquired at 20,000 psi. Complete strain data was acquired up to a pressure of 19,000 psi and tabulated in Tables 3.4-1 and 3.4-2. Average strain gage readings were calculated and are presented in Table 3.4-3. The test report prepared by Hydrospace Engineering Services is given in Appendix C.

\subsubsection{Strains}

Plots of the acquired strain versus pressure data are presented in Figs. 3.4.1-1 through 3.4.1-7. As may be seen from Fig. 3.4.1-1 interior wall midbay hoop strain levels of $0.8-0.9 \%$ were achieved with this specimen. The gage located at the $120^{\circ}$ location (gage \#2) recorded an increasingly greater compressive hoop strain with pressure than did the gages located at $0^{\circ}$ or $240^{\circ}$ (gages \#1 and \#3, respectively). However, on the exterior of the cylinder (see Fig. 3.4.1-2), the gage at the $120^{\circ}$ location (gage \#9) showed an increasingly smaller compressive hoop strain with pressure than did the gages at the $0^{\circ}$ or the $240^{\circ}$ locations (gages \#8 and \#10, respectively). This would suggest that circumferential bending, producing tension on the exterior wall and compression on the inner wall, was occurring as a function of pressure at the $120^{\circ}$ location.

To a lesser extent a similar situation occurred with respect to the midbay axial strains as shown in Figs. 3.4.1-3 and 3.4.1-4. The gage at the $0^{\circ}$ location (gage \#1) shows an increasingly smaller axial strain with pressure on the interior wall, while showing an increasingly greater axial compressive strain with pressure on the exterior wall at the $0^{\circ}$ location (gage \#8). This would tend to indicate the progression of some axial bending which produced compression on the exterior wall and tension on the interior wall, or a bowing inward of the cylinder at midbay. 


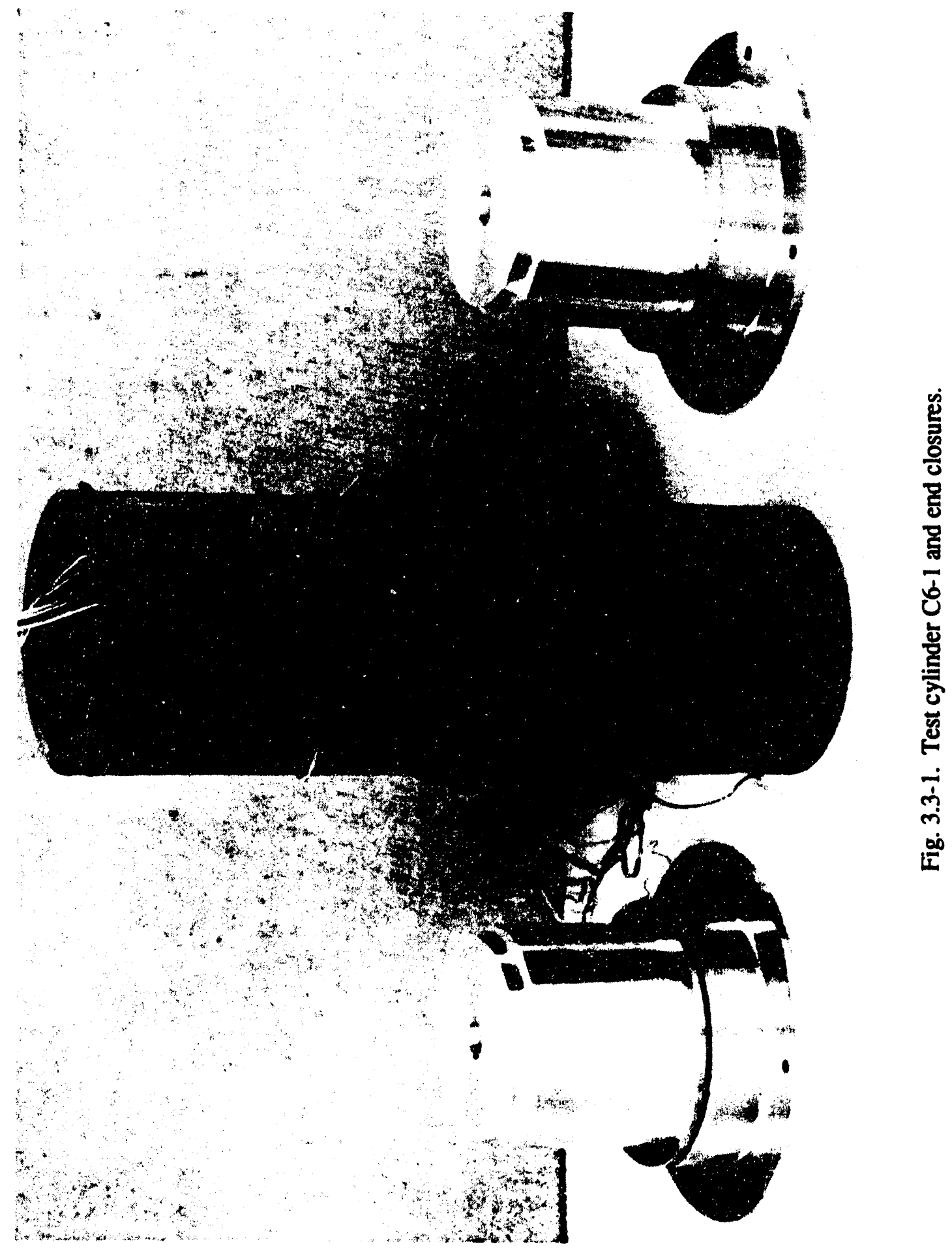




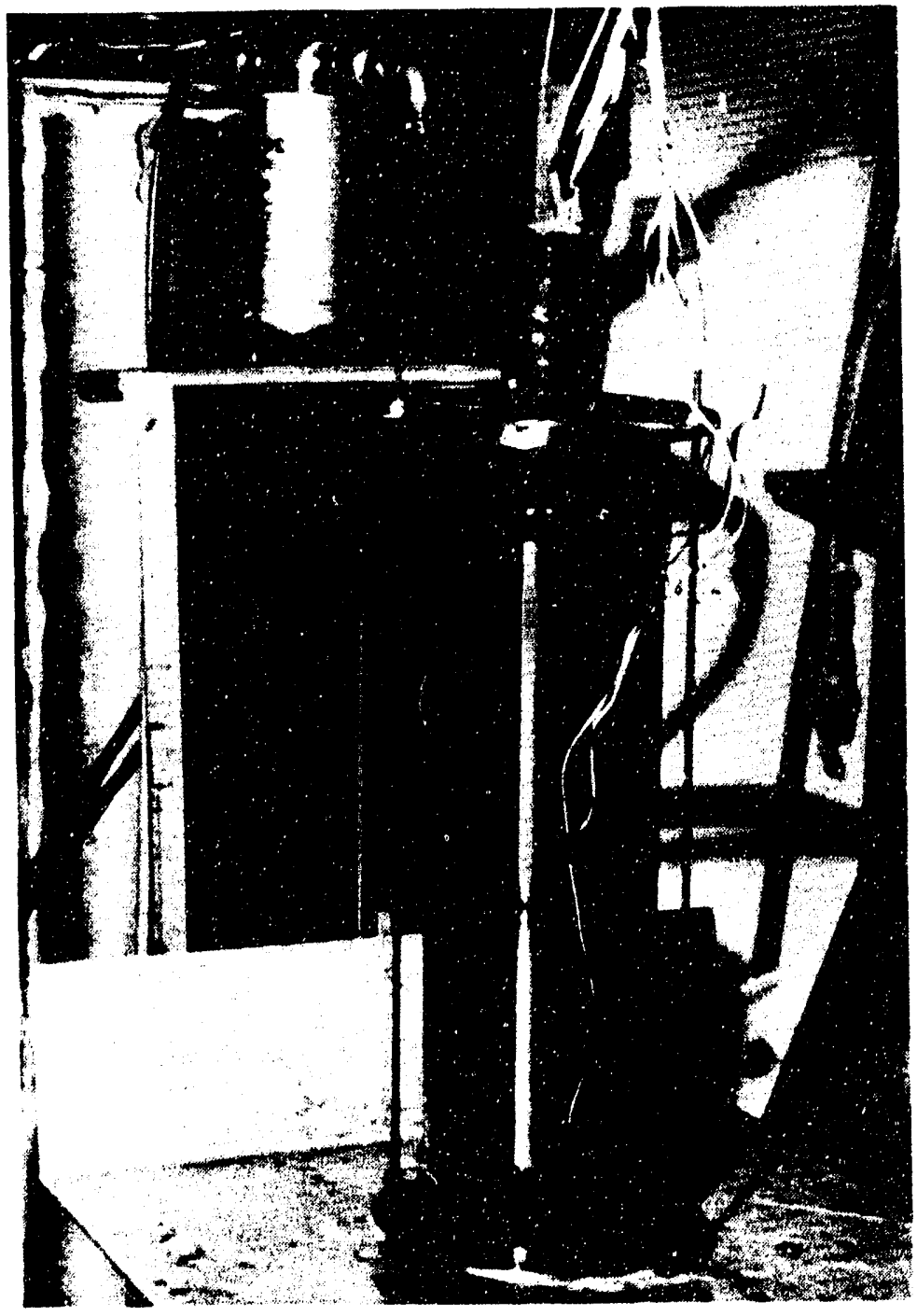

Fig. 3.3-2. Cylinder C6-1 test assembly. 


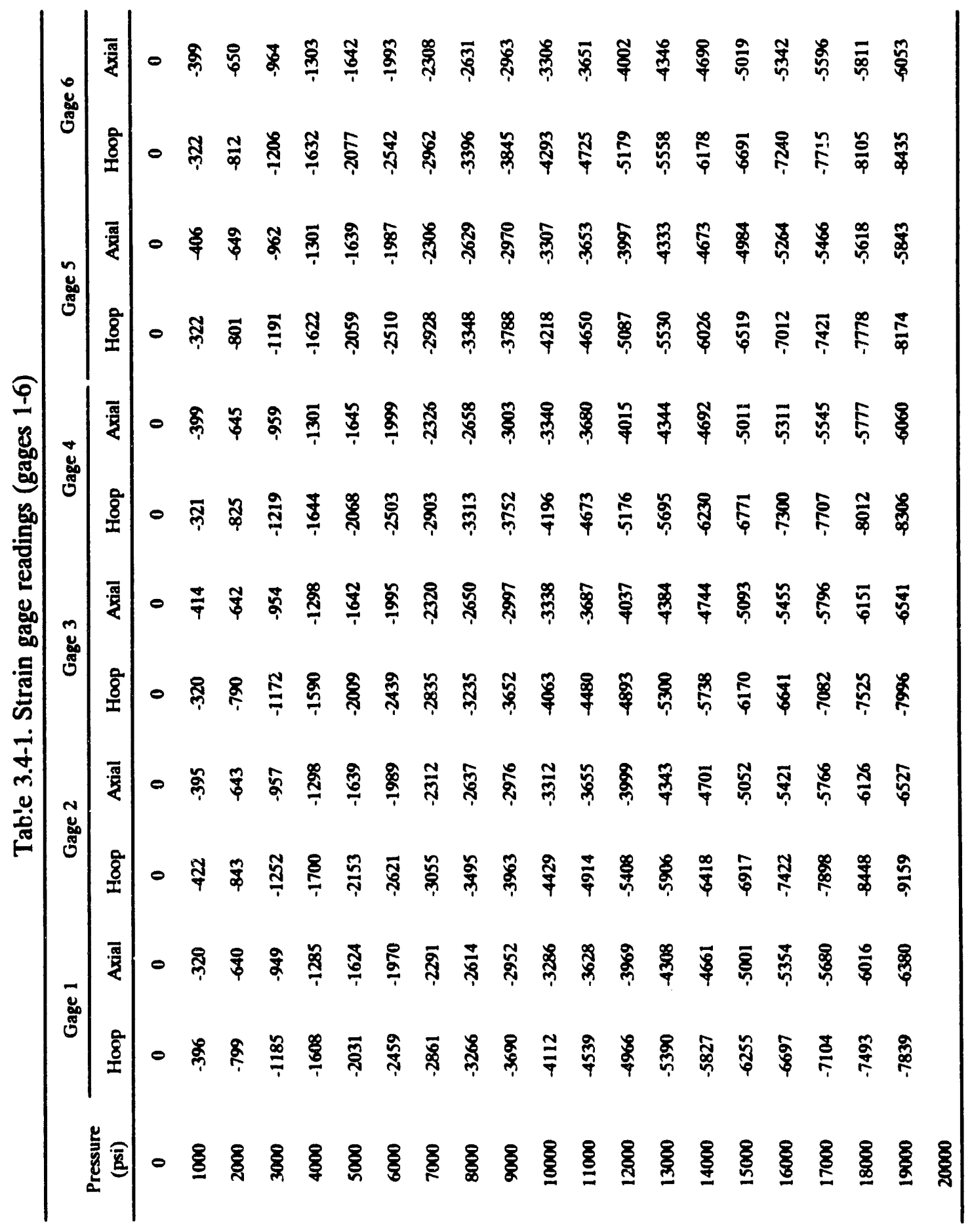




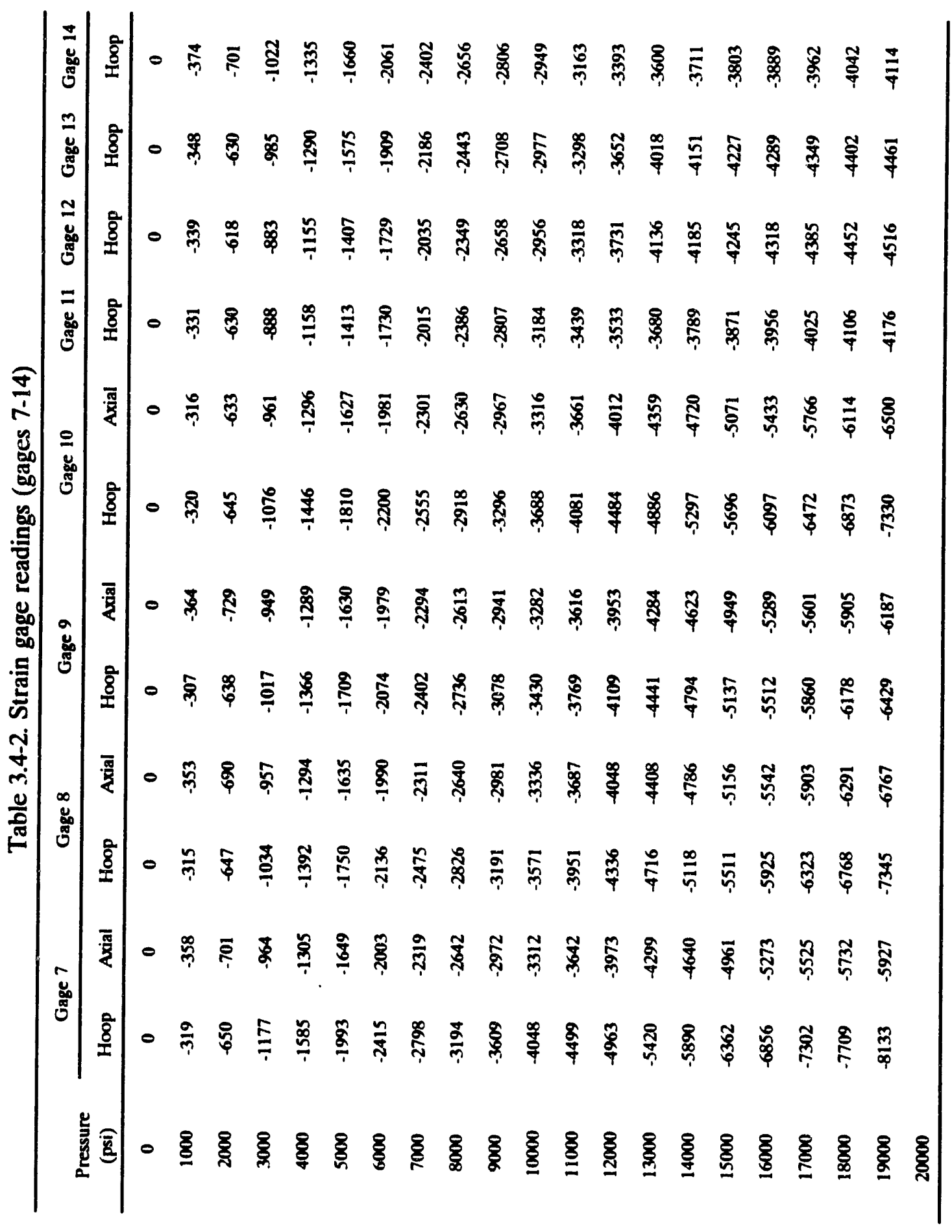


Table 3.4-3. Average strain gage readings

\begin{tabular}{|c|c|c|c|c|c|c|c|}
\hline \multirow{2}{*}{$\begin{array}{c}\text { Pressure } \\
\text { (psi) }\end{array}$} & \multicolumn{2}{|c|}{ Midbay int. } & \multicolumn{2}{|c|}{ Midbay ex. } & \multicolumn{2}{|c|}{$4.5 \mathrm{in.}$} & \multirow{2}{*}{$\frac{0.5 \text { in. }}{\text { Hoop }}$} \\
\hline & Hoop & Axial & Hoop & Axial & Hoop & Axial & \\
\hline 0 & O & 0 & 0 & 0 & 0 & o & 0 \\
\hline 1000 & .379 & -376 & -314 & -344 & -321 & -391 & -348 \\
\hline 2000 & -811 & -642 & -643 & -684 & -772 & -661 & -645 \\
\hline 3000 & -1203 & -953 & -1042 & -956 & -1198 & .962 & -945 \\
\hline 4000 & -1633 & -1294 & -1401 & -1293 & -1621 & -1303 & -1235 \\
\hline 5000 & -2064 & -1635 & -1756 & -1631 & -2049 & -1644 & -1514 \\
\hline 6000 & -2506 & -1985 & -2137 & -1983 & -2493 & -1996 & -1857 \\
\hline 7000 & -2917 & -2308 & -2477 & -2302 & -2898 & -2315 & -2160 \\
\hline 8000 & -3332 & .2634 & -2827 & -2628 & -3313 & -2640 & .2459 \\
\hline 9000 & -3768 & -2975 & -3188 & -2963 & -3749 & -2977 & .2745 \\
\hline 10000 & -4201 & -3312 & -3563 & -3311 & -4189 & -3316 & -3017 \\
\hline 11000 & -4644 & .3657 & -3934 & -3655 & -4637 & -3657 & .3305 \\
\hline 12000 & -5089 & -4002 & -4310 & -4004 & -5101 & -3997 & -3577 \\
\hline 13000 & -5532 & -4345 & -4681 & -4350 & -5551 & -4331 & -3859 \\
\hline 14000 & -5994 & -4702 & -5070 & -4710 & -6081 & -4674 & -3959 \\
\hline 15000 & -6447 & -5049 & -5448 & -5059 & -6586 & -4994 & .4037 \\
\hline 16000 & -6920 & -5410 & -5845 & -5421 & .7102 & -5298 & .4113 \\
\hline 17000 & -7361 & -5747 & -6218 & .5757 & -7536 & -5533 & -4180 \\
\hline 18000 & -7822 & -6098 & -6606 & -6103 & -7901 & -5735 & -4251 \\
\hline 19000 & -8331 & -6483 & -7035 & -6485 & -8262 & -5971 & -4317 \\
\hline 20000 & 0 & 0 & o & 0 & 0 & o & 0 \\
\hline
\end{tabular}


The two gages at the axial location of 4.5 inches from each end of the cylinder (gages \#4, \#5, \#6, and \#7) measured the interior hoop and axial strains 0.5 inches from the end of the contoured end closures. The design of the end closures was such that at $20,000 \mathrm{psi}$ the interior of the cylinder wall would be supported by the end closures along their entire 4-inch length. The results in Fig. 3.4.1-5 show slightly larger hoop strains were experienced 4.5 inches from the end of C6-1 as compared to the midbay interior results (see Fig. 3.4.1-1). In comparing the interior axial strain results shown in Figs. 3.4.1-6 and 3.4.1-2, the strains 4.5 inches from the end are nearly identical to the midbay strains up to approximately 16,000 psi. Beyond the 16,000-psi pressure, the results for the interior axial strains at 4.5 inches from the end exhibit an axial stiffening behavior as a function of applied pressure.

In Fig. 3.4.1-7, the hoop strains at 0.5 -inch from the cylinder end versus pressure showed a change of slope at approximately $10,000-13,000$ psi of external pressure, where the contracting cylinder begins to contact the internal plug, thus providing increased hoop stiffness to the assembly. The contoured end closures were designed to have an initial radial clearance between the plug and the interior of the C6-1 cylinder. The change in slope corresponds to the point at which the radial clearance is eliminated and the cylinder starts to be supported along the length of the contoured end closure.

After pressurization, the cylinder and end closures were disassembled and the cylinder was inspected visually. No visual evidence of damage was noted, with the exception of some slight scuffing on the interior of the cylinder at the approximate location of the end of the aluminum end plugs. This would indicate the cylinder experienced enough radial contraction to be in contact along the full length of the contoured end plug. 


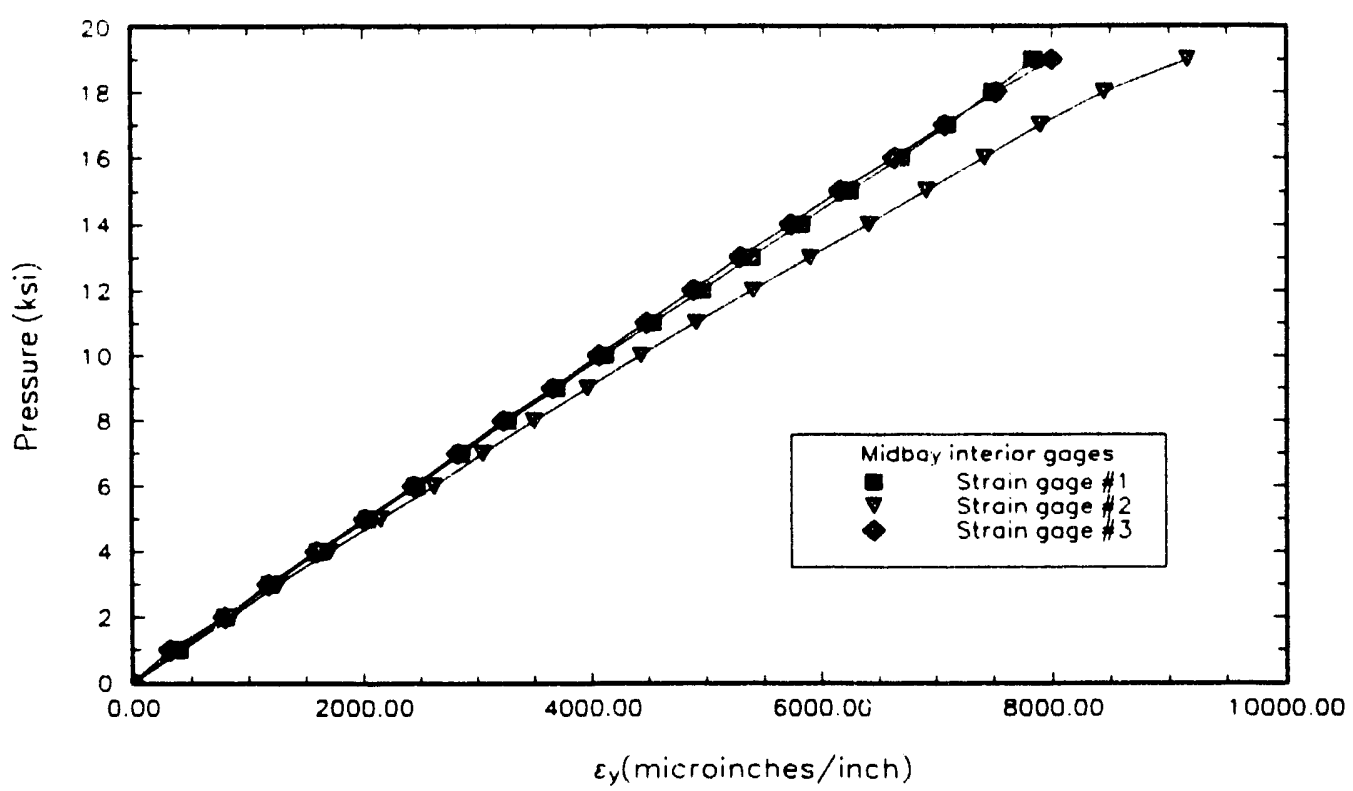

Fig. 3.4.1-1. Midbay interior hoop strains versus pressure.

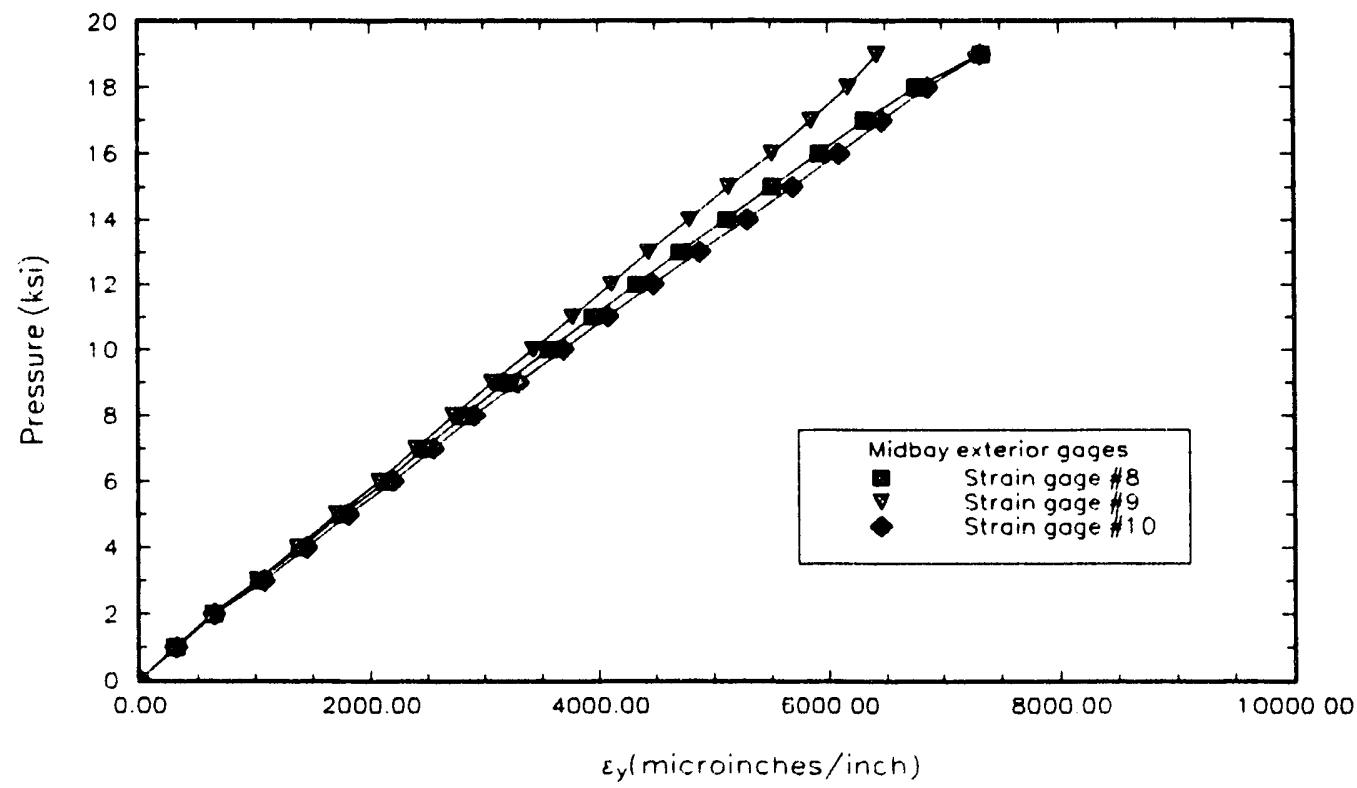

Fig. 3.4.1-2. Midbay exterior hoop strains versus pressure. 


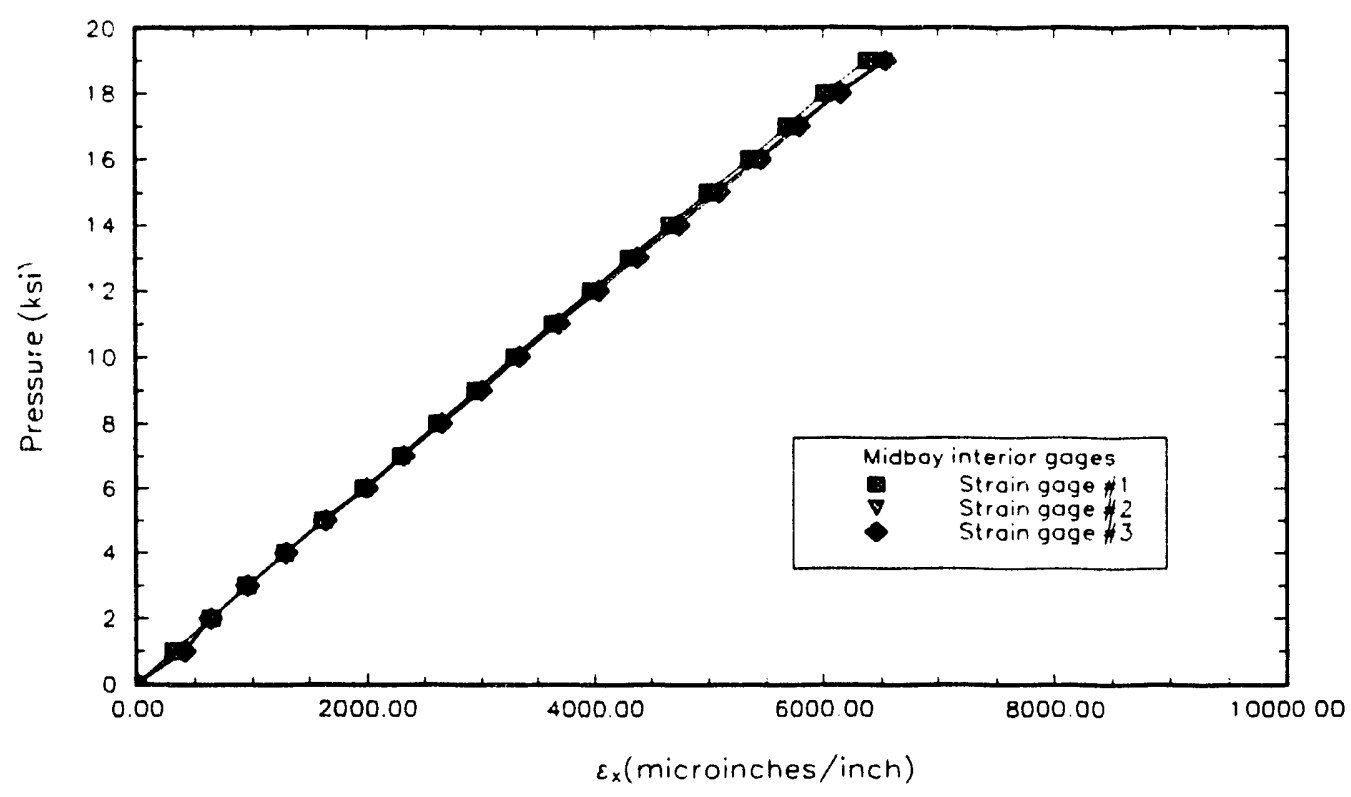

Fig. 3.4.1-3. Midbay interior axial strains versus pressure.

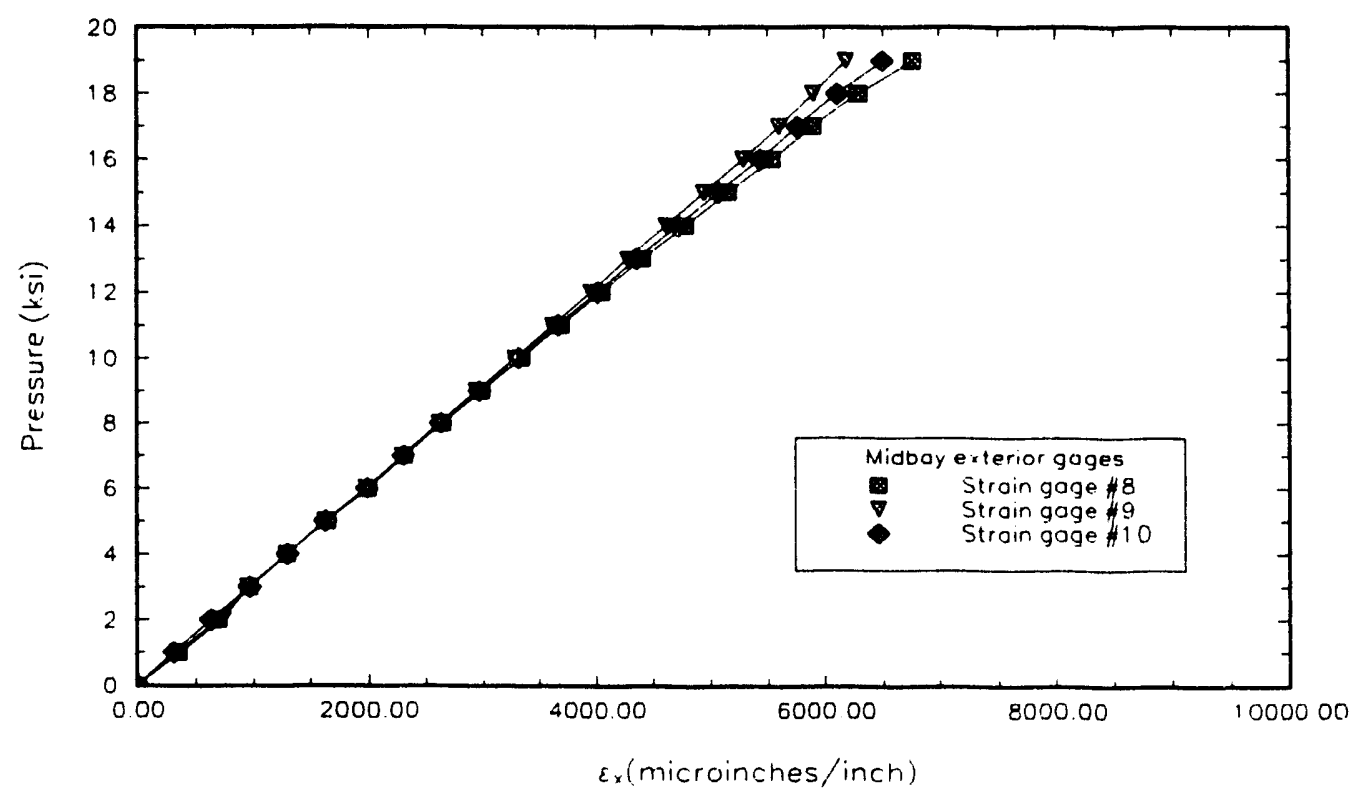

Fig. 3.4.1-4. Midbay exterior axial strains versus pressure. 


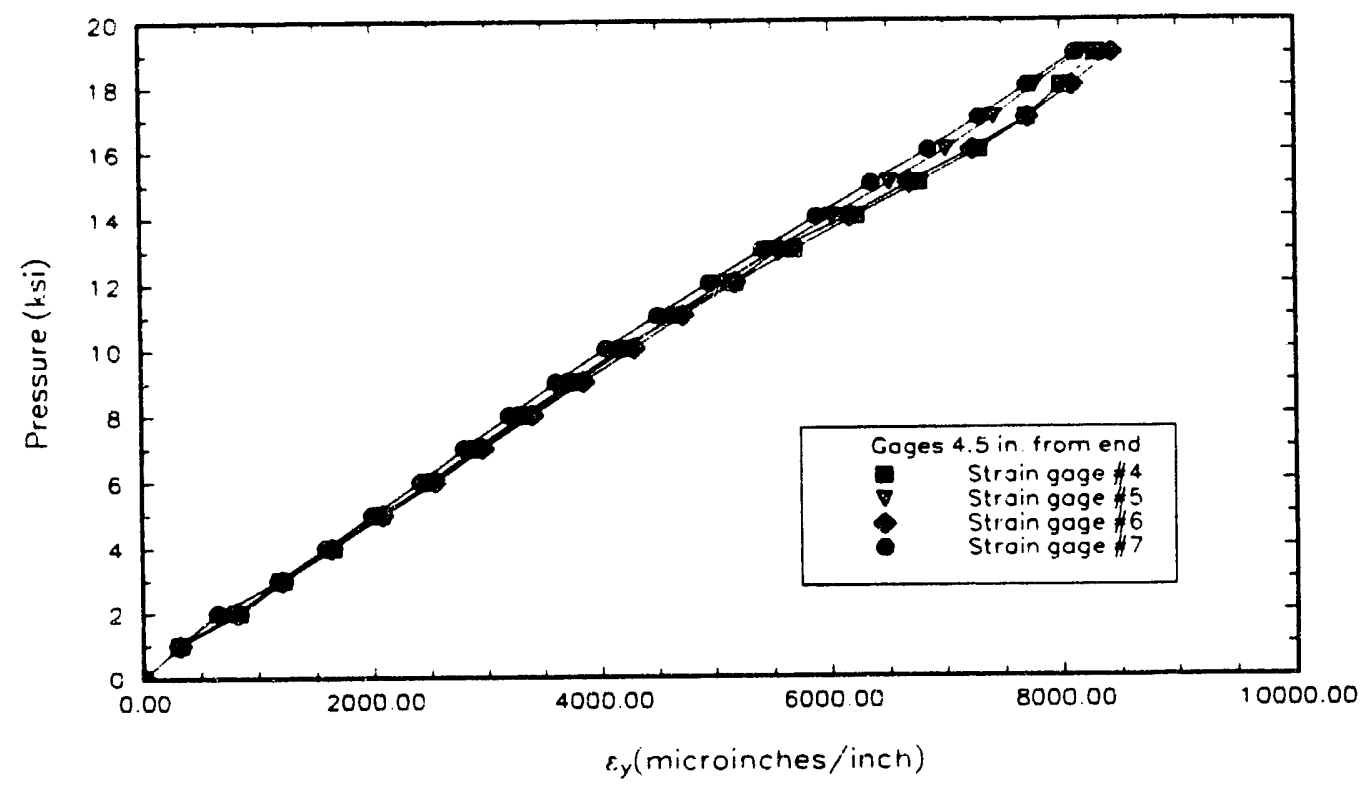

Fig. 3.4.1-5. Interior hoop strains at 4.5 in. from end versus pressure.

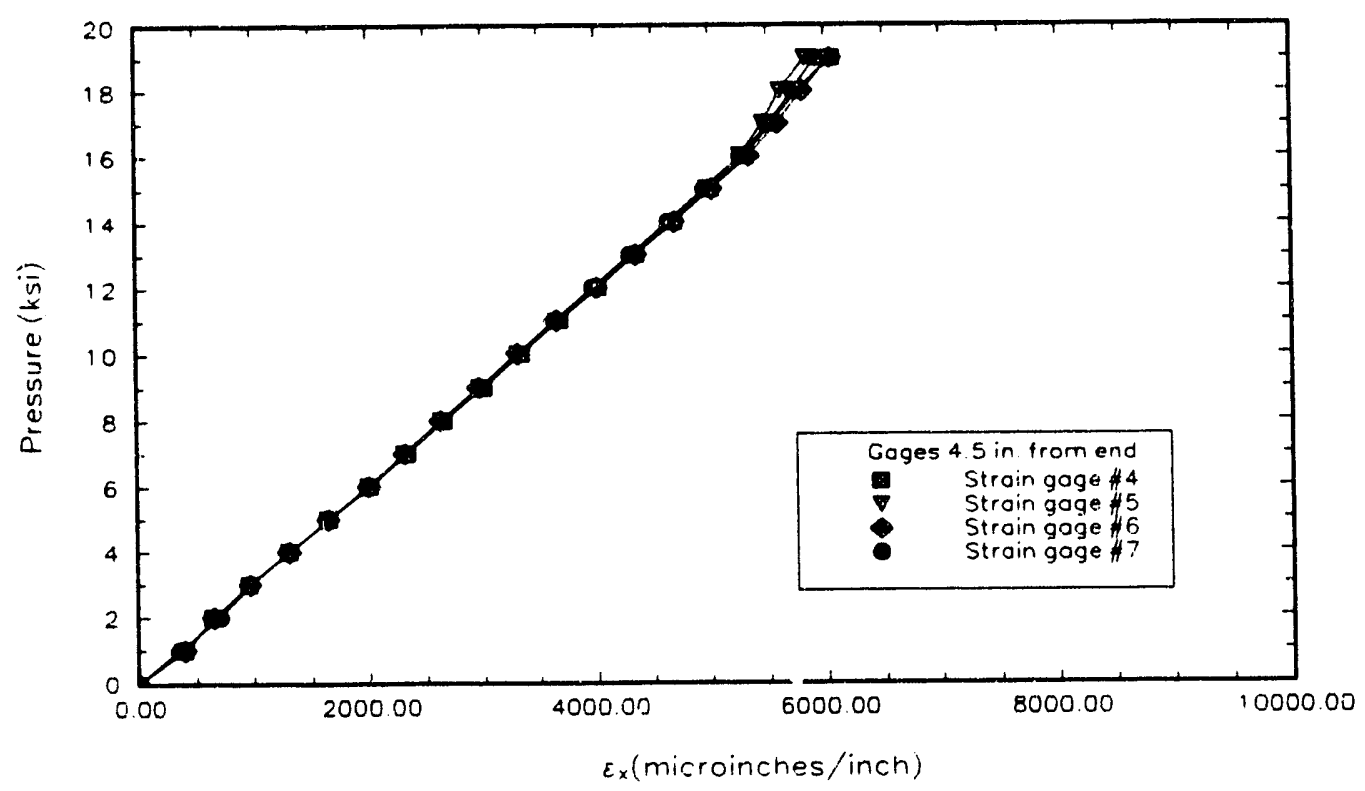

Fig. 3.4.1-6. Interior axial strains at 4.5 in. from end versus pressure. 


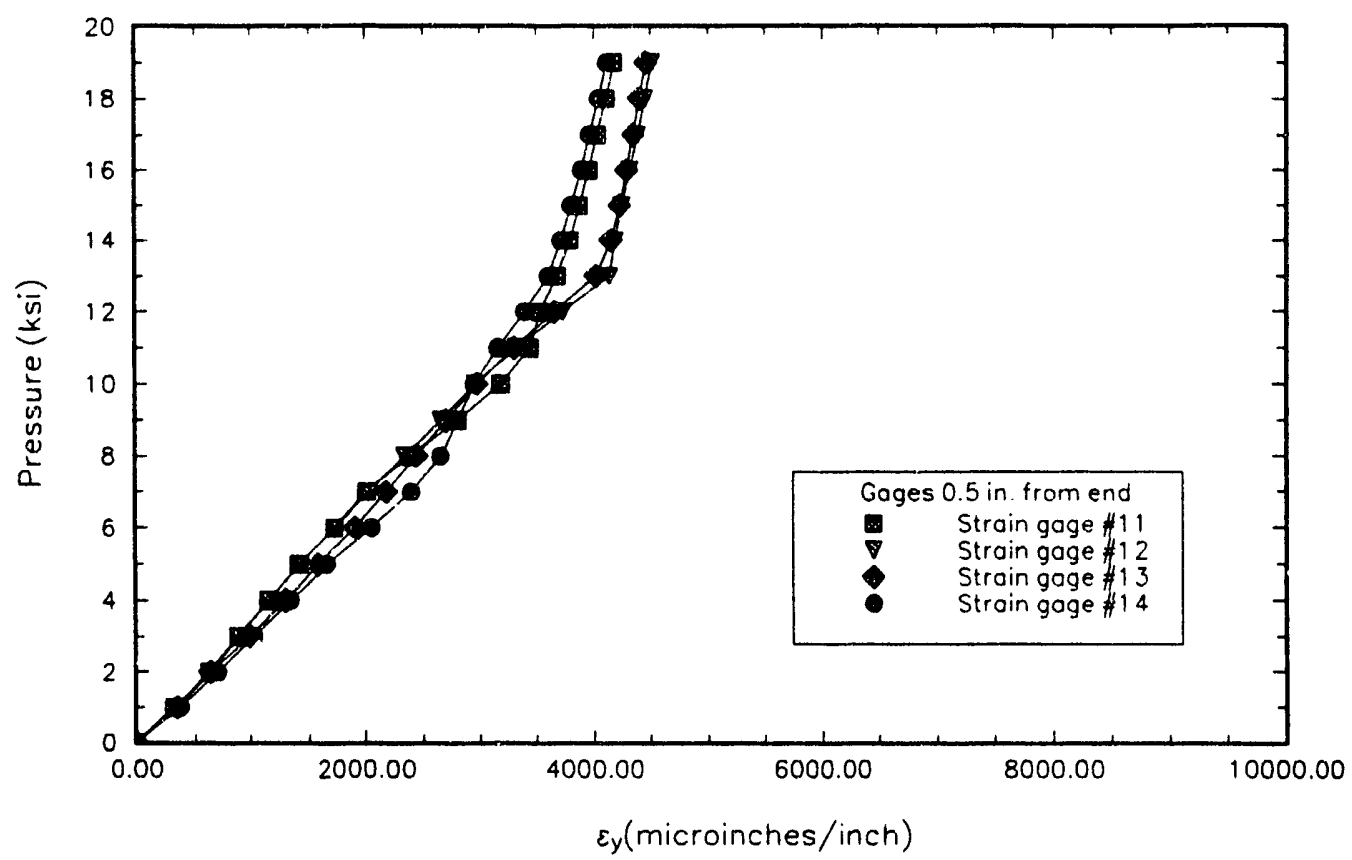

Fig. 3.4.1-7. Exterior hoop strains at 0.5 in. from end versus pressure.

\subsubsection{Experimental Correlation}

The capabilities of various analytical tools in the design and analysis of C6-1 were demonstrated in Sect. 1. In addition to these analytical capabilities, the development of a performance model requires the testing of articles as discussed in this section. From the results of the failure analysis in Sect. 1.4, for an initially assumed transverse compressive strength of $15 \mathrm{ksi}$, the cylinder test pressure of $20 \mathrm{ksi}$ is seen to be consistent with the range of predicted failure pressures. Based on the failure predictions for a 30-ksi transverse compressive strength, a test pressure of $26 \mathrm{ksi}$ was achievable. However, the revised stabilty analysis that included the effects of transverse shear deformations indicated that at $20 \mathrm{ksi}$ the cylinder was approaching its critical buckling pressure. This could be seen experimentally by the divergence of the midbay hoop strains located $120^{\circ}$ apart (see Figs. 3.4.1-1 and 3.4.1-2).

For the test pressure of $20 \mathrm{ksi}$ the calculated maximum hoop and axial layer stresses are $194 \mathrm{ksi}$ and $178 \mathrm{ksi}$, respectively (see Table 1.2.1-3). The maximum composite stress values obtained from the smeared property analysis are $137 \mathrm{ksi}$ for the hoop stress and $72 \mathrm{ksi}$ for the axial stress. These are the highest reported values achieved to date in a graphite composite cylinder. The experimentally measured peak hoop and axial strains are $0.84 \%$ and $0.73 \%$, respectively. The theoretical predictions from CCAP for the interior hoop strains at the cylinder midbay are compared with the experimental results in Figure 3.4.2-1. 
The predicted strains are in excellent agreement with two of the three strain gages. The average value of the three midbay interior gages at a pressure of $19 \mathrm{ksi}$ is equal to $0.83 \%$, which is slightly larger than the calculated strain of $0.80 \%$. The comparison between theory and experiment for the midbay exterior hoop strains is presented in Figure 3.4.2-2. The average measured strains are again seen to be slightly larger than the theoretical strains with the agreement between the two being acceptable. Figures 3.4.2-3 and 3.4.2-4 illustrate the correlation between theory and experiment for the midbay interior and exterior axial strains, respectively. The theoretical results for the axial strains slightly overpredict the measured results but are considered to be in satisfactory agreement with each other. The calculated maximum strains at a test pressure of $20 \mathrm{ksi}$ were reported in Table 1.2.1-1.

The correlation of predicted ply-level strains and implementation of a specific failure criteria associated with an observed damage mode is an important step in developing performance models. However, this phase of the experimental correlation was not performed for cylinder C6-1 because of the record 20-ksi pressure achieved without failure and with no observed damage.

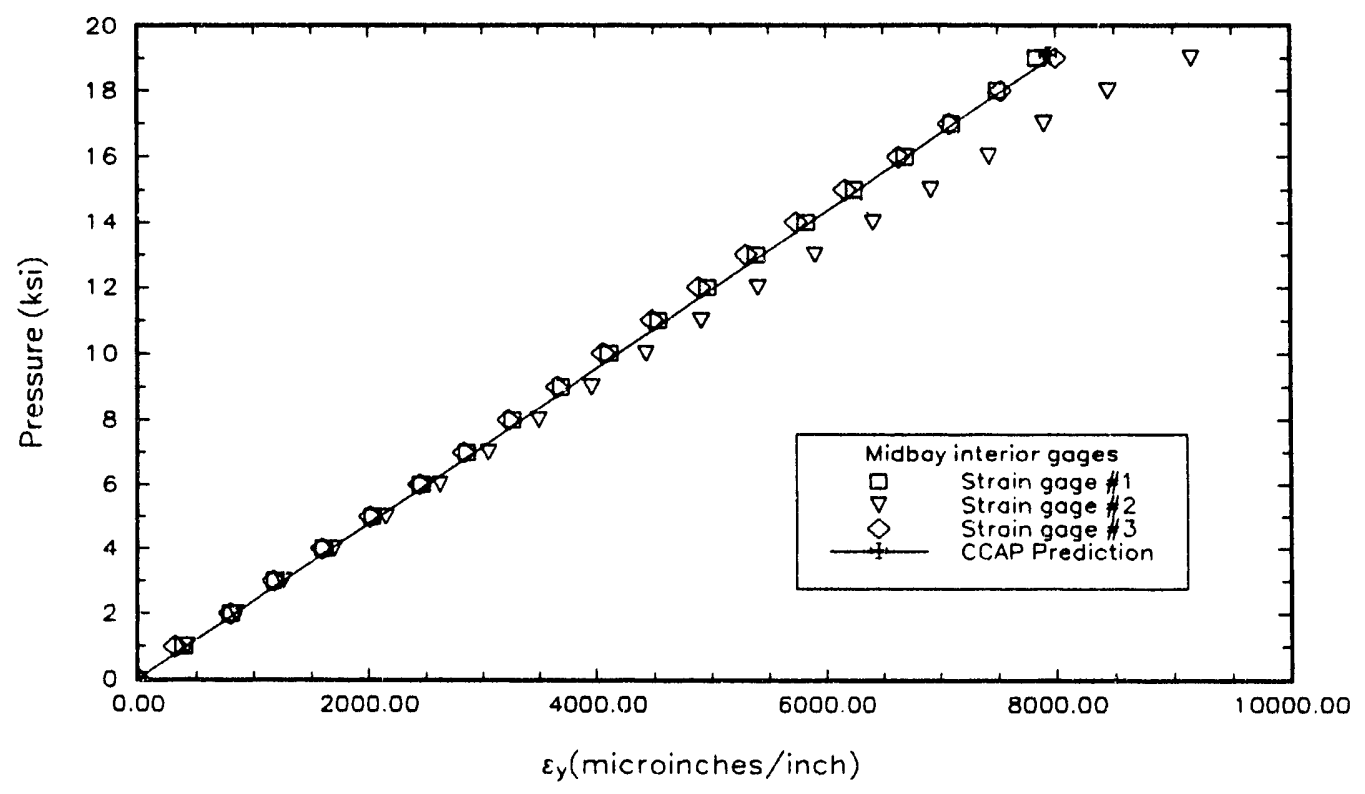

Fig. 3.4.2-1. Analytical/experimental comparison for the midbay interior hoop strains. 


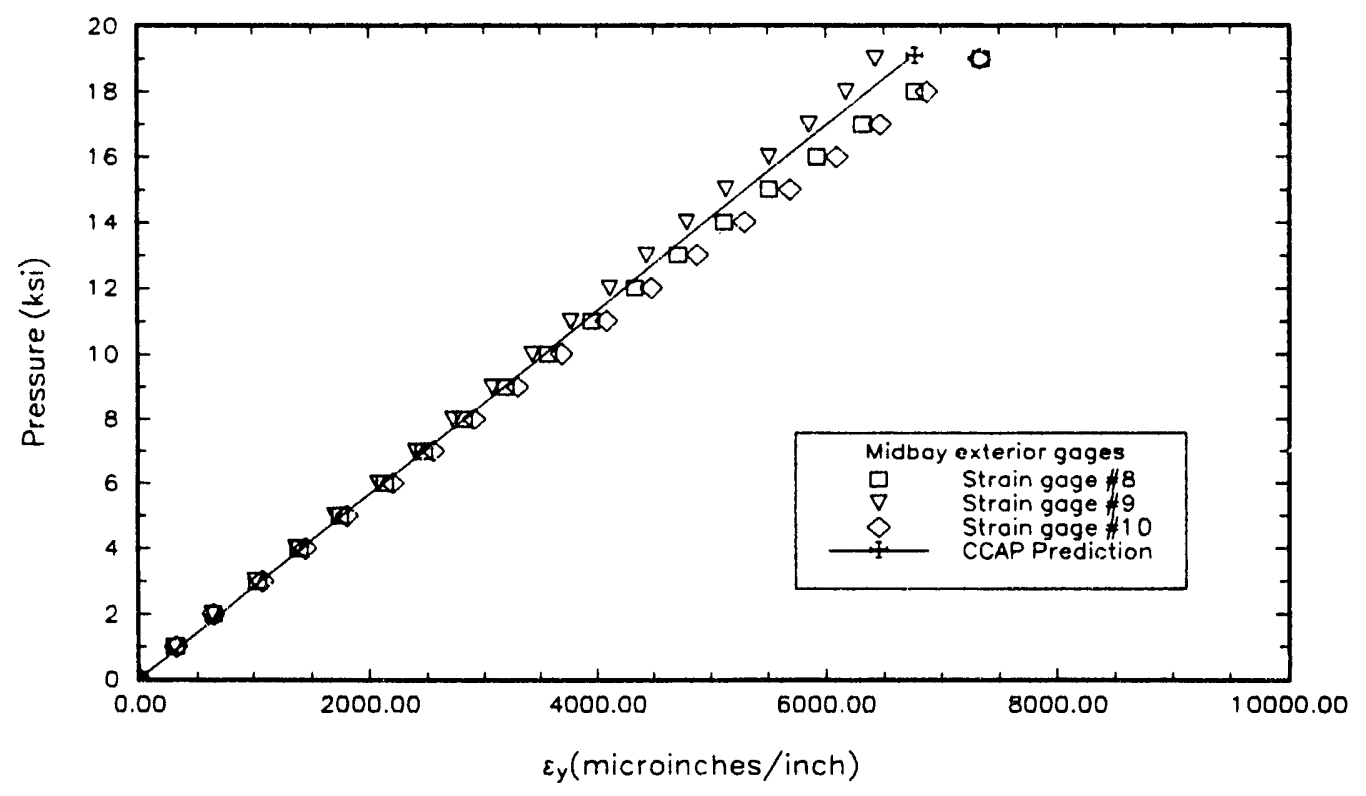

Fig. 3.4.2-2. Analytical/experimental comparison for the midbay exterior hoop strains.

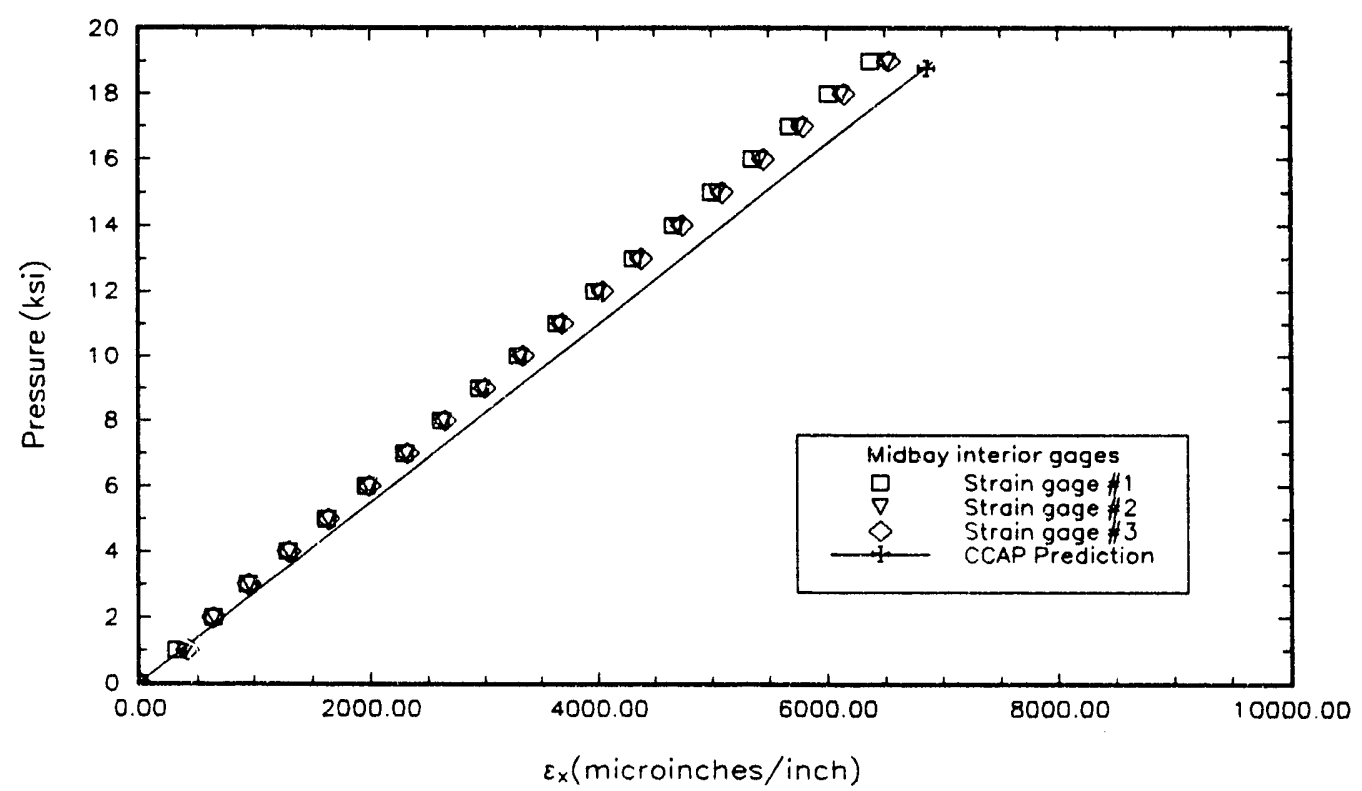

Fig. 3.4.2-3. Analytical/experimental comparison for the midbay interior axial strains. 


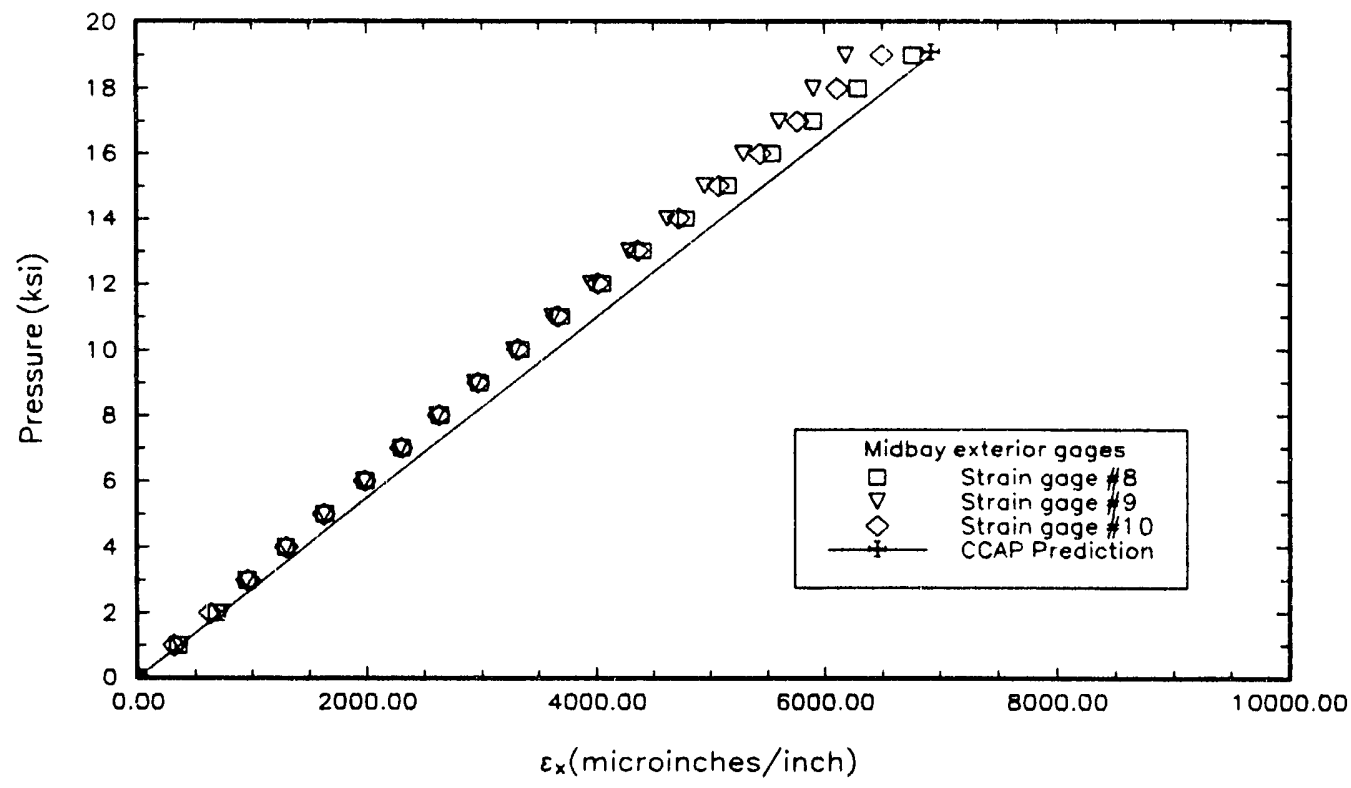

Fig. 3.4.2-4. Analytical/experimental comparison for the midbay exterior axial strains.

\subsubsection{Ring Tests}

Tests of ring specimens cut from each end of the cylinder were performed. The rings were tested in the ORNL 6-inch diameter strain-controlled ring test fixture. ${ }^{34}$ This fixture places the rings in the central tapered bore of a large steel cylinder. A matching piston forces the rings, through lateral pressure, down the tapered bore, producing increasing hoop compressive strain in the rings. The level of compressive strain achieved is monitored by strain gages attached to the ring ID surface. Estimates of the strains are also derived from piston displacement measurements.

Three rings cut from each end of cylinder C6-1 (labeled " $A$ " and "B") were tested. The rings had a 6.3-inch OD, a 5.3-inch ID, and a 0.5-inch axial length. The rings were ground to remove approximately 0.020 inches diametral from their as-wound outer surface. This was done to provide a uniform ring thickness and circular ring OD for contacting the tapered bore of the fixture. The grinding removed approximately half the thickness of the outer circwound layer.

Because the radial thickness and OD of cylinder C6-1 were less than the nominal values assumed for the design of the bore of the test cylinder, the starting position of these rings was approximately 5.6 inches down the bore of the cylinder. The usual starting position for nominal thickness rings is approximately 0.25 inches down the bore, which is approximately half the ring width. 
In the case of nominal dimension rings, the top edge of the ring is visible through the slot in the top of the cylinder through which the ring is inserted. The ring is carefully seated in the tapered bore by hand. Also, the alignment of the ring can be verified by observing the initial contact between the face of the piston and the top lateral surface of the ring. If the ring is properly aligned, then the gap between the piston face and ring top surface closes uniformly as the piston is lowered to initially contact the ring prior to loading.

In the case of the smaller diameter rings, visual observation was not possible; therefore, a method for installing the ring was devised. The method was to support the ring off the piston by means of a circular aluminum plate placed under the ring and attached to the piston. The aluminum plate was held by a single screw through a central hole in the plate into a threaded hole in the center of the piston. This same screw also secures the teflon disk, which is placed between the piston face and the top surface of the ring. The screw was tightened by hand to provide a light clamping force between the ring and piston. This provided contact with the piston while allowing radial alignment with the tapered bore of the cylinder.

The rings were instrumented with two hoop-direction uniaxial strain gages located $180^{\circ}$ apart on the ring ID surface. Piston displacement was also measured. Acoustic emission was monitored by attaching an acoustic emission pickup to the outer surface of the steel cylinder at the approximate axial location of failure of the rings.

The order of testing was rings from the "A" end and then from the "B" end. The rings were placed into the bore of the test fixture and the piston rate was adjusted to displace the rings down the tapered bore at a rate of $1 \mathrm{in} . / \mathrm{min}$. This produced an approximate hoop strain rate on the ring ID of $1159 \mu$-in./in./min. During testing, the piston load, the piston diplacement, the strain gage readings, and the acoustic emission count were recorded as a function of time. Testing continued until maximum load capability was reached.

In addition to the direct strain measurements by strain gages mounted on the ring ID, the strain was computed from the measured piston displacement and the known taper of the cylinder bore. This provided an independent estimate of the strains and a check of the strain gage readings.

The piston displacement is multiplied by the taper to obtain the radial displacement of the outer radius of the ring. This value is then multiplied by a ratio factor to obtain the radial displacement at the ring inner radius. Next, the strain value is then obtained by dividing the displacement by the ring inner radius. The ratio factor is obtained from the CCAP code as the ratio of the inner radius displacement to the outer radius displacement. The appropriate material properties and ring dimensions are used in CCAP to determine the displacement ratio for each test cylinder.

The results of these calculations are summarized in Table 3.4.3-1 along with the strain gage results. The strain gage values are the average for the two gages for each ring. 
Table 3.4.3-1. Ring test data for cylinder C6-1

\begin{tabular}{|c|c|c|c|c|c|}
\hline Ring No. & $\begin{array}{c}\text { Piston } \\
\text { displacement } \\
\text { (in.) }\end{array}$ & $\begin{array}{c}\text { Radial } \\
\text { displacement } \\
\text { at outer radius } \\
\mathbf{u}_{o} \\
\text { (in.) }\end{array}$ & $\begin{array}{c}\text { Radial } \\
\text { displacement } \\
\text { at inner radius } \\
u_{i} \\
\text { (in.) }\end{array}$ & $\begin{array}{l}\text { Hoop strain } \\
\text { from piston } \\
\text { displacement } \\
\left(u_{i} / r_{i}\right) \times 10^{6} \\
(\mu \text {-in./in. })\end{array}$ & $\begin{array}{c}\text { Hoop strain } \\
\text { from strain } \\
\text { gage } \\
(\mu \text {-in./in. })\end{array}$ \\
\hline C6-1/A-1 & 6.90 & 0.02484 & 0.02329 & 8759 & 7999 \\
\hline C6-1/A-2 & 6.25 & 0.02250 & 0.02109 & 7932 & 6661 \\
\hline C6-1/A-3 & 6.85 & 0.02466 & 0.02312 & 8695 & 8505 \\
\hline C6-1/B-1 & 5.97 & 0.02149 & 0.02015 & 7578 & 7081 \\
\hline C6-1/B-2 & 7.35 & 0.02646 & 0.02481 & 9331 & 8997 \\
\hline C6-1/B-3 & 7.15 & 0.02574 & 0.02413 & 9075 & 8366 \\
\hline
\end{tabular}

Average failure strain values were calculated from the strain gage and the displacement based strains. The average strain at failure from strain gage measurements was $7935 \mu$-in./in. with a standard deviation of $894 \mu$-in./in. The average strain from displacement measurements was $8562 \mu$-in./in. with a standard deviation of $675 \mu$-in./in.. The displacement based strains are consistently higher than the average strain from the two gages for each ring. In the past, checks of strain values from each method have been very close. This would suggest a possible problem with the calibration of the strain acquistion system for this group of rings.

The failure mode observed for the rings from C6-1 was a shear type fracture at an angle to the axial plane, usually accompanied by a single major delamination at the midthickness of the ring. Failure resulted in a single drop in load carrying capability of the ring to zero.

Rings were also cut from one end of cylinder C6-3, a 90/0 construction. In contrast, the failure mode observed for the rings from C6-3 was a progressive failure, with the initial failure observed to be delamination of the innermost ply, followed by a partial reduction in load from its peak value. Further increases in load caused delamination of the second innermost ply, which usually resulted in gross failure of the remainder of the ring. Much more postfailure delamination through the thickness of the ring was observed in these rings. Previously tested hoop-wound rings of this material showed only local delaminations near the fracture site. By comparison, much more global delaminations were seen in these two materials. The greater amount was seen in the material with the greater proportion of axial plies, cylinder C6-3. 
Table 3.4.3-2. Ring test data for cylinder C6-3

\begin{tabular}{|c|c|c|c|c|c|}
\hline Ring No. & $\begin{array}{c}\text { Piston } \\
\text { displacement } \\
\text { (in.) }\end{array}$ & $\begin{array}{c}\text { Radial } \\
\text { displacement } \\
\text { at outer radius } \\
u_{\circ} \\
\text { (in.) }\end{array}$ & $\begin{array}{c}\text { Radial } \\
\text { displacement } \\
\text { at inner radius } \\
\mathbf{u}_{\mathrm{i}} \\
\text { (in.) }\end{array}$ & $\begin{array}{c}\text { Hoop strain } \\
\text { from piston } \\
\text { displacement } \\
\left(u_{i} / r_{i}\right) \times 10^{6} \\
(\mu \text {-in./in. })\end{array}$ & $\begin{array}{c}\text { Hoop strain } \\
\text { from strain } \\
\text { gage } \\
(\mu \text {-in./in. })\end{array}$ \\
\hline C6-3/A-1 & 7.55 & 0.02718 & 0.02607 & 9806 & 10122 \\
\hline C6-3/A-2 & 6.85 & 0.02466 & 0.02365 & 8897 & 9266 \\
\hline C6-3/A-3 & 8.00 & 0.02880 & 0.02762 & 10391 & 10586 \\
\hline C6-3/A-4 & 6.50 & 0.02340 & 0.02244 & 8442 & 8512 \\
\hline C6-3/A-5 & 7.50 & 0.02700 & 0.02590 & 9741 & 9818 \\
\hline C6-1/A-6 & 7.55 & 0.02718 & 0.02607 & 9806 & 9734 \\
\hline
\end{tabular}

The rings from cylinder C6-3 exhibited an average failure strain of $9673 \mu$-in./in. with a standard deviation of $717 \mu$-in./in. The average strain computed from displacement measurements was $9514 \mu$-in./in. with a standard deviation of $710 \mu$-in./in. These values are in closer agreement for cylinder C6-3 than for cylinder C6-1.

To further investigate the comparison of strain gage and displacement based strain values, a linear regression analysis was performed on each data set. The strain values from each method were first cross-plotted for comparison (see Figs. 3.4.3-1 and 3.4.3-2). The linear regression line was also plotted in each case. Exact agreement between strain values would yield a $45^{\circ}$ line through the plotted points. The fitted line to the C6-3 ring data is close to the $45^{\circ}$ relationship; however, the line for the C6-1 rings is shifted above a $45^{\circ}$ line, indicating that the displacement based strains are consistently higher than the strain gage values. These results indicate a bias for the C6-1 data that is not evident in the C6-3 data. This suggests the possibility of a calibration problem with the data acquisition equipment for the C6-1 ring tests. 
LINEAR REGRESSION FIT TO STRAIN DATA

C6-I RINCS

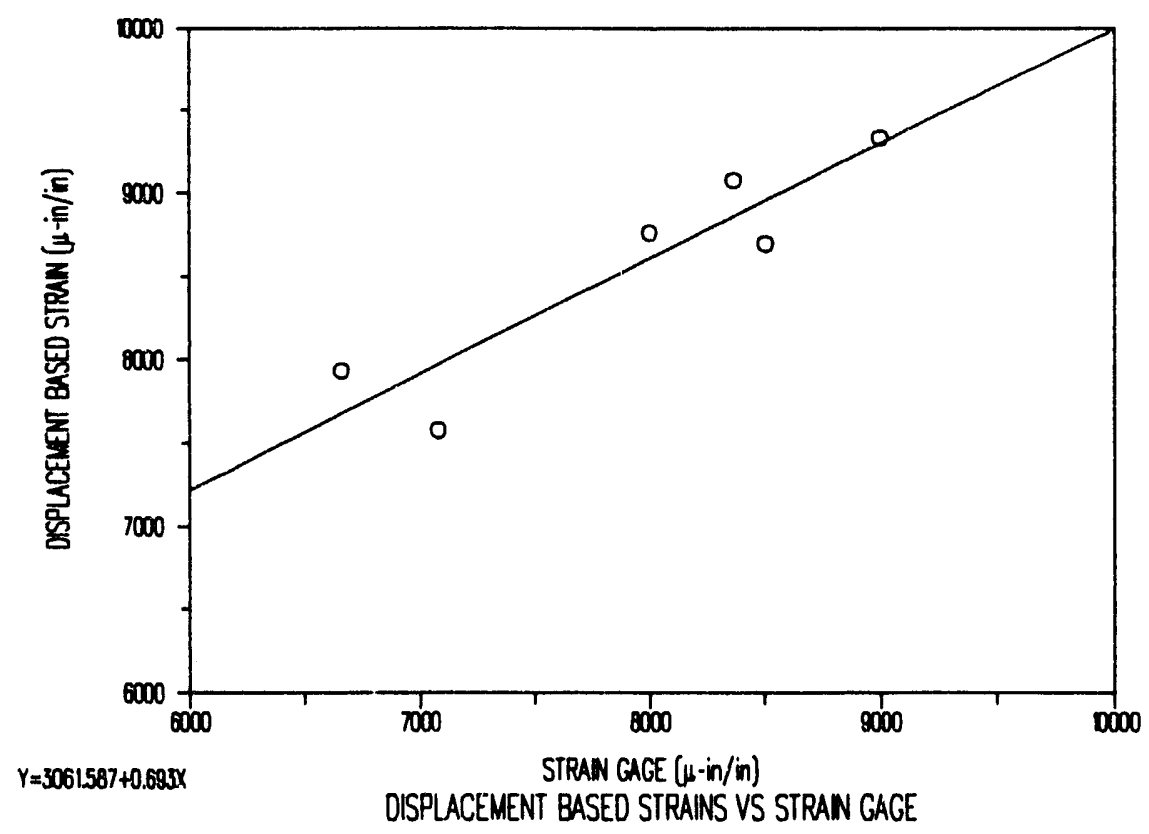

Fig. 3.4.3-1. Linear regression fit to C6-1 ring data.

LINEAR RECRESSION FIT TO STRAIN DATA

C6-3 RNCS

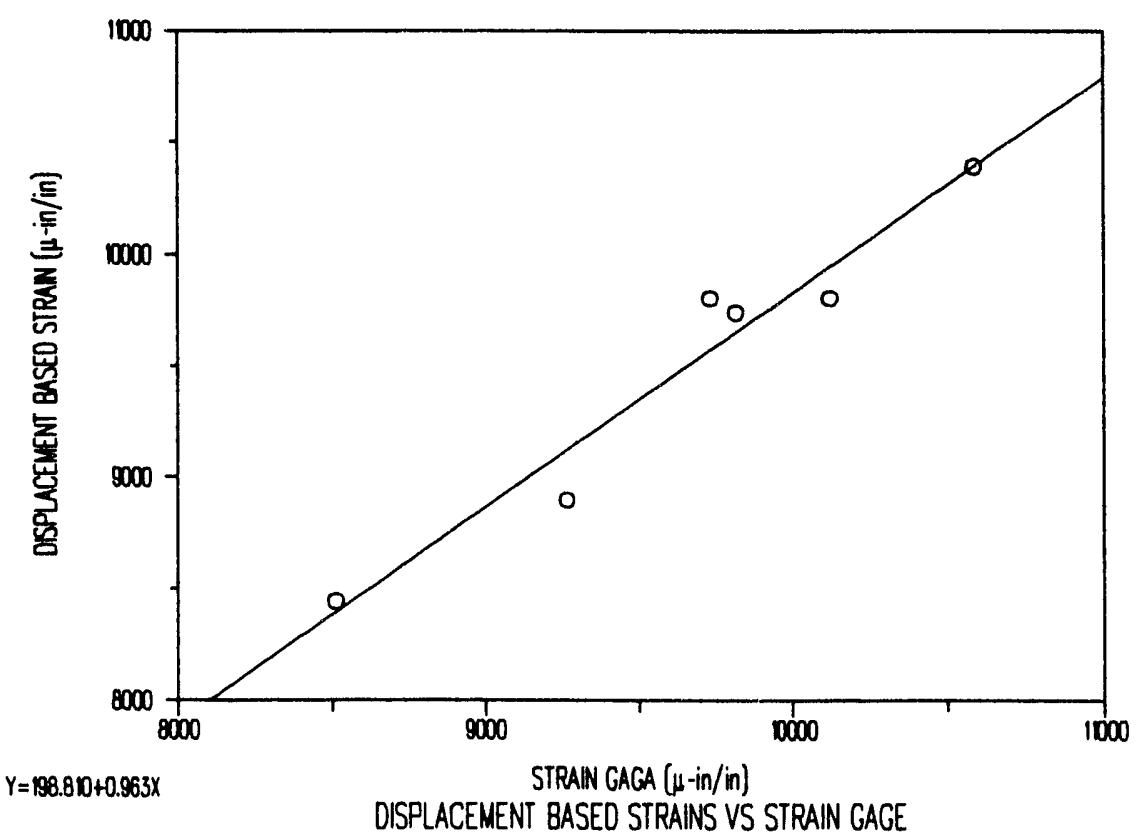

Fig. 3.4.3-2. Linear regression fit to C6-3 ring data 


\section{CONCLUSIONS}

This report details the design, construction, and testing of cylinder C6-1, the first of a series of thick-section composite cylinders investigated under an ORNL Laboratory Directed Research and Development seed-money project. This cylinder had a 2:1 hoop:axial cross-ply layered construction with IM6/ERL-2258 graphite/epoxy plies. An improved design for the metal end closures, in conjunction with the high quality of the cylinder material, resulted in an outstanding performance for this test article. This cylinder sustained a record hydrostatic pressure for graphite/epoxy material in a test conducted at the Stachiw Associates test facility in El Cajon, California. The cylinder test achieved a hydrostatic pressure of $20 \mathrm{ksi}$ without failure and had the highest reported stress level, to date, of $194 \mathrm{ksi}$.

Closed-form analytic solutions based on the theory of anisotropic elasticity were used to accurately determine the ply-level stresses. Composite stresses were obtained by using the closed-form solution with smeared laminate properties and also by finite element analysis. Analytic solutions were also used to calculate the buckling pressure and to determine the required unsupported length for a strength critical design. The preliminary results from these analyses and the application of various first-ply failure criteria indicated failure would occur at $\mathbf{2 0 . 2 2} \mathrm{ksi}$, with the innermost hoop ply failing first in the compressive matrix mode. This cylinder design was indicated to be buckling critical by subsequent analyses that incorporated a transverse compressive strength measured from an all circwound graphite cylinder test and by a stability analysis that included transverse shear deformations. Based on further evaluations of the analytical and experimental results, the following conclusions and recommendations are made:

1. The demonstration testing of cylinder C6-1 included the design, analysis, and fabrication of both test article and test hardware, where the test hardware was specifically designed for the cylinder construction being tested. This was done to mimimize the influence of the cylinder end conditions on the test results. The aim was to achieve material failure initiating in the uniformly stressed portion of the cylinder. The test objective was to validate the performance model being developed under this program for predicting the compressive response of composite cylinders.

2. An increase in the transverse compressive strength allowable from the preiiminary value of $15 \mathrm{ksi}$ to the measured value of $30 \mathrm{ksi}$ (obtained in the later test of an allcirc-wound cylinder) changed the mode of failure when applying Hashin's criteria from a compressive matrix mode to a compressive fiber mode. In conjunction with this result and an updated stability criterion that included transverse shear deformations, the design of cylinder C6-1 was seen to be buckling critical. The onset of a possible buckling mode of failure was experimentally observed by the divergence of the midbay hoop strain traces taken from gages located $120^{\circ}$ apart.

3. Comparison of failure predictions based on the Tsai-Wu and Hashin criteria indicate a divergence of predicted failure pressures for values of the transverse compressive strength greater than $15 \mathrm{ksi}$. The divergence is attributed to a mode transition from matrix mode to fiber mode in the Hashin criteria. Mode of failure (i.e., matrix versus fiber) is not delineated for the Tsai-Wu criterion. 
4. Revised performance model predictions were based on a measured transverse compressive strength obtained from the test of an all-circ-wound cylinder. These predictions illustrated the importance of developing representative test articles for determining the required strength parameters for the failure criteria.

5. The predicted strains based on a linear-elastic stress analysis were comparable to the experimentally measured strains at the cylinder midbay. The midbay interior and exterior hoop strains were slightly underpredicted by the analysis, whereas the interior and exterior axial strains were slightly overpredicted. The average measured maximum hoop and axial strains were $-0.8331 \%$ and $-0.6485 \%$, respectively, at an applied pressure of 19,000 psi.

6. Accurate predictions for normal components of strain, radial displacements, and radial stresses are possible by modeling the laminated cylinder as a single homogeneous layer having equivalent smeared properties. This is true only for cylinders that have a large number of layers with an interspersed stacking sequence and a layer thickness which is much smaller than the total wall thickness.

7. Accurate predictions for the hoop and axial stress components, which are discontinuous functions in the radial direction, require a layered analysis or a methodology for decomposing the smeared composite stress values into their layerby-layer values. The results from a smeared property, single-layered, composite cylinder analysis severely underpredicted the maximum hoop and axial layer stresses.

8. The interaction of the test cylinder and the metal end closures can produce significant bending and shear stresses near the cylinder ends. This can cause premature failure unless the peak stresses are controlled to acceptable values by the design of the end closures. The usual approach of using end closures of a standard design to test a variety of cylinders does not adequately control these discontinuity stresses. The approach taken was to design and fabricate a unique set of end closures for a specific cylinder. This approach permits the optimization of the end closures for each cylinder material and stacking sequence. End closures with a linear taper plug that significantly reduced the stresses were designed and used in the testing of cylinder C6-1.

9. Finite element analyses of the test cylinder and end closure assembly were performed to validate the design of the taper and gap of the plug. The plug was designed with a taper that would minimize the axial bending and shear stresses in the cylinder near the end of the plug. The initial clearance between the plug and the cylinder wall was set so the cylinder wall would be in contact with the entire plug length at an applied pressure of 20,000 psi. Radial displacement and interface pressure plots were used to validate the correct gap. Computed strain values at selected points of attachment of strain gages near the cylinder ends and adjacent to the end plugs were compared to measured values.

10. Stability analysis results are presented that illustrate the effects of using different curvature expressions in the kinematic relations for the strains. The solutions for computing the critical pressures were based on an orthotropic laminated shell 
theory with displacements that satisfied simply supported boundary conditions. The results based on the Donnell approximations for the curvatures were seen to overpredict the critical buckling pressures for the C6-1 test article. For the thick composite cylinder described in this report, inaccurate buckling predictions resulted from retaining only the terms having derivatives of the radial displacement in the curvature expressions.

11. Including transverse normal strains in the curvature expressions had a negligible effect on the predicted buckling pressure for the C6-1 cylinder, whereas the effects of transverse shear deformations were seen to be very significant. Accounting for transverse shear effect reduces the critical buckling pressure from 24,813 psi to $21,238 \mathrm{psi}$ ( $\mathrm{L}=10.0$ inches). An approximate solution that includes transverse shear effects is given for calculating the critical buckling pressure for an infinite length cylinder.

12. Buckling predictions are presented which indicate that accurate results can be obtained for the C6-1 cylinder construction by treating the laminated cylinder as a single homogeneous layer having an equivalent set of smeared orthotropic properties.

13. Failure analysis results are presented in the form of a stress ratio defined by the ratio of the maximum allowable stress to the applied stress level. For mechanical loading only and an applied unit load, the magnitude of the stress ratio defines the first-ply failure load. In the present failure theory, stress ratios are calculated for several different modes of failure and arranged in ascending order by magnitude. The lowest of these is reported as the critical mode. Degradation of the material properties above the first-ply failure load is not considered in the calculation of the higher modes. The highest mode thus provides an upper bound on the expected performance.

14. When the mode of failure in Hashin's criteria changes from a compressive matrix mode to a compressive fiber mode, as discussed above in item 3 , the results based on the Hashin criteria start to diverge from the Tsai-Wu failure criterion results. Failure predictions based on the Tsai-Wu and Hashin criteria agree closely for values of the layer transverse compressive strength less than $20 \mathrm{ksi}$ but diverge rapidly for values greater than $20 \mathrm{ksi}$. According to the Hashin criteria, the point of divergence corresponds to the mode transition from matrix failure to fiber failure.

15. When the mode of failure is compressive fiber and the first ply to fail is the innermost hoop ply, the failure prediction based on Hashin's criteria is the same as the maximum stress criterion.

16. The actual average layer thickness, determined by diameter build-up measurements taken during fabrication, was found to be greater than the preliminary value used in the laminate design. This necessitated dropping one repeating sublaminate during winding to achieve the target wall thickness. 
17. Dimensional inspection data including ID, OD, wall thickness, and TIR indicated significant dimensional variations, especially on the cylinder OD. Maximum TIR on the OD (tail stock end) was 0.0115 inches. The TIR of the ID was only 0.0005 inches to 0.0006 inches, a factor of 10 less than the OD. The variation in wall thickness (high-low) was 0.0056 inches, 0.006 inches, and 0.006 inches, respectively, at the head stock, center, and tail stock cross sections. Hydrostatic performance of this cylinder was exceptional in spite of these dimensional variations.

18. Composition and voids were determined from three samples cut from cach end of the cylinder. Results from the different samples for each end were consistent. Also, the samples from both ends were consistent. These results suggest that the overall variation in composition and voids was low. The material uniformity was also evident in the photomicrographs taken of the cross sections.

19. Strain gage data from gages, equally spaced around the circumference at the cylinder midplane, indicated significant variation in response between gages of the same orientation. The "spread" between the strain traces for hoop-oriented gages increased noticeably near the maximum pressure of 20,000 psig. Several traces showed an increasing nonlinearity with increasing pressure.

20. Comparison of analytically derived hoops strains with the experimental strain values from hoop-oriented gages indicated good agreement. The theoretical results for axial strains slightly overpredict the data. Averaging the values from individual gages improved the agreement in the case of the hoop strains. 


\section{RECOMMENDATIONS}

The following recommendations are based on the initial analytical and experimental results.

1. A three-dimensional elasticity solution for thick-section laminated composite cylinders, including the effects of axial bending and transverse shear, should be developed. This solution is needed to provide a stress analysis capability with realistic boundary conditions for analyzing composite cylinders.

2. To provide an interim analysis capability, existing shell theories that include transverse shear deformation effects should be applied to the analysis of laminated composite cylinders subjected to axial bending and transverse shear.

3. Additional failure modes, e.g., ply buckling, need to be incorporated into the closed-form analytic solution. This will require a non-axisymmetric analysis to allow the deformations to vary around the circumference of the laminated cylinder. These modes could also be incorporated ii.to the failure criteria as submodels for computing the compressive strength allowables.

7. Continued effort is needed towards designing, fabricating, and testing demonstration articles for validation of failure criteria. Particular attention should be given to improving the fabrication methods to reduce the cylinder dimensional variability and to improve the uniformity of the laminate construction. Analytical efforts to determine the effects of dimensional and material variability on cylinder performance should be explored.

8. A hydrostatic test capability beyond the present capacity of 20,000 psig is needed to permit testing of thicker cylinders to ultimate material failure. Present facilities are marginal for evaluating available materials.

9. Efforts to standardize test method and equipment for hydrotesting thick-section laminated composite cylinders should be increased. Particular attention should be given to the standardization of the methodology for the design of metal end closures. This must include the setting of acceptable maximum values for bending and transverse shear stresses. Appropriate tests of each material should be conducted to establish the maximum values. 
Appendix A

END CLOSURE DESIGN/ANALYSIS 
Metal end closures of the contoured end plug type are used to seal the ends of the test cylinders for hydrotesting. End plugs with constant linear taper are being developed under this program. The linear taper is expected to provide lower discontinuity stresses at the cylinder ends than obtained with end plugs of the constant radius variety. The cylinder discontinuity stresses are proportional to the values of the cylinder deflection and bending slope at the point of departure of the cylinder from the end plug contour; the higher the value of the slope, the higher the stress value that results. A plug with linear taper can provide a lower slope and, consequently, lower stresses than a plug with constant radius.

The design of the end closures also provides an initial radial clearance between the inner radius of the cylinder and the outer radius of the end plug. The advantages provided by this clearance are a less steep taper and a shorter plug length than would otherwise be possible and, consequently, lower discontinuity stresses. However, this clearance requires that the cylinder ends be allowed to slide relative to the end plate as the cylinder diameter constricts initially under increasing pressure. At a particular value of the pressure, the cylinder comes in contact with the end plugs, after which, the ends of the cylinder are supported by the plugs. The initial clearance is chosen to provide contact at a desired value of the applied pressure. Metal end rings between the cylinder ends and the metal end plates are used to assist the sliding action. The material stiffness of the end rings is chosen so that the radial displacement of the ring under pressure matches that of the cylinder. This provides for sliding between the end rings and end plates while minimizing relative sliding between the cylinder ends and the end rings. The initial radial clearance is calculated to provide contact at a value of pressure that is slightly below the calculated buckling pressure for an unsupported cylinder. The radial support of the end plugs at pressures higher than the contact pressure prevents buckling of the cylinder that otherwise would occur if the cylinder were not supported.

After the initial contact with the plug, as the pressure increases, the axial length of the shell contacting each end plug increases as the point of departure moves down the taper. The unsupported length of the cylinder, between the points of departure at each end, decreases as the pressure is increased. The total length of the cylinder, including the length in contact with the end plugs and the unsupported length between the end plugs, must be sufficient to provide the desired unsupported length at the expected maximum pressure.

The initial analysis for design of the metal end closures was based on Miller's theory for designing contoured end plugs for composite cylinders subjected to external pressure. ${ }^{33}$ Miller's paper gives solutions for compound (cubic-parabolic) and constant radius end plugs. Because we wanted to explore the linear taper plug, we first had to derive the solution for a constant taper. In this solition, we also included the initial radial clearance between the inner radius of the cylinder and the outer radius of the end plug.

In reformulating Miller's solution, we were not able to duplicate Miller's expression for the parameter $\beta$ (see Eq. [A-2] in this report). Only by setting the axial strain in the shell to zero, were we able to obtain an expression for $\beta$ similar to Miller's. This result would indicate that Miller's solution was formulated for radial pressure loading only (i.e., no axial thrust) instead of for hydrostatic pressure. 
This observation was not certain because Miller did not explicitly define the shell stiffness parameters $B_{y}$ and $D_{y}$ and Poisson ratios $\mu_{x y}, \mu_{y x}$. Also, an inconsistency was uncovered in Miller's equations that prevented resolving this question entirely. Starting with his differential equation for the deflection,

$$
y_{\operatorname{socx}}+4 \beta^{4} y=\frac{P}{D_{x}},
$$

where $\beta$ is defined by Miller as

$$
\beta=\left(\frac{B_{y}}{4 R_{m}^{2} D_{x}}\right)^{1 / 4} \text {. }
$$

We find the following particular solution from these two equations

$$
y_{-}=\frac{P}{4 \beta^{4} D_{x}}=\frac{P R_{m}^{2}}{B_{y}} \text {. }
$$

However, this result does not agree with the particular solution given in his general solution (see the constant term in Miller's equation [3]), which gives instead

$$
y_{\infty}=\frac{P R_{m}^{2}}{B_{y}}\left(1-\mu_{y x} \mu_{x y}\right) \text {. }
$$

This discrepancy is likely a result of the omission of the Poisson ratio product term in either the differential equation or the expression for $\beta$. It was not possible to resolve this question because these terms were not defined in his paper, and we were not able to obtain the two relevant papers that were referenced. ${ }^{35,36}$

In formulating the solution for the linear taper plug, we kept Miller's notation but used the standard definitions for the shell stiffnesses as defined, for example, by Ashton et al. ${ }^{37}$ We restrict the laminate to be balanced and symmetric (i.e., $B_{i j}=0$, and $A_{16}=A_{26}=D_{16}=D_{26}=0$ ). In this case, and assuming zero axial strain, we obtain for $\beta$,

$$
\beta=\left(\frac{A_{22}}{4 R_{m}^{2} D_{11}}\right)^{1 / 4},
$$

which is similar to Miller's result. 
However, for the case of hydrostatic loading (i.e., $N_{x} / N_{\theta}=1 / 2$ ), we find a different expression for $\beta$.

$$
\beta=\left[\frac{A_{11} A_{22}-A_{12}^{2}}{2 R_{m}^{2} D_{11}\left(2 A_{11}-A_{12}\right)}\right]^{1 / 4} .
$$

The particular solution in this case is

$$
y_{-}=\frac{P R_{m}^{2}\left(2 F_{11}-A_{12}\right)}{2\left(A_{11} A_{22}-A_{12}{ }^{2}\right)} .
$$

Equation (A-7) gives the radial deflection of the shell for the case of a free, unsupported cylinder.

Equations (A-6) and (A-7) were used in developing the solution for the constant taper plug. The differential equation Eq. (A-1) was used along with the expression for $\beta$ in Eq. (A-6). The particular solution given in Eq. (A-7) provided the shell deflection for points far removed from the end plug. The assumption was made that the cylinder length was sufficiently long that the stress perturbation at the cylinder end does not significantly affect the shell stress and deflection in the cylinder midregion. The cylinder length required to achieve this situation can be estimated from the value of $\beta$. This condition simplified the derivation of the solution by allowing a semi-infinite-length cylinder assumption to be made in the formulation.

In this case, the general solution for the unsupported region of the shell is

$$
y=y_{-}+e^{-\beta x}\left(c_{3} \cos \beta x+c_{4} \sin \beta x\right),
$$

where

$$
c_{3}=y_{0}-y_{\infty}
$$

and

$$
c_{4}=y_{0}-y_{\infty}+\frac{y_{0}^{\prime}}{\beta} \text {, }
$$

where $y_{0}$ and $y_{0}^{\prime}$ are, respectively, the deflection and slope at the point of departure of the shell from the end plug. 
The solutions for the bending moment and shear force for the region of unsupported cylinder are

$$
M_{x}=M_{0} e^{-\beta x}(\cos \beta x+\sin \beta x)+\frac{Q_{0}}{\beta} e^{-\beta x} \sin (\beta x)
$$

and

$$
Q_{x}=-2 \beta M_{0} e^{-\beta x} \sin \beta x-Q_{0} e^{-\beta x}(\sin \beta x-\cos \beta x)
$$

The quantities $M_{0}$ and $Q_{0}$ in Eqs. (A-11) and (A-12) are, respectively, the bending moment and shear force at the point of departure (i.e., at $x=0$ ). These quantities are related to the deflection and slope as follows

$$
M_{0}=2 D_{11} \beta\left[y_{0}^{\prime}-\beta\left(y_{\infty}-y_{0}\right)\right],
$$

and

$$
Q_{0}=2 \beta^{2} D_{11}\left[2 \beta\left(y_{\infty}-y_{0}\right)-y_{0}^{\prime}\right]
$$

For a plug with linear taper, the value of the moment $M_{0}$ is zero. We take $y_{00}$ as the initial radial clearance between the cylinder and the outer radius of the plug at the start of the taper. The slope of the taper is $m$, and the distance from the start of the taper to the departure point is $a$. The shell deflection and slope at the point of departure are then

$$
y_{0}=y_{00}+m a \text {, }
$$

and

$$
y_{0}^{\prime}=m
$$

Substituting Eqs. (A-15) and (A-16) into Eq. (A-13) and setting $M_{o}$ to zero there results

$$
\beta\left[y_{\infty}-\left(y_{\infty 0}+m a\right)\right]-m=0 \text {. }
$$

Eq. (A-17) is solved for the required length $a$ for the taper, which gives

$$
a=\left(\frac{y_{\infty}-y_{00}}{m}\right)-\frac{1}{\beta} .
$$


Eq. (A-18) is used to calculate the required plug length $a$ for the linear tapered plug for a specified value of the taper $m$, the initial clearance $y_{00}$, the maximum pressure $P$, or the free shell deflection $y_{\infty}$.

It is important that the plug length be sufficient that the point of departure does not move beyond the end of the plug before the maximum pressure is reached. If the plug length is too short, the shell can contact over the entire length of the plug before the maximum pressure is attained. In this case, high localized stresses develop near the end of the plug when the pressure is increased beyond this point. The shell is then subjected to very localized bending over the edge of the plug, which causes high shear stresses and possible premature failure of the cylinder. For a conservative value for the plug length, we recommend instead of Eq. (A-18) that $a$ be calculated from

$$
a=\left(\frac{y_{-}-y_{00}}{m}\right) \text {. }
$$

Alternatively, the plug length can be specified and the required taper calculated for a given maximum pressure or deflection. In this case, Eq. (A-17) is solved for $m$ rather than for $a$, which gives

$$
m=\frac{y_{-}-y_{00}}{\left(a+\frac{1}{\beta}\right)}
$$

For a conservative value of the taper we recommend instead of Eq. (A-20) that $m$ be calculated from the equation

$$
m=\frac{y_{-}-y_{00}}{a} .
$$

The bending moment and shear force at the point of departure for the case of a linear taper is obtained using Eqs. (A-15), (A-16), and (A-18) in Eqs. (A-13) and (A-14), which gives

$$
M_{0}=0 \text {, }
$$

and

$$
Q_{0}=2 \beta^{2} D_{11} m \text {. }
$$

The moment and shear for points in the shell beyond the point of departure (i.e., within the unsupported length) are given by 


$$
M_{x}=2 \beta D_{11} m e^{-\beta x} \sin \beta x,
$$

and

$$
Q_{x}=2 \beta^{2} D_{11} m e^{-\beta x}(\cos \beta x-\sin \beta x)
$$

The maximum values of the moment and shear are found by determining the critical point of these transcendental functions by setting their first derivatives to zero. The critical points for these are

$$
x=\frac{\pi}{4 \beta}, 5 \frac{\pi}{4 \beta}, 9 \frac{\pi}{4 \beta}, 13 \frac{\pi}{4 \beta}, \ldots
$$

for the moment and

$$
x=\frac{\pi}{2 \beta}, 3 \frac{\pi}{2 \beta}, 5 \frac{\pi}{2 \beta}, \ldots
$$

for the shear. Examination of the computed values of the moment and shear at these critical points and at the point of departure indicated that the maximum moment occurs at $\beta x=$ $\pi / 4$ and the maximum shear occurs at the point of departure (i.e., at $x=0$ ). Thus the maximum values are

$$
M_{\max }=\sqrt{2} \beta D_{11} m e^{-\frac{\pi}{4}}
$$

and

$$
Q_{\max }=Q_{0}=2 \beta^{2} D_{11} m
$$

Eqs. (A-28) and (A-29) reveal one desirable property of the linear taper end plug. The maximum moment and shear do not depend on the applied pressure or deflection of the shell but rather depend only on the values of the taper $m$, the wavelength parameter $\beta$, and the bending stiffness $D_{11}$. Thus, the discontinuity stresses do not increase with the pressure as is the case with constant radius type contoured end plugs. This result means that the bending and shear stresses are constant and therefore decrease in proportion to the shell membrane stresses with increasing pressure. This is important because the absolute maximum stresses are obtained by superposition of the discontinuity stresses and the shell membrane stresses. The linear taper plug has the advantage that the discontinuity stresses are added as a constant increment to the increasing membrane stresses. 
Maximum values for the bending stress and shear stress are obtained from Eqs. (A-28) and (A-29) as follows:

$$
\sigma_{\max }=6 \frac{M_{\max }}{t^{2}}
$$

and

$$
\tau_{\max }=1.5 \frac{Q_{\max }}{t}
$$

These stresses are not la'yer stresses but are rather the composite stresses (i.e., derived from smeared material elastic properties). Equations (A-30) and (A-31) are useful for estimating the cylinder peak bending and shear stresses for a particular end closure design. Maximum values must be established for each composite material and lay-up. The adequacy of a particular choice for the limiting values can only be established by tests of different designs and posttest examination of the failed cylinders.

Detailed failure analysis could be applied to assess the impact of the discontinuity stresses on cylinder failure. In that case, the analysis should be based on the layer stresses rather than the smeared composite stresses. The layer stresses could be extracted from the shell solution or from finite element analysis. If the finite element analysis is done using smeared elastic properties, then the stress values obtained are composite stresses and the layer stresses must be extracted in a postprocessing step. An alternative approach is to model the individual layers; however, this requires a very fine mesh and the models tend to be large if the entire cylinder is modeled with a fine mesh. The size of the finite element model can be reduced by applying substructuring, mesh gradation using transition elements, or by using smeared material properties in part of the cylinder. These schemes use either a coarse mesh or smeared material properties for the cylinder midregion where stress gradients are low. The cylinder end regions are modeled using a substructure or using mesh refinement for the individual layers. To date, no comparison of these various approaches has been made.

The design of the end closures for cylinder C6-1 was based on Miller's theory as modified for the linear tapered end plug. The design was constrained by the available vertical clearance within the pressure vessel at the Stachiw test facility. The approach taken for the design was to first set the length-to-diameter ratio (L/D) for the unsupported length of the cylinder and to then select the greatest length for the end plugs allowed by the available clearance. The nominal $L / D$ was set at 1.6 and the end plug length at 4.0 inches The total length of test cylinder C6-1 was 18 inches. These dimensions provided an overall length of the test assembly of approximately 25 inches (see Fig. 1.1-1). This length includes the penetrator for the strain gage lead wires through the top end closure and the tie rod extensions beyond the bottom end plate. 
The material laminate stiffnesses calculated for cylinder C6-1 are summarized in Table A-1.

Table A-1. Material stiffnesses for cylinder C6-1 Design : 2:1 [90/0] IM6/ERL-2258

\begin{tabular}{cc}
\hline Stiffness & Value \\
\hline $\mathrm{A}_{11}\left(\mathrm{lb}_{\mathrm{f}} / \mathrm{in}.\right)$ & $4.1581 \mathrm{E}+06$ \\
$\mathrm{~A}_{12}\left(\mathrm{lb}_{\mathrm{f}}\right.$ /in.) & $2.3121 \mathrm{E}+05$ \\
$\mathrm{~A}_{22}\left(\mathrm{lb}_{\mathrm{f}}\right.$ /in.) & $7.8592 \mathrm{E}+06$ \\
$\mathrm{D}_{11}\left(\mathrm{lb}_{\mathrm{r}}\right.$-in. $)$ & $8.0775 \mathrm{E}+04$ \\
\hline
\end{tabular}

The mean radius of the cylinder is 2.9065 inches, the wall thickness is 0.495 inches, and the plug length is set to 4.0 inches. The calculations were done for a maximum pressure value of 20,000 psi. This is the design limit pressure for the Stachiw pressure vessel. Applying Eqs. (A-6) and (A-7) we obtain the following values for cylinder C6-1:

$$
\begin{aligned}
& \beta=1.31132 \text { in. }^{-1} \\
& y_{\infty}=2.09342 \mathrm{E}-02 \text { in. }
\end{aligned}
$$

We select the value of the initial clearance $y_{00}$ as half of the value of $y_{\infty} ;$ thus, the cylinder should contact the plug at 10,000 psi pressure. This pressure is well below the critical buckling pressure for cylinder C6-1 for the case of an unsupported cylinder. Using this value of $y_{00}$ in Eq. (A-20) gives the taper value for the end plug as

$$
\mathrm{m}=2.19778 \mathrm{E}-03 \text { in./in.. }
$$

From Eqs. (A-28) and (A-29) we calculate the maximum moment and shear to be the following:

$$
\begin{aligned}
& M_{\max }=150.1034 \text { in.-lb } / \text { in. } \\
& Q_{\max }=610.5322 \quad b_{f} / \text { in.. }
\end{aligned}
$$

Finally, from Eqs. (A-30) and (A-31) we calculate the bending and shear stress values as follows:

$$
\begin{aligned}
& \sigma_{\max }=3675 \mathrm{psi} \\
& \tau_{\max }=1850 \mathrm{psi} .
\end{aligned}
$$

These stresses were judged to be acceptable for this initial test. The stress values are significantly lower than peak stress values achieved on earlier cylinder tests in which closefitting rigid end plugs were used. 
The stresses could be reduced by decreasing the taper of the end plugs; however, this would have required that the length of the plugs be increased or the maximum pressure be decreased. Increasing the plug length would have required that the $L / D$ of the unsupported length be decreased in order to avoid increasing the total length of the test assembly. This option was ruled out because of the concern that the discontinuity stresses might affect the stresses in the cylinder midregion .

Alternatively, the taper could be reduced by increasing the initial clearance without increasing the plug length. The greater clearance would cause the cylinder to contact the end plugs at a higher pressure. This would increase the possibility that the cylinder could fail prematurely due to buckling in the unsupported mode or growth of the cylinder out-ofroundness caused by prebuckling deformations. It was decided to use a conservative value of the clearance for the first test.

Estimates of the peak bending and shear stresses were also derived from the finite element analysis of the cylinder test assembly. The peak stress values were obtained from contour plots of the axial and shear stress components. A series of contour plots were made for each stress component using different maximum and minimum contour limits to precisely determine the peak values. Representative contour plots for the axial and shear stresses are given Figs. 1.2.2-7 and Fig. 1.2.2-9.

The bending stress was extracted from the peak local values of the axial stress component on the cylinder inner and outer surfaces near the end of the plug. The peak axial stress values were $-63,000$ psi for the inner radius and $-74,000$ psi at the outer radius. A first estimate for the bending stress is obtained by taking one-half the difference between these two values, which gives 5500 psi. This estimate is high because it includes the stress difference that results from the radial gradient of the axial stress caused by the threedimensional stress state that occurs in a thick-wall cylinder. This difference is present even in the absence of axial bending of the cylinder and is thus present at the cylinder axial midplane where the bending is negligible. A correction to the initial estimate was made by subtracting half the difference between the surface values of the axial stress at the midplane. The values of the midplane axial stresses were $-66,400 \mathrm{psi}$ at the inner radius and $-72,200$ at the outer radius. These values gave a half difference of $2900 \mathrm{psi}$ for the midplane location. Subtracting the 2900-psi value from the first estimate of 5500 psi gave a final value of 2600 psi for the estimated peak bending stress from the finite element analysis.

The shear stress value was obtained directly from the shear stress contour plots. The location of the peak value was found at an axial position corresponding to the end of the plug and at a radial location near the thickness midplane. The peak shear stress value was $780 \mathrm{psi}$. The peak stress results from the shell and the finite element analyses are compared in Table A-2.

Table A-2. Comparison of shell solution and finite element stress values

\begin{tabular}{lcc}
\hline Stress component $(\mathrm{psi})$ & Shell solution & Finite element analysis \\
\hline Bending & 3675 & 2600 \\
Shear & 1850 & 780 \\
\hline
\end{tabular}


Based on this comparison, the shell solution gives a higher value for each stress component. One likely cause for the observed difference is that the shell formulation does not include transverse shear deformations. Miller's shell theory included only bending and in-plane deformations. The finite element analysis does include transverse shear deformations. The effect of transverse shear on the peak stress values is probably significant because of the low value of the transverse shear modulus of graphite-epoxy laminates. This was also evident in the buckling results where the critical pressure decreased from 24,948 without transverse shear to 21,238 psi with transverse shear. For the case of an infinitely long cylinder, the effect of transverse shear reduces the critical buckling pressure from 20,097 psi to 16,041 psi. Additional analysis on the shear effect is in progress and results will be reported later.

The end closure assembly is made of four parts: a steel end plate, an aluminum end plug, a steel end ring, and an o-ring seal (see Figs. A-1 through A-3). The aluminum end plug is joined to the end plate by thermal shrink fit of the plug over a boss on the end plate. The two-piece design of the end plate/end plug assembly allows the end plates to be used with several different end plug designs and facilitates the replacement of the plug whenever it is damaged during a cylinder failure. The use of an aluminum end plug instead of an all steel closure reduces the weight of the end closure assembly. The robust design of the end plate and end plug insured that the stresses in the metal components were low. The steel end plates were hardened to reduce wear and pitting to facilitate their reuse on subsequent tests.

The end plates have an integral flange and bolt circle that provide points of attachment for threaded tie rods which connect between the two end closures. The tie rods are tensioned via locking nuts to obtain an initial clamping force to secure the end closures against each end of the cylinder. These features were not expected to significantly affect the cylinder stresses because the stiffness of the flange is low and the clamping load is small compared to the loads that result from the hydrostatic pressure. One of the two end plates (No. 1) has a 1-inch threaded hole in the end plate for the penetrator. The penetrator provides feedthrough for the lead wires from the interior strain gages.

The end ring is held in place in the end closure assembly by an o-ring. The o-ring provides centering of the end ring relative to the end plate and end plug. This insures that the end ring is held concentric with the end plug until the end closures are secured with the tie rods. After the initial test, the o-ring was replaced by a "quad" ring. The quad ring has a greater cross section than the o-ring and thus more completely fills the o-ring groove when fully compressed. This change was made to increase the support of the end ring after initial contact between the cylinder and end plug. The end ring has a slight conical taper on the side adjacent to the end plate. The initial clearance due to this taper closes as the pressure is applied. This action provides for a controlled rotation of the cylinder end to allow the cylinder to conform to the taper of the end plug.

The end plug nominal dimensions are calculated based on the computed values of the taper $m$, the initial clearance $y_{00}$, and the measured ID of the cylinder. The starting diameter for the taper is found by subtracting the target diametrical clearance value from the average value of the cylinder ID measurements (see Table 2-3). The OD tolerance for the plug profile is set based on the measured run-out of the cylinder ID (see Table 2-4). 
The shop drawings for the end closures (see Fig. A-1) are given as Figs. A-2 through A-9. All parts were fabricated within drawing tolerances. The aluminum end plugs were rough machined as blanks and then assembled to the steel end plates before final machining of the end plug taper. Both end closure assemblies were within tolerances after final machining.

The functionality of the end closure design was evaluated by analysis and by means of strain measurements taken during the cylinder test. The finite element model of the test assembly (see Sect. 1.2.2) provided analysis results on cylinder displacements, stresses, and strains that were compared to the shell solution and to the measured strain data. The objective here was the validation of the expected interaction between the test cylinder and the end closures. The expected behavior was initial contact between cylinder and end plug at approximately 10,000 psi of pressure after which the plug provides increasing support to the cylinder at higher pressures. This action should be evident as a change in slope of the strain versus pressure traces from strain gages located near each end of the cylinder. The slope change results from the increasing support provided by the end plug to the cylinder after contact. The break in the slope of the strain trace should indicate the approximate pressure at which actual contact occurs.

Figure A-10 compares the calculated strain and measured strain values for gages located 0.5 inches from the cylinder ends. Two gages were applied at each end located $90^{\circ}$ apart on the cylinder OD circumference. These gages were oriented in the circumferential direction. The finite element strain values were extracted from the two elements located adjacent to the 0.5 -inch axial position at the cylinder OD surface. The hoop strain values from the Gauss integration points nearest the 0.5 -inch location were averaged.

Figure A-10 indicates that the slope change in the strain traces occurred at different pressures for each strain gage. Two of the four gages showed that the slope change occurred at a higher pressure than predicted by the finite element analysis. One possible explanation for this difference is the frictional drag between the end ring and end plate. A higher than expected drag would retard the radial displacement of the ends of the cylinder and delay contact to a higher value of pressure. Also, the analysis was based on an assumed small value of the coefficient of friction for relative sliding between mating surfaces. A dry powder type high-pressure lubricant was applied to all mating surfaces prior to test to reduce the friction. It is likely that the actual friction coefficient is somewhat larger than the ideal value supplied with the lubricant. The results in Fig. A-10 indicate reasonable agreement between the predicted and actual strains. The expected slope change is seen in the traces from all four gages. This suggests that the end plugs functioned as designed.

The finite element and strain gage results indicate that initial contact occurs at a higher pressure than predicted by the shell solution. The actual contact occurred at approximately 12,000 psi rather than at $10,000 \mathrm{psi}$. This is not surprising because the shell formulation does not consider the frictional drag on the ends of the cylinder. However, this result has implications to the end plug design for buckling considerations. If the contact pressure is set too high by the choice of the initial radial clearance then the cylinder may buckle in the unsupported mode or fail in circumferential bending due to growing out-of-roundness. In setting the initial clearance, adequate margin should be provided between the pressure for actual contact and the critical pressure for buckling for a unsupported cylinder. 


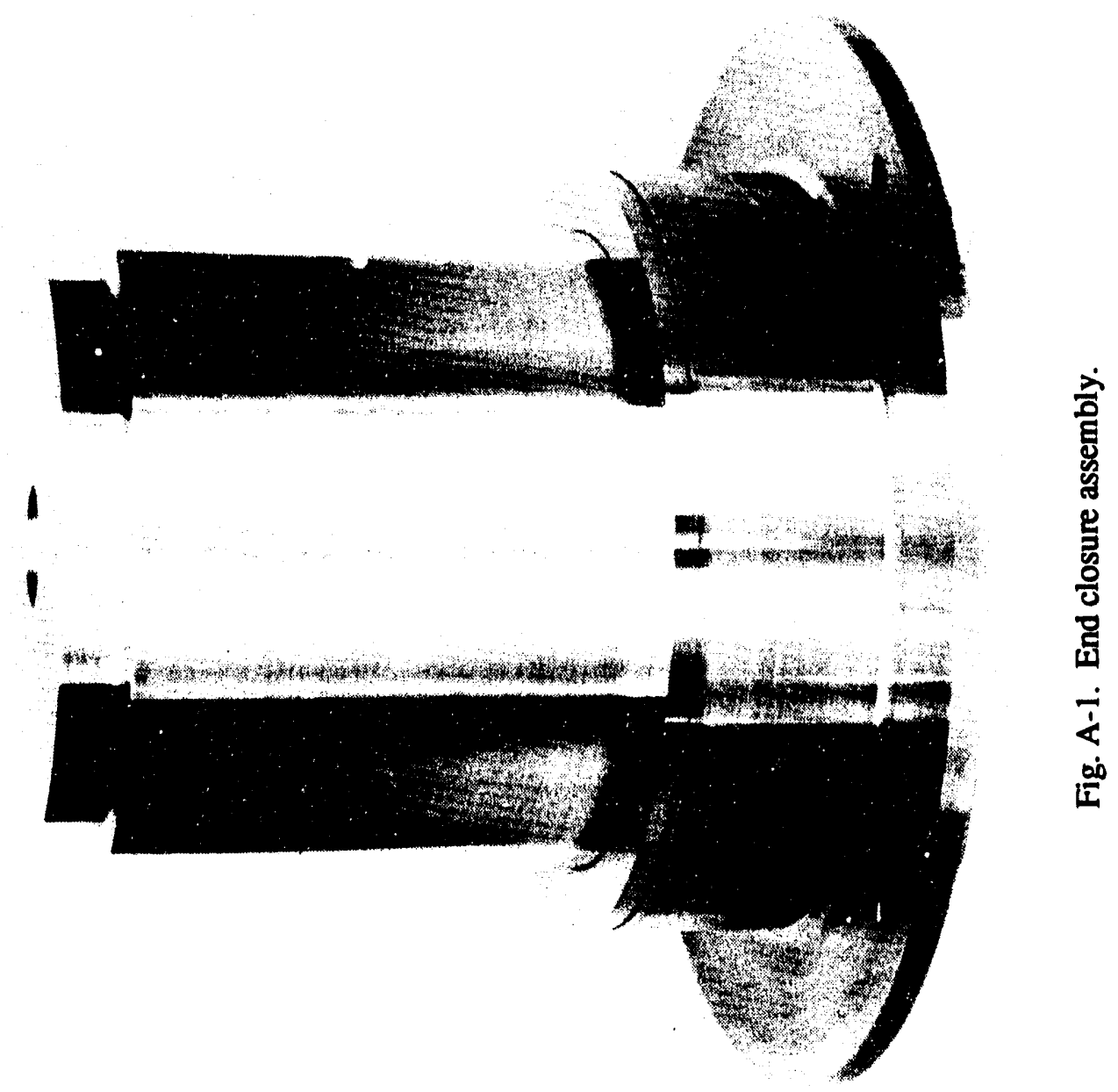


(1) END PLATE !

(2) PLUG

(3) RING

(4) I RING (PARKER 2-250)

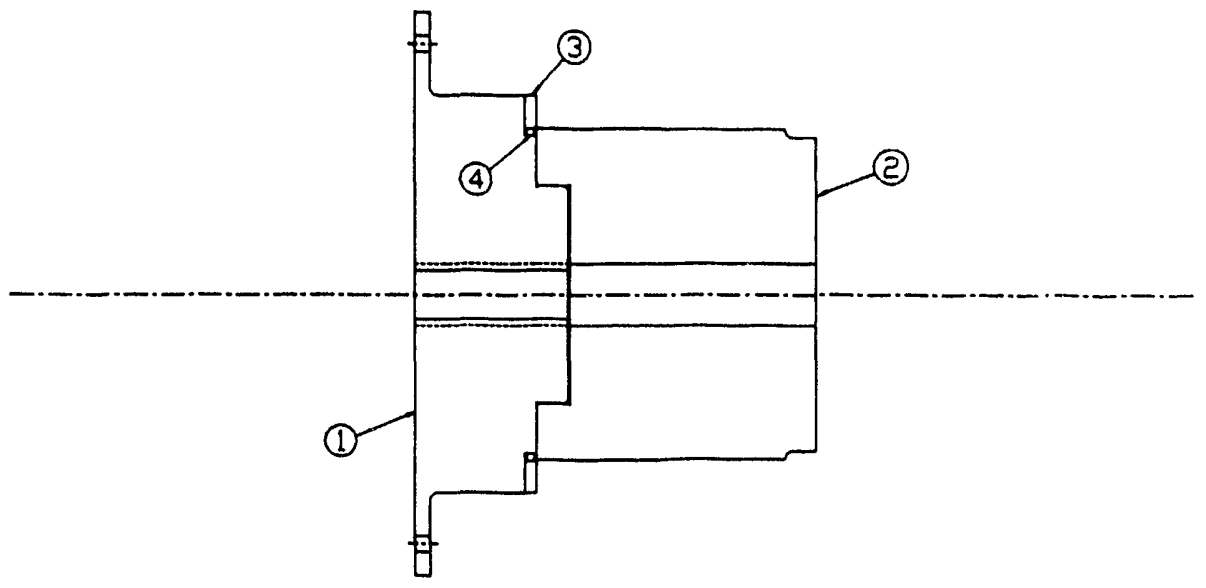

END CLOSURE ND. 1 ASSEMBLY

WB052290-1 REV 0

Fig. A-2. End closure No. 1 assembly.

(1) END PLATE 2

(2) PLUG

(3) RING

(4) R RING (PARKER 2-250)

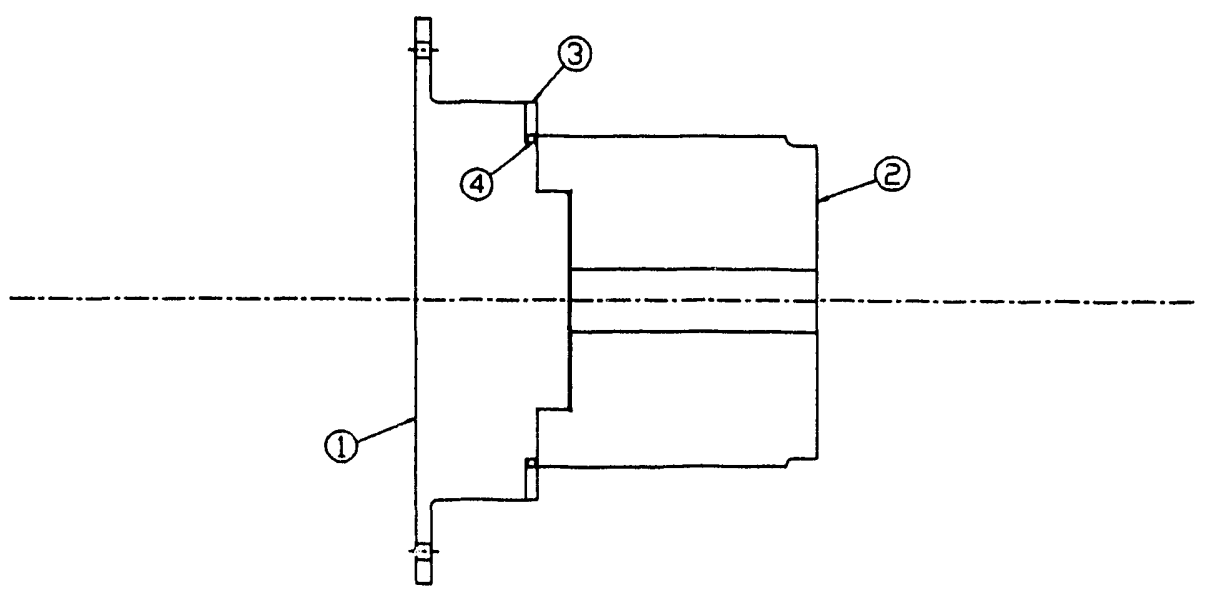

END CLISURE ND. ? ASSEMBLY

WB052290-2 REV 0

Fig. A-3. End closure No. 2 assembly. 
(1) END PLATE 1
(2) END PLUG

NDTESI I. SHRINK FIT PARTS I \& 2 BEFORE FINAL DD CUT OF PART 2

2. O.0OL MAXIMUM GAP BETWEEN 2. 0.001 MAXIMUM GAP BETWEEN
PARTS AT SECTION A-A AFTER INTERFERENCE ASSY.

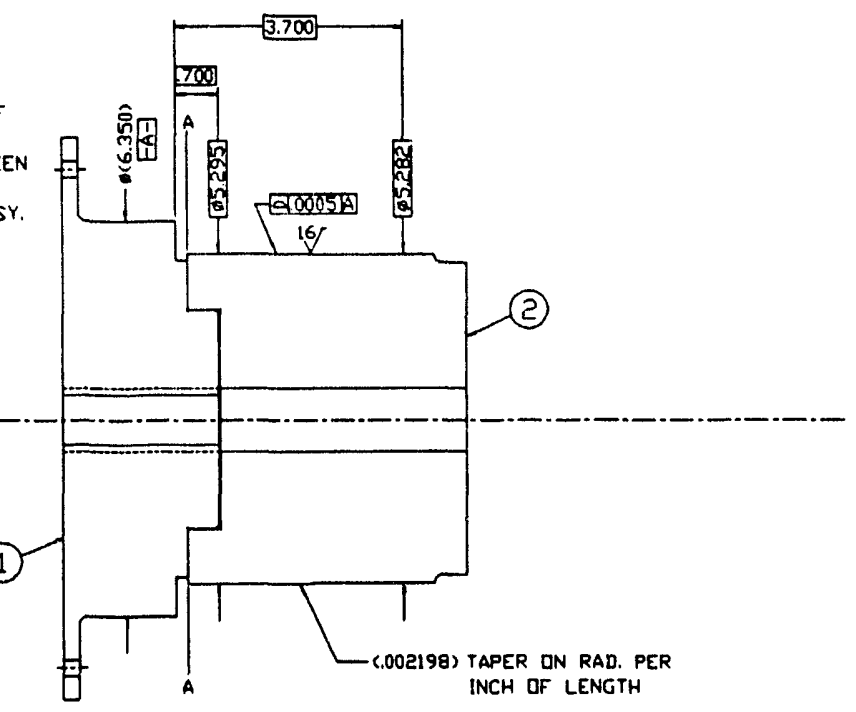

END CLISURE ND, 1 H.W. BLAKE MACHINING $05 / 2 ! / 90$ SCALE $1^{\circ}=1^{\prime}$ WB052190-1 REV 0

Fig. A-4. End closure No. 1 machining.
(1) END PLATE 2
(2) END PLUG

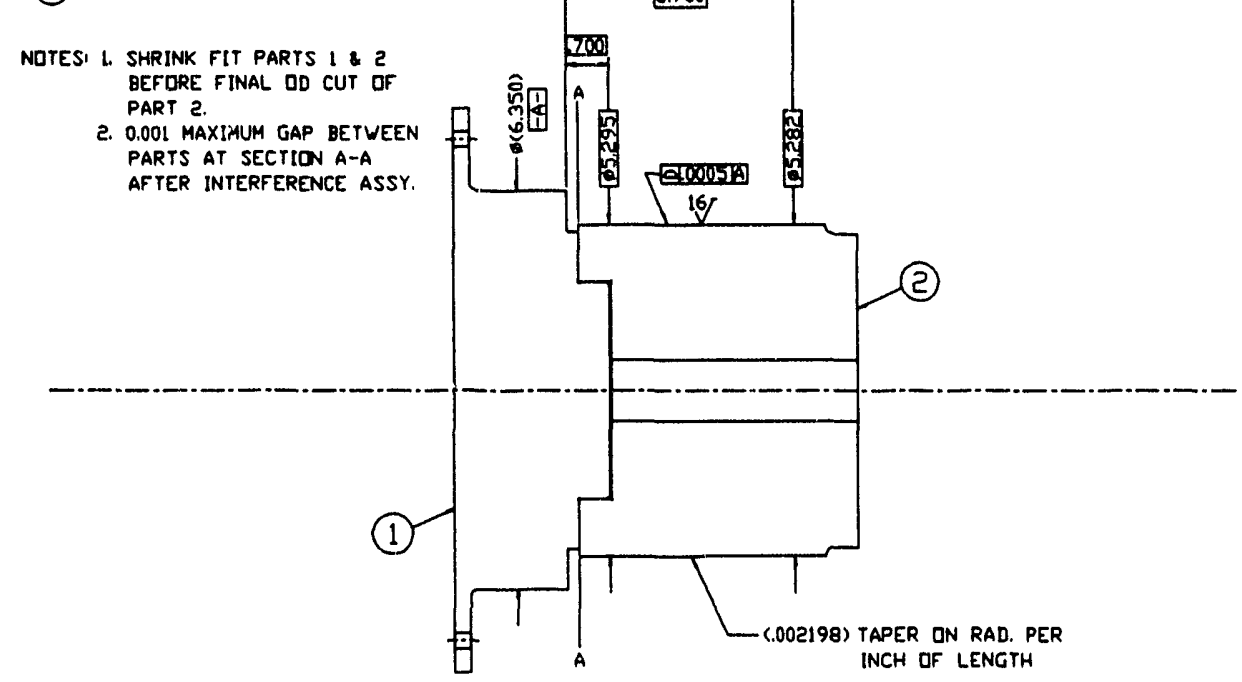

$$
\begin{array}{ll}
\text { END CLISURE ND. } 2 & \text { H.W. BLAKE } \\
\text { MACHINING } & \text { SCI/91/90 } \\
& \text { SCALE } 1^{\circ}=1^{\circ} \\
& \text { WBO52190-2 REV } 0
\end{array}
$$

Fig. A-5. End closure No. 2 machining. 
BREAK ALL CORNERS .005-.010 UNLESS DTHERWISE NDTED

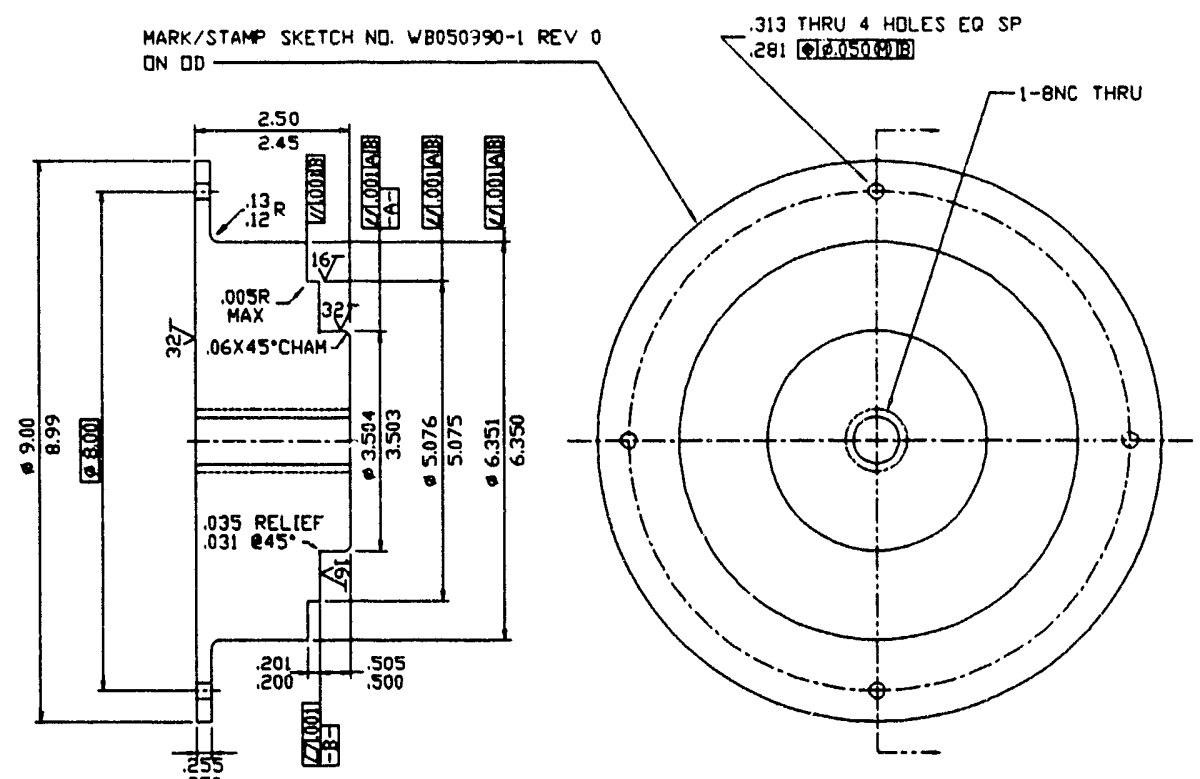

END PLATE 1

MAT'L AISI 4340 STL

HEAT TREAT RC 50-55

QUENCHED \& TEMPERED

ALL DIMENSIONS FINAL AFTER HEAT TREAT

Fig. A-6. End plate No. 1.

BREAK ALL CORNERS .005-.010 UNLESS DTHERWISE SPECIFIED

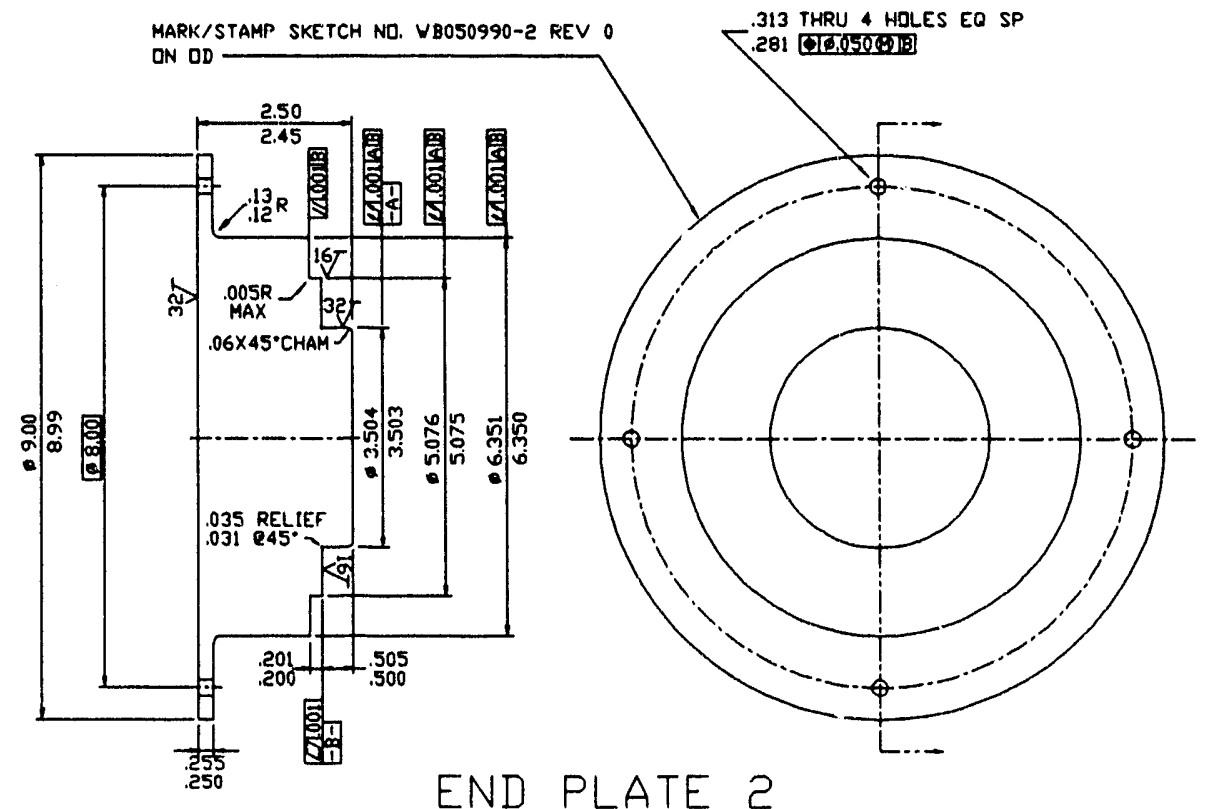

MAT'L AISI 4340 STL

HEAT TREAT RC 50-55

QUENCHED \& TEMPERED

H.W. BLAKE

$05 / 09 / 90$

SCALE $\mathrm{l}^{\prime}=\mathrm{l}^{\circ}$

ALL DIMENSIONS FINAL AFTER HEAT TREAT

WBO50990-2 REV 0

Fig. A-7. End plate No. 2. 


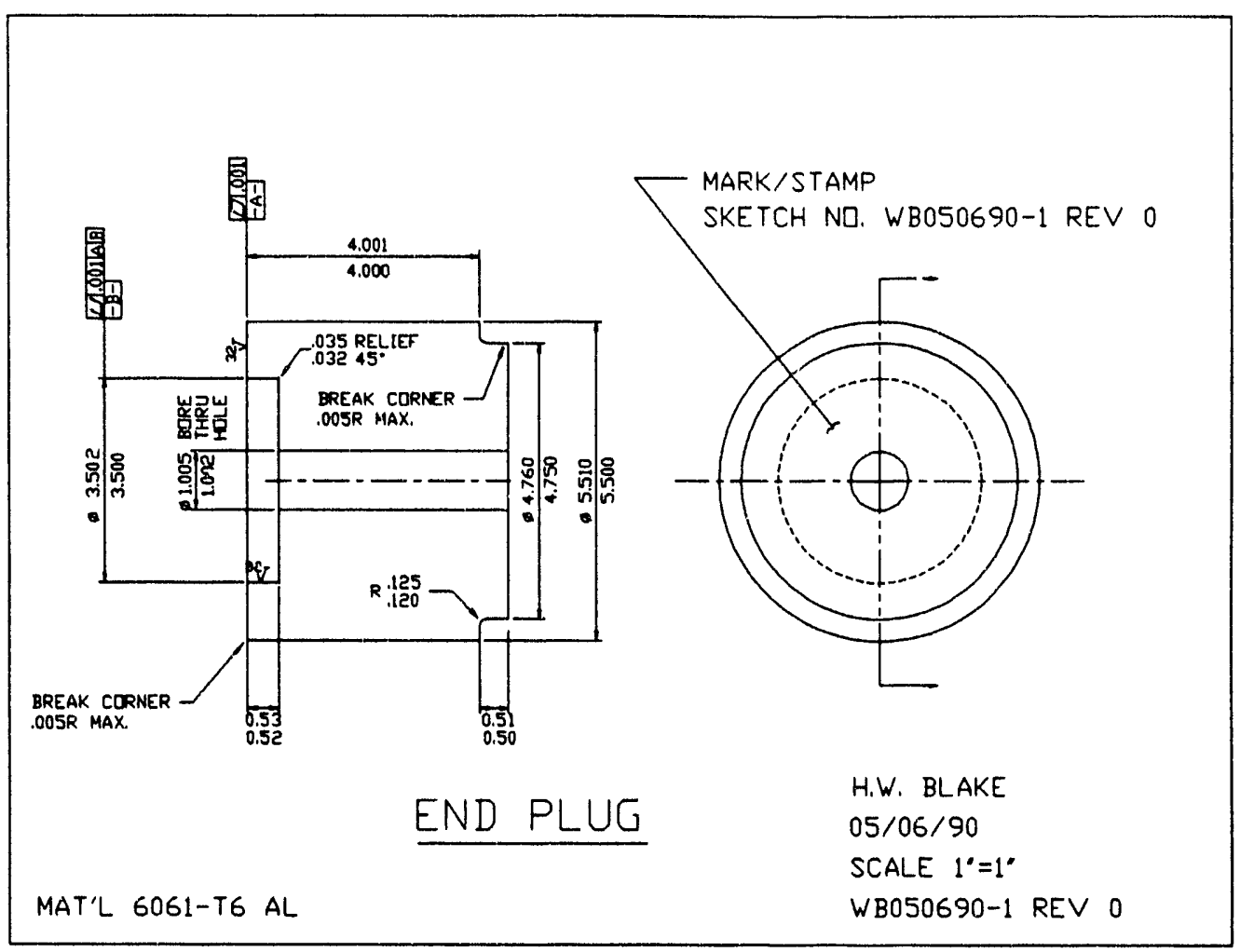

Fig. A-8. End plug.

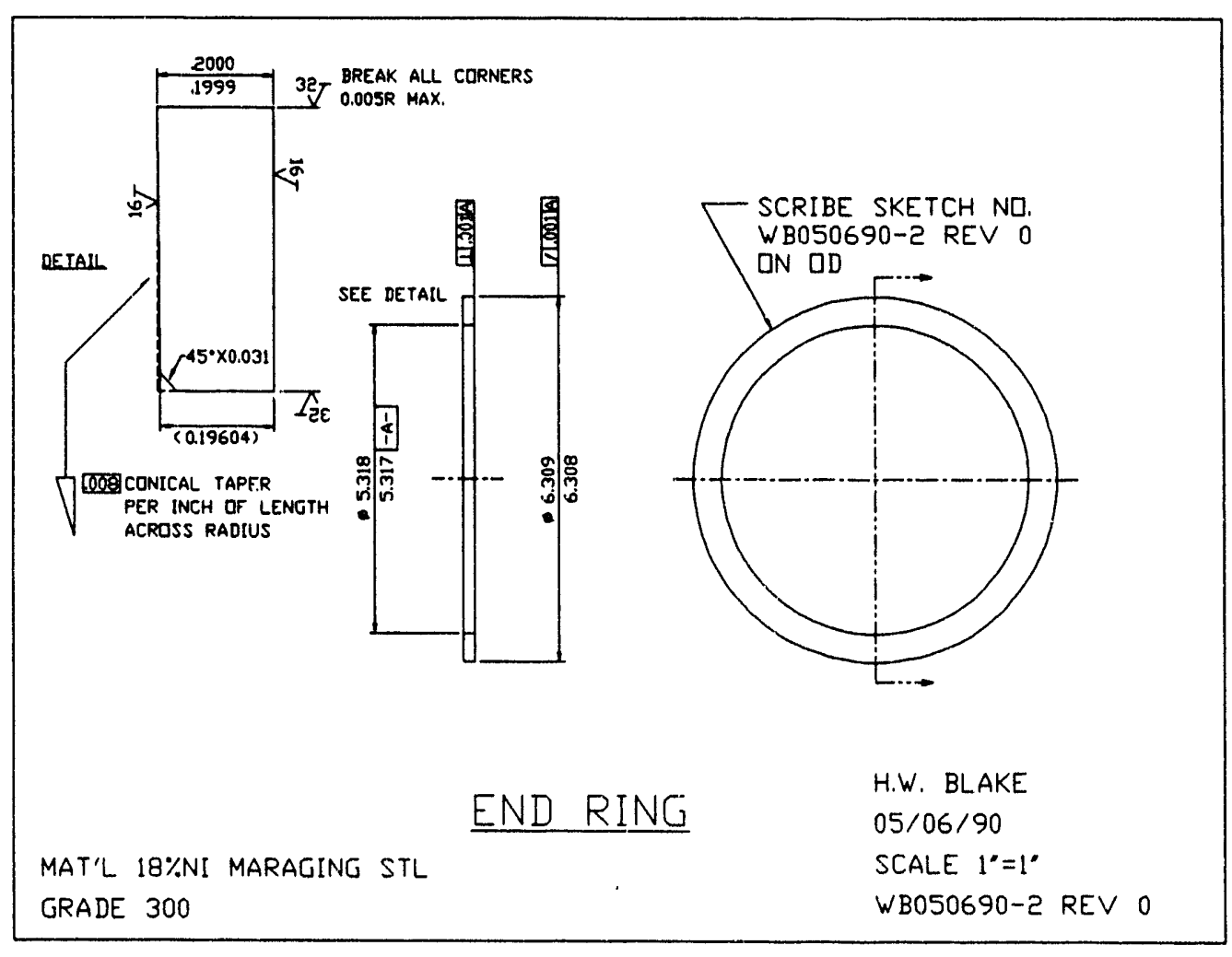

Fig. A-9. End ring. 
For the present cylinder test, the end plug design was based on the buckling results without shear correction and the suell solution. The critical pressure for the unsupported cylinder (i.e., infinite length cylinder) was 20,097 psi. The initial radial clearance was selected to achieve contact at 10,000 psi using the shell analysis. The design margin between the contact pressure and the critical pressure was approximately $10,000 \mathrm{psi}$. The actual margin was much less because of the higher contact pressure and the lower critical pressure for buckling resulting with shear correction. The critical pressure was reduced to $16,041 \mathrm{psi}$. The actual margin was thus 16,000 psi $-12,000$ psi $=4000$ psi rather than 10,000 psi.
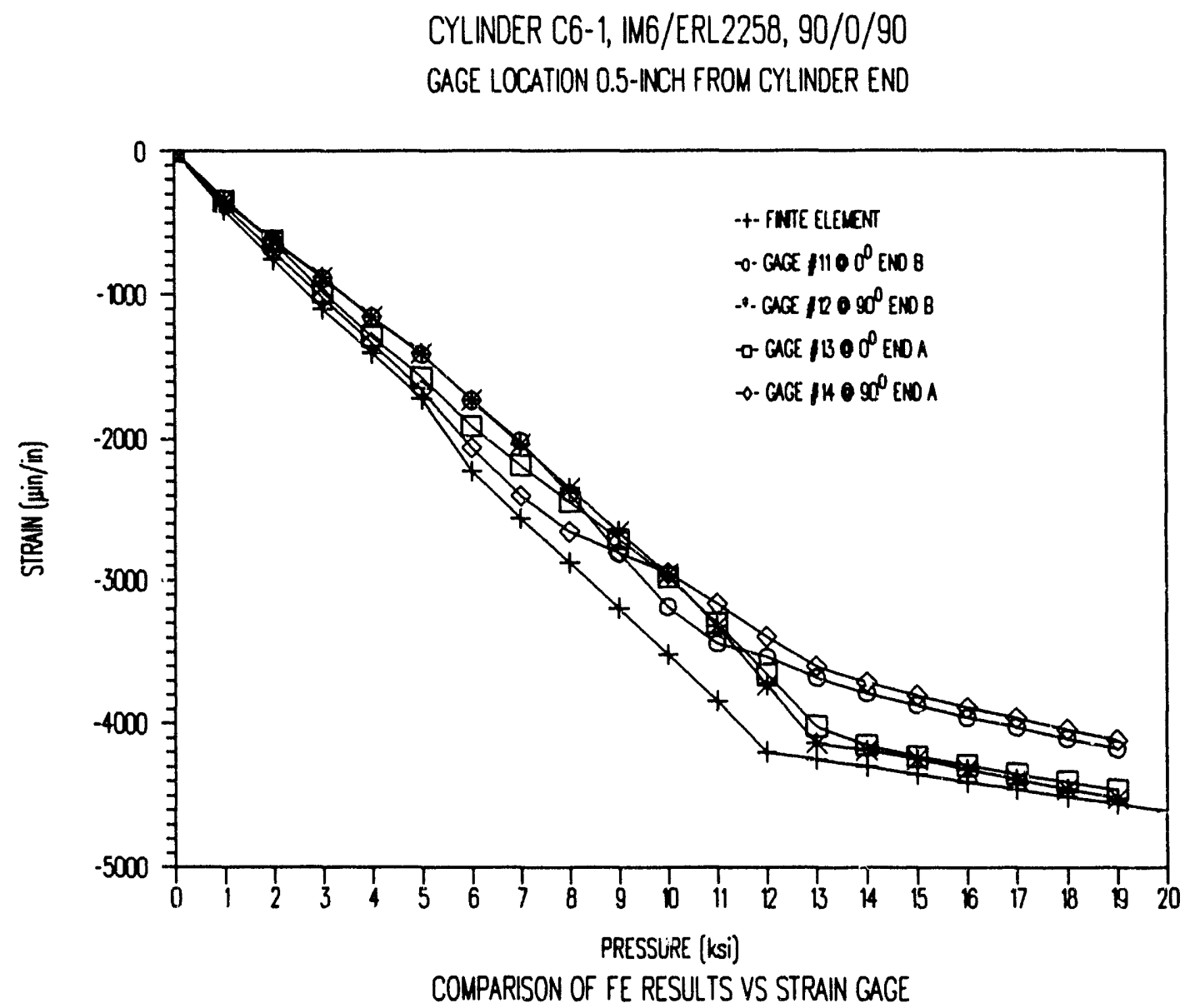

Fig. A-10. Comparison of finite element derived and experimental strains.

The pressure at which the point of departure reaches the end of the plug is also an important design parameter. The initial plug design was based on a maximum pressure of 20,000 psi and a 4-inch plug length. Based on the shell solution, the point of departure would reach the end of the plug at 20,000 psi. The finite element analysis indicated that the shell would reach the edge of the end plug at a pressure that is slightly below the maximum pressure. This was confirmed after the test by visual inspection of the cylinder. Slight scuff marks were observed on the cylinder ID surface at the axial locations corresponding to the end of the plugs. These marks were likely caused by the edge of the plug rubbing the cylinder surface. The shell prediction is nonconservative because it predicts a pressure which is too high. A comparison of the radial displacements from the shell and finite element 
solutions indicated that the displacement from the shell solution is significantly less than the finite element displacement for the cylinder inner radius. This would cause the shell solution to predict a higher pressure than the finite element analysis. To avoid this problem, Eqs. (A-19) and (A-21) should be used rather than Eqs. (A-18) and (A-20) for calculating the required plug length and taper.

The observations and experience gained from this initial effort provide a methodology for designing contoured end plugs having lower discontinuity stresses than achieved with previous designs. The end closures described in this appendix are based on one initial design, which is by no means optimized. The aim of this first design was to evaluate the linear taper end plug with initial radial clearance as an approach for reducing the discontinuity stresses. The results of this initial effort indicate that this type of end closure can achieve much lower peak stresses than is possible with close-fitting rigid end plugs. Also, the linear taper plug can achieve significantly lower stresses than a contoured plug having a constant radius. The linear taper contour also has the advantage that the peak stresses do not increase with pressure.

Other contours have been identified that should further reduce the peak stresses. The practicability and functionality of these concepts must be established through a coordinated design and testing effort. Some concepts may not be practical because of constraints on test assembly length or weight caused by test facility limitations. Complex contours may also be difficult to fabricate or have unacceptable cost. Various methods for machining of complex contours should be explored to establish the preferred method for achieving lowest cost and highest accuracy.

The optimum design will be application dependent. For example, the linear taper type of end closure may not be suitable for cyclic fatigue tests of cylinders because of the slight relative sliding between the cylinders ends and the end rings. The sliding might cause abrasion of the cylinder end surfaces with increasing number of cycles. This could lead to premature local failure at the ends in an axial splitting mode. Whether this is a real problem rather than merely a perceived one could only be established by a carefully designed and executed experiment. Other contours which do not require sliding have been identified that may be applicable to the fatigue situation.

End closures for use in creep or stress-life tests of cylinders loaded by sustained constant pressure should have the lowest achievable discontinuity stresses to avoid premature end failures. Contoured end plugs with compound-curve profiles are envisioned that potentially could entirely eliminate the discontinuity stresses at a particular value of pressure. However, these plug contours would not be suitable for tests spanning a range of pressure such as in the fatigue test. 
Appendix B

CYLINDER WEIGHT-TO-DISPLACEMENT RATIO 
The cylinder weight-to-displacement ratio calculations are summarized in this appendix. The metal end closures were not included in the ratio calculation. The end closures used in the cylinder test are not representative of end closures that would be used in a deep submergence application.

The cylinder was inadvertently not weighed before the application of the strain gages. After the test, the strain gage lead wires were removed and the cylinder was weighed. The weight, including strain gages and gage coating was $9.46 \mathrm{lb}_{\mathrm{m}}$. The cylinder weight was also derived from the measured density and cylinder dimensions. Average measured values were used. The values and calculations are as follows:

Inside radius: $\quad$ IR $=2.659$ in.

Outside radius: $\quad O R=3.154$ in.

Average density: $\quad \rho_{\mathrm{C}}=1.57533 \mathrm{~g} / \mathrm{cc}=0.0569125 \mathrm{lb} / \mathrm{min}^{3}$

The derived weight is then $\mathrm{W}_{\mathrm{C}}=$ density $\times$ volume $=\rho_{\mathrm{C}} \mathrm{L} \pi\left(\mathrm{OR} \mathrm{R}^{2}-\mathrm{IR}^{2}\right)=$

$$
0.0569125 \mathrm{lb}_{\mathrm{m}} / \mathrm{in}^{2} \times 18.0 \text { in. } \times \pi \times\left[(3.154 \mathrm{in} .)^{2}-(2.659 \text { in. })^{2}\right]=9.26 \mathrm{lb} \text {. }
$$

This value differs from the measured weight by only 2.1 percent. Most of this difference is likely due to the weight of the strain gages and gage coating.

The weight of seawater displaced is $\mathrm{W}_{\mathrm{D}}=\rho_{\mathrm{W}} \mathrm{L} \pi \mathrm{OR}^{2}=$

$3.726851 \mathrm{E}-02 \mathrm{lb}_{\mathrm{m}} /$ in. $^{2} \times 18.0$ in. $\times \pi \times 3.154^{2}=20.98 \mathrm{lb} \mathrm{m}$.

The weight-to-displacement ratio is then $\mathrm{W}_{\mathrm{C}} / \mathrm{W}_{\mathrm{D}}=9.26 \mathrm{lb}_{\mathrm{m}} / 20.98 \mathrm{lb} \mathrm{m}=0.44$

Thus, the cylinder weight is $44 \%$ of the weight of water displaced. 
Appendix C

CYLINDER C6-1 TEST REPORT 


\section{HYDROSPACE ENGINEERING SERVICES}

Specializing in research and development for industry

July 18, 1990

Mr. Don Welch

Oak Ridge National Laboratory

P.O. Box 2003

Oak Ridge, Tennessee 37831-7294

Dear Mr. Welch:

Enclosed are the original charts and graphs of the test data gathered during the hydrostatic testing of the cylinder marked ORNL 6-1. Also enclosed is a test report summarizing the results of the hydrostatic test. I have also included a copy of our bill to your purchasing department.

We enjoyed working with you on this project and hope that we will be given the opportunity to assist your group again in the near future. We are looking forward to meeting you during your visit to pleasanton. Once your schedule is set, please let me know when you will have a free evening so that we may host you to dinner.

Sincerely,

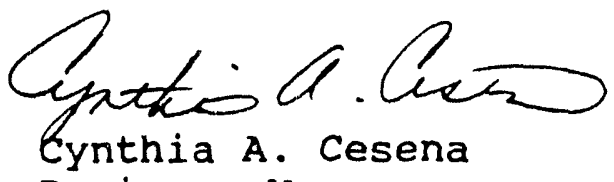

Business Manager

$\mathrm{CAC} / \mathrm{pbC}$

Enclosures: $\mathrm{a} / \mathrm{s}$

SENT VIA OVERNIGHT COURIER

CC: Stachiw Associates

El Cajon, California 
July 18,1990

TEST REPORT

\section{Instrumentation}

The cylinder was instrumented with a combination of 0.250 and 0.125 inch electric resistance straingage rosettes. The acoustic emission detector was bonded to the outside of the pressure vessel. The ORNL 6-1 cylinder was instrumented with a total of 14 strain gage rosettes. The rosettes were affixed to the cylinder as shown on the attached diagram supplied by the Mr. Don Welch of the Oak Ridge National Laboratory.

\section{Test Procedure}

The cylinder was tested in a 10 inch ID pressure vessel with 20,000 psi pressure capability. The pressurizing medium was Tellus 30 oil. Pressurization was accomplished with an air operated pump raising the pressure inside the vessel at 2,000 psi/minute rate. Pressurization was interrupted at 1,000 psi intervals and strains recorded at 2 seconds per channel rate. Acoustic emission was recorded continuously.

\section{Test Results}

The pressure test on SN\# 6-1 cylinder was terminated at 20,000 Psi without failure to the cylinder. 


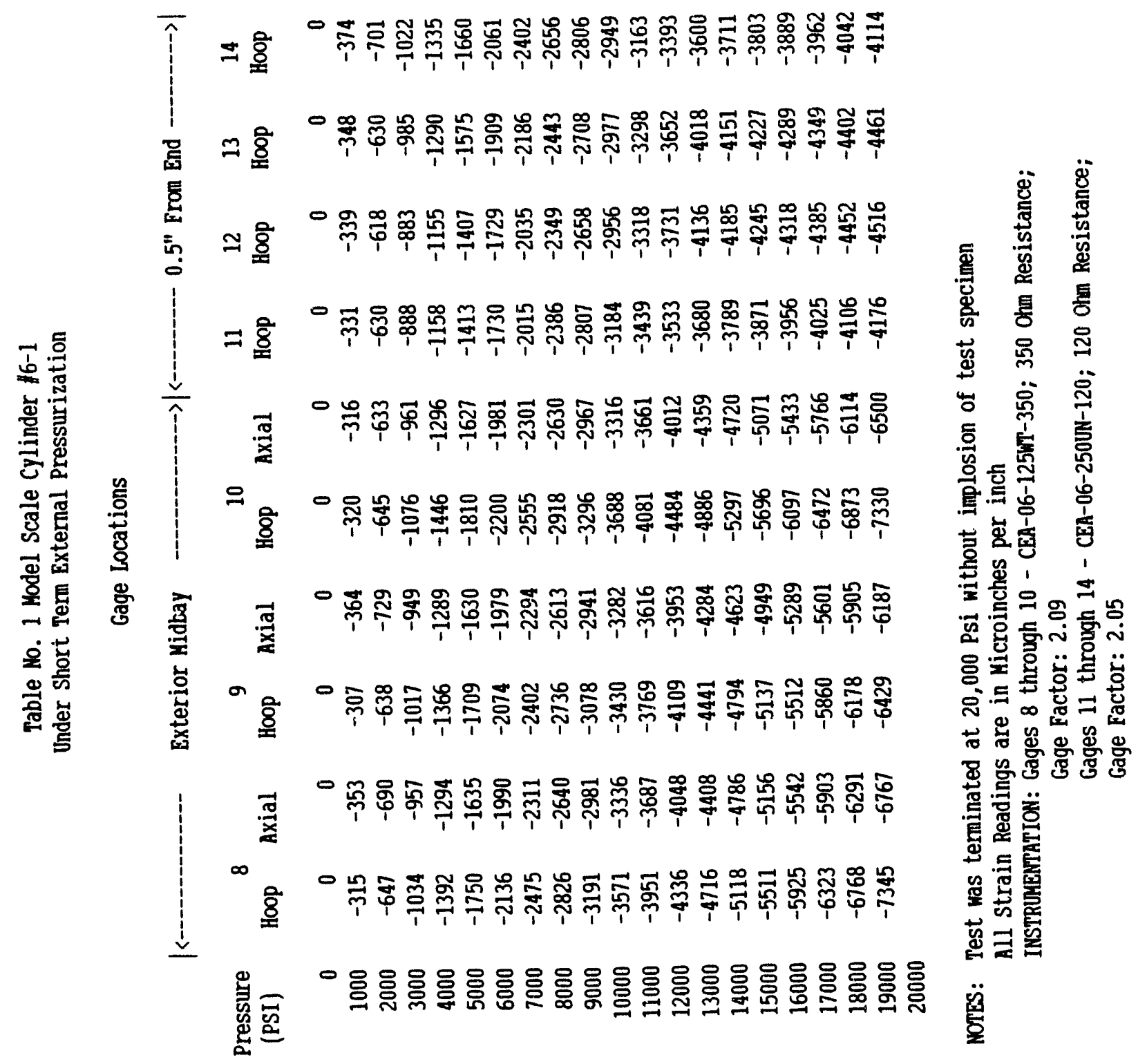




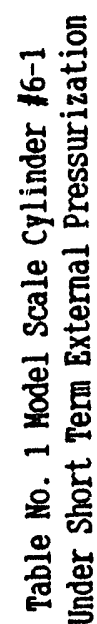

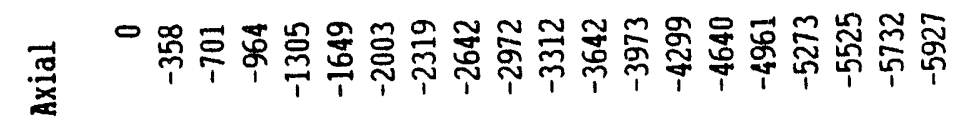

-

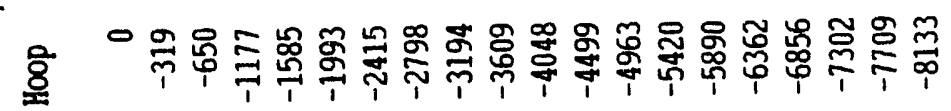

。

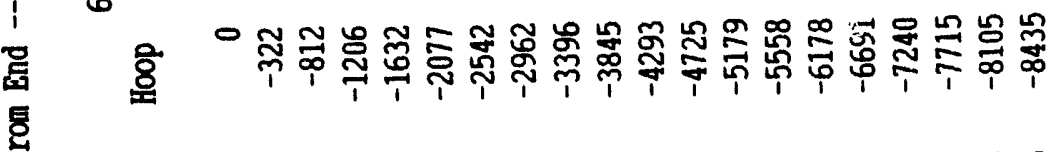

8

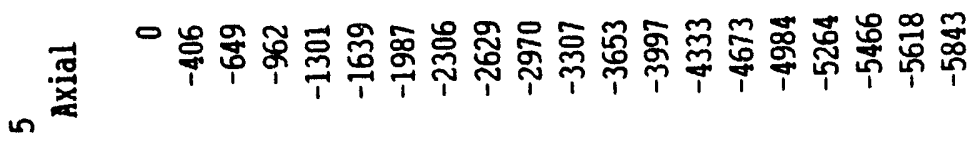

0 策

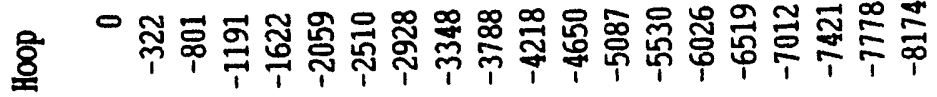

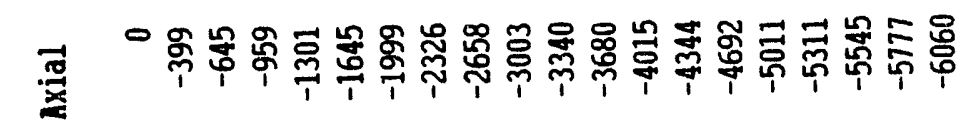

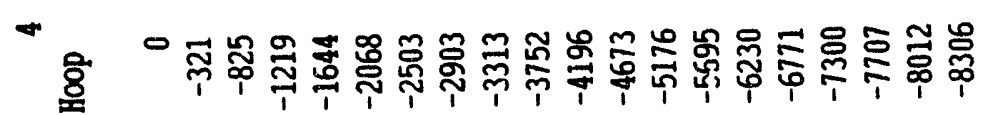

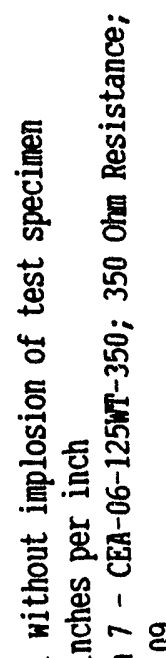

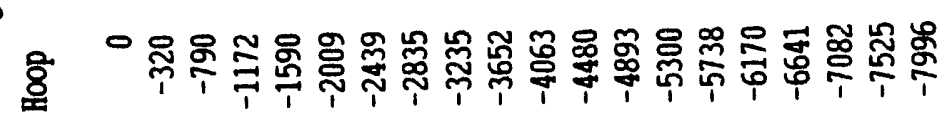

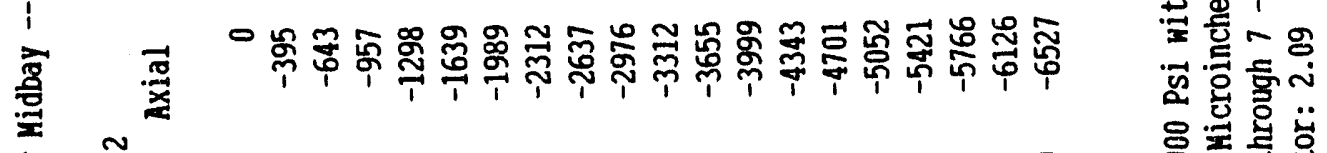

녕

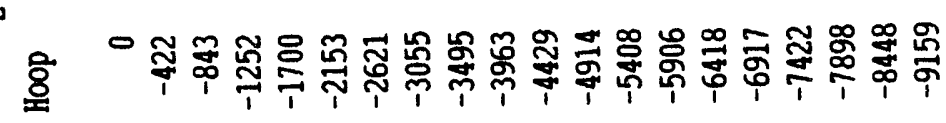

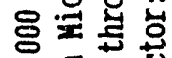

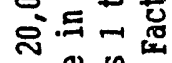

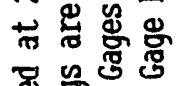

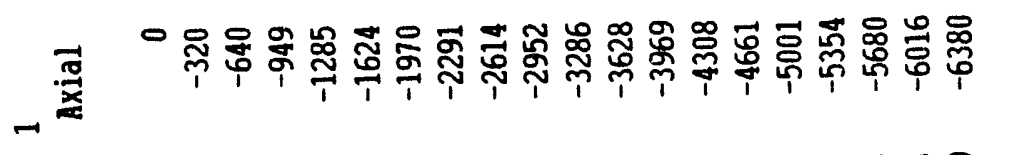

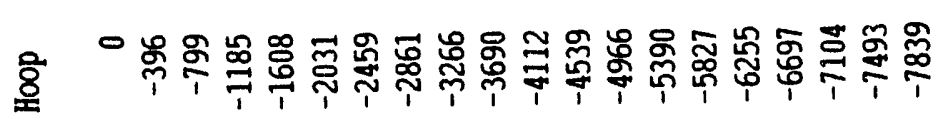

兽

总

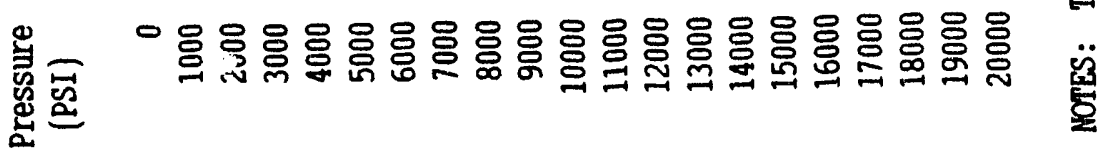




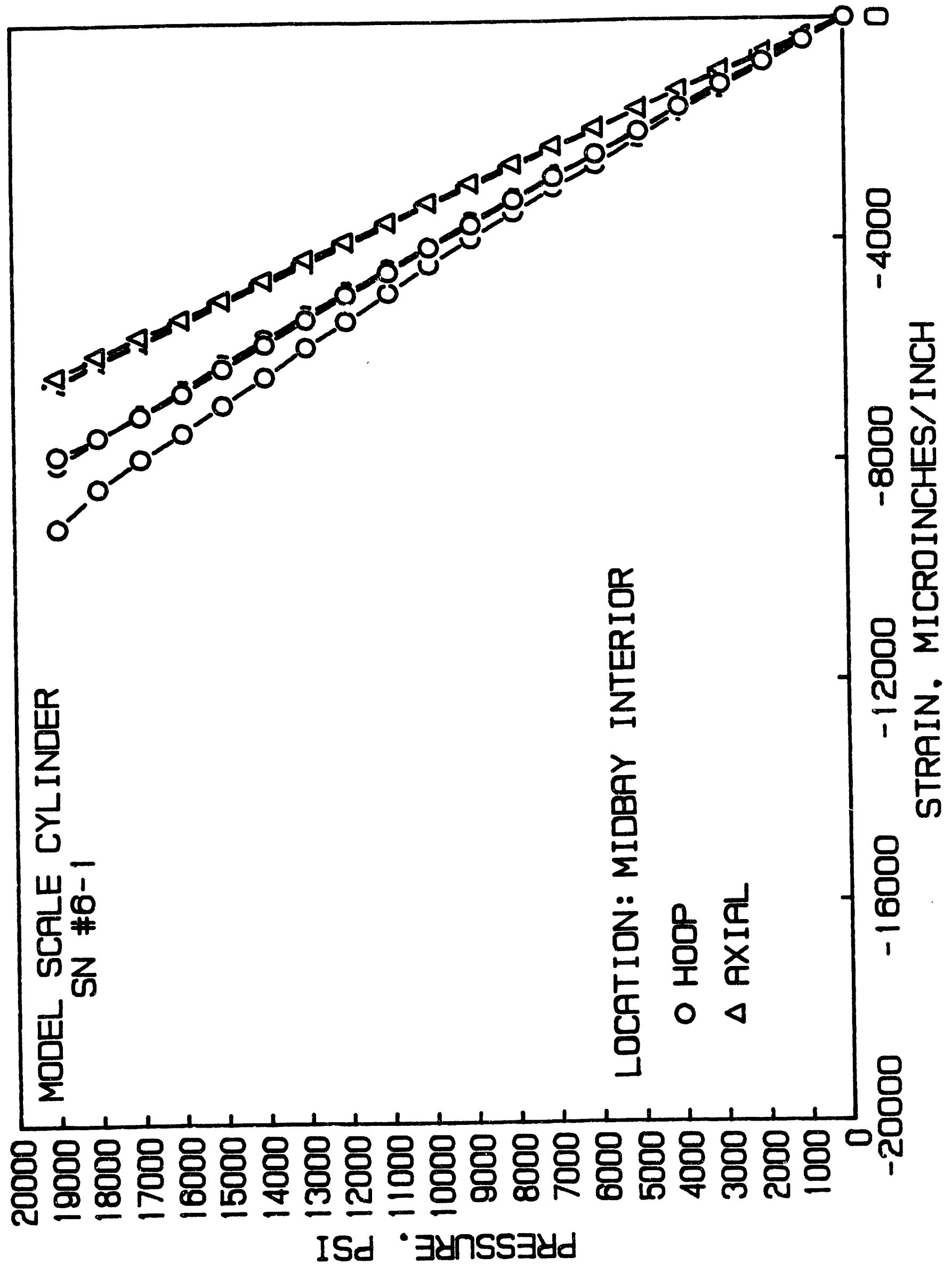




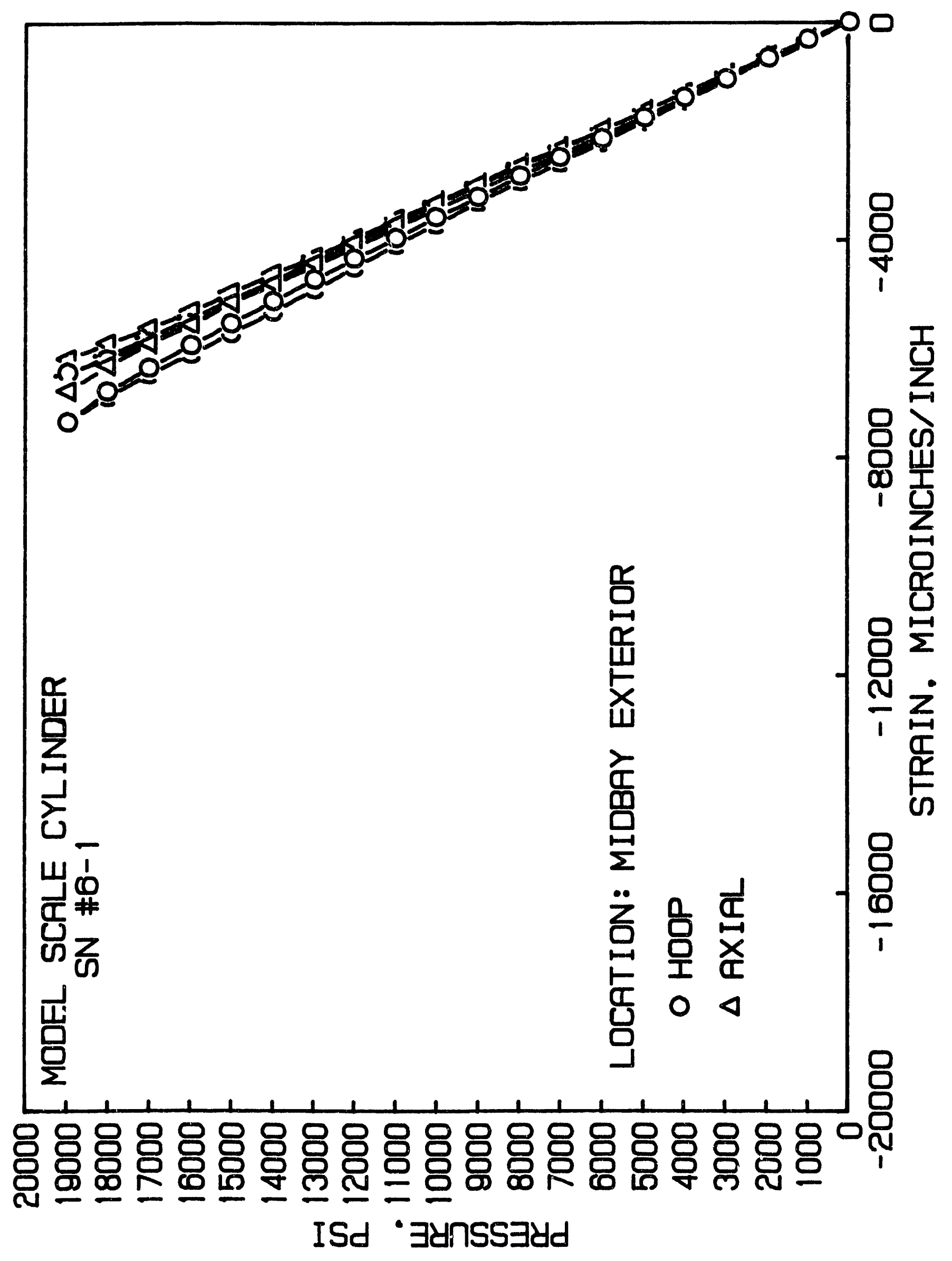




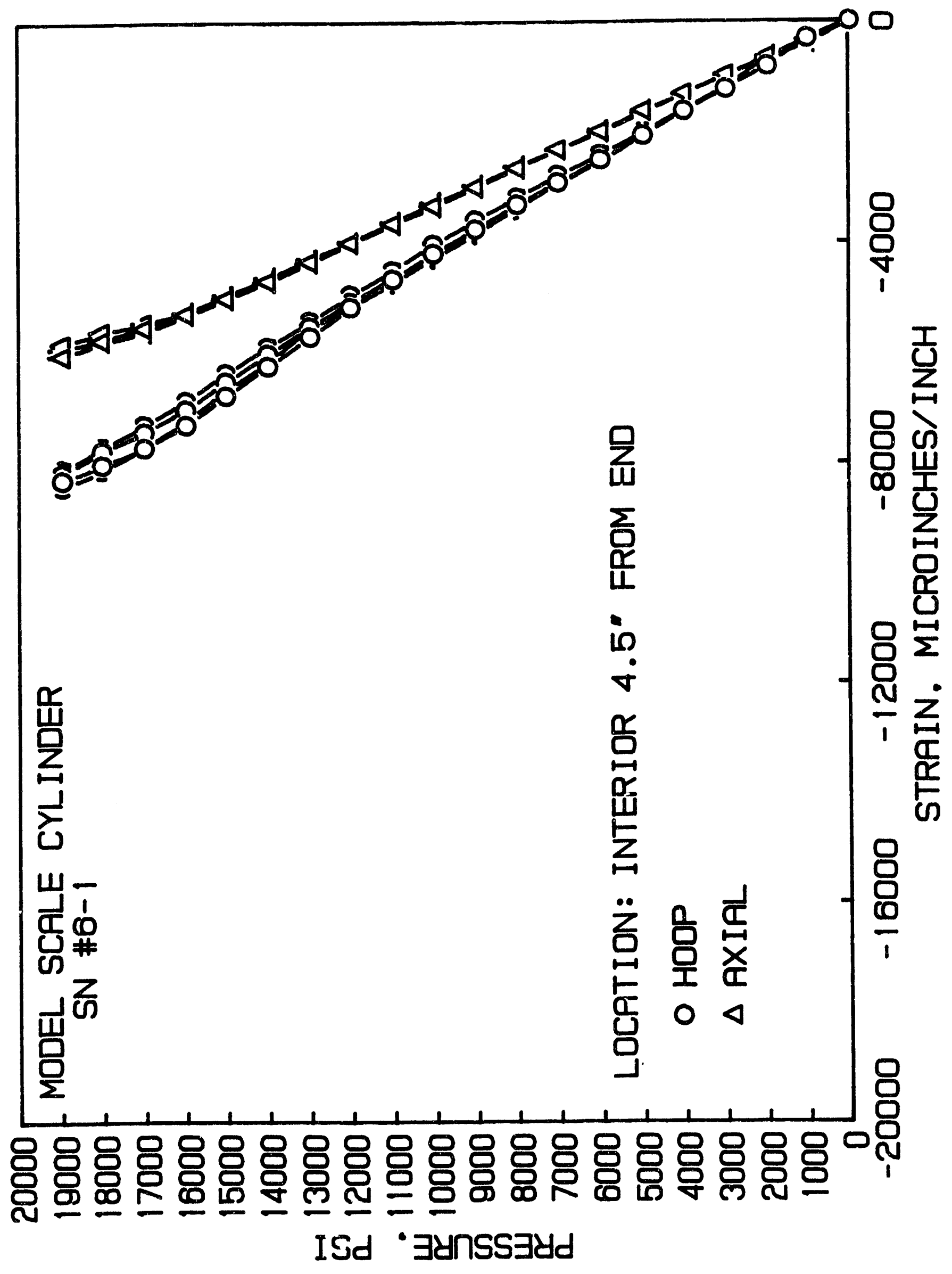




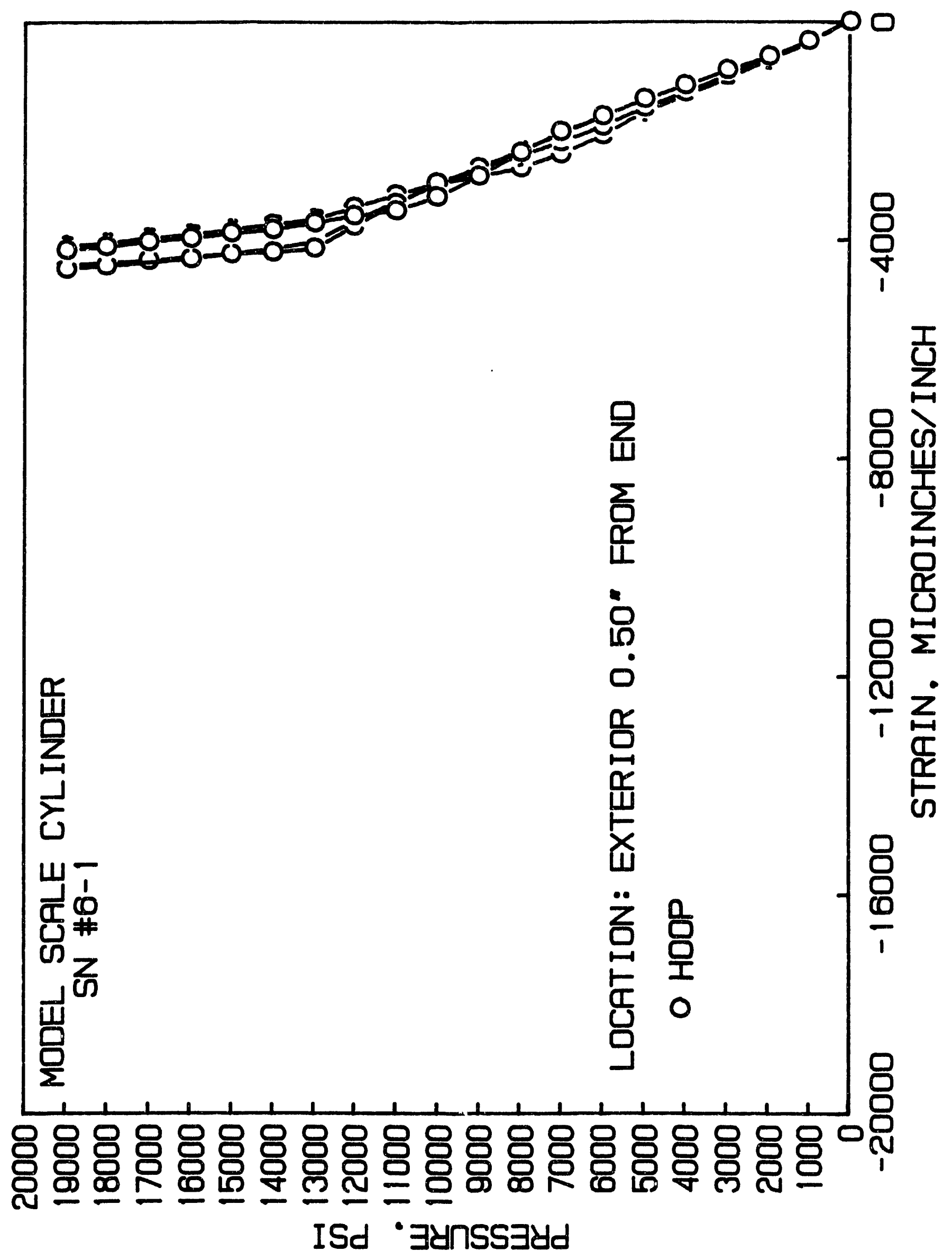




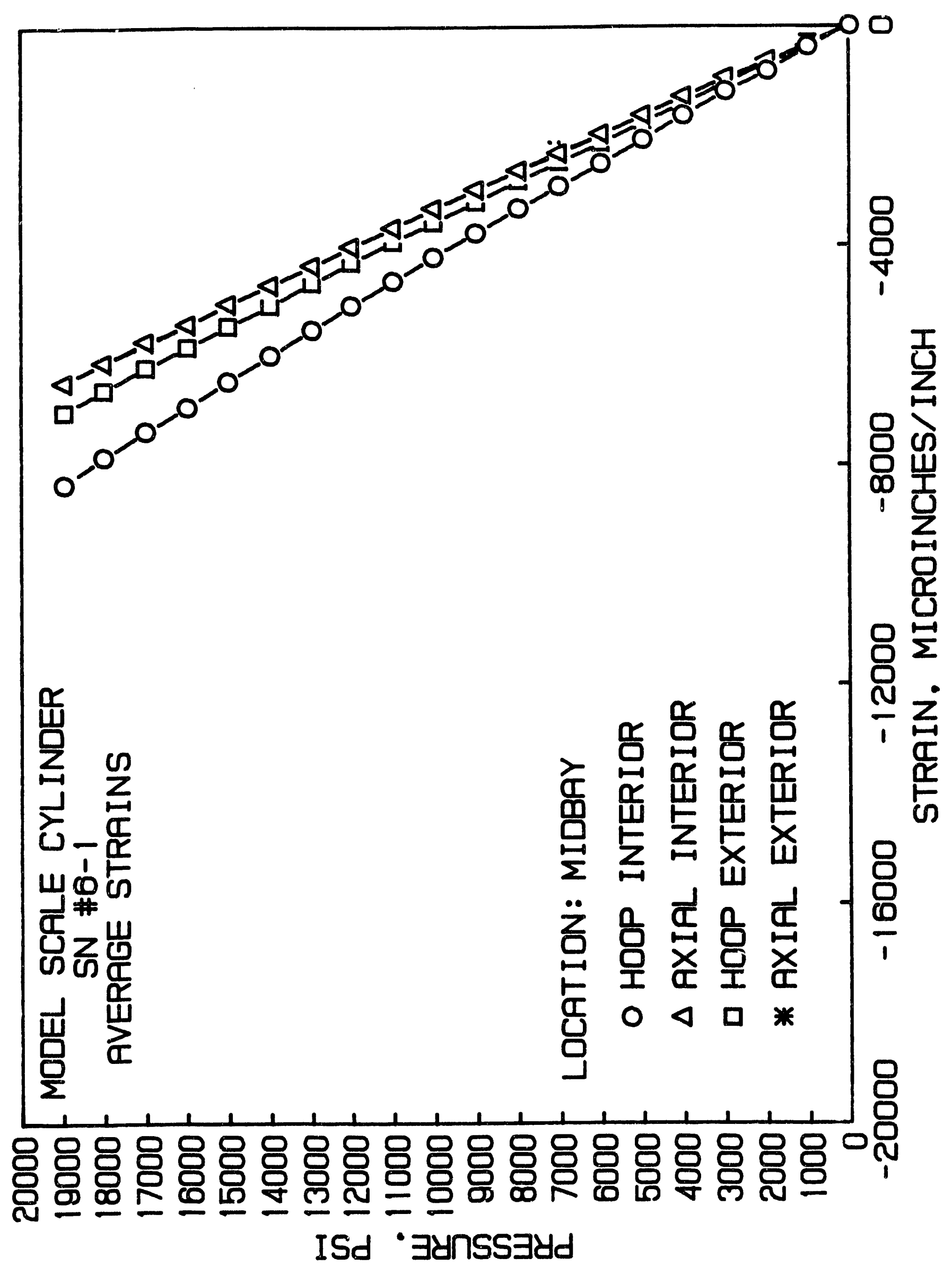




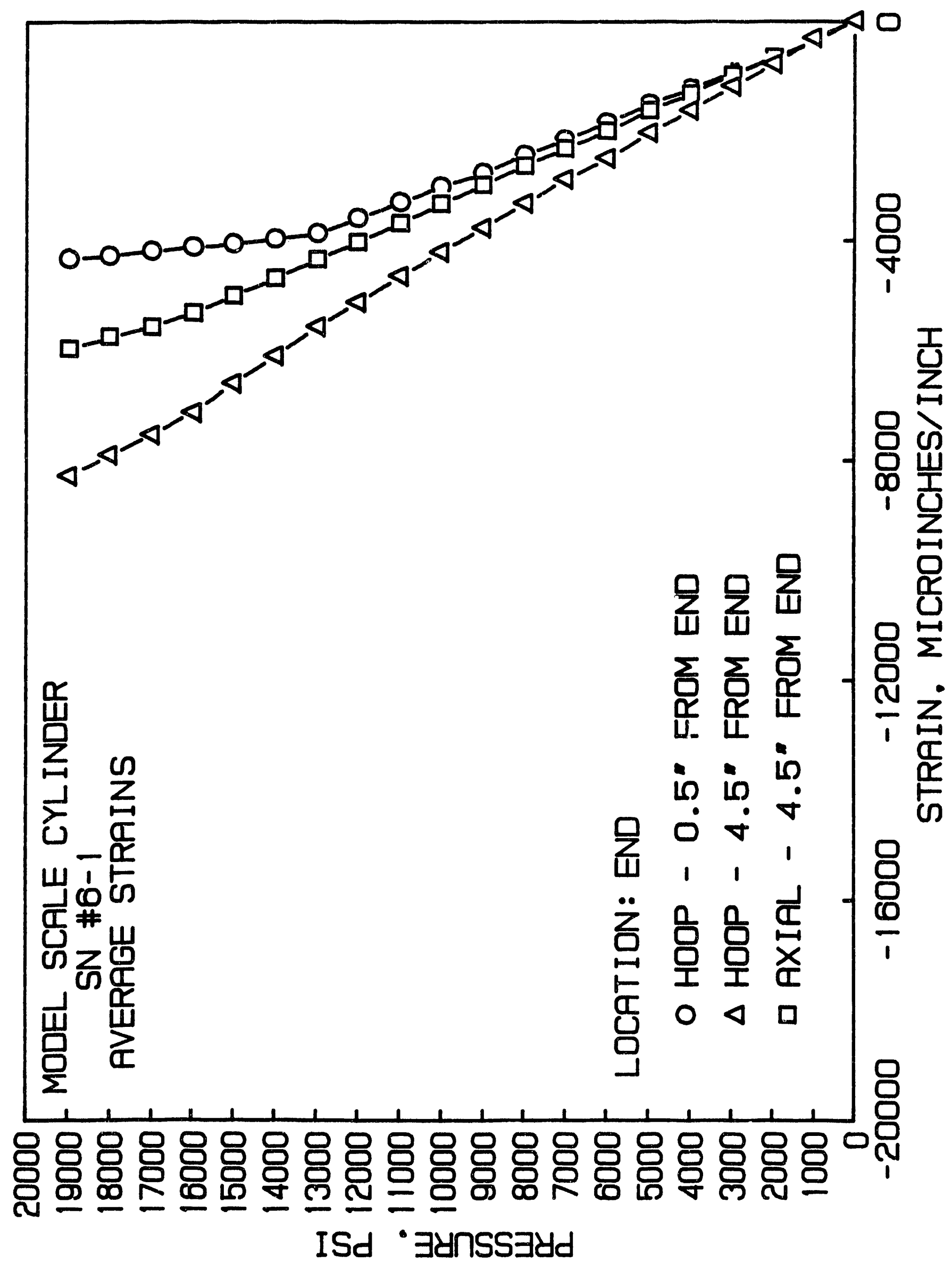




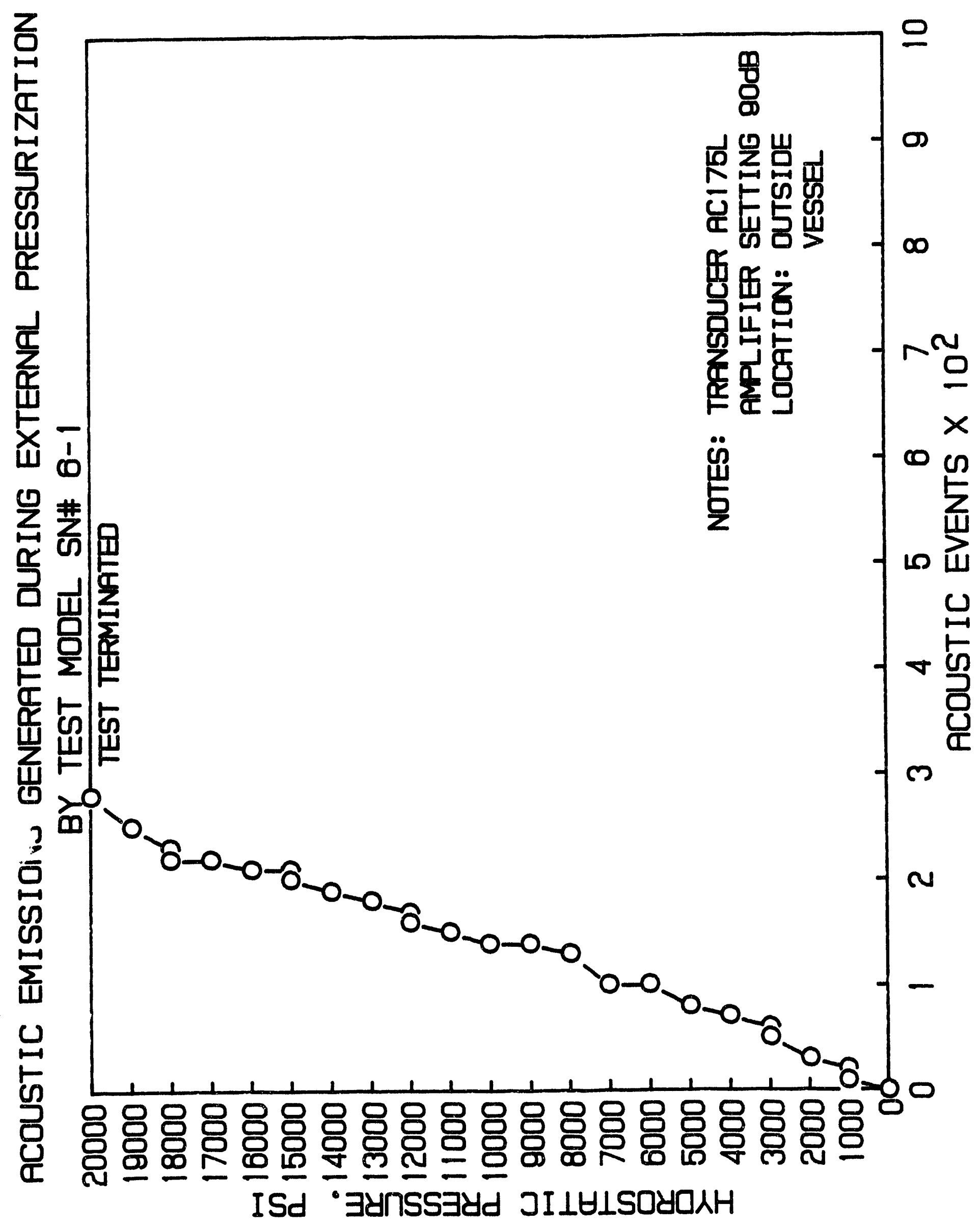



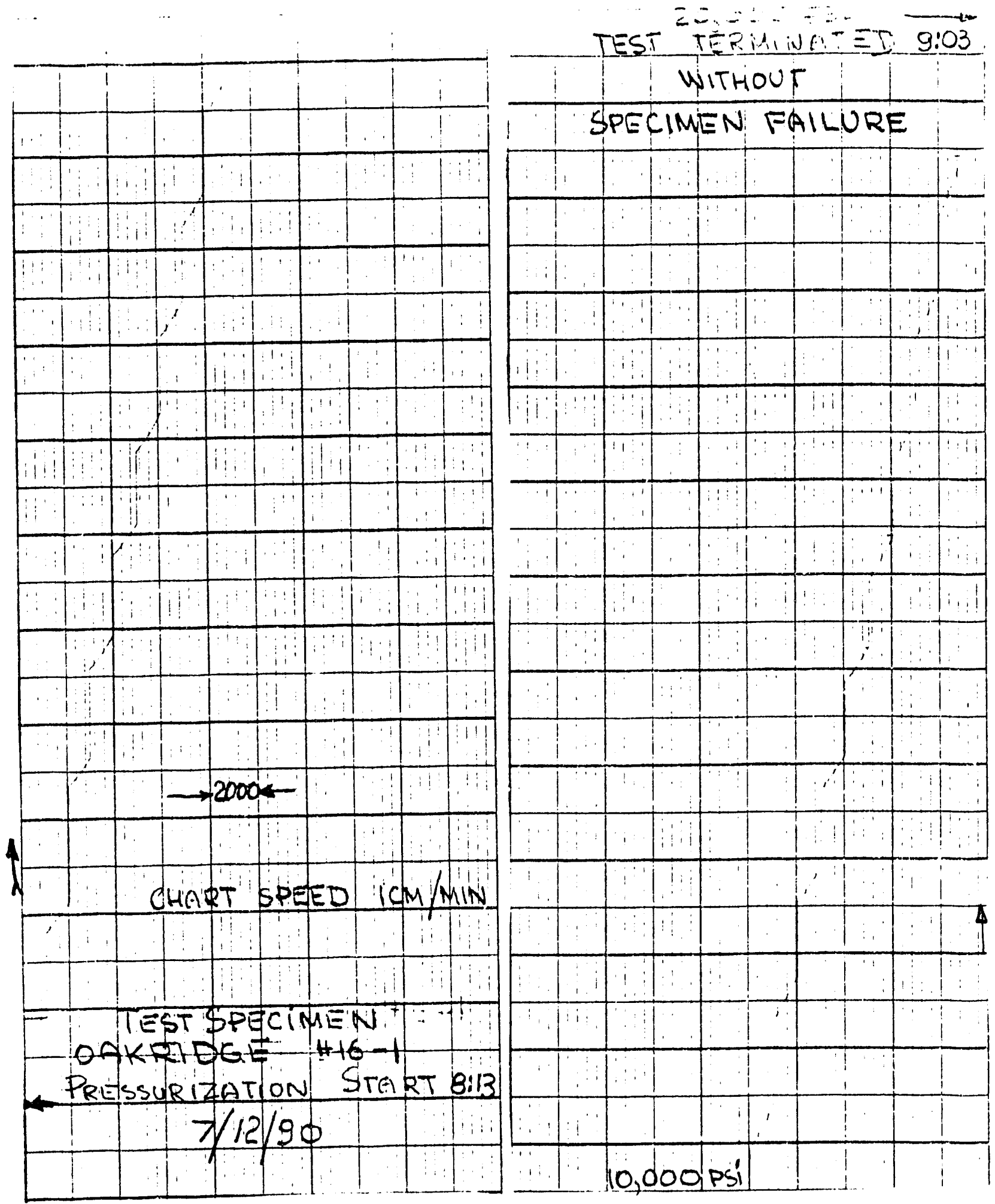
111

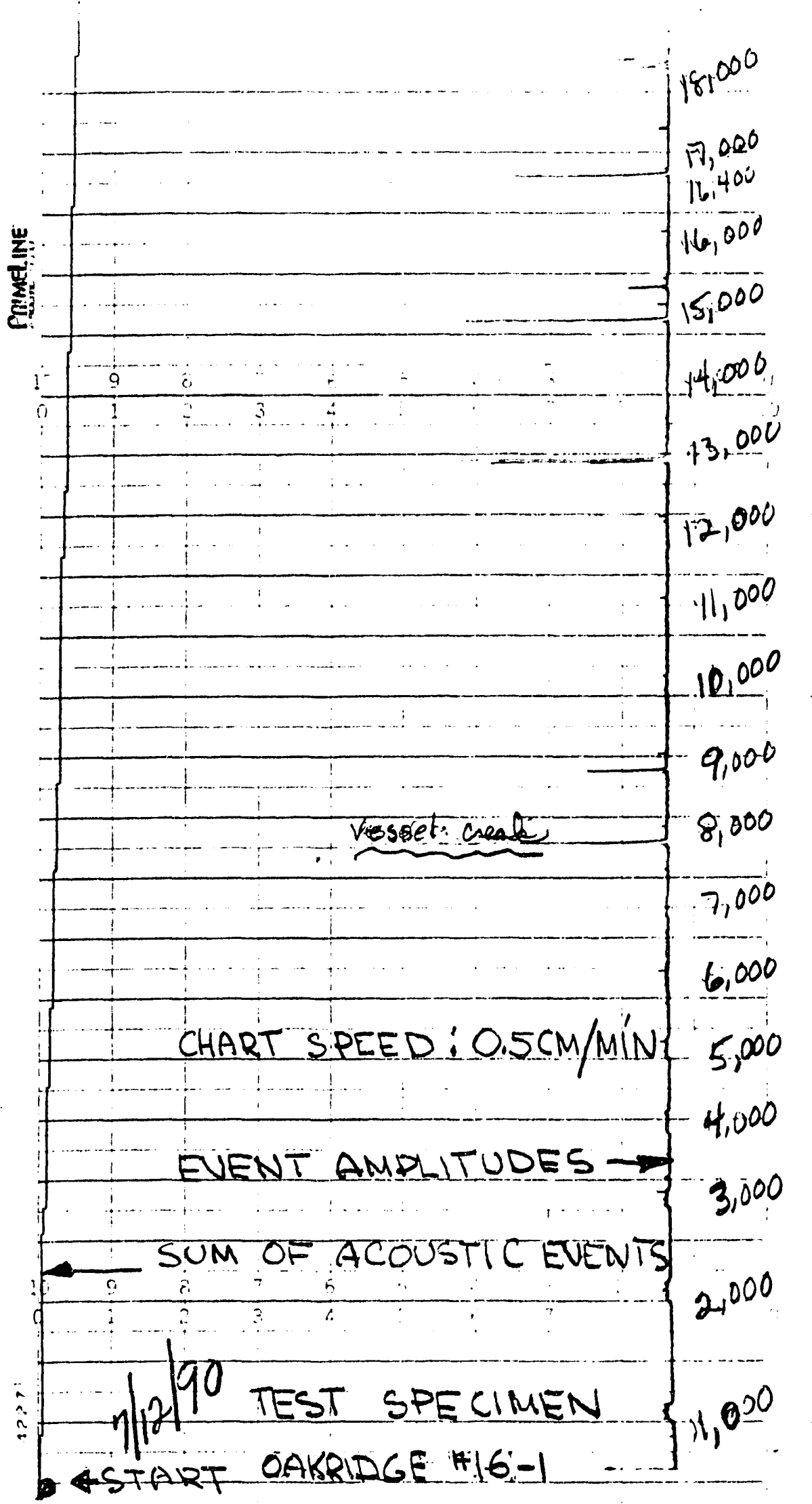




\section{REFERENCES}

1. H. J. Garala, Structural Evaluation of Externally-Pressurized, 4-Inch Diameter, Graphite Composite Cylinders, NDW-DTNSRDC 4610/3 (Rev. 3-80), David Taylor Naval Ship Research and Development Center, Bethesda, MD 20094-5000, Aug. 1984.

2. H. J. Garala, Experimental Evaluation of Graphite-Epoxy Composite Cylinders Subjected to Hydrostatic Compression Loading, Society of Experimental Mechanics.

3. H. J. Garala, Structural Evaluation of 8-Inch Diameter Graphite-Epoxy Composite Cylinders Subjected to External Hydrostatic Compressive Loading, DTRC-89/016, Ship Structures and Protection Department, David Taylor Research Center, Bethesda, MD 20084-5000, Sep. 1989.

4. J. S. Mayes, Prelimi iary Consideration for Developing Designs of Composite, Ring-Stiffened Cylinders Under Hydro-Static Loading, DTRC-SSPD-91-172-41, Ship Structures and Protection Department, David Taylor Research Center, Bethesda, MD 20084-5000, Apr. 1991.

5. J. D. Stachiw and B. Frame, Graphite-Fiber-Reinforced Plastic Pressure Hull Mod 2 for the Advanced Unmanned Search System Vehicle, Technical Report 1245, Naval Ocean Systems Center, San Diego, Ca. 92152-5000, Aug. 1988.

6. J. J. Kibler, CLASS - Composite Laminate Analysis Systems, MSC TIR 1801, Material Sciences Corporation, Blue Bell, PA 19422, 1986.

7. J. Goering, NDPROP - N Direction Composite Effective Property Program, MSC TIR 1506, Material Sciences Corporation, Blue Bell, PA 19422, Jul. 1984.

8. University of Delaware Engineering Research Center for Composites Manufacturing Science and Engineering, Users Manual for CYLAN - Cylinder Analysis, Technomic Publishing Co., Inc., Lancaster, PA 17604, Aug. 1987.

9. J. O. Hallquist, NIKE2D - A Vectorized, Implicit, Finite Deformation, Finite Element Code for Analyzing the Static and Dynamic Response of 2-D Solids, UCID-19677, Lawrence Livermore National Laboratory, Feb. 1983.

10. M. W. Hyer, "Hydrostatic Response of Thick Laminated Composite Cylinders", Jrl. Reinforced Plastics \& Composites, Vol. 7, pp. 255-262, Aug. 1988.

11. H. W. Blake, H. J. Grimsby, J. M. Starbuck, and D. E. Welch, Development of Performance Models for Thick Composites in Compression, ORNL/ATD-62, Oak Ridge National Laboratory, Martin Marietta Energy Systems, Inc., Nov. 1991.

12. V. Z. Vlasov, General Theory of Shells and its Applications in Engineering, NASA Technical Translation, NASA TTF-99, 1964.

13. S. A. Ambartsumyan, Theory of Anisotropic Shells, NASA Technical Translation, NASA TTF118, 1964. 
14. J. M. Whitney, "On the Use of Shell Theory for Determining Stresses in Composite Cylinders", J. Comp. Matl., Vol. 5, pp. 340-353, Jul. 1971.

15. C. A. Cesena, Hydrospace Engineering Services, private communication - Test Report, to D. E. Welch, Oak Ridge National Laboratory, Jul. 1990.

16. J. O. Hallquist, MAZE - An Input Generator for DYNA2D and NIKE2D, UCID-19029, Rev 2, Lawrence Livermore National Laboratory, Jun. 1983.

17. J. O. Hallquist, ORION - An Interactive Post-Processor for the Analysis Codes NIKE2D, $D Y N A 2 D$, and TACO2D, UCID-19310, Rev. 1, Lawerence Livermore Laboratory, Ju!. 1983.

18. Engineering Mechanics Research Corporation, Users Manual for NISA II, Numerically Integrated Elements for System Analysis, Version 90.0, Apr. 1990, 1607 East Big Beaver Road, Troy, MI 48083.

19. Hibbit, Karlsson, and Sorensen, Inc., ABAQUS Users Manual Ver. 4.7, 100 Medway Street, Providence, RI 02906.

20. ADINA R \& D, INC., ADINA 5.0, A Finite Element Program for Automatic Dynamic Incremental Nonlinear Analysis, 71 Elton Avenue Watertown, MA 02172, Jun. 1987.

21. S. B. Dong, K. S. Pister, and R. L. Taylor, "On the Theory of Laminated Anisotropic Shells and Plates," Jrl. Aero. Sci., pp. 969-975, Aug. 1962.

22. H. R. Jacobsen, Optimum Construction of Reinforced Plastic Cylinders Subjected to High External Pressure, Final Report, Douglas Report SM-45871, Mar. 1964.

23. E. H. Baker, L. Kovalevsky, and F. L. Rish, Structural Analysis of Shells, Krieger Publishing Co., Inc., Malabar, Fla., 1972.

24. R. M. Jones, "Buckling of Circular Cylindrical Shells With Multiple Orthotropic Layers and Eccentric Stiffeners," ALAA Jrl., Vol. 6, No. 12, pp. 2301-2305, Dec. 1968.

25. R. M. Jones and H. S. Morgan, "Buckling and Vibration of Cross-Ply Laminated Circular Cylindrical Shells," ALAA Jrl., Vol. 13, No. 5, pp. 664-671, May 1975.

26. W. Flügge, Stresses In Shells, Springer-Verlag, New York, 1967.

27. S. P. Timoshenko and J. M. Gere, Theory of Elastic Stability, Eng. Soc. Monographs, 2nd. ed., McGraw-Hill, New York, 1961.

28. A. E. H. Love, $A$ Treatise on the Mathematical Theory of Elasticity, 4th. ed., Dover Publications, New York, 1944.

29. A. P. Christoforou and S. R. Swanson, "Analysis of Simply-Supported Orthotropic Cylindrical Shells Subject of Lateral Impact Loads," Jrl. Appl Mech.,Trans. of ASME, Vol. 57, pp. 376-382, June 1990. 
30. Z. Hashin, "Failure Criteria for Unidirectional Fiber Composites," J. Appl. Mech., Vol. 47, pp. 329-334, Jun. 1980.

31. S. W. Tsai and E. M. Wu, "A General Theory of Strength for Anisotropic Materials," J. Comp. Matl., Vol. 5, p. 58, 1971.

32. A. K. Roy and S. W. Tsai, "Design of Thick Composite Cylinders," Jrl. of Pressure Vessel Tech., Trans. of ASME, Vol. 110, pp. 255-262, Aug. 1988.

33. R. J. Miller, End Plugs for External Pressure Tests of Composite Cylinders, ASTM STP 460, American Society for Testing and Materials, 1969.

34. H. W. Blake, Compression Failure Modes of Six-Inch-Diameter Composite Rings, ORNL!ATD37, Oak Ridge National Laboratory, Martin Marietta Energy Systems, Inc., May 1990.

35. R. J. Miller, Principal Elastic Moduli for Filament Reinforced Plastic, Douglas Report No. SM47748 , Oct. 1964.

36. L. B. Greszczuk, Membrane Analysis Methods for Composite Structures, Douglas Report No. SM-41543, Mar. 1962.

37. J. E. Ashton, J. C. Halpin, and P. H. Petit, Primer on Composite Materials Analysis, Progress in Materials Science Series, Vol. III, Technomic, Westport, Conn., 1969. 


\section{DISTRIBUTION}

\section{Martin Marietta Energy Systems, Inc.}

B. R. Appleton

H. W. Blake (10)

R. G. Boeman

R. S. Carlsmith

J. L. Cook

B. J. Frame

W. Fulkerson

D. R. Johnson

J. E. Jones Jr.

W. S. Key

W. R. Martin

W. C. McWhorter

R. O. Meyers

R. E. Norris

D. U. O'Kain

J. T. Shaffer

B. B. Smith

J. M. Starbuck

J. O. Stiegler

A. J. Szady

R. C. Ward

D. A. Waters

D. E. Welch

G. E. Wrenn

R. E. Ziegler

A. Zucker

Manager, Laboratory Directed Research and Development

Laboratory Records - RC

Laboratory Records Department (2)

Central Research Library

Applied Technology Library

\section{Department of Energy Field Office, Oak Ridge}

Assistant Manager, Energy Research and Development

\section{External Distribution}

M.G. Abdallah, Hercules Advanced Materials and Systems Company, Mail Stop 2343L,

P. O. Box 98, Magna, Utah 84044-0098

D. F. Adams, Mechanical Engineering Department, Composite Materials Research Group, University of Wyoming, P. O. Box 3295, Laramie, Wyoming 82071 
A. Alexander, Custom Analytical Engineering Systems, Inc., Star Route Box 4A, Flintstone, Maryland 21530

J. M. Augl, Code R-31, Naval Surface Warfare Center, White Oak Laboratory, 10901 New Hampshire Avenue, Silver Spring, Maryland 20903-5000

R. Badaliance, Code 6380, Michanics of Materials Branch, Naval Research Laboratory, 4555 Overlook Avenue, Southwest, Washington, D.C. 20375-5000

D. L. Bonanni, Ship and Structures and Protection Department, Naval Surface Warfare Center, Carderock Division, Bethesda, Maryland 20084-5000

C. E. Browning, Structural Materials, WRDC/MLB, Wright Research Development Center, Wright-Patterson Air Force Base, Ohio 45433-6523

B. P. Burns, Mechanics and structures Branch, SLCBR-1B-M, U. S. Army Ballistic Research Laboratory, Aberdeen Proving Ground, Maryland 21005-5066

A. A. Caiazzo, Materials Sciences Corporation, Union Meeting Corporate Center, 930 Harvest Drive, Blue Bell, Pennsylvania 19422

E. T. Camponeschi, Code 2802, Composites Program Office, Naval Surface Warfare Center, Annapolis Facility, Annapolis, Maryland 21042-5067

J. R. Carlberg, Ship and Structures and Protection Department, Naval Surface Warfare Center, Carderock Division, Bethesda, Maryland 20084-5000

R. F. Charette, Ship and Structures and Protection Department, Naval Surface Warfare Center, Carderock Division, Bethesda, Maryland 20084-5000

R. O. Claus, Electrical Engineering Department, Fiber and Electro-Optics Research Center, Virginia Polytechnic Institute and State University, 648 Whittemore Hall, Blacksburg, Virginia 24061

S. J. DeTeresa, Lawrence Livermore National Laboratory, Mail Stop L-338, P.O. Box 808, 7000 East Avenue, Livermore, California 94550

D. J. Dorr, Advanced Structures and Materials, McDonnell Douglas Aircraft Company, D.390, Mail Code 1021310, P. O. Box 516, St. Louis, Missouri 63166-0516

S. Earle, 5128 Department of Commerce, National Oceanic and Atmospheric Administration, 14th \& Constitution Ave, NW, Washington, DC 20230

D. Flaggs, Lockheed Missiles \& Space Company O/93-30 B/251, 3251 Hanover Street Palo Alto, California 94304

G. S. Friar, Advanced Technology Section, Research Branch, Benet Weapons Laboratory, Armament Research and Development Center, SMCAR-CCB - Watervliet Arsenal, Watervliet, New York 12189-4050 


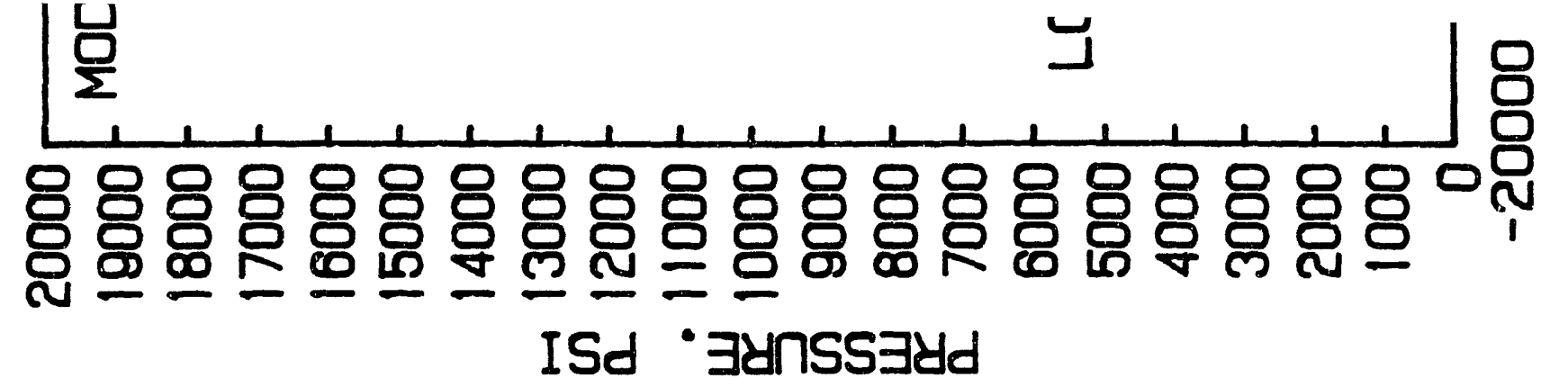

119

H. J. Garala, Code 1720.2, Naval Surface Warfare Center, Carderock Division, Bethesda, Maryland 20084-5000

J. W. Gillespie, Jr., Center for Composite Materials, University of Delaware, $201 \mathrm{CMSL}$, Newark, Delaware 19716

R. G. Gilliland, Engineering Materials and Processes, Aluminum Company of America, Alcoa Technical Center, Alcoa Center, Pennsylvania 15069

L. B. Greszczuk, MícDonnell Douglas Space Systems Company, Mail Stop 13/3, 5301 Bolsa Avenue, Huntington Beach, California 92647

H. T. Hahn, The Pennsylvania State University, 227 Hammond Building, University Park, Pennsylvania 16802

B. M. Halpin, Jr., Composites Development Branch, SLCMT-MEC, U.S. Army Materials Technology Laboratory, Arsenal Street, Watertown, Massachusetts 02172-0001

M. W. Hyer, Engineering Science amd Mechanics Department, Virginia Polytechnic Institute and State University, 225 Norris Hall, Blacksburg, Virginia 24061

R. F. Jones, Code 1720, Submarine Structures Division, Naval Surface Warfare Center, Carderock Division, Bethesda, Maryland 20084-5000

J. J. Kelly, DARPA/STP-ASTO, Defense Advanced Research Projects Agency, 1400 Wilson Boulevard, Arlington, Virginia 22209

R. Y. Kim, University of Dayton Research Institute, 300 College Park Avenue, Dayton, Ohio 45469-0168

S. R. Kopf, E. I. du Pont de Nemours \& Company, Chestnut Run Plaza, P. O. Box 80702, Wilmington, Delaware 19880-0702

G. Lee, Hitco, Inc., MS15C, 13722 Harvard Place, Gardenia, California 90249

G. F. Leon, Electric Boat Division/General Dynamics, Mail Stop D442, 75 Eastern Point Road, Groton, Connecticut 06340

J. S. Mayes, Ship and Structures and Protection Department, Naval Surface Warfare Center, Carderock Division. Bethesda, Maryland 20084-5000

T. Morton, Code 2802, Composites Program Office, Naval Surface Warfare Center, Annapolis Facility, Annapolis, Maryland 21402-5067 R. J. Nuismer, Hercules Composite Structures, Mail Stop X11 K4, P.O. Box 98, Magna, Utah
$84044-0098$

G. P. O'Hara, Applied Math and Mechanics Section, Research Branch. Benet Weapons Laboratory, Armament Research and Development Center, SMCAR-CC.B - Watervliet Arsenal, Watervliet, New York 12189-4050 
W. Phyillaier, Code 1720.2, Naval Surface Warfare Center, Carderock Division, Bethesda, Maryland 20084-5000

V. Peros, Martin Marietta Aero \& Naval Systems, Mail Stop 700, 103 Chesapeake Park Plaza, Baltimore, Maryland 21220

Y. D. S. Rajapakse, Code 1132-SM, Office of Naval Research, 800 North Quincy Street, Arlington, Virginia, 22217-5000

E. A. Rasmussen, Code 1720.4 Ship and Structures and Protection Department, Naval Surface Warfare Center, Carderock Division, Bethesda, Maryland 20034-5000

D. B. Rogers, School of Engineering and Technology, Tennessee State University, 3500 John A. Merritt Boulevard, Nashville, Tennessee 37209

R. Rockwell, Code 1720, Submarine Structures Division, Naval Surface Warfare Center, Carderock Division, Bethesda, Maryland 20084-5000

B. W. Rosen, Materials Sciences Corporation, Union Meeting Corporate Center, 930 Har'est Drive, Blue Bell, Pennsylvania 19422

A. J. Roy, University of Dayton Research Institute, 300 College Park Avenue, Dayton, Ohio 45469-0001

B. E. Sandman, Code 8215, Design and Structures, Naval Undersea Warfare Center, Division Newport, Newport, Rhode Island 02841

F. J. Spicola, Code 8215, Design and Structures, Naval Undersea Warfare Center, Division Newport, Newport, Rhode Island 02841

J. D. Stachiw, Code 9402, Naval Ocean Systems Center, 273 Catalina Boulevard, San Diego, California 92152-5000

J. L. Stachiw, Stachiw Associates, P.O. Box 2343, El Cajon, California 92021 (2)

M. S. Stahl, College of Business Adminstration, The University of Tennessee, Knoxville, 8 Humanities Building, Knoxville, Tennessee 37996-0100

S. Starrett, Mechanics Division, Southern Research Institute, 2000 Ninth Avenue, South, P.O. Box 55305, Birmingham, Alabama 35205

K. B. Su, Engineering Technology Laboratory, E. I. du Pont de Nemours \& Company, 80304 Experimental Station, Wilmington, Delaware 19880-0304

R. F. Swan, Code 92RL, Advanced Submarine Research and Development, Naval Sea Systems Command, Department of the Navy, Washington, D. C. 20362-5101

S. R. Swanson, Department of Mechanical and Industrial Engineering, University of Utah, 3209 MEB, Salt Lake City, Utah 84112 
S. W. Tsai, Department of Aeronautics and Astronautics, Durand Building, Stanford University, Stanford, California 94305

S. S. Wang, National Center for Composite Materials Research, University of Illinois, 216 Talbot Laboratory, 104 South Wright Street, Urbana, Illinois 61801

J. M. Whitney, Department of Graduate Materials Engineering, University of Dayton, 300 College Park, Dayton, Ohio 45469

I. Wolick, Code 6383, Naval Research Laboratory, Washington, D. C. 20375-5000

E. M. Wu, Code AA/WU, Department of Aeronautics, Naval Postgraduate School, Monterey, California 93943

Office of Scientific and Technical Information (2), P.O. Box 62, Oak Ridge, Tennessee 37831 

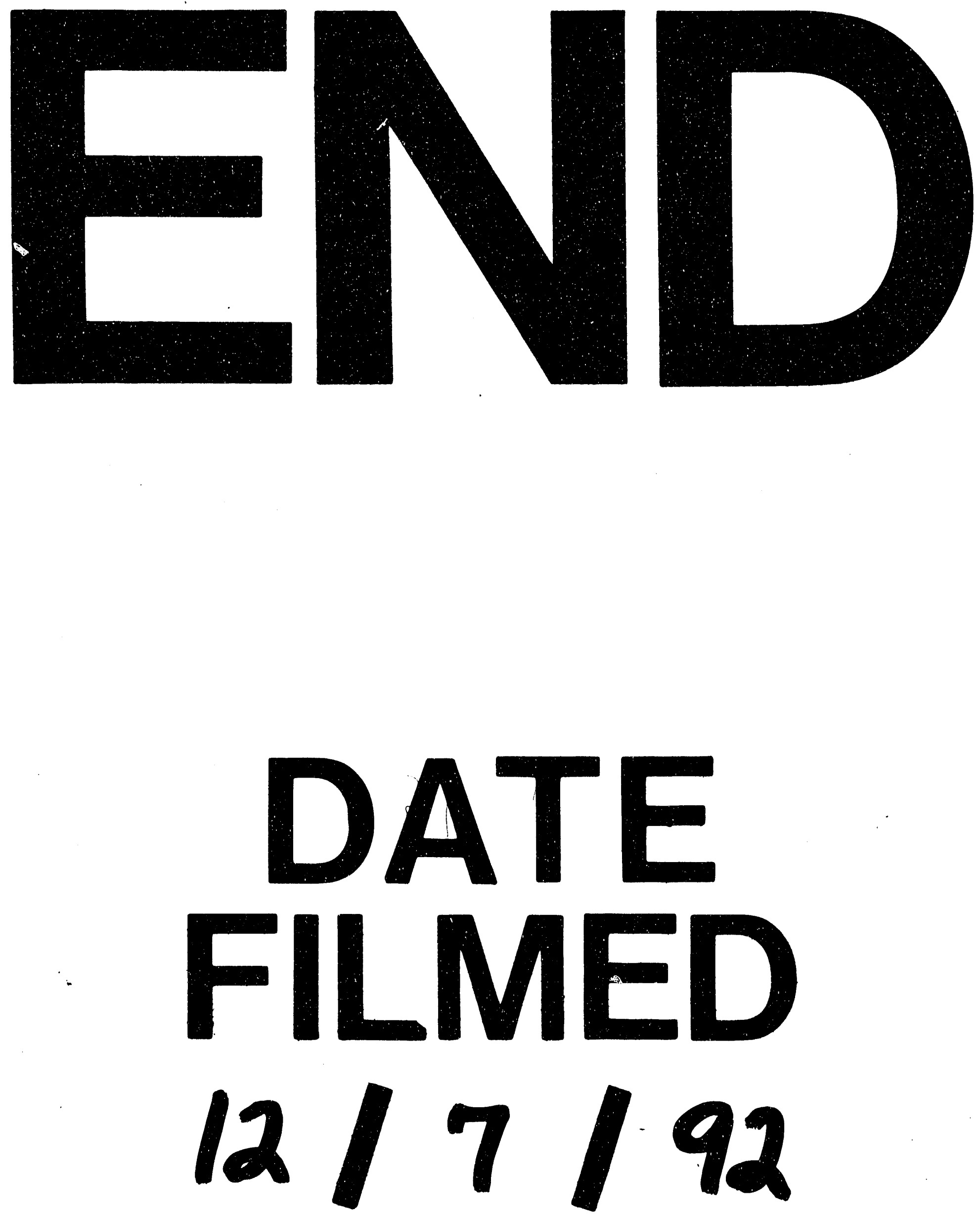
